\title{
Education for Sustainable Development and Global Citizenship Adult and Community Learning in Wales - from Policy to Pedagogy
}

\author{
Jenkins, Alyson
}

How to cite:

Jenkins, Alyson (2018) Education for Sustainable Development and Global Citizenship Adult and Community Learning in Wales - from Policy to Pedagogy. Doctoral thesis, Swansea University.

http://cronfa.swan.ac.uk/Record/cronfa48775

Use policy:

This item is brought to you by Swansea University. Any person downloading material is agreeing to abide by the terms of the repository licence: copies of full text items may be used or reproduced in any format or medium, without prior permission for personal research or study, educational or non-commercial purposes only. The copyright for any work remains with the original author unless otherwise specified. The full-text must not be sold in any format or medium without the formal permission of the copyright holder. Permission for multiple reproductions should be obtained from the original author.

Authors are personally responsible for adhering to copyright and publisher restrictions when uploading content to the repository.

Please link to the metadata record in the Swansea University repository, Cronfa (link given in the citation reference above.)

http://www.swansea.ac.uk/library/researchsupport/ris-support/ 


\title{
Education for Sustainable Development and Global Citizenship in Adult and Community Learning in Wales
}

\author{
From Policy to Pedagogy
}

Alyson Jenkins

Submitted to Swansea University in fulfilment of the requirements for the degree of Doctor of Philosophy

Swansea University

2018 


\begin{abstract}
Education for Sustainable Development and Global Citizenship (ESDGC) is an educational response to the Welsh Government's commitment to sustainable development. This thesis provides a detailed case study of the implementation of a strategy for ESDGC in the Adult and Community Learning ( $\mathrm{ACL}$ ) sector in Wales. An international, UK and local Welsh policy background influenced the development and implementation of ESDGC. An examination of this policy background contextualises detailed qualitative research undertaken with those involved with developing the ESDGC strategy, as well as tutors and managers in ACL across Wales responsible for its implementation. A variety of research methods, including interviews, questionnaires and focus groups were employed, in an integrated fashion, to examine the policy process and the perceptions of the different groups of research respondents, as well as factors that influenced the implementation of the strategy. The findings demonstrate a range of features contributing to an inconsistent and ad hoc implementation, including difficulties posed by the ACL infrastructure; a marginalisation of the sector; and a policy-practice gap characterised by a lack of investment. ESDGC was not linked to wider government priorities, such as community development. Accordingly, synergies between ACL and ESDGC theory and practice were not fully realised. The research uncovered certain key deficiencies in articulating and communicating a sense of purpose and revealed varying degrees of conceptual confusion amongst respondent groups. Clarifying the conceptual basis of ESDGC - and education for global citizenship per se - is shown to be of vital importance. This, alongside a discussion of ACL learning theories, provides a rationale for a new approach to ESDGC through its reconceptualisation. Threads from the findings and the theoretical literature are drawn together, and recommendations are made for policy and research with the aim of creating relevance so that policy may be translated into practice in the future.
\end{abstract}




\section{Declaration}

This work has not previously been accepted in substance for any degree and is not being concurrently submitted in candidature for any degree.

Signed

(candidate)

Date

\section{Statement 1}

This thesis is the result of my own investigations, except where otherwise stated. Where correction services have been used, the extent and nature of the correction is clearly marked in a footnote(s).

Other sources are acknowledged by footnotes giving explicit references. A bibliography is appended.

Signed

(candidate)

Date

\section{Statement 2}

I hereby give consent for my thesis, if accepted, to be available for photocopying and for interlibrary loan, and for the title and summary to be made available to outside organisations.

Signed

(candidate)

Date 


\section{Contents}

\section{Contents}

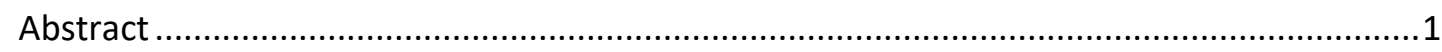

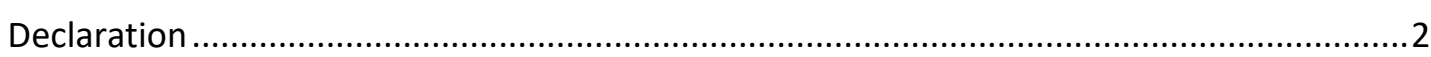

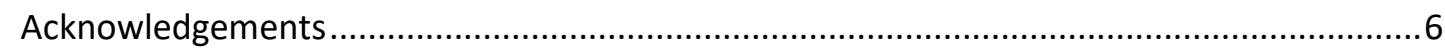

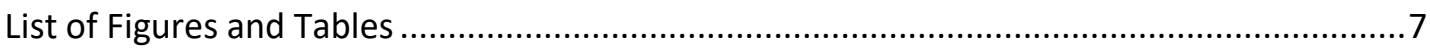

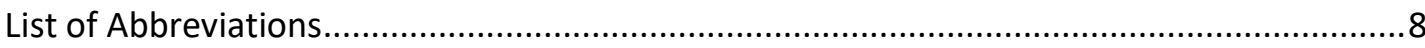

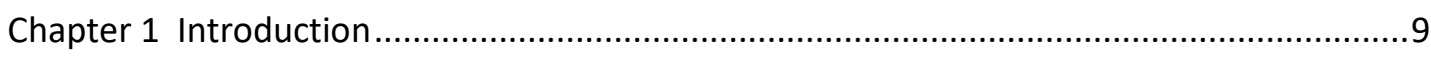

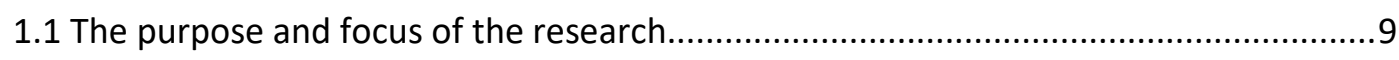

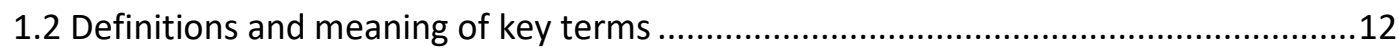

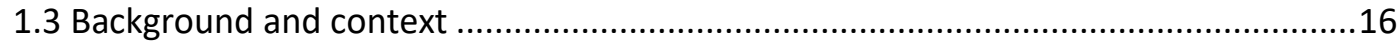

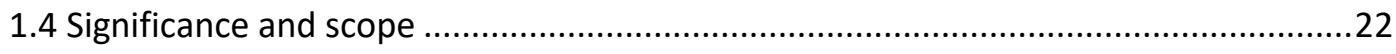

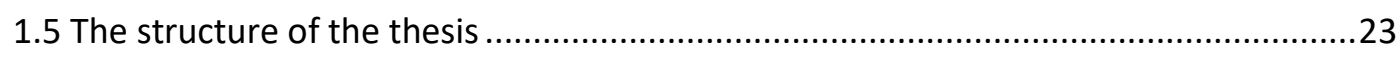

Chapter 2 Literature Review: Grounding a Research Agenda...........................................26

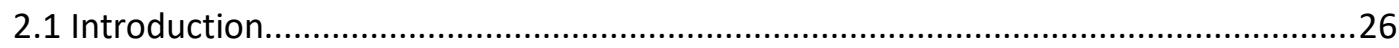

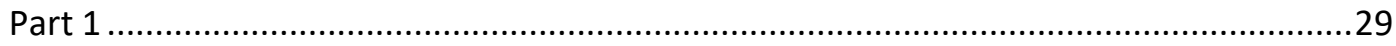

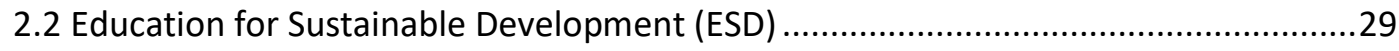

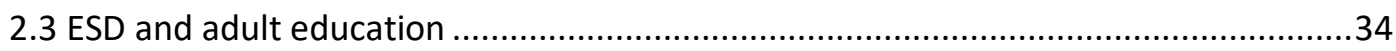

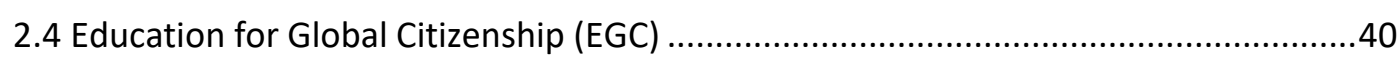

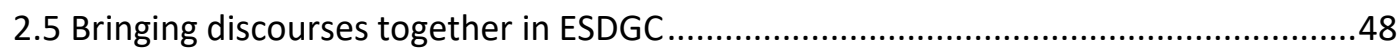

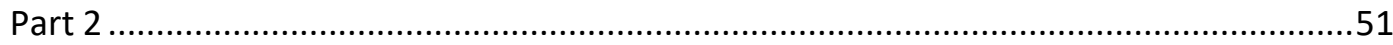

2.6 Adult and Community Learning and ESDGC ...........................................................

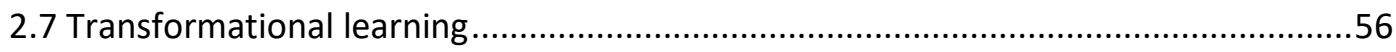

2.8 Pedagogy for ESDGC - critical, plural and agonistic ...................................................

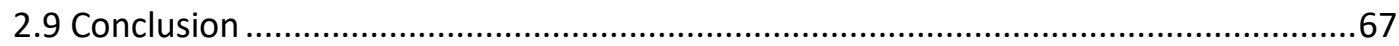

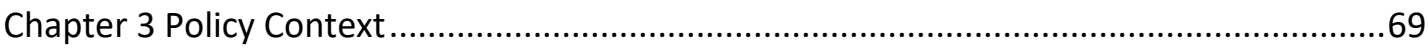

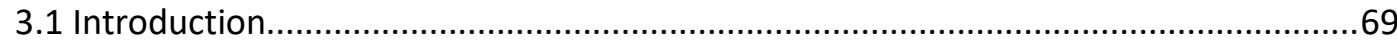

3.2 Literature on policy development and implementation ...........................................70

3.3 International context and background to the ESDGC strategy ...................................75

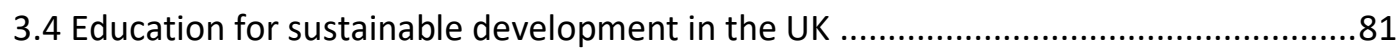

3.5 Citizenship education policy and education for global citizenship in the UK ..............84

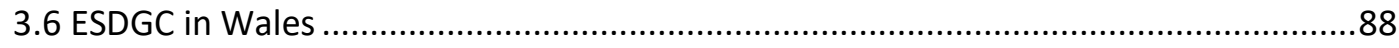

3.7 Lifelong learning policy in Wales and its links to ESDGC .........................................93

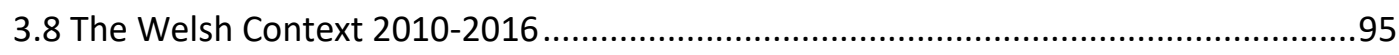

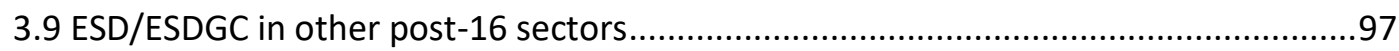


3.10 Conclusion

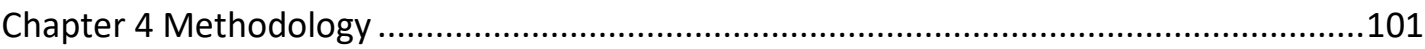

4.1 Introduction to mode of inquiry and research questions .....................................101

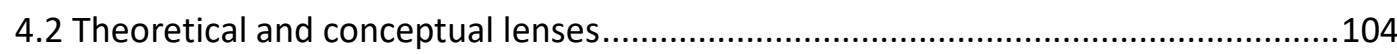

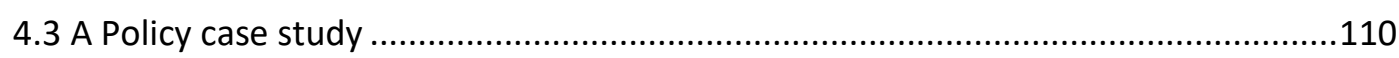

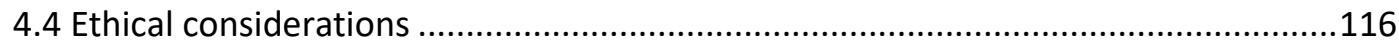

4.5 Research process - overview and summary .................................................119

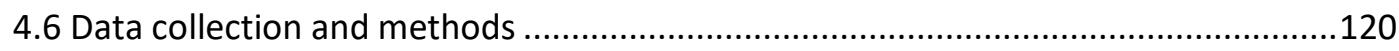

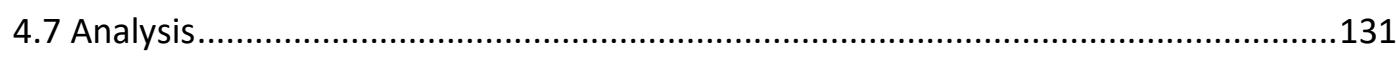

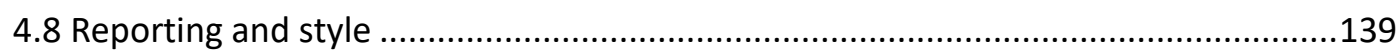

4.9 Reflection on the research process ....................................................... 140

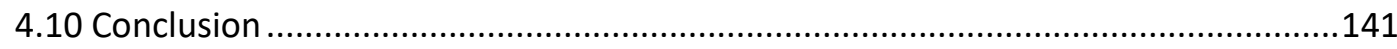

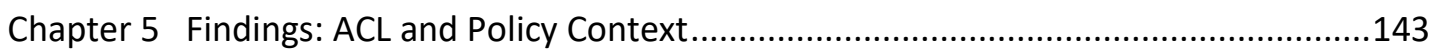

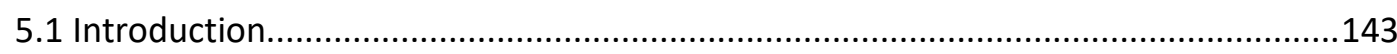

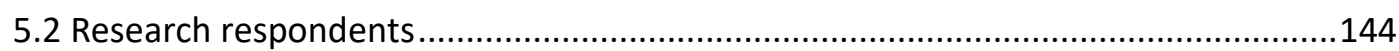

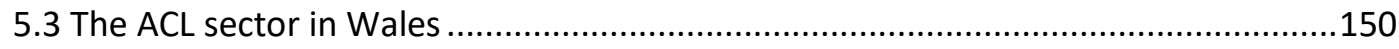

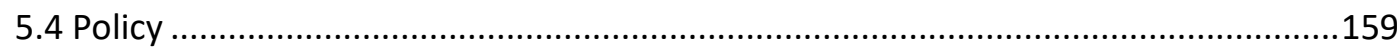

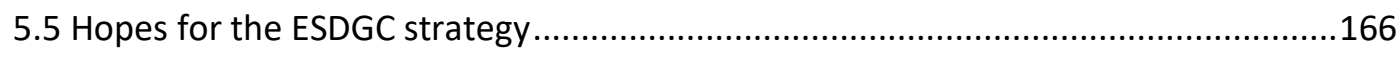

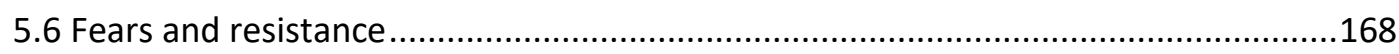

5.7 Wider policy issues - lack of strategic integration................................................177

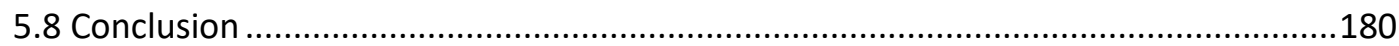

Chapter 6 Practice, Practitioners and the Policy-Practice Gap ......................................184

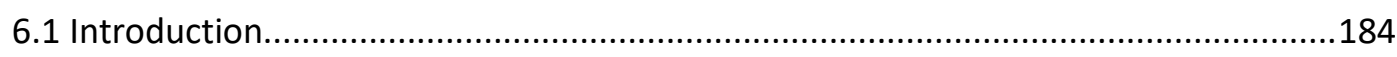

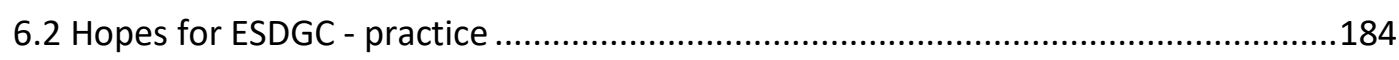

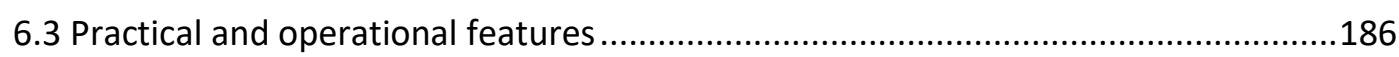

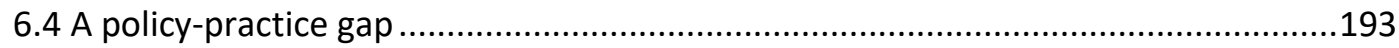

6.5 Conceptual confusion - purpose and perceptions .........................................196

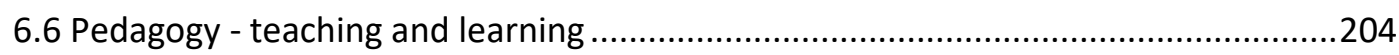

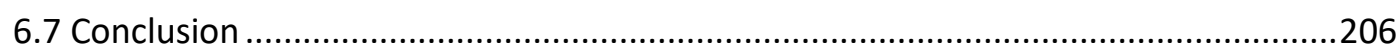

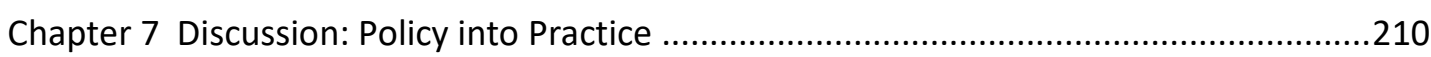

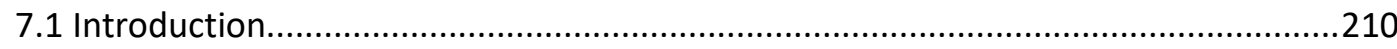

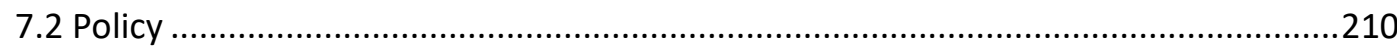

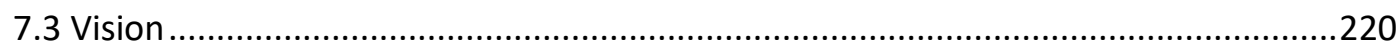

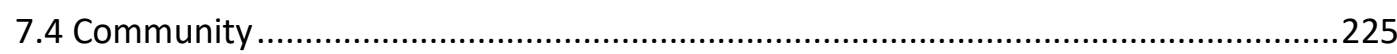

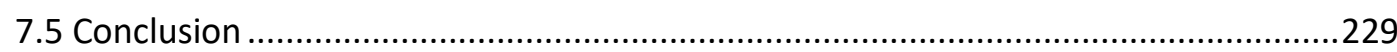

Chapter 8 Discussion: Synergy and Future Approaches...........................................231 
8.1 Introduction.

8.2 ACL and ESDGC: synergy in purpose ..........................................................231

8.3 Transformational approaches in ACL and ESDGC .............................................234

8.4 Re-conceptualising ESDGC as ecological global citizenship education .....................241

8.5 Key elements in a pedagogy for ecological global citizenship education ..................249

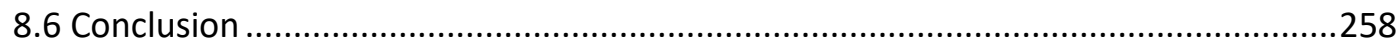

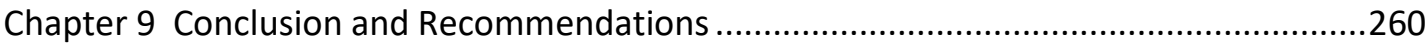

9.1 Introduction: the research aims and questions ...................................................260

9.2 The background features which influenced the ESDGC strategy development and

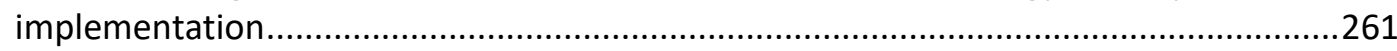

9.3 The features contributing to the 'piecemeal' delivery and provision.......................265

9.4 What is the 'latent' contribution of ACL to ESDGC and how can this contribute to translating policy into practice?

9.5 Features illustrating some of the difficulties surrounding the implementation of EGC and

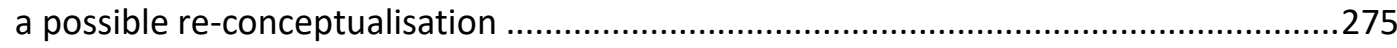

9.6 Contribution of the research, generalisability and reflections ............................278

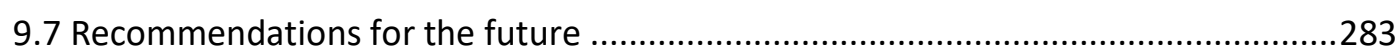

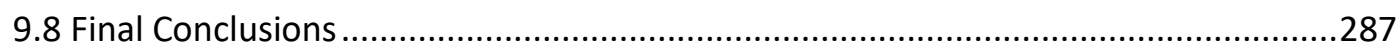

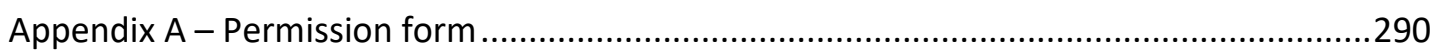

Appendix B - Executive Summary DCELLS Report 2010 ..............................................291

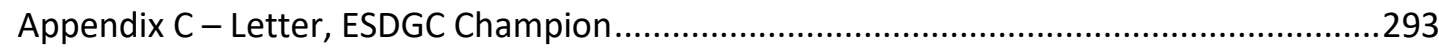

Appendix D - Example of data: Notes from ACL Partnership meetings .............................294

Appendix F - Sample of a Manager Questionnaire Matrix ................................................300

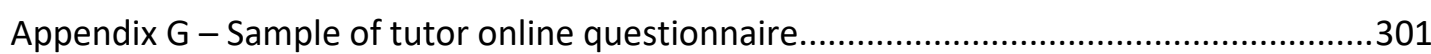

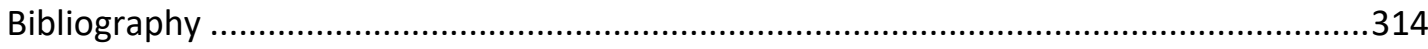




\section{Acknowledgements}

I am grateful to everyone who responded to this research who gave me their time and honest input, especially the ACL practitioners in Wales.

I would like to thank my supervisors, particularly Professor David Clarke and Dr Keith Halfacree for their advice, support and encouragement. Dr Esther Barrett and Professor Lesley Griffiths deserve special thanks for their unflagging support and friendship throughout. Gratitude is extended to my dear and patient friends and of course to my daughters Nico and Meg for simply being there. 


\section{List of Figures and Tables}

Fig 1.1 World population, 10,000BC to the present ..................................... 17

Fig. 1.2 The great acceleration: Tends since 1750 ...................................... 18

Fig. 4.1 A series of related assumptions ..................................................... 103

Fig. 4.2 Empirical data collection: chronology and employment status .. $\quad 113$

Fig. 4.3 Summary of the research process ................................................... 120

Fig. 4.4 Diamond Ranking ................................................................... 129

Fig. 4.5 An example of recording method from the focus groups ........... 130

Fig. 4.6 Components of data analysis: interactive model .......................... 133

Fig. 5.1 How managers identified themselves - Questionnaires ............. 145

Fig. 5.2 How managers identified themselves - Interviews ...................... 146

Fig. 5.3 The sectors where managers worked - Questionnaire ................. 146

Fig. 5.4 The sectors where managers worked - Interviews ......................... 147

Fig. 5.5 How tutors identified themselves ....................................................

Fig. 5.6 Who tutors work with/for ............................................................. 148

Fig. 5.7 Curriculum areas that tutors teach/train...................................... 149

Fig. 6.1 Training received by tutors .......................................................... 191

Fig. 6.2 Tutor confidence levels to take ESDGC forward in their work ...... 192

Fig. 6.3. Managers' levels of confidence - Questionnaires .......................... 193

Fig. 6.4 Tutor responses - 'Have you heard about ESDGC?'"....................... 194

Fig. 7.1 Policy encoding and decoding ...................................................... 212

Fig. 7.2 Layers of influence and lines of communication ............................ 216

Fig. 8.1 Intersections between critical thinking and critical pedagogy .... 236

Fig. 8.2 A simple model for ecological global citizenship education ......... 250

Fig. 8.3_Key elements of an ecological global citizenship education........ 251

\section{Tables}

Table 4.1 Methods used, and data collected ............................................... 121

Table 4.2 Summary of methods employed ................................................ 122

Table 4.3 Data sources - contributing to addressing research questions .. $\quad 134$

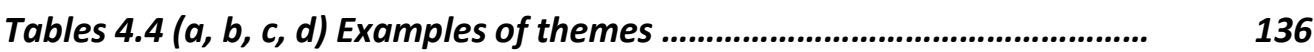

Table 4.5 Supervision ............................................................................ 140 


\section{List of Abbreviations}

\begin{tabular}{|c|c|}
\hline $\mathrm{ACL}$ & Adult and Community Learning \\
\hline BME & Black and Minority Ethnic \\
\hline CPD & Continuing Professional Development \\
\hline DCELLS & $\begin{array}{l}\text { Department for Children, Education and Lifelong Learning and Skills at the } \\
\text { Welsh Government }\end{array}$ \\
\hline DfES & Department for Education and Skills - UK Government \\
\hline DFID & Department for International Development \\
\hline EGC & Education for Global Citizenship \\
\hline ESD & Education for Sustainable Development \\
\hline ESDGC & Education for Sustainable Development and Global Citizenship \\
\hline Estyn & Her Majesty's Inspectorate for Education and Training in Wales \\
\hline ESOL & English for Speakers of Other Languages \\
\hline $\mathrm{FE}$ & Further Education \\
\hline GCE & Global Citizenship Education \\
\hline $\mathrm{HE}$ & Higher Education \\
\hline HEA & Higher Education Academy \\
\hline LSC & Learning and Skills Council \\
\hline NGO & Non-Governmental Organisation \\
\hline PGCE & Post Graduate Certificate of Education \\
\hline PSE & Personal and Social Education \\
\hline TVET & Technical and Vocational Education and Training \\
\hline UN & United Nations \\
\hline UNEP & United Nations Environment Programme \\
\hline UNESCO & United Nations Educational, Scientific and Cultural Organisation \\
\hline WAG & Welsh Assembly Government \\
\hline WBL & Work Based Learning \\
\hline WCED & The World Commission on Environment and Development \\
\hline WEA & Workers Educational Association \\
\hline
\end{tabular}




\section{Chapter 1 \\ Introduction}

\subsection{The purpose and focus of the research}

Against a global backdrop of environmental degradation, social and economic instability and increasing inequality, education is seen in many countries as a means of achieving progress towards sustainable development. Indeed, Sustainable Development Begins with Education is the title of a United Nations Educational, Scientific and Cultural Organisation (UNESCO) document outlining education's role in realising the United Nations (UN) Sustainable Development Goals (UNESCO, 2014b).

In line with this emphasis, Wales' devolved government, uniquely among EU nations, has positioned sustainable development as its central operating principle. As such, it has a binding legal duty to pursue sustainable development in all functions of government. The Sustainable Development Action Plan 2004 - 2007 (Welsh Government, 2003) identified education for sustainable development and global citizenship (ESDGC) as one of the top ten priorities for government, and the Welsh Government's Department For Children, Education And Lifelong Learning and Skills (DCELLS) produced Education for Sustainable Development and Global Citizenship: A Strategy for Action (Welsh Government, 2006, 2008a) with the intention of highlighting actions for driving the sustainability agenda forward.

Other countries have adopted education for sustainable development (ESD) in which the global aspect is implicit. However, Wales explicitly linked education for global citizenship (EGC) with ESD and that, potentially, created an opportunity to develop different approaches in ESDGC. Moreover, there was a feeling of optimism at the time in Wales that education could contribute to the transformations needed to realise sustainable development. Jane Davidson, the then Minister for Children, Education, Lifelong Learning and Skills, said in her foreword to the 2006 ESDGC strategy:

This is a highly ambitious Action Plan but one which I believe is fundamental to us ensuring that the principles of education for sustainable development and global citizenship are built in to every aspect of our day-to-day life. It is key to us not only 'Starting to Live Differently' but to ensuring that we completely transform the mindset of future generations. (Welsh Government, 2006: i) 
All education sectors are covered by the ESDGC strategy: schools, youth, further education (FE), work-based learning, higher education (HE) and adult and continuing education, as it was called in the strategy. This thesis focuses on the latter, on the adult and community learning $(\mathrm{ACL})$ sector in Wales. Discussions are framed by the discourses of lifelong learning, and, through theoretical inference, the thesis can be of wider interest and significance in post-16 education more generally.

Whilst working in $\mathrm{ACL}$ and delivering ESDGC awareness training to $\mathrm{ACL}$ tutors across Wales during 2008, it soon became apparent, not least through discussions with ACL providers, that courses under the ESDGC umbrella were not recruiting. They were being cancelled; there was an apparent lack of interest. There was frustration from colleagues interested in ESDGC at the limited success in running ESDGC courses and in embedding ESDGC into teaching and learning. I became curious as to why this situation had arisen.

Curiosity was reinforced by the findings of Estyn's (Her Majesty's Inspectorate for Education and Training in Wales) review in 2008 on ESDGC in the youth and ACL sectors. This found that even though nearly all providers of $\mathrm{ACL}$ were carrying out some work involving elements of ESDGC, and some had institutional policies, the majority were failing to develop an integrated approach and there was a general lack of understanding at all levels (Estyn, 2008). Whilst the review was not a research study, it did provide some evidence of a lack of understanding and non-engagement with ESDGC in the ACL sector. A further primary motivation for this thesis was to find out the reasons for this situation.

The empirical research for this thesis was conducted between 2008 and 2010. It is concerned with the perceptions of those developing the ESDGC strategy - members of the ESDGC panel at the Welsh Government - and those expected to implement it - managers and tutors across all institutions and organisations delivering $\mathrm{ACL}$ in Wales. A qualitative case study design is adopted which provides a 'snapshot' of this particular education strategy in a particular geographical location, during a particular time-frame; it is essentially a policy case study. This research design is chosen because the combination of rich descriptions of context, the use of different data collection methods, multiple perspectives and the holistic treatment of the data, best addressed the research questions. From the findings and from the context, generalisations are possible. 
There is little work to date that specifically looks at ESD in the adult education sector.

However, there are some that examine community perspectives, environmental education and adult learning for example. Similarly, there is not much literature that links EGC with ACL, although there is a substantial literature on citizenship education in ACL. These gaps in the literature provided still further motivation for conducting my research. Understanding the policy background is essential, and research thus also involved a policy review (Chapter 3). Lifelong learning and sustainable development are both policy objectives of the UK and Welsh Governments; both are seen as instrumental in bringing about social change. As such, examining the policy process in ESDGC is a significant part of this case study. Questions about how the strategy was developed, and issues of consultation, representation and communication, are some of the important elements for any successful implementation.

Consolidating, the research questions for this $\mathrm{PhD}$ are:

1. What were the background and contextual features which influenced the development and implementation of the ESDGC strategy?

2. What were the features described by respondents which subsequently contributed to the 'piecemeal' delivery and provision of ESDGC in ACL in Wales?

3. From the literature and from the data, can we distinguish the 'latent' contribution of ACL to ESDGC, and how this contributes to an understanding of implementation processes in translating policy to practice?

Following an initial analysis of all data sets and a policy and literature review, a further question emerged. This is not untypical of a qualitative research study (Suter, 2011: 343). The additional question is related to questions one and two and helps address them; it is concerned with developing conceptual clarity regarding EGC:

4. How can features emerging from the research assist in identifying some of the difficulties surrounding the implementation of EGC? Can these inform a reconceptualisation of ESDGC more aligned to the translation of policy into practice in the future?

Use of the term 'piecemeal' to describe ESDGC in ACL is taken from ESDGC: A Strategy for Action (Welsh Government, 2008a: 70) and encompasses the inconsistent, patchy, fragmentary and ad hoc delivery and provision of ESDGC in ACL that Estyn describes in its 
review (Estyn, 2008). The phrase, 'the "latent" contribution of ACL to ESDGC' is taken from the ESDGC strategy, which states:

There are similarities between ESDGC principles and adult and continuing learning approaches. These similarities may mask the 'latent' contribution that this sector may have to the incorporation of ESDGC within teaching and learning activities. (Welsh Government, 2008a: 70-71)

The research avoided formulating early hypotheses and initially there was a simple question: 'What is going on here?' (Silverman, 2013: 103). Further early questions were open-ended and exploratory in nature and, as the study proceeded, other questions rapidly emerged from analysis of the resulting data. As Silverman (2013: 20) states, this is often the case in interpretative studies. From the findings relating to the first three research questions the thesis then reached the 're-conceptualisation' referred to in question four. This was not to construct a completely new vision of ESDGC but to take existing discourses and combine and emphasise elements differently in the context of the examination of ACL learning theory. Certain discourses that have not formed the mainstay of ESDGC to date are brought into the discussions, with the overall intention of increasing understanding and engagement with ESDGC, enhancing future pedagogy and effectively translating policy into practice.

\subsection{Definitions and meaning of key terms}

ESDGC and each of its constituent elements - education, sustainability, development, and global citizenship - embody highly contested concepts that encompass a complex array of interpretations and understandings based on different world views, ideologies and interests. ESDGC is complex and using one definition is not appropriate or possible; likewise, $A C L$ is informed by many discourses and has a plethora of possible definitions. This section therefore outlines some definitions as understood and used in this thesis, starting with ESD and EGC and then engaging with ACL. The literature review in Chapter 2 and the review of policy in Chapter 3 provide further detail on definitions.

Definitions of ESD and EGC from a 2002 document on personal and social education (PSE) in Wales provide broad-brush indications. The two definitions are very similar: 


\section{Education for Sustainable Development:}

Enables people to develop the knowledge, values and skills to participate in decisions about the way we do things individually and collectively, both locally and globally, that will improve the quality of life now without damaging the planet for the future.

\section{Education for Global Citizenship:}

Enables people to understand the global forces which shape their lives and to acquire the knowledge, skills and values that will equip them to participate in decision making, both locally and globally, which promotes a more equitable and sustainable world.

(Welsh Government, 2002: 6)

Generally, both ESD and EGC are viewed as approaches rather than prescriptive lists of curriculum content.

ESD is an approach to teaching and learning based on the ideals and principles of sustainable development, defined in the 1987 Brundtland Report, and now widely recognised:

"Sustainable development is development that meets the needs of the present without compromising the ability of future generations to meet their own needs" (UN, 1987: 43). Sustainable development is, however, a problematic term, as some see it as an oxymoron (Redclift, 2006). This is because 'development' is often conceptualised as progress framed by Western economic, political and cultural models, where the dominant paradigm is a neoliberal ideology based on ideas of development that are proving to be ecologically and economically unsustainable (Jackson, 2009a, 2009b; Steffen, Sanderson, Tyson ... \& Wasson, 2004; Steffen, Persson, Deutsch ... \& Molina, 2011; Steffen, Richardson, Rockström ... \& Folke, 2015). ESD, however, challenges accepted notions of growth, progress and development (Huckle \& Wals, 2015) and asks us to examine the way we think and live, individually and collectively. Reflecting such terminological tension, many authors prefer to use the term 'education for sustainability' (Parker \& Wade, 2008) and there are other terms such as 'sustainability education' (Sterling, 2011a, 2011b). However, ESD is used in this thesis to maintain consistency and the integrity of ESDGC.

Recently, UNESCO has stated that ESD empowers people to change the way they think and work towards a sustainable future.

It is about including sustainable development issues, such as climate change and biodiversity into teaching and learning. Individuals are encouraged to be responsible 
actors who resolve challenges, respect cultural diversity and contribute to creating a more sustainable world. ${ }^{1}$

ESD is a form of education that will help us meet the sustainable development goals ${ }^{2}$ introduced by the UN in 2015: an ambitious a seventeen-point plan to end poverty, combat climate change and fight injustice and inequality. The aspiration of sustainable development, according to a parallel UNESCO document on rethinking education (UNESCO, 2015: 9), requires us to resolve common problems and tensions and to recognise new horizons. Learning is vital in this process.

Turning now to EGC, global citizenship is not an entirely new idea but defining it is problematic. One of the main objections to the use of the word 'citizenship' is that it has traditionally been linked with a polity and there is no 'global political community'. Global citizenship in this thesis is, however, discussed in terms of a cosmopolitan ethic, or a frame of mind or consciousness in the first instance. Armstrong (2011: 166) puts it thus: "We have rights or responsibilities of universal scope. These might be enjoyed or owed simply in virtue of our status as human beings, or as shared inhabitants of the planet Earth, or perhaps in virtue of the existence of global social relations". It denotes a sense of collective and individual responsibility for and in the world; it considers global poverty and inequality, conflict, the violation of human rights and environmental degradation (Dower, 2000: 553). EGC is, as UNESCO states, a response to these challenges ${ }^{3}$.

Thirdly, ACL is a term that covers a wide range of learning opportunities, which do not always lend themselves easily to short definitions. It includes a variety of informal non-accredited learning, accredited courses up to level 2 in the Welsh and English Frameworks ${ }^{4}$ and the English Qualifications and Credit Framework, ESOL (English for Speakers of Other Languages), basic skills and Welsh for adults, workshops and a variety of other informal provision. This thesis takes into account the definition in the ESDGC Strategy document which is taken from the policy document Delivering Skills that Work for Wales: A New Approach to Adult Community Learning. This defines ACL as "provision for adults aged 19+, which is offered in local community settings and which is not occupation-specific in nature." (Welsh Government,

\footnotetext{
${ }^{1}$ https://en.unesco.org/themes/education-sustainable-development [Accessed: 01/07/2018] 2http://www.globalgoals.org/ [Accessed: 01/07/2018]

${ }^{3}$ https://en.unesco.org/themes/gced [Accessed: 01/07/2018]

${ }^{4}$ https://eal.org.uk/support/document-library/7-uk-qualifications-comparison-table/file [Accessed: 01/08/2018]
} 
2008d: 1). Another similar definition of ACL is "Flexible learning opportunities for adults, delivered in community venues to meet local need" and includes: "increased participation by those who have benefited least from education in the past or who are most at risk of not benefiting in the future" (Welsh Government, 2010: 3, 5).

The thesis also takes account of the definition on the Welsh Government website in 2017:

Flexible learning opportunities for adults, delivered in community venues to meet local needs.... [and it] caters mainly for adults aged 19+, with courses being offered in local community-based venues, as well as main college campuses. This includes both formal and informal/non-accredited learning opportunities and six purposes have been identified: first steps learning, skills for life and embedded basic skills, skills for independent living, skills for work, personal development and well-being and learning for active citizenship and/or community development ${ }^{5}$.

This definition applies to Welsh Government funded provision.

$\mathrm{ACL}$ is part of the continuum of lifelong learning. It can be formal, in that it is linked to accreditation and it can be informal, although this definition has shifted at times, depending on the separation between skills and learning and associated budgets within government. Work-based learning or technical and vocational education and training (TVET) is included in $A C L$ in some definitions and in policy. However, it is not explicitly included in the focus of this thesis. The location, context and purpose of $\mathrm{ACL}$ are interrelated, and these elements in workbased learning distinguish it from the provision and the professionals that have been included as part of this case study. There is some overlap at times, especially where policy has combined the different adult learning provision into overarching definitions and some literature is therefore included (for example, Fien, Maclean and Park, (2009), Fien and Maclean (2009), Martin et al. (2008) on ESD in TVET).

During the time it has taken to write the thesis, the adult education policy landscape has changed considerably. Chapters 3 and 9 describe these changes and how they have impacted on $\mathrm{ACL}$ delivery and provision.

${ }^{5}$ http://gov.wales/topics/educationandskills/learningproviders/communitylearning/?lang=en [Accessed: 01/01/2017]: 


\subsection{Background and context}

\subsubsection{Global context}

Not least with the term 'global' noted frequently throughout the thesis, it is worth introducing the global context. This considers the damage human beings are inflicting on the biosphere, including other life forms and each other. Once living in nomadic tribes as hunter gatherers, about 12,000 - 10,000 years ago human beings domesticated animals, settled and tilled the land. Today we produce food on an industrial scale and move it around the globe to feed a population of over 7 billion (Figure 1.1). Of this population, today in 2018 about 55 per cent of the world's population live in urban areas and this is expected to increase to 66 per cent by 2050 (UN, 2015).

Authors from Bronowski (1973) to Harari (2014), have chronicled the human journey from agricultural communities to empires, the creation of nation states, colonialism and the Industrial Revolution, the latter fuelled by what Hartmann (2001) calls, 'ancient sunlight'. Coal and oil are condensed sunlight energy from 350 million years ago, and this fossil fuel has made it possible for us to exploit more resources using technology and to produce ever increasing amounts of food. We are more efficient at producing food and because of this, along with medical, scientific and other technological advances, the population grows exponentially. 
Fig. 1.1 World population, 10,000BC to the present (US Census, 20156)

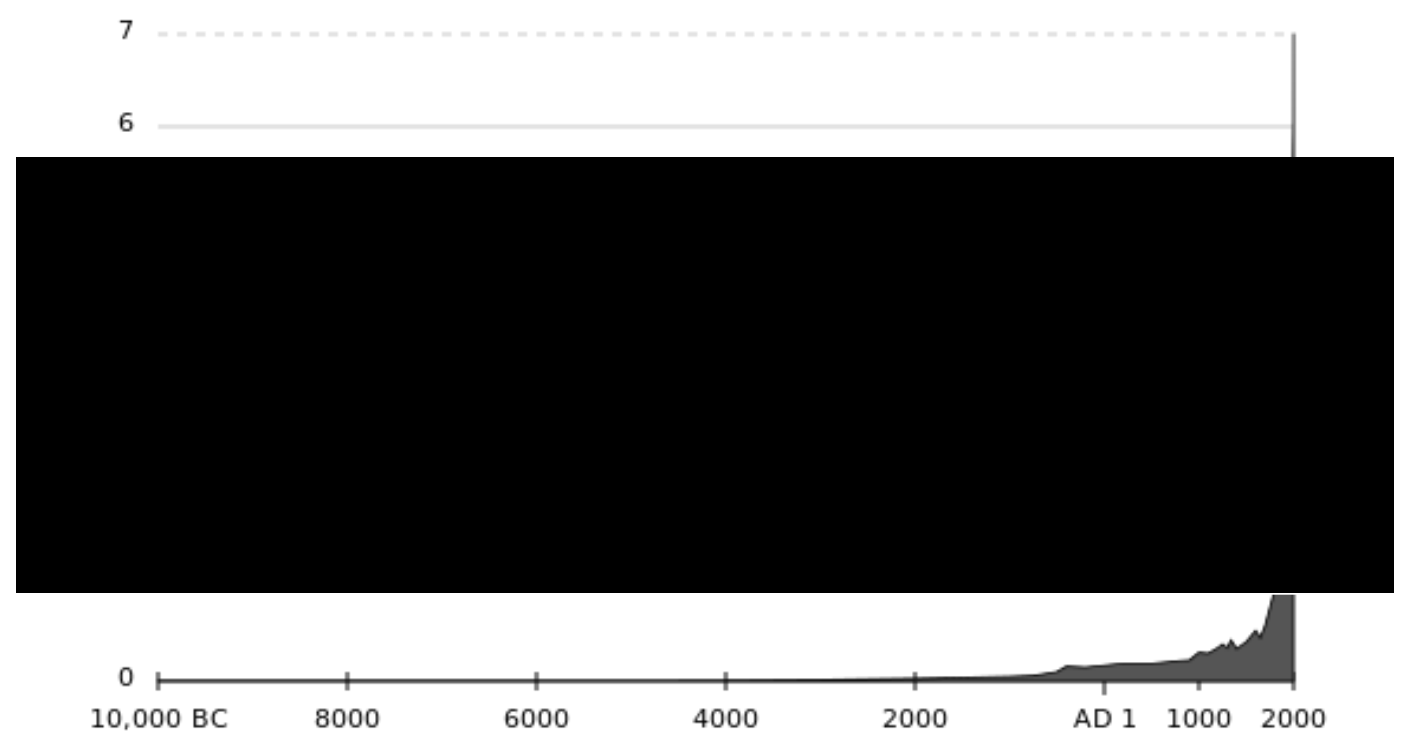

Since the 1950s, there has been a growing realisation that the dominant global economic model is unsustainable. This model gives primacy to the free market and encourages the exploitation of natural resources to satisfy the needs and wants of an increasingly consumerist society (Bauman, 2007a, 2007b). Global trends have been identified and mapped by Steffen et al. $(2004,2011,2015)$, and they illustrate a 'great acceleration' as illustrated in Figure 1.2. Their research mapped many trends, environmental, economic and social, from car ownership to GDP, global temperatures to biodiversity loss.

${ }^{6}$ https://www.census.gov/population/international/ 
Fig. 1.2 The great acceleration: Trends since 1750 (from Steffen et al., 2004: 132-133)

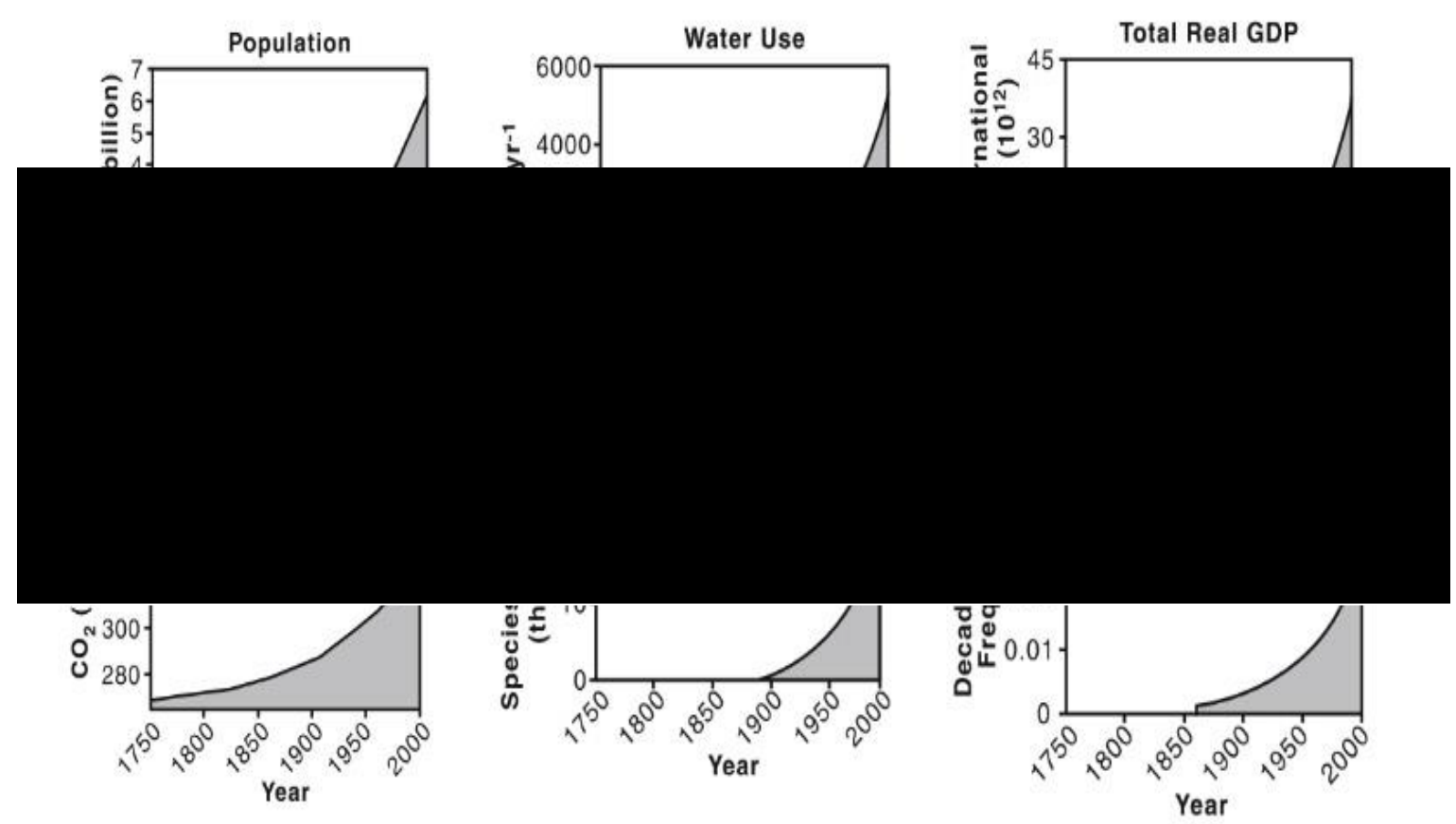

Steffen et al. (2011: 756) state that the great acceleration indicates that "'Business-as-usual' cannot continue. We are passing into a new phase of human experience and entering a new world that will be qualitatively and quantitatively different from the one we have known". It is estimated that over 60 per cent of the world's ecosystems have been degraded and carbon emissions globally have risen by 40 per cent since 1990 . Evidence is pointing to a pressing need to change as the earth shifts into a 'new state' that is becoming less hospitable to human life (Steffen et al., 2011, 2015). Reinforcement of this point comes from the State of the World (Auth, Mastny, Prugh, Worldwatch Institute, Gardner \& Renner, 2015), an annual publication by the Worldwatch Institute ${ }^{7}$ chronicling environmental degradation. For the first time, the 2015 edition examined the dominant economic model as the hidden threat to sustainability.

Hobsbawm (1994), in his exposition of the 20th Century, paints a picture of an allencompassing global crisis: economic, political, moral and one of human relations. It is, he argues, a crisis of all forms of social organisation, in all parts of the world. In sum, therefore,

7http://www.worldwatch.org/ 
the Earth today presents a global context of multiple crises. We do not have the maps and charts we once had; it is both a time of uncertainty and an opportunity to explore new territory as education and learning are given a new urgency.

\subsubsection{Welsh context}

Following devolution in 1998, the Welsh Government has a legal duty to sustainable development in all its functions. This presented a favourable policy landscape in Wales for the development of ESDGC. In the same year, the Environmental Education Council in Wales (EECW) was formed and the first sustainable development scheme called Learning to Live Differently, was adopted in November 2000 (Welsh Government, 2000). It follows that education as a major function of government would be a key vehicle for delivering the aims of this vision and an ESDGC Champion was appointed and an ESDGC panel established in 2004. Developments leading up to the publication of the ESDGC strategy in 2006 and subsequent developments are later described in Chapter 3.

Adult education has a long and rich history in Wales, beginning in the late 1600 s with literacy classes to enable people to read the Bible, which had been translated into Welsh. This was followed by the Welsh circulating schools in the eighteenth century, that used Welsh language materials and were open to all. During the Industrial Revolution, chapels, churches and the factory owners provided adult and community education, mainly through Sunday schools and later the Miners' Institutes, which were, until the later $20^{\text {th }}$ century, distinctive features of coalmining communities. These institutes became the hubs of adult learning, supporting miners in their quest for knowledge and self-improvement. They incorporated reading rooms and a library, primarily containing collections of books on philosophy, politics, economics and religion. The Workers Education Association (WEA) had a strong base in Wales and became part of the Labour movement in the late nineteenth/early twentieth century. In 2015, WEA Cymru and YMCA Wales Community College merged to form one body, delivering a range of adult education provision. This is now known as Addysg Oedolion Cymru/Adult Learning Wales. 
In the UK, publication of the Leitch Report in $2006,{ }^{8}$ Prosperity for all in the Global Economy: World Class Skills (Leitch, 2006), delivered a blow to 'liberal' adult education programmes, which had already experienced funding cuts but were surviving under the rubric of lifelong learning (Field, 2006; Schuller \& Watson, 2009; Usher et al., 2011). Lifelong learning implies learning throughout the life-course and "it is also a way of thinking about and structuring our society's approach to education" (Field, 2006: 2). It has, in the past, enjoyed considerable support, with the first UK Minister for Lifelong Learning appointed in 1997 under the 'New Labour' Government. At that time, there was a recognition "in the relatively innocuous world of intergovernmental think tanks such as UNESCO and the OECD" of its value (Knoll, 1998 cited in Field 2006: 11). Since then, the $21^{\text {st }}$ Century has seen the learning society become geared more towards jobs and the knowledge economy (Aldridge \& Tuckett, 2005; Castells, 2008, 2010; Giddens, 2003; Jarvis, 2008b).

ACL changed considerably at this time. Courses had to be accredited to attract funding and liberal adult education was under threat. The European Social Fund (ESF) which, given its low GDP, Wales benefited from, had, over the previous decade, funded many lifelong learning programmes where it had been possible to embed ESDGC. However, these varied and flexible learning programmes were also being terminated in favour of vocational provision. It is worth noting here that $23 \%$ of people in Wales live in poverty where household income is below $60 \%$ of the median (between $2013 / 14$ and $2015 / 16^{9}$ ) - the highest in the UK.

During the time of data collection for this thesis a constriction, repositioning and restructuring of $A C L$ in Wales was taking place. ACL strategic learning partnerships were being established, sometimes representing counties and sometimes representing clusters. All sectors delivering $A C L$ are represented on these partnerships, set up at the behest of the Welsh Government to strategically plan ACL provision for greater efficiency and to best meet local needs. Another wave of changes began in 2010, with the Conservative-Liberal coalition Government, as funding was redirected from ESDGC towards the economic and vocational agenda in lifelong learning, signalling further changes that influenced the implementation of the ESDGC strategy.

\footnotetext{
${ }^{8}$ http://www.delni.gov.uk/leitch_finalreport051206[1]-2.pdf

${ }^{9} \mathrm{https}: / /$ gov.wales/statistics-and-research/economic-indicators/poverty_wealth?lang=en [Accessed: 11/08/2018]
} 


\subsubsection{Researcher context}

Describing the researcher's background can provide valuable context for the research and contribute to the clarification of the subjectivity and positionality for the researcher. This section uses first-person narration to show how a number of experiential currents converge on the broad subject of this PhD.

Growing up in a coal mining community on the edge of the Brecon Beacons, social deprivation and its links with the exploitation of natural resources was a reality I became aware of from an early age. I spent a great deal of my childhood outdoors among the crumbling, rusting and often dangerous detritus left in the landscape once it became uneconomic to mine coal or smelt and refine metals.

My first degree was in Geology and I was interested in palaeontology and paleoecology, and I was also interested in education and its potential to change lives and societies. Literacy and education had influenced change in Nicaragua and I became involved with a local Nicaragua Solidarity group during the early 1980s, where most members were older people. One had served in the International Brigade in the Spanish Civil War (1936-39). I also became involved with the WEA (Workers Educational Association) in south Wales, as a tutor and development worker and holding committee positions in local groups. Through colleagues and people in my immediate environment, including my father, who would frequently talk about international politics, I became interested in issues of race, equality, poverty and power relations, alongside a continued interest in lifelong learning, ecology and the natural world.

I trained as a science teacher following my degree and shortly after began work in a development education centre in Carmarthenshire. I was involved in developing teaching materials which linked environmental and development issues. At that time, environmental and development education were separate; environmental groups did not want to engage in political discourses and most practitioners in development education were not recognising the links between environmental and human exploitation. Since then I have worked in a range of roles in environmental education: as the education officer at the National Wetlands Centre in Llanelli, then as education adviser for Wales with the Royal Society for the Protection of Birds (RSPB). I studied for an MA in Adult Education with the Open University, continued to work with the WEA, then worked for several years as a project manager for a large ACL partnership project in south Wales and as project manager in adult education at Swansea University. I have 
also worked in health-science research and as a freelance research and evaluation consultant. I taught ESDGC awareness to adult education tutors and FE tutors across Wales after the publication of the ESDGC strategy, and I draw on this experience and use evidence gathered during teaching for this present thesis.

\subsection{Significance and scope}

We need to take heart that EfS [Education for Sustainability] is indeed, of necessity, a life-long learning process, where much of our learning will take place outside the formal sector. If it were left to formal, statutory education processes to embed learning for sustainability we might wait for ever to develop a society which is able to live sustainably. (Parker \& Wade, 2008: 25-26)

There is little exaggeration involved in stating that very little work has been conducted on ESD or ESDGC in ACL; most research is undertaken in the formal education sector even though the significance of informal learning for ESD/ESDGC is recognised in the literature and in policy. The HE sector has seen a surge of interest in this area and, in 2000, the International Journal of Sustainability in Higher Education was launched. The academic discourses in ESD and ESDGC are largely from this HE perspective, and this is to be expected, given that academics are usually located here. However, these discourses do not always translate meaningfully into practice, particularly in post-16 education outside HE and, indeed, the formal sector per se. A review of the literature demonstrated that, as far as can be ascertained, there has been no research conducted on ESDGC in the ACL sector in Wales and very little internationally on ESD in Adult Education. There are many synergies between ESDGC and ACL that have not been previously examined in detail, and this thesis therefore explores new territory.

Empirical evidence from managers and tutors and those developing the ESDGC strategy is the starting point and stimulus for a conceptual enquiry which, when combined with an examination of the policy process as described by respondents, provides a different and valuable perspective. This can then in turn inform policy, theory and practice and indicate areas for further research. Hammersley (2002), in examining the links between research and practice in education, distinguishes between 'scientific' and 'practical' enquiry. The immediate audience for scientific enquiry is researchers and that of practical enquiry is primarily practitioners and policymakers; the aim of scientific research is to contribute to a cumulating body of knowledge about some aspect of the world, whilst practical enquiry aims to provide 
knowledge that will be of practical use (Hammersley, 2002: 123). In education, there is frequently a tension between the two forms of enquiry and this thesis takes a pragmatic approach that strives to include both orientations (Torres, 2013).

Examples of ESDGC in action are not examined in this case study. It is concerned with the perceptions of practitioners and policymakers, their feelings and thoughts about ESDGC and the strategy. Examining examples of good practice in ESDGC in ACL is beyond the scope of this thesis, which is concerned with identifying features that inhibit the full implementation of the strategy. It was decided that these would highlight areas that could be addressed for successful policy implementation, delivery and provision of ESDGC in ACL in the future.

\subsection{The structure of the thesis}

Following on from this introduction, the review of the literature provided in Chapter $\mathbf{2}$ grounds the research agenda and, within the limitations of this thesis, introduces a range of different perspectives. It is divided into two parts. The first part reviews literature associated with ESDGC and provides a background to the key concepts of sustainable development and global citizenship. The focus is maintained through examining literature relevant to key themes and discourses in $\mathrm{ACL}$ and to the research questions. The second part centres on adult learning. Some background on traditions and purpose are a precursor to reviewing literature on transformational learning theories and approaches. As a precursor to reviewing the literature on global citizenship and EGC, the concept of citizenship is examined. This clarifies some of the debates in ESDGC and begins answering the research question on why EGC was a neglected element in EGC in ACL in Wales. Key texts, that bring the concepts and practices of ESDGC together with those in $\mathrm{ACL}$, underscore the synergy between them and contextualise discussions later in the thesis.

The intent of Chapter $\mathbf{3}$ is to provide a more policy-oriented contextualization of the research. It begins by reviewing literature associated with policy in education, including the policy process and the introduction of change and innovation. This frames ESDGC as an educational innovation and provides evidence, through referring to empirical research studies, for discussing the development of the ESDGC strategy and its subsequent implementation in the ACL sector in Wales. Following the review, an examination of UN conferences and summits and their resulting reports and recommendations situates the ESDGC strategy within international 
policy discourses. Trends and policy drivers that have influenced ESDGC are highlighted. Relevant UK and Welsh policies relating to ESDGC and ACL are reviewed and policy drivers and influences that helped shape ESDGC in ACL in Wales identified and discussed. The review describes events up to 2016, Chapter 9 providing an update to 2018.

Having provided a comprehensive account of how the present research is situated in relation to the literature and policy context, Chapter 4 describes and discusses the methodology and the research process in detail. It includes a section on the case study design, examining validity and generalisability. The research paradigm and its theoretical and philosophical underpinning provides a rationale for the research approach which, through addressing the research questions, seeks to include and connect policy with theoretical and practical concerns that emerge in the findings. The different groups of research respondents are described, and the different data collection methods used discussed in detail. Concluding the chapter is a section on the analysis of the empirical data.

The findings from the empirical research are presented in Chapters 5 and 6 . The main themes and sub-themes that emerged from the analysis of the data are used to structure the chapters. Policy and related issues are covered in Chapter 5 , whilst Chapter 6 focuses on practical and operational issues and the policy-practice gap. The voices of people at policy level are to the fore when discussing the policy process and the voices of managers and tutors are used throughout the two chapters to illustrate points and provide evidence.

Chapter 5 begins by describing the characteristics of the research respondent groups and their professional roles and locations. An overall picture of the ACL sector in Wales and the challenges it faced in implementing the ESDGC strategy is provided through the words of research respondents, and a summary of the different sectors delivering $\mathrm{ACL}$ draws on data from managers in those sectors. Main themes in Chapter 5 include the policy process, hopes and fears, and the wider policy integration of ESDGC. Issues of representation and consultation are discussed as sub themes, and the hopes and fears of ACL managers and tutors encompass many of the different themes within the findings. Whereas chapter 5 has a focus on the policy process, Chapter 6 focuses on practitioner perceptions, their hopes, needs and concerns regarding the implementation of ESDGC. The policy-practice gap is one of the main themes. Features described by respondents that highlight operational and conceptual barriers to the implementation of the ESDGC strategy are also explored and examined here. 
Chapter $\mathbf{7}$ discusses the findings that relate to policy within the wider context of educational policy and innovation and literature reviewed in Chapter 3. The features identified as problematic are examined and discussions structured around key themes. The first substantive theme is 'policy' and this includes a range of issues that emerged from the findings such as roles, communication and representation, and the disjuncture between policy rhetoric and the realities of practical implementation. 'Vision and purpose' is the second theme. Within this, perceptions of the purpose of ESDGC are discussed; the importance of developing shared visions and issues of conceptual clarity are examined and connected to the broader literature. This is linked to the third theme which considers a behaviour-change model and the call for a paradigm change identified in the literature. Finally, the theme of 'community' includes examining and links between community development theory and practice and ESDGC, especially focusing on collective and citizenship discourses in ACL and their relevance for EGC.

The discussion in Chapter $\mathbf{8}$ is a more conceptual analysis of the findings. It addresses the research questions in a broader context, examining the synergies between ESDGC and ACL and the potential therein for a new approach to ESDGC. Transformational learning theories and approaches that resonate with both ESDGC and ACL are discussed, and other related discourses introduced and connected to the theory and purpose of ESDGC in ACL. From analysis of the data, it was deemed necessary to examine and clarify the concept of global citizenship. This contextualises a re-conceptualisation of ESDGC which is informed by the policy and literature reviews, the findings and previous discussions. A consideration of key elements of a pedagogy to support this re-conceptualisation concludes the chapter.

Chapter 9 provides a concluding statement summing up the contribution made by this thesis. It brings together the various elements of the research study and reviews the main findings as they address the four research questions. With reference to the generalisations possible in a case study of this sort, it draws conclusions and makes recommendations for policymakers, researchers and practitioners, to inform work related to ESDGC in post-16 education and the introduction of policies and their implementation in the future. 


\section{Chapter 2 \\ Literature Review: Grounding a Research Agenda}

\subsection{Introduction}

\subsubsection{Outlining the literature review}

This chapter reviews a broad literature that underpins the thesis and addresses the research questions. The review includes elements of a wide range of contemporary discourses that have, and are, influencing policy and practice in ESDGC and ACL. Whilst it cannot claim to be as comprehensive as the systematic literature reviews common in evidenced-based medicine and health science, and not unknown in the social sciences (Pettigrew and Roberts, 2006), it uses selection criteria and draws on the author's knowledge in a range of fields. Authorial judgements are made within the limits of the concerns and principles in ESDGC and ACL. One of the hierarchies for choices made was credibility, therefore scholars who have worked in the field and have a substantial body of literature are included as well as more recent works that explore emerging perspectives. Another consideration was maintaining a balance between literature that was relevant for policy, theory and practice. Chapter 3 (3.1) reviews policy literature that has informed this thesis.

It is precisely the broad range of discourses and influences involved here that can make ESDGC appear unwieldy and nebulous, as practitioners said many times during this research. However, it is in the breadth that the potential and possibilities for ESDGC in ACL exist, and it was therefore decided not to contract the review but to expand it from its initial starting point as outlined in Chapter 1. For example, an in-depth review of the literature on citizenship and global citizenship education was deemed necessary to fully understand the conceptual confusion that surrounded EGC. The choice of literature is guided by the need to clarify the conceptual elements of ESDGC and address the research questions.

Preliminary findings highlighted the need for conceptual clarity, and therefore, each of the constituent concepts in ESDGC is considered in turn. The 'piecemeal' delivery and provision of ESDGC in ACL is addressed and understood through the different debates in the literature about purpose, ideology and the different approaches to ESDGC as well as through the lens of 
policy (Chapter 3). The 'latent' or implicit contribution of ACL to ESDGC is highlighted in this literature review as theories in ACL are juxtaposed with those in ESDGC. The chapter concludes by reviewing literature on pedagogy to provide context and a grounding for discussing the difficulties surrounding EGC and ways forward. Definitions of key terms in the introduction are further clarified in this chapter, and it underlines the connections and synergy between discourses.

This literature review is in two parts:

- $\quad$ Part 1 - ESD and EGC

- Part 2 - ACL, pedagogy and conclusion

Part 1 begins by looking at the concept of 'sustainable development' before considering ESD through an examination of key discourses. These are chosen from among the multitude of perspectives as ones that address the research questions and are identified in the literature as being most pertinent. Literature that includes both ESD and ACL is then examined; this addresses the research question on the latent contribution of $A C L$ to ESDGC. Prior to reviewing the growing body of literature on EGC, a section considers 'globalization', 'citizenship' and 'global citizenship' as concepts that deserve attention if we are to fully understand EGC. Bringing the discourses of ESD and EGC together with reference to ACL summarises and concludes the first part of the literature review.

Part 2 outlines the main discourses in ACL that are relevant to this thesis, and through this, continues to examine ACL's latent contribution to ESDGC. Transformational learning is a focus within the review of literature, and some of the different perspectives and approaches pertinent to ESDGC are explored. A section on pedagogy includes elements contributing to a re-conceptualisation of ESDGC and a conclusion draws the threads of the review together.

\subsubsection{Literature searching}

A broad literature review was conducted before, during and following data collection, this includes the literature on policy, on ESDGC and on ACL. The university catalogue was used, through which a wide range of databases fed into the searches. Specifically, in science, these are: Web of Science, Scopus, Science Direct and the ProQuest Social Sciences and Humanities Database. Known journals, such as Environmental Education Research, Journal of Education for 
Sustainable Development, Globalisation, Societies and Education, International Journal of Sustainability in Higher Education and the International Journal of Sustainability in Education, were searched, and further searches were conducted based on references in relevant papers. The British Education Index and ERIC (Education Resources Information Centre) databases were used as was Google Scholar.

$\mathrm{ACL}$ does not have a database as such, so the university catalogue and specific journals were searched. These journals include: International Journal of Lifelong Education, Adult Education Quarterly, Journal of Adult and Continuing Education, Studies in the Education of Adults, Journal of Adult Education, and New Directions for Adult and Continuing Education.

In the second wave of the literature review, following the analysis of the empirical data, there was a focus on citizenship and global citizenship within a humanities context; there is no database associated with these and search terms associated with the research questions were used with the library catalogue of books and journals. Specifically, policy in ACL was searched, using search terms such as 'introducing innovation', and other themes such as 'hope' in ESDGC were searched using the databases and journals mentioned above. Further journals were explored, such as the Journal of Transformative Education, Critical Studies in Education, Educational Philosophy and Theory, Journal of Education Policy and the Journal of Education Policy.

The large amount of literature on schools, children and young people was not included unless it provided general theoretical and policy background. Studies looking at quantitative research tools such as scales for measuring attitudes and behaviour change or for determining baselines for evaluations and measurements are not considered in this review, even though a few have been referred to when they have relevance to this case study.

Time limits were not used in the first searches. However, as the research progressed there was more of a focus on literature from the past decade. Most of the literature is from Anglophone countries, and the UK was used as a search filter. Considering and including the voices of people from the global South to the extent that would do them justice was not possible given the focus of the thesis, and inevitable constraints. 


\section{Part 1}

\subsection{Education for Sustainable Development (ESD)}

\subsubsection{Clarifying the concept of sustainable development}

ESDGC is a composite concept that contains within it other complex and contested concepts; analysing the constituent parts is necessary to synthesise and articulate a holistic conceptualisation.

If we are educating for sustainable development, it is important to articulate inherent ambiguities; this thesis can only indicate some of these. "There is no such thing as a single unified philosophy of sustainable development" (Hopwood, Mellor \& O'Brien, 2005: 47) and there has been a proliferation of definitions and meanings attributed to it. Interestingly, from the first edition of her book on sustainable development in 1994, to the most recent 4th edition in 2012, Elliot's work $(1994,1999,2006,2012)$ illustrates a shift that is reflected across the literature. Conceptions of development move from a third world deficit model to a reflection on what development means in an increasingly globalised world, with rapidly changing technologies, economies dominated by global corporations and "development processes [which] are characterised by the loss or degradation of primary environmental resources" (Elliot, 2006: 1).

'Development' has traditionally implied economic growth and western cultural patterns, ideologies and models, and Milana, Rasmussen and Holford (2016) categorically state that maintaining the link between sustainability and economic growth supports the current and unsustainable dominant neoliberal paradigm. In a paper that examines the role of adult education and learning policy in fostering societal sustainability they argue for a rethinking of the ontology of sustainability. This, they say, can shed new light on its relationship with adult education through its foregrounding of social justice. Supporting this is an argument challenging the notion that prosperity is linked to economic growth by Jackson (2009a, 2009b), the former head of the UK government's sustainable development commission. His research demonstrated that social capital and relationships contributed to perceptions of prosperity and it was not solely an economic state. 
The Brundtland Report from the World Commission on Environment and Development (WCED, 1987) established an accepted definition of sustainable development: "Sustainable development is development that meets the needs of the present without compromising the ability of future generations to meet their own needs" (WCED, 1987: 43). However, this maintains the view of environment as resource within an economic growth model. The argument of economics having primacy over the social is an argument that reverberates throughout the literature on sustainable development and ESD. It is why some authors do not use the term 'development', preferring to use' learning for sustainability' or 'sustainability education' (Sterling, 2011a).

Blewitt $(2004,2004,2008,2013)$ is one of the few authors who examines sustainable development, ESD, adult education, lifelong learning and community. He sees sustainability as a heuristic (Blewitt, 2008: 51) and sustainable development as a 'dialogue of values' (Blewitt, 2008: 21). His comprehensive examination of sustainable development contains both an ecological grounding, seeing the human and natural world as one, whilst also discussing economic, social and cultural aspects of development. The interrelationship between the local and global is recognised (Blewitt, 2008: 2). However, Blewitt's assertion that sustainable development is simply "the idea that the future should be a better, healthier place than the present" (2008: ix) does not address complexity and dissonance, it is normative and highlights the problem that “one person's world of resource depletion is another person's world of resource abundance" (Redclift, 1989: 202). Over simplifying the issues, whilst making the subject and concept more accessible, does not provide the whole and plural picture.

A recurring theme in the literature is paradox and conflict within the concept of sustainable development as discussed above, and Redclift $(1989,2006)$ highlights the clash and divergence of environmental and political discourses. Besides these are the economic and social tensions discussed by Baumgartner and Korhonen (2010: 73) who examine the clash and gap between a natural/engineering science model and a social science model in the discourses of sustainable development. This, they contend has contributed to the current difficulties in clarifying definitions and concepts and can, in part, explain the lack of integration of ESD and EGC that was underlined in an Estyn (2008) report. 


\subsubsection{Key discourses in ESD}

ESD in the UK emerged from the coming together of development education and environmental education. This process began in the 1980s and 1990s and has been described and discussed by Bourn (2008), from the perspective of development education, and Sterling (2010: 216), from the perspective of environmental education. In Western Europe and North America in the 1980s, development education emerged as a community of practice; it is related to, and linked with, global learning and sometimes called global education. It includes human rights education, peace education, multi and intercultural education and global citizenship education, as well as ESD/ESDGC. Bourn (2000, 2005, 2008, 2011, 2014a, 2014b), Selby $(2006,2009)$ and Selby and Kagawa $(2011 a, 2014 a)$ are among those who discuss the history, theory, policy and practice of development education. Bourn states that:

"Development Education is an approach to education that is not generally well known" (Bourn, 2014a: 4); it has a strong critical element and Bourn focuses on critical pedagogical approaches and their impact.

In contrast, environmental education and the transition to ESD is discussed by many scholars in the field such as Bonnett (1999), Huckle (1993, 2004, 2006, 2008b), Jickling \& Wals, 2008; Kopnina (2012; 2014), Sauvé (1996, 1999), Sterling (2004b) and Tilbury (1995). The politicisation of the environment and environmental education is regarded as a central theme; a reorientation in times of increasing globalization and international consensus following the Rio or Earth Summit and Agenda 21 (UN, 1992a, 1992b). The need to politicise discourses in environmental and sustainability education is emphasised in the work of Sund and Öhman (2014) who draw on the work of feminist scholars to discuss universalism and cosmopolitan ethics. What is called for is "unmasking the political dimension, re-politicising education, seeing beyond the relativist and objectivist divide and using passion as a moving force" in ESD (Sund \& Öhman, 2014: 639).

Approaches in ESD reflect different ideologies and perspectives and certain themes and discourses are chosen for their relevance to the research questions. Scott and Gough (2003, 2004) provide an analytical overview of the central issues for learning and sustainable development in two volumes that explore a range of views, sometimes opposing ones. Inclusivity, multiple and plural perspectives and ongoing engagement with the complexities, debates and shifting political contexts emerge as essential elements. Authors in the field agree 
that ESD requires a multidisciplinary, and multi-layered approach. Jickling and Wals (2008) distinguish three broad approaches to ESD which they term 'Big Brother ESD', 'Feel good ESD', and 'Enabling thought and action'. These are self-explanatory and discussed later in the thesis.

An influential thinker in ESD with a strong environmental or earth-focused approach, Orr (1994) proposes an eco-centric approach and implores us to ask the fundamental question: what is education for? (Orr, 1994: 8). In his seminal work Earth in Mind, Orr (1994) questions the underlying paradigm and intent of Western education and is critical of the reductionist paradigm. Whilst not denying the need for political engagement and civic participation, this is not a strong theme in Orr's vision. However, Bowers $(2001,2002)$ and Jucker $(2002)$ are among those who, as well as stridently challenging the fundamental purpose of Western education and its role in promoting ESD, state that the dominant neoliberal ideology, and its values, are opposed to sustainable development. In a paper that examines key publications from the United Nations Decade of ESD, Huckle and Wals (2015) criticise UNESCO's approach for failing to challenge the neoliberalism at the root of most unsustainable development (Huckle \& Wals, 2015: 497).

Selby and Kagawa summarise some of the key issues.

Characterised by definitional haziness, a tendency to blur rather than lay bare inconsistencies and incompatibilities, and a cosy but ill considered association with the globalization agenda, the field has allowed the neoliberal marketplace worldview into the circle so the mainstream ESD tacitly embraces economic growth and an instrumentalist and managerial view of nature that goes hand in glove with an emphasis on the technical and tangible rather than the axiological and intangible. (Selby \& Kagawa, 2010: 37)

This emphasises the need for a paradigm shift, a transformation and a re-conceptualisation of ESD. A redefinition of terms therefore becomes necessary and Sterling uses 'sustainability education' as a

catch-all to include environmental education (EE), education for sustainable development (ESD), education for sustainability (EFS) and education for a sustainable future (ESF). Beyond these terms, 'sustainable education' is used to suggest a change of educational paradigm, rather than a modification of, or to, the existing paradigm. (Sterling, 2011b: 44)

Sterling calls for a focus on the education in ESD "towards a deeper attention to education itself: its paradigms, policies, purposes and practices (these are linked of course) and its adequacy for the age we find ourselves in" (Sterling, 2008: 63). He advocates a holistic, 
systemic and relational approach and reminds us that although the environment has become politicised in the discourses of ESD, this does not preclude our need to understand ecological processes and connect with nature on a physical, emotional and spiritual level, the axiological and intangible elements referred to by Selby and Kagawa above.

Sterling's work does not engage in ideology critique, but he advocates the need to adopt a different model from one that is informed by Western thought and imbued with dualism, dissociation and separation, and within this perspective, a holistic approach is frequently referred to (Welsh Government, 2009). Albeit universally recognised, holism is sometimes seen as problematic and a little naive as discussed by Stables and Scott (2002), but despite this "The quest for holism remains one voice in a continuing dialogue, or series of simultaneous and sometimes overlapping dialogues, about the environment and the human relation-ship with it" (Stables \& Scott, 2002: 53). It is an ideal to be aspired to in ESD according to Bonnett $(2002,2004)$ and Sterling $(2001,2003)$. Systemic or systems thinking is a related and prevalent discourse in ESD. Sterling (2003, 2004a) and others, including Bhola (2005) and Bonnett (2009), advocate a systemic view in line with holism and notions of an eco-pedagogy as advocated by Orr (1994) and Bowers (2001). The indivisibility of humans and their environment is a key motif in Sterling's work and viewing the world relationally (Sterling, 2010a) is another way of conceptualising systemic approaches.

A relational approach to sustainable development which explores an expanded concept of well-being is explored by Helne and Hirvilammi (2015). The resilience of the global ecosystem is at peril and "Since human well-being is totally dependent on the health of the ecosystems, we face the challenge of how we, along with future generations, will be able to live good lives - and even survive at all" (Helne and Hirvilammi, 2015: 168). It is not through a lack of knowledge and intelligence that we face environmental crisis because as many authors point out, it is leading scientists and economists that have created unsustainability, environmental degradation and human suffering. What is needed is wisdom and a different form of humane, ecological intelligence that includes feelings and emotions (Orr, 1994: 7, 16, 50). This holistic approach to learning and education is examined by Swartz and Tisdell (2012) and Tisdell (2011a, 2011b) through the lens of adult education theory, practice and purpose. Complexity and developing wisdom in challenging times are addressed.

Although advocates of holistic approaches allude to, or draw attention to, macro and geopolitical systems that leads to unsustainable actions ideology critique does not feature in many 
of the discussions; this aspect is frequently absent or lacking. In contrast, a perspective on ESD underpinned by critical theory is adopted by many authors including Huckle (1993, 2001a, 2001b, 2004, 2006, 2008a, 2008b, 2010, 2012a, 2012b, 2014, 2015), who consistently and explicitly critiques ideology in an overtly political approach that examines the dominant capitalist ideology that shapes our lives and our education system, underpins notions of sustainable development and has given rise to the current global crises (Huckle, 2010, 2012b).

Democracy, political participation and the discourses of citizenship are key features of Huckle's work. His focus on critical pedagogy and citizenship within the discourses of ESD resonate with ACL literature reviewed in Part 2. Critical realism (Huckle, 2004) and prospects for an ecological citizenship (Huckle, 2001a, 2001b, 2015) are strands that are also pertinent to the thesis. Huckle's work, like many authors in the field, focuses on the mainstream curriculum, his approach is practical and pragmatic. He advocates a critical and 'realistic' approach to ESD, one which is

More alert to issues of inequality, social class, and sustainability politics; more firmly anchored in the realities of the dominant forms of unsustainable development and underdevelopment shaping the contemporary world; and more attentive to the struggles of the workers and citizens to introduce more sustainable alternatives. My argument moves from sustainability as a frame of mind through sustainability ethics to political economy and the current crisis of neoliberal capitalism. (Huckle, 2012b: 35)

Affective learning elements are not prominent in his arguments, although he is attuned to relational learning in a broad sense:

It suggests that learning for sustainability is essentially about learning to value sustainable relations between people (social relations); between people and the rest of the bio-physical world (environmental relations); and between the elements that make up that non-human world (ecological relations). (Huckle, 2012a: 35)

\subsection{ESD and adult education}

\subsubsection{Key themes and discourses}

In Wales, there has been research on ESDGC in the schools' sector (Bennell \& Norcliffe, 2010; Notcliffe \& Bennell, 2010) and in HE where SQW Consulting (2009) looked at good practice. Glover, Peters and Haslett, (2011), Glover and Peters (2013) and Glover, Jones, Claricoates et 
al. (2013) focus on baseline and auditing tools in HE, however, this latter literature and this current thesis have divergent perspectives and approaches and are not addressing the same issues within ESDGC.

The lack of literature on ESD in ACL follows in part from environmental education's historical lack of prominence in ACL. Exceptions include Leal-Filho (1997) who presented an instrumental and scientific approach to adult education and environmental education. He made a significant contribution to starting conversations about the environment in $\mathrm{ACL}$ and saw the global environment as a unifying theme in adult education and lifelong learning.

More transformative approaches in environmental education that recognise the political nature of adult education in empowering individuals and mobilising collective action can be found in the work of Clover (2002) and Clover, Jayme, Hall and Follen (2013). Clover et al. (2013) examine and combine different discourses in ACL with radical and emancipatory environmental education which incorporate feminist and anti-racist perspectives and creativity. Clover criticises approaches in environmental education and ESD that centre on a behaviour change model, which ignores "the strengths, knowledge and power of people on the streets, as well as the larger structural and ideological problems at the root or environmental destruction" (Clover, 2002: 315).

Lifelong learning in the discourses of ESD is examined by Blewitt (2013) who refers to the Delors report (Delors, 1996) which:

Declared that learning throughout life would be one of the keys to our success and survival in the 21st century. The report presented as paramount the need to understand other people in the world and to fashion educational opportunities around four pillars': 1 learning to do; 2 learning to know; 3 learning to be; 4 learning to live together. (Blewitt, 2013: 25)

The global environment is a central trope in the works of some adult educators such as O'Sullivan (1999) and O'Sullivan and Taylor (2004) who discuss individual and social transformation through learning in a globalized world and who consider consciousness and cosmology within the discourses. Their transformational perspective is in response to the separation of the individual from community and the earth (O'Sullivan, 1999: 6). In his wideranging arguments Jarvis (2006b, 2008a, 2008b), a scholar in lifelong learning, also refers to the environment and to an emerging ecological consciousness. In his later work, Freire, the Brazilian educator and theorist, significantly referred to it as a vital element in any critical 
educational practice (Freire, 2004: 7).

\subsubsection{Community learning and collective approaches}

Non-formal community education is often cited as being crucial in raising awareness, building partnerships, and influencing action to engage people in working towards sustainability. However, community and community development are discourses often lacking in the literature on ESD, illustrating a disjuncture in the rhetoric. Agyeman (2005a, 2005b), Elliot (2012), M. Mayo (1997) and Warburton (2013) are among those who argue that sustainability can only be realized by reducing inequality and poverty in specific localities through appropriate, participatory and iterative policy creation through including the voices of disenfranchised and marginalised people, locally and globally.

Agyeman's $(2005 a, 2005 b)$ position is one that centres on social justice where the links between human and resource exploitation are examined. Agyeman's arguments focus on how vulnerable communities - those with less power - frequently suffer disproportionately because of environmental destruction and unsustainable practices. This is similar to the positionality of Bowers (2017) whose work in education is shaped by discourses of eco-justice (2001a, 2002, 2017). He emphasises a critical cultural ecoliteracy that values indigenous and traditional knowledge. Exploring community-centred alternatives to consumerism, he focuses on communities whose voices are not heard. His re-vision highlights the recognition of high and low status knowledge and the value systems that accompany them and contribute to systemic racism and prejudice (Bowers, 2001: 17).

Overall, despite the literature on sustainable development and ESD being permeated with the discourses of social justice, Bowers is one of the few who discusses the importance of understanding the differences in cultural ways of knowing. This perspective echoes that of Andreotti whose work is in the field of development education and $\operatorname{EGC}(2006,2011,2012)$. Bowers is critical of Freire, in that Freire does not take into account that not all people, at the deep symbolic level, share the modern understanding of the Enlightenment ideals of progress and individual freedom (Bowers, 2001: 2; Bowers \& Apffel-Marglin, 2005) and that people might not want to transform their values and beliefs that have lasted centuries and enabled them to live ecologically stable and sustainable lives. Similarly, Burns (2015) in a study on indigenous teaching about the whole self, which does not recognise a separation between 
people and nature, examines and advocates acceptance of multiple and different ways of knowing the world in an ecological pedagogy for sustainability. This is a context and landbased approach with a strong spiritual element.

Warburton (2013), in an edited collection that includes work on community development and sustainability, draws attention to the fact that even though sustainable development includes social and environmental domains, it is the environment that receives most of the funding. This is especially true in the areas of climate change and resilience. Fagan (2013) highlights the divide between the bio-physical and the social, and in his practice in the Scottish Highlands and Islands, he advocates taking the middle ground between biodiversity imperatives and human well-being. Whilst compromises must be reached in practice, integrating discourses as much as possible is preferable to proportioning.

Focusing on practice, on awareness raising and the potential of adult education and community engagement to realise sustainability goals, Tilbury and Wortman $(2004,2008)$ discuss the contribution community education can make in an Australian context. One of the strengths of $A C L$ is that it relies on and creates partnerships between government and community which are the cornerstones for engagement. Their critical overview highlights many of the issues in this current research such as the need for funding for community education. They highlight the need for academic research and echo the work of academics who discuss the connections, or lack of, between policy, theory and practice (Hammersley, 2002; Torres, 2013, Usher et al., 2011)

People living in poverty, struggling to make ends meet often conceptualise environmental problems as too distant (geographically and temporally). Why should they care? What relevance does it have to them and their lives? These were the findings of research by Burningham and Thrush (2001) for the Joseph Rowntree Foundation, and they argue that priority should be given to immediate problems, that the starting point is with local concerns. Sustainable development (and global citizenship) needs to be brought close to home, to be related to peoples' everyday lives. There are only a handful of authors who address local and community development in the context of ESD. Among these are O'Riordan and StollKleemann (2002) and Warburton (2013), who integrate the discourses of community engagement and development with those of sustainable development. However, these authors do not make strong connections with community learning. 
The 'connate' domain is discussed by Cotton et al. (2016) in their research with students on energy-saving behaviour. Their research "illustrates the potential risks of focusing solely on behaviour change and on individual action at the expense of collaborative or democratic endeavours" (Cotton et al., 2016: 3). Collective learning is not the same as community learning in $A C L$, but it is part of it. The social nature of learning in ESD is examined in an edited collection by Wals (2009) and the emphasis is on how people learn together, what they want to know and what is useful learning. Issues addressed include transcending social norms, resilience, building on people's experiences, the importance of dissonance and creating safe spaces for learning. Tilbury (2009) examines three key concepts which underpin the notion of social learning for sustainability: the need to challenge the mental models which have driven communities to unsustainable development; the need for new learning approaches which help us explore sustainability and build skills that enable change; and the need for utilising pluralism and diversity in joint explorations of more sustainable futures (Tilbury, 2009: 118).

Even though the literature above addresses different contexts and the authors perspectives or the lenses through which they examine sustainability and ESD are different, there is a common thread. That is the need for dialogue between community and sustainable development, where community is the ecological embodiment of where living, working and learning take place; it is the site of relationship between people and people and the environment.

\subsubsection{Behaviour change}

Challenging and changing people's behaviour to realise the goals of sustainable development is a prominent discourse in, and driver for, ESD and ESDGC, particularly in relation to action for climate change. Literature on behaviour change in ESD is referred to in this thesis, but, as Bourn (2008) and other including Clover et al. (2013) state, behaviour change is complex, and concentrating on it detracts from real education and learning, and from authentic engagement and structural change. Therefore, it is not an explicit focus, and the literature provides some background rather than a substantive grounding to the thesis. However, as Pykett (2016), in an outline of behaviour change in social policy, points out: policy is increasingly being devised with behaviour change in mind. "Whilst governments have always been implicated in shaping the behaviour of citizens, a more explicit governmental agenda of 'behaviour change' has emerged recently" and this "raises important political and ethical issues" (Pykett, 2016: 55). 
Empirical work and modelling in behaviour change brings the disciplines of psychology and behavioural science together (Bamberg \& Möser, 2007; Biel \& Thøgersen, 2007), and in relation to ESD, Kollmuss and Agyeman (2002) and Stern (2000) propose models and frameworks for looking at pro-environmental behaviour change. They note that, despite research in this area (Agyemean, 2002; Palmer, Suggate, Robottom \& Hart, 1999), there is no explanation or solution regarding the gap between knowledge and behaviour and in a review of the literature on environmental education and behaviour change, Heimlich and Ardoin (2008) conclude that a lack of understanding about how and why behaviours occur is perhaps the greatest barrier to effecting change in ESD. As well as underlining a gap in collective approaches, Cotton et al. (2016), found that focusing on behaviour change without simultaneously enhancing understanding was not effective in eliciting pro-environmental behaviour change. This corroborates the view that a different approach is needed.

Whilst individual behaviour change is often seen as a goal of ESD, a social perspective is presented and promoted by Van Poeck and Vandenabeele (2012) who emphasise the importance of articulating sustainability as 'public issues'. Invigorating the public sphere though pedagogy in ACL is also explored by Biesta (2012) and relates to civic action, concepts of active citizenship and addresses issue of public togetherness. This is behaviour change with a foundation in collective learning and approaches as addressed in Part 2 of this review.

\subsubsection{Conclusion}

ESD has an ever-expanding literature which is becoming more diverse. A growing body of literature is found in HE where a great deal of the research in this field is conducted. However, despite the many references across all education sectors, subjects and approaches to adult education theorists, there is little explicitly connecting ACL theory and practice within ESD. This section has reviewed literature that increases our understanding of a range of different perspectives and debates in ESD; it has also underlined certain areas where synergy exists synergy between $A C L$ and ESD. The latent contribution of ACL to ESDGC through community approaches and citizenship discourses become apparent through this literature, and it contributes to an understanding of, and explanations for, the ad hoc delivery of ESDGC in ACL. 


\subsection{Education for Global Citizenship (EGC)}

\subsubsection{Introduction: globalization and citizenship}

The literature associated with EGC provides insights into why it was problematic in $A C L$ in Wales. It identifies elements of the 'latent' contribution of ACL to ESDGC, and the various conceptualisations of global citizenship and orientations in EGC provide a rationale for a reconceptualisation.

Firstly, some of the background literature on globalization and citizenship is outlined, because understanding these antecedents of global citizenship and how they are variously conceptualised is vital if educators are to meaningfully integrate EGC with ESD. As Axtmann (2010: 28) observes, 'globalization' is a meta-narrative featuring in a wide range of works in different domains. It is understood as a process that relates to the interconnection of economies, cultures and societies and became part of our common vocabulary in the 1980's as it was increasingly linked to the global market. It is the speed, scope, velocity and intensity of today's interconnections that characterise globalization which is a process whereby we become increasingly interdependent.

Many authors such as Held $(1995 a, 2000,2010)$ chronicle the process of globalisation, and Held and McGrew $(2000,2002)$ and those who address the meta-narrative such as Castells (2008, 2010), Bauman (1998, 2001a, 2001b, 2013) and Beck (1992, 2000a, 2000b, 2011) agree that the view of globalization, seen as the uniform spread of modernity, progress, western capitalism, democracy and the ideas, ideals and ideologies therein should be rejected. Instead they contend that it serves a powerful minority and creates more and greater inequalities on a global scale. "The effects of the condition (globalization) are radically unequal", it is a destructive force, producing new economic and geopolitical patterns of inequality (Bauman, 1998: 2).

Offering a positive, hopeful voice in the discourses of globalization is adult educator M. Mayo $(1997,2005)$. She looks at the spread of democratic ideals through networks of NGOs and community groups focused on global concerns about the environment and human rights; a process imbued with learning that could, she contends, lead to a global civil society. Mayo's view is one of hope and optimism, where the discourses of ESD and EGC find a place within 
adult learning. Themes include democratic participation and citizenship specifically.

Globalization and its effect on ACL policy and pedagogy is explored by many authors in adult education such as Edwards and Usher (2007) and Jarvis (2006b, 2007) and discussed below in Part 2.

Scholars in global education and global citizenship often prefix their work with an introduction on citizenship, and Gaudelli (2003) and Schattle (2008a, 2012) emphasise the importance of understanding this core concept before fully comprehending the discourses of EGC. Citizenship has traditionally been linked to the nation state (Heater, 2013) and "the creation of such a bond between citizenship and nationality, however problematic and restricted, has been seen as strongly influencing the nature of education offered within nation states" (I. Davies, Evans \& Reid, 2005: 69). Gaining some understanding of this is important, and even though it is not possible to examine the large and diverse literature on citizenship and its different typologies, it is worth examining citizenship literature as a precursor to looking at global citizenship.

The origins of citizenship and the different traditions thereof are outlined by Delanty (2000), Heater (2004, 2013), Lister (2003) and Pattie, Seyd and Whiteley (2004). Authors agree it is a contested concept, traditionally linked to bounded states or countries dating back to Greece. Citizenship has traditionally been associated with a status, conferred through membership of a community, usually a political one, defined by governance, legislation, an ethical code, or codes of conduct. This is in keeping with the liberal definition of citizenship (Marshall, 1950: 28-9) based on civil, political and social rights. It is now strongly contested in the context of globalization, but it persists as a dominant model. Other recognised citizenship traditions include the civic republican and communitarian models (Delanty, 2000; Dobson, 2003a; Heater, 2013; Pattie et al., 2004: 137). Central to the civic republican model is an ethic of civic virtue where serving the common good is how people fulfil their potential as citizens. In this model, involvement in public life is more important than private or personal interests, in contrast to the liberal model which prioritises the individual and individual freedoms. Yet, ideas on citizenship all include certain fundamental elements, namely participation, rights, responsibilities (duties/obligations) and identity (Williams \& Humphrys, 2003: 4).

Pattie et al. (2004) document and discuss the findings from the 'Citizenship Audit', a survey conducted in 2000-2001 with 13,999 British adults. The study concurs with Lister's (2003) perspective on the exclusive nature of the public sphere, where those "whose networks, 
associational life and involvement in politics is very limited" are excluded, in comparison the more affluent and educated who dominate public discourses (Pattie et al., 2004: 267-268). Lister's feminist analysis $(1997,2003)$ highlights the need for an inclusive citizenship given that patriarchal and Western cultural ideologies have dominated and contributed to the language and practices of citizenship. This argument is extended to the global sphere by Andreotti, (2010), Cabrera (2010) and Torres (2006) who have the experience of marginalised groups, particularly in the global South, at the centre of their expositions on global citizenship. In short, as with globalization, citizenship can be seen as 'exclusive' and selective in its benefits; this, and its diverse conceptualisations can, in part, explain misunderstandings of EGC.

\subsubsection{Global citizenship}

Notwithstanding the problem of 'citizenship', clarifying what we mean by 'global citizenship' is essential (Schattle, 2012). The Greek philosopher Diogenes, around 400 BC, said he was a citizen of the world; it is not a new idea, but it is problematic as it brings with it the discourses outlined above and expands these into a global frame of reference.

Global citizenship and its links to global learning are summarised succinctly by Davies (2006) in her examination of the usefulness of the concept in schools' education:

What seems to happen with global citizenship education is a confirmation of the direct concern with social justice and not just the more minimalist interpretations of global education which are about 'international awareness' or being a more rounded person. Citizenship clearly has implications both of rights and responsibilities, of duties and entitlements, concepts which are not necessarily explicit in global education. (Davies, 2006: 6)

Key cosmopolitan and global citizenship discourses are outlined by Delanty $(2000,2006)$ and many others (Heater, 2001, 2002; Hayden, 2005; Linklater, 2002, 2010), and the dilemma of citizenship in an age dominated by global capitalism, where individuality, individualization and autonomy are promoted above all else is a key theme in Delanty's work. Parallel arguments that see the nation-state caught between individualization and the forces of globalization, where collectivism can be lost, are emphasised by Beck (2000a, 2000b, 2011) and Castells (2010).

Whilst global citizenship and cosmopolitanism are terms often used interchangeably, cosmopolitanism is associated with more neoliberal, universalist perspective centred on 
Western ideas and ideals (Tully, 2014). Nonetheless, cosmopolitanism is frequently used to suggest a moral community and Dower (1989) believes we have a responsibility to work towards creating a more egalitarian world. He consistently recognises the environment as one of the main ethical concerns and unifying elements in a globalizing age (Dower, 1989, 2005, 2007) and is thus not a sceptic; he sees how certain aspects of the 'common good' can unify humanity. Similar ethical discourses about, and for, global citizenship can be found in the work of philosophers Singer $(2004)$ and Rorty $(1989,1998)$, who both contend that it is wrong for leaders to give absolute priority to the interests of their own citizens. Instead there is a moral obligation to feel a sense of solidarity with all other human beings. Singer extends the arguments to include non-human life whilst Rorty examines ethics from a pragmatic standpoint.

Gerzon (2010) and Schattle (2008a, 2008b) pose the question 'who is a global citizen?' Both are concerned with acting as global citizens. Gerzon (2010) does not question political realities, he looks mainly at internationalisation and cross-border thinking and working and the five levels of globalness which he proposes are hierarchies. This is problematic when applied to learners as there is always the dichotomies of better or worse, less or more. Employing heuristics to analyse visions of global citizenship, Gaudelli (2009) identifies the main discourses as: neoliberal, nationalist, Marxist, world justice/governance, and cosmopolitan whilst Schattle (2008b) sees it aligning with four ideological constellations: moral cosmopolitanism, liberal multiculturalism, neoliberalism and environmentalism. Each of these are Anglo-centric perspectives, and even though Schattle (2008b) presents an integrated, plural model, the agenda is not one of transformation.

In a review of the literature on global citizenship Oxley and Morris (2013) present typologies intended for educators. They identify two general forms of global citizenship: cosmopolitan based and advocacy based. The former incorporates the political, moral, economic and cultural and the latter incorporates the social, critical, environmental and spiritual (Oxley \& Morris, 2013: 301). Their categories include both normative and empirically grounded conceptions and they identify different approaches currently used to describe and distinguish models of global citizenship, such as the use of binary polarisations by Andreotti (2006), who juxtaposes soft v critical or Tully's $(2008,2014)$ modern v diverse, with the 'diverse' orientated towards freedom of participation. Another approach identified by Oxley and Morris is based on underpinning ideology, and it is this approach that this thesis focuses on (Andreotti, 2006, 2011; Ellis, 2013, 
2015, Huckle, 2015; Johnson \& Morris, 2010). Typologies and models provide clarity in a diverse field, however, whilst being useful, they can oversimplify the issues, for example, the moral and economic can be de-politicised and economic discourses lack reference to the cultural and moral context. There is a need to remain critical and engage with complexity.

One of the categories identified by Oxley and Morris (2013) is environmental global citizenship. Dobson places the environment at the centre of his work on green political thought (Dobson, 2000,2005 ) and ecological citizenship (Dobson, 2003a). He emphasises that "Globalisation is an asymmetrical process in which not only its fruits are divided up unequally, but also in which the very possibility of 'being global' is unbalanced" (Dobson, 2005: 262). Hence there is a need to re-appraise citizenship in a global, ecological context where responsibilities come to the fore and to redress the emphasis on rights in the liberal model. The environment is increasingly recognised as a key dimension in the discourses of globalization, especially as part of climate change discourses (Held, 2010).

Global citizenship "can be seen as part of commitment to a broad moral purpose or as a directly political form or social action that has global consequences" according to Bourn (2014a: 83). These are not mutually exclusive and the moral and political can combine in a form of education that recognises that there are many different pathways to global citizenship. Tully (2014) emphasises that "Many of the central and most enduring struggles in the history of politics have taken place in and over the language of citizenship and the activities and institutions into which it is woven" (Tully, 2014: 3) and he proposes the idea of a public philosophy approach towards examining new ideas and conceptualisations of global citizenship. This model has much in common with $\mathrm{ACL}$, in that it is not concerned with developing normative theories, it is self-reflective, critical, practice has primacy and it questions deeply held assumptions and aims to empower people to participate (Tully, 2014). It is essentially, informal, collective learning.

\subsubsection{Citizenship education and ACL}

Before considering the literature on EGC it is worth examining citizenship education from which we can possibly learn lessons and gain understandings and insights to address the research question on the latent contribution of $A C L$ to $E S D G C$ and also the question on problematic issues relating to EGC. 
There has been a proliferation of interest in citizenship education in the first decades of the 21st century according to Brooks and Holford (2009) due to the rise of extremism, population migrations and civic unrest. The UK report Education for Citizenship and the Teaching of Democracy in Schools (Crick, 1998) stressed the importance of political literacy and democracy and Crick $(1998,2000)$, who is an influential voice in citizenship education in the UK, develops this theme, which encompasses global citizenship, democracy, values and anti-racist perspectives. However, the anti-racist perspective is not fully developed by Crick.

There is an empirical void in adult education and citizenship education according to M. Mayo and Annette (2010) because young people are the focus of initiatives and research. Most of the contemporary research and literature on citizenship education relates to formal, school's education and stresses that this is an education that prepares young people for becoming citizens. 'Adult' is equated with citizen (Callan, 1997; Crick, 1999; I. Davies et al.,2005; L. Davies, 2001, 2006; Lister, 2003; Osler \& Starkey, 2006). "The schools-focus of much provision is also underpinned by the belief that it is young people who are perhaps most in need of citizenship education, and who may - by virtue of their age - be most inclined to change their behaviour and/or attitudes as a result" (Brooks \& Holford, 2009: 12). In Wales, the crosscurricular theme ' $Y$ Cwricwlwm Cymreig' is a focal point for citizenship education. It relates to the Welsh cultural dimension of the curriculum and was the focus of a study on citizenship education by Andrews and Lewis (2000). They found that citizenship was a neglected area of the school curriculum, and Bennell, Egley, Norcliffe and Sullivan (2011) who conducted research on citizenship education in schools in Wales concurred with Andrews and Lewis' findings.

In contrast, citizenship is well developed in $\mathrm{ACL}$ and is central to and implicit in much of the literature on adult education and in the policy rhetoric of a learning society (Fryer, 2010; Martin, 2003; Preece, 2006). There are historical connections between adult learning, popular education and the emergence of the public sphere (in Europe). Fostering participation and deliberative democracy is central to the purpose of lifelong learning according to many educators including Annette (2009a, 2009b, 2010), Biesta (2011, 2012), Brookfield (1995), Dewey, (1916), Freire (1970a) and M. Mayo (1997).

Adult education and citizenship are inextricably linked in the discourses of community development or community regeneration as variously termed according to Annette (2010). The Active Learning for Active Citizenship (ALAC) project is an English programme launched in 
2004 that advocates the participatory and experiential leaning model of Paulo Freire'; outcomes include: increase levels of participation in civic activism, increased roles within communities, particularly in leadership roles, and increased skills and confidence for participation, particularly for those from disadvantaged communities (M. Mayo \& Annette, 2010). In the ACL literature the 'active' element is central, however, English and P. Mayo (2012: 51) are critical of work on citizenship in ACL that does not include enough emphasis on social, collective learning and action.

The research findings of M. Mayo, Gaventa and Rooke (2009) illustrate the importance of community-based learning for active citizenship in the UK. They highlight "the relevance of the global and indeed the regional levels, when addressing concerns with active citizenship, locally" (M. Mayo, et al., 2009: 161) and the findings of research by M. Mayo and Rooke (2006) include the need to listen to community voices and a recognition of difference and shared political identity which contributes to an understanding of global interdependence.

Merrifield (2010) discusses the skills agenda in the context of citizenship education and she comments that throughout education in the UK, where skills for employment and economic competitiveness have come to the fore, the space for citizenship education in ACL has all but disappeared (Merrifield, 2010: 269). M. Mayo concedes that making a difference locally in the context of neoliberal globalisation is not easy but is part of the ACL project where active learning for adults should be firmly rooted in civil society itself (M. Mayo, 2010: 53).

The literature demonstrates the tradition in $\mathrm{ACL}$ of placing a strong emphasis on empowering people in order that they can participate in civic life in keeping with Dewey's vision (Dewey, 1916), which is not simply about democratic opportunities, but includes participatory democracy as part of pedagogy (Annette, 2009b). Participatory approaches, citizenship discourses and pedagogy are all part of ACL latent contribution to ESDGC.

\subsubsection{Education for Global Citizenship (EGC) and ACL}

Torres is one of the few critical adult educators whose work moves between adult education (Torres, 2013) and global citizenship education (Torres, 2015). He sees global citizenship as part of a project for social justice and transformation which is recognised as especially challenging in the current political climate. In a UNESCO paper that examines global citizenship 
education Tawil (2013) discusses a continuum of possible approaches, from the conservative to the progressive. He highlights political and ethical dimensions and conceptualises EGC as a paradigm that can frame the collective purpose of education (Tawil, 2013: 4).

One of the key objectives of EGC is to stimulate political participation within a global frame of reference (I. Davies et al., 2005; Evans, Ingram, MacDonald \& Weber, 2009) and ACL therefore has a critical role in challenging unequal global systems and reducing poverty according to Bhola (2005) and Veen and Preece (2005). "Adult education over the lifespan, which relative to other sectors of education has the most important role to play in projects helping to reduce poverty reduction worldwide, is regretfully the least supported by the policy elite" (Bhola, 2005: 405).

Reflecting on the American higher education system, Nussbaum (1997), in her discussion of global citizenship, moves beyond the knowledge based, rational curriculum to talk of love and imagination and of the importance of examining our lives in the context of the lives of global others. For Nussbaum $(2002,2010)$, global citizen education involves working "To make all human beings part of our community of dialogue and concern" (Nussbaum, 2010: 9). She discussed concentric circles of concern moving from self to intimates into society and the world in the same way as Whiting, Konstsntakos, Misiaszek, Simpson and Carmona (2018: 7) represent stoic cosmopolitanism as concentric circles moving from self to earth. There is not however, a homogenous humanity, and Todd (2011) is critical of the liberal visions promoted by Nussbaum (1997). Todd (2011) strongly advocates a plurality which is not simply about cultural diversity but is a complex and ontological recognition and acceptance of difference within a universal or global web of relationships and interdependencies.

Education is sometimes promoted as a panacea, a modernist project, helping us create a better future, but Todd feels we must be more contingent, modest and accept imperfection in all its forms (Todd, 2015). She points out that philosophers in the West define humanity and the human condition, usually without reference to ecology or our connection with nature, hence citizenship is often visualised as the Western, urban human (Todd, 2009: 11).

Post-colonial perspectives are recognised as being important in $\mathrm{ACL}$ by English and $\mathrm{P}$. Mayo (2012) and examples of this perspective in EGC include the work of Andreotti (2006, 2010, 2011), Andreotti and de Souza (2012), Mignolo (2010) and Pashby, Ingram and Joshee (2014). These authors challenge the Euro centric and Western assumptions that underpin educational 
structures, practices and philosophies, including those in ESD. Within Andreotti's work, which is informed by work from the global South, there is a strong emphasis on critical pedagogy that questions ontological and epistemological assumptions. Our ways of being in and knowing the world, highlighting epistemic racism and paternalism and invisible prejudices are included in pedagogical de-colonial perspectives, and Andreotti (2011) highlights the tension between a rational, academic analysis and the pull towards a deeper, more embodied pedagogy. Her call for a more passionate engagement echoes Sund and Öhman who argue for "using passion as a moving force" (Sund \& Öhman, 2014: 653). A "pluri-versal response and confrontation with universal Eurocentrism" is called for (Mignolo, 2010: 126) as the assumptions of a dominant culture, no matter how well meaning and global in perspective, cannot go unexamined.

In a similar vein, Pashby, Ingram and Joshee (2014) examine citizenship education for immigrant adults and compare it with secondary school curriculum in Canada. Both programmes foreground a neoliberal vison where social justice and diversity are deemphasised. Their findings "reveal how colonial legacies and historical discourses of citizenship remain present in both $\mathrm{K}-12$ policy and adult immigrant citizenship education materials." (Pashby et al., 2014: 19). Through reviewing literature from liberal democratic contexts (Pashby, 2011) and from examining the work of PhD students on critical global citizenship education (Eidoo, Ingrams, MacDonald, Nabavi, Pashby \& Stille, 2011), the need for a reconceptualisation of citizenship and global citizenship that is not based on normative Western assumptions emerges as a priority. Eidoo et al. (2011) examine a wide range of theoretical work on multiculturalism, race, religion, gender, language and literacy, and ecojustice, and insights from the intersections of these discourses result in principles for pedagogy. Uncritical approaches, oversimplification and reinforcing cultural hierarchies results, according to the authors, in superficial understandings and practices. Unfortunately, this paper does not go into much depth on the perspectives, but the multi-voiced examination provides insights related to this current thesis.

\subsection{Bringing discourses together in ESDGC}

Estyn (2008) found very little integration of ESD and EGC in ACL in Wales and examining the literature on why and how ESD and EGC are being integrated, or not, helps address conceptual clarity for future policy development and implementation. 
Increasingly, discourses, debates and issues within ESD and EGC are merging and have come together in Wales as ESDGC. ESD has been the more prominent form of education, however, Bamber, Bullivant, Glover, King and McCann (2016) in their review of ESD and ESDGC policy and practice for in teacher education across the four nations of the UK highlight the growing importance of global citizenship in UK policies. It provides an inescapably political dimension. Huckle and others promote it as a means of using critical, deliberative, democratic approaches (Huckle, 2001a, 2001b, 2014; Huckle \& Wals, 2015).

Environmental global citizenship can provide a unifying concept (Dobson, 2003a) and a new theoretical space (Valencia Sáiz, 2005) where global citizenship and sustainable development discourses come together. A re-imagining and a re-construction of notions of citizenship and global citizenship are called for in the literature and an ecological ethos is a key discourse that many authors are recognising. There is a need, as Valencia Sáiz (2005) puts it for 'a new architecture' for global citizenship and the global environment is a cornerstone in this.

Parker, Wade and Atkinson (2004) bring local and global concerns together with the integration of development and environmental discourses and there are other perspectives that bring ESD and EGC together such as futures studies which is an often-neglected temporal dimension in education. With the advent of the Future Generation Act in Wales (See Chapter 3) ideas about the future have added relevance. Hicks (2001a, 2001b, 2002), who focuses on futures education, does not discuss $A C L$ in his work which centres on schools and young people, however, his holistic perspective links local to global and he recognises the central importance of "sustainable futures in which the welfare of both people and planet are of equal importance" (Hicks, n.d). Values is another discourse that unities themes but is not explicitly discussed as a separate form of education here. It is recognised as a fundamental approach that is inherent in the purpose of education (Biesta, 2010). Discussing values in EGC, Biesta (2010) considers that there is a deficit due to the prevalence of evidence-based practice, which is primarily concerned with questions of truth and normativity and reduces complexity. This in turn raises question of power and the inclusion and exclusion of certain discourses in education (Biesta, 2010: 500).

Sustainable citizenship is a term used by Huckle (2014) and Dobson (2011), it emerges from the discourses of ecological or environmental citizenship. It is understood as a citizenship that moves from the human sphere to include all life and life support systems, includes the private sphere as well as the public. It has a global and critical perspective. Writing from a progressive, 
transformational perspective Kahn and Kahn (2010) take an earth-focused position which places ecoliteracy and critical pedagogy on an equal footing. Ecopedagogy is emerging as a field where critical discourses come to the fore and where environmental discourses merge with those of citizenship and global citizenship. Misiaszek (2016) through extensive research with eco-pedagogues and with scholars of citizenship, concurs with many authors on the need for a paradigm shift in education and concludes that ecological pedagogy is an essential part of citizenship education (and vice versa). In the work of these authors, social justice is inseparable from environmental discourses and Misiaszek echoes the work of Bowers (2001, 2017) in that the connection between environmental degradation and social injustices is central (Misisazek, 2011). His work is rooted in critical pedagogy traditions and he addresses the concerns that become apparent in this current thesis relating to the need to reframe the concept of development in the context of ESD and to consider, as he calls it, "multiple citizenship spheres" (Misiaszek, 2016: 604). Similar to Ellis (2013, 2016), Misiaszek's research focuses on the views of educators and he has explored this area of work in adult education in north and south America (Misiaszek, 2012). Transformation, social justice and a need to save the planet from environmental destruction are key characteristics (Misiaszek, 2011, 2015, 2016, 2017).

Huckle and Wals (2015: 492) use the term 'global education for sustainability citizenship (GESC)', further illustrating the coming together of ESD and EGC and 'Global citizenship as sustainable development' is how Ellis $(2013,2015)$ brings together ESD and EGC in her work on critical global educators (Ellis, 2013: 22). She conducted research with those who identified as global citizens and educators: teachers, NGO workers, teacher educators, civil society stakeholders and academics. It was a lack of coherence in theory and praxis she says, that prompted her to use critical realism as the lens through which to explore a new approach to global citizenship pedagogy. This resonates with this current thesis. However, aspects of Ellis' work, such as the stratified critical realist ontology, where the physical, chemical and biological are separated does not represent the holistic, ecological, systems approach that is advocated (Ellis, 2015: 9). She and Schattle (2008) conduct research with those who identify with or are committed to global education or global citizenship education, they are educated, many are internationally mobile and represent elite cohorts. This is in contrast to the respondents in this current research who are a more mixed population. 
UNESCO is integrating ESD and EGC, for example, 'Global Citizens for Sustainable Development' is the title of a recent UNESCO guide for teachers (UNESCO, 2016) and UNESCO's Asia and Pacific Bureau for Education use the term Education for Sustainable Development and Global Citizenship ${ }^{10}$. In a review of global education in schools across Europe, it was found that sustainable development and human rights were included under the heading of global citizenship, global learning and development education (Tarozzi \& Inguaggiato, 2016: 23), and although this research was conducted in primary schools it indicates a trend where sustainable development is increasingly linked with, and subsumed within, global citizenship discourses.

Part one of the literature review has underscored the complexity of ESD and EGC and the discourses relating to EGC begin to explain the problems associated with EGC. Some of the links between ACL and ESDGC have been made and Part 2 explores these further.

\section{Part 2}

\subsection{Adult and Community Learning and ESDGC}

\subsubsection{Introduction}

This second part of the literature review examines the adult education and lifelong learning literature that underpins the thesis, some of it overlapping with the literature in Part 1. The overarching discourses of the learning society and learning for social change briefly contextualise ACL before transformational theories and approaches are examined. Adult education covers a broad range of provision; however, the focus is on informal learning that often takes place in the community. The review examines theories and approaches that help us understand the 'latent' contribution of ACL to ESDGC, it examines similarities and synergy in the discourses to make this more explicit. Building on the concepts discussed in the preceding sections, literature on learning theory and pedagogy are examined for their contribution to a theoretical re-conceptualisation of ESDGC discussed in Chapter 8. Social movements, trade union and work-based learning are not included although there is some reference to specific examples relating to ESDGC.

\footnotetext{
${ }^{10}$ https://bangkok.unesco.org/theme/education-sustainable-development-and-global-citizenship
} 
Usher et al. (2011), from a postmodern perspective and Brookfield (1995) from a critical one, decry the weakness of adult education theory which has, generally, been secondary to considerations of practice and experience. However, there are different theories of adult education and learning, and whilst it is not possible to give a comprehensive account, transformational learning and the emancipatory traditions of adult education provide insights that address the research questions.

\subsubsection{ACL discourses as part of a latent contribution to ESDGC}

By way of an introduction, a range of discourses including informal learning, lifelong learning and the emancipatory model of adult education are discussed. Ecological visions are introduced, and the section concludes by examining the way in which different discourses intersect.

Lifelong learning in Anglophone countries means from cradle to grave but is often a term used to imply learning in adults (Field, 2006; Jarvis, 2006b, 2007, 2008a, 2008b; Merriam, Caffarella \& Baumgartner, 2012; Schuller \& Watson, 2009). It is "a way of thinking about and structuring our society's approach to education" (Field, 2006: 2). Public policy drivers exert a strong influence on lifelong learning, and currently in Wales, the UK and Europe, there is an emphasis on adult education as part of the skills agenda for economic growth (English \& P. Mayo, 2012; Leitch, 2006; Welsh Government, 2010). However, policy continues to acknowledge that adult education "also provides equally valuable benefits for individuals, families, and their communities, opening up new learning pathways and promoting social justice, health and wellbeing" (Welsh Government, 2010: 2). The report of the inquiry by the National Institute of Adult Continuing Education (NIACE) to develop a coherent strategy for lifelong learning (Schuller \& Watson, 2009) identified 'citizenship and belonging' and 'sustainable development' as two main themes. Adult education has traditionally placed importance on concepts associated with citizenship as seen in Part 1 of this review, whilst sustainable development as a substantive topic in the discourses of lifelong learning has remained on the periphery.

In the UK, informal learning is the submerged two thirds of the iceberg according to Coffield (2000a) who has extensively researched and written on the ACL sector. Nonformal or informal adult education according to Taylor (2008: 81) is "typically described as more focused on the present, learner centred, less structured, and responsive to localized needs, and there is an 
assumed non-hierarchical relationship between the learner and the nonformal educator". This is of course idealised. Tough (1979) demonstrated that most adults undertake self-directed learning projects outside of school or work-based training, usually as part of informal learning initiatives; other authors acknowledge this (Jarvis, 2004; McGivney, 1999; Merriam et al., 2012). These learning endeavours and initiatives are often part of the humanistic, liberal tradition (Faure, 1972) but recently, in the UK and other Western, industrialised countries there has been a departure from this form of provision towards more instrumental, skillsbased learning. Critical adult educators such as English and P. Mayo (2012) explore these issues in their analysis of lifelong learning policy, and despite the trends away from both humanistic and critical education towards vocational skills, there is a belief that ACL can contribute to strategies for social transformation in an age in crisis by adult educators such as M. Mayo (1997) and Torres (2013).

Freire's (1970a) influential theoretical perspective sees adult education as transformative for the individual and holds the potential of being transformational for society and the world. This model, particularly when it takes place in communities and begins with the learners' experiences, exemplifies how $A C L$ is, by its very nature, political according to many authors in the field (Coffield, 2000b; Freire, 1970a; Merriam et al., 2012; Moreland \& Lovett, 1997; Torres, 2013). Adult education projects are frequently "mechanisms for the political and pedagogical empowerment of subordinate social sectors" (Torres, 2013: 17) achieved through a critical and emancipatory approach rooted in Freire's Pedagogy of the Oppressed (Freire, 1970a). Torres' work embodies Freire's approach and he includes the discourses of democracy and diversity in his critical exposition of adult education (Torres, 1998a, 2006, 2013). The Workers Educational Association (WEA) in the UK is an example of the radical, popular adult education tradition of Freire and Torres.

One of the frequently reiterated goals in ESDGC is to support and facilitate participation. A key purpose of adult education is to facilitate participation in learning by those failed by the education system and socially excluded groups; however, this is not the focus in this thesis where participation in a broader sense is examined. Many authors (Brookfield, 1983, 1986, 2001; Brookfield \& Holst, 2011; Dewey, 1916; Merriam et al., 2012) note how ACL has historically supported civil societies through promoting and facilitating participation and deliberative democracy, whether it is in a classroom, community or on a national or global platform as citizens. This aligns with citizenship education, EGC and connects to the discourses 
of community development and learning as addressed in work by Annette \& M. Mayo (2010), Jarvis (2004, 2006b) and Moreland and Lovett (1997). Community development and ACL have shared goals, as described by English and P. Mayo, (2012: 131) who state that in the process of creating communities and in being "enabled" and "improving" conditions, a great deal of learning takes place. In Northern Ireland, Moreland and Lovett (1997) examine the ways in which community development contributes to an overall system of lifelong education, they look at three case studies and in each, informal adult learning providers were aware of being involved in wider learning process, linked to wider benefits for learners and society. The need to recognise the enormous impact of informal and community groups is stressed (Moreland \& Lovett, 1997: 215).

The influential, humanistic educational theories of Dewey $(1916,1938 a)$ and Knowles (1973, 1980) have formed the bedrock of liberal adult education in the West, however, there are elements of their work that are temporally and culturally constrained. For example, the stable life cycle, familiar to them no longer exists (Bauman, 1998, 2001a, 2001b, 2013; Jarvis, 2007) and their pragmatic and idealistic approach demonstrates at times, a paternalistic and problem-solving ethos without reference to different cultures and epistemologies. Globalization, ecological understandings and an awareness of interconnection and interdependence have revealed the need for a re-appraisal of liberal models of $A C L$ and pedagogy (Torres, 2013).

One such re-appraisal is that of Fenwick (2006) who sees ethical, relational and ecological discourses as part of a new model of critical pedagogy. In a theoretically driven discussion, she problematises the moral essentialism in some of the discourses of well-meaning pedagogy where a controlling and sometimes authoritarian 'expert' view is promoted. A more contingent approach is advocated. Whilst relationships and interconnections and complexity are recognised by many authors, it is important that our ecological responsibilities and interconnections are considered as part of these discourses. Indigenous epistemology is permeated with these understandings and highlighted by Bowers (2017), Burns (2015) and Fenwick (2006: 18) as sources of knowledge.

A range of critical and philosophical discussions on a wide range of issues are undertaken by Jarvis $(2004,2006 a, 2006 b, 2007,2008 a, 2008 b)$. A focus on his work therefore covers many of the discourses relevant to this thesis, including globalization and the intersecting political and 
personal dimensions. From why and how we learn (Jarvis, 2006a) to issues of the learning society and democratic participation (Jarvis, 2008b), to the impact of globalization (Jarvis, 2007), Jarvis is interested in the process of learning and the social context of that process. He is consequently sceptical of how behaviourism can point to the outcomes of the learning process but is incapable to explaining the processes themselves (Jarvis, 2006a: 35). The importance of emotions in personhood and embodied learning is a theme in Jarvis' analysis, and complexity and fluidity characterise the learning processes, as we construct ever changing and multiple identities and examine our values, beliefs and attitudes, which are an intrinsic part of our being. He characterises learning as a transformational experience (Jarvis, 2006a: 87, 2007: 6).

In an examination of learning in a global context, Field (2006) along with Jarvis (2007) recognises that an outcome of global capitalism is that adult education, as radical and emancipatory, has been replaced (in the West) by discourses of lifelong learning and the information and knowledge society. The commodification of knowledge, the domination of the scientific discourse (also in social science) and reductionist approaches are limiting the production of new knowledge (Jarvis, 2007: 88), and liberalism's global reach and its emphasis on the individual is to the detriment of society where values, norms and rules must be negotiated (Jarvis, 2008b). Like Torres (2013) who couples the adult education project explicitly with social justice, Jarvis calls for a re-imagining, re-purposing or re-inventing of adult education in light of globalisation, the ecological crisis and escalating inequalities of wealth and power.

Torres, a critical adult educator examines the political sociology of adult education (2013) which includes the political underpinnings and implications of educational policies. He identifies trends which are particularly relevant to this thesis such as the disjuncture between research, conducted by academics, and the world of public policy (2013: 7) and the constant tension between individualism and the collective. Other trends include the cybernetic culture which facilitates distance and self-directed learning, and the move from education to lifelong learning which is inclusive and covers a range of purposes. Socially excluded groups are often the focus of ACL and Torres champions this central purpose. 


\subsection{Transformational learning}

"The outcome of every learning situation is that the person is changed ... The outcome of almost all learning is the creation of new situations" (Jarvis, 2008b: 9).

\subsubsection{Transformational learning, critical approaches}

Transformational learning is an umbrella term used for an education that is transformative for individuals and at the same time seeks to transform society (Merizow, 2000; Taylor \& Cranton, 2012). Critical reflection, critical thinking and critical pedagogy are all part of this radical approach and theoretical framework in adult education (Baumgartner, 2001, 2012; Brookfield, 1981, 1986, 1993, 2001; Burbules, 2000; English \& P. Mayo, 2012; Fenwick, 2001; Johnson \& Morris, 2010). In reviewing a large body research on transformative learning between 2006 and 2010, Taylor and Snyder (2012) conclude that transformative learning is not a 'one size fits all' and that context is vital. They also note that, like critical theory, it is Eurocentric.

Since Mezirow (1981, 1990, 1991, 1997, 2000) first proposed transformative learning in the 1970s, it has been an important theory in ACL. It has changed and developed, but there are fundamental principles based on a critical approach that explicate the meaning-making process and valorise process and method above content (Baumgartner, 2012). Perspective transformation, expanding awareness, critical reflection on experience and a fuller realisation of agency are the changes experienced by individuals (Mezirow, 2000: 25). Previously uncritically assimilated assumptions, beliefs, values and perspectives are questioned so that the mindset becomes more open and permeable and we revise our world view.

Transformation Theory's focus is on how we learn to negotiate and act on our own purposes, values, feelings, and meanings rather than those we have uncritically assimilated from others-to gain greater control over our lives as socially responsible, clear-thinking decision makers. (Mezirow, 2000: 8)

Four key elements are identified by Mezirow (2000): experience, critical reflection, reflective discourse and action. This is based on Freire's model of developing critical consciousness through reflection, dialogue and experiential learning where learners and teacher engage in a dialectic. Mezirow identifies precursors to transformation as 'disorienting dilemmas'; these are starting points to learning. 
Even though he is criticised for focusing on the autonomous individual, Mezirow did place learning within a social context. He saw that "identity is formed in webs of affiliation within a shared life world" (Mezirow, 2000: 27,) and meaning is created as we validate it thorough interaction with others and the world (Mezirow, 1991). He briefly discusses social movements and emerging paradigms, notably the ecological crisis that was emerging and mobilising people (Mezirow,1991: 188). Another criticism of Mezirow's work is its emphasis on rationality without much recourse to the whole person and affective learning.

Many adult education scholars, including Jarvis (2004), Kucukaydin and Cranton (2012), P. Mayo (2003), Newman (2012) and Taylor (2007), have reviewed, questioned and revised Mezirow's theories of transformative learning. A unifying and more holistic theory is called for:

Currently, there is a diversity of theoretical perspectives, which brings a rich complexity to our understanding of transformation, but there is also a tendency to think in dualisms. For example, theorists and researchers write about rational or extrarational processes, a focus on individual change or a focus on social change, autonomous learning or relational learning. (Cranton \& Taylor, 2012: 3)

Freire's (1970a) critical and emancipatory model is one of transformative learning for systemic change (Kaufmann, 2010) and many adult educators such as English and P. Mayo (2012), M. Mayo (1997), Mezirow (1981) and Torres (2013) use critical theory as the conceptual basis of their work. This involves examining ideology and questioning the assumptions, ways of thinking and behaviours associated with them to bring about transformation. This approach calls for a critical pedagogy, critical self-reflection on the part of adult educators and a move from the individual to the collective ethic (Brookfield \& Holst, 2011: 7). The common good, which foregrounds collective approaches, compassion and responsibility, underpins Brookfield and Holst's (2011) vision and they emphatically link adult education with democratic socialism. This can, however, be limiting even if educators agree about the need to challenge the dominance of a capitalist ideology and they do not discuss the environment as a theme, apart from the common resources for survival orientation.

Transformative learning has been criticised by Bowers (2005) who raises many questions regarding its humanistic and constructivist assumptions which include the assumption that humans have the urge to self-realization and autonomy, based in a Eurocentric philosophy 
(Cranton \& Taylor, 2012: 5). Bowers suggests that transformative learning shares many of the assumptions of neoliberalism which demands constant change and innovation to maintain consumerism. He also criticises Freirian pedagogy, saying, that despite its anti-imperialist stance it perpetuates models of Western progress that are (often unconsciously) paternalistic. Another concern of Bowers $(2001,2002,2005,2011)$ and Bowers and Apffel-Marglin (2005) is that through constant change, traditions, indigenous cultures, and the knowledge and wisdom therein are lost. Bowers challenges the cultural practices of education and systemic injustice and he calls for a focus on the global commons and ecological well-being.

Experiential learning is frequently referred to in adult education; it can be thought of in two ways, though an organised learning experience or as a learning that begins with the lived experience of learners. The latter is the form of education discussed here. Kolb's (1984) influential model of experiential learning in adult education begins with the learner's experience, moves to observation and reflection, explores and makes links with abstract concepts, then tests new insights, perspectives and knowledge in new situations. This is aligned with developing critical thinking skills and with the model of critical pedagogy. Fenwick $(2000,2001)$ examines different orientations to experiential learning, all of which are discussed under the rubric of transformative learning. She examines debates about how to understand and use experiences and perceptions of experiences for learning (Fenwick, 2001: 7). Building on Fenwick's work, Jordi (2010) combines a study of reflection with consciousness and experiential learning. This emphasises affective learning in the discourses of critical pedagogy.

Dialogue and discussion are frequently the methods used to facilitate critical thinking. They are the teaching methods Brookfield uses (Brookfield, 1981, 1983, 1993, 1995, 2001, 2006, 2011) and Brookfield and Preskill (2012) use in HE. They outline in detail elements of classroom practice, including preparation, safety, seating, ways of talking and listening and teacher attributes; Brookfield's work on discussion and how to facilitate discussion is invaluable in the adult educator's repertoire. The process of becoming critical thinkers, Brookfield says, is emotive as well as rational, as it explores alternative ways of thinking and acting (Brookfield, 1993, 2006, 2011; Jordi, 2010). Critical reflection combined with self-directed learning and with a moral, social or political purpose, as distinct from education with an instrumental purpose, are essential if learning is to be transformational (Brookfield \& Holst, 2011: 23). In ESD, many such as Clover et al. (2013), Thomas (2009) and Wals and Corcoran (2006) advocate transformational approaches and Sterling (2004b, 2011a) advocates systemic and relational 
approaches to transformation.

\subsubsection{Transformational holistic approaches}

A range of discourses are brought together under the heading of holistic learning for transformation. Some have been chosen from a plethora of perspectives because they connect $A C L$ and ESDGC and help address the research questions. Some of the discourses are not prominent ones and are included for that reason, as they can potentially help explain research respondents' perceptions of ESDGC and the strategy and clarify the implicit contribution $A C L$ can make to ESDGC.

Authors that include the concepts inherent in ESDGC into their holistic approaches include O'Sullivan (1999) and O'Sullivan and Taylor (2004) who describe and discuss a learning that is political, moral and spiritual, their frame of reference is global, and they combine holistic and critical perspectives. Even though the environment is not examined as a theme by Jarvis he comments that learning should include "Learning to care for the planet - because it is more than a resource - it is a home for us all" (Jarvis, 2008b: 219). He says we can learn from 'primitive' people, displaying a Eurocentric frame of reference and at the same time challenging it.

Resonating with discourses in EGC and foregrounding the themes of interconnection, CurryStevens (2007) examine a 'pedagogy for the privileged', an approach aimed at connecting learners to humanity and not merely identifying with people like themselves. Emotions become a central part of the learning process here, as people feel fear, guilt, grieving, discomfort and positive emotions such as joy and excitement through examining long held beliefs and assumptions and re-connect with a wider human community. Taylor (2008) in a paper on emotions in critical, non-formal learning states that even though little is known about this area, evidence suggests that a major advantages of learning activities in non-formal settings over those in formal settings may lie in the affective domain. "Developing an awareness of learner emotions and their relationship to nonformal learning experiences is an essential practice for the nonformal educator" (Taylor, 2008: 79).

Emotions and feeling do not have prominence in the theory and discourses of ESD and ESDGC; they are part of the affective domain, where typically values and attitudes are examined. In 
addressing complex, and often emotive issues, the affective domain can expand the possibilities for learning and help explain reasons for non-engagement amongst adult learners as discussed by Dirkx $(2001,2006)$. There is a consensus that holistic adult education "underscores the importance of attending to emotions and feelings in contexts, interactions, and relationships" (Dirkx, 2001: 68) and enables the development of higher-order skills in line with Bloom's taxonomy of learning objectives (Anderson, Krathwohl \& Bloom, 2001).

In discussing emotion-laden experiences in adult education Dirkx (2008) focuses on the positive role emotions play in transformative learning. Other adult educators such as Jarvis (2006) and Merriam et al. (2012) reject the previously held notion of emotion as a barrier to reason and knowledge (Dirkx, 2008: 8), and acknowledge that emotions are part of reasoning, rationality, learning, and meaning making; they are a way of knowing. This is sometimes referred to as embodied knowing and learning (Merriam et al., 2012). The affective domain discussed here involves developing communication and empathic skills and emotional intelligence which are recognised as vital components of learning by adult educators (Dirkx, 2001, 2006; Jarvis, 2004, 2006a; Larsson, 2000; More, Woodruff \& Gottschalk, 1974; Tisdell, 2003, 2011a, 2011b) and by some working in ESD such as Bonnett (2009) and Shephard (2008). The work of Heron (1992) linking learning and psychology and Immordino-Yang (2015) and Immordino-Yang \& Damasio (2007) in neuroscience demonstrates the crucial role emotions have in helping us make meaning.

Relational learning is a discourse within ESD and it is visible in ACL learning theory through collective and community learning as discussed above (sections 2.3 .2 and 2.6 for example). It is referred to in the different bodies of literature in this review including critical, transformative learning (English \& P. Mayo, 2012), ESD (Helne \& Hirvilammi, 2015; Sterling, 2010a) and care theory (Noddings, 2013a) for example. Another example of a relational approach is that of Murphy and Brown (2012), who, in the context of HE in the UK, consider the importance of the teacher, student relationships and emphasise intersubjectivity and the coming together of critical and psychoanalytic theory. These relational orientations can help address issues in EGC and expand the possibilities for pedagogy in ESDGC in ACL. 


\subsection{Pedagogy for ESDGC - critical, plural and agonistic}

\subsubsection{A re-examination of pedagogy in a global age}

An examination of literature that can contextualise the findings and help explain the problems with delivery and provision of ESDGC in ACL, includes considering elements of pedagogy, many of which have been included in previous discussions within this chapter.

Pedagogy literally means the art and science of teaching children, and andragogy was a term proposed by Knowles, one of the founders of humanist adult education theory in the 1960's, as the art and science of teaching adults (Knowles, 1973, 1980). However, pedagogy is now a term understood and used across all age ranges. Bernstein refers to pedagogy as "the social, political and cultural mediation of the process of knowledge reconstruction" (Bernstein, 1996: 6).

There is a consensus, across the different theoretical orientation in ESD, EGC and in ACL, of the need for a re-appraisal of pedagogy. Edwards and Usher (2007) examine pedagogy in adult education through the lens of globalization and are critical of the cultural dominance of white males and the assumptions made in the literature about globalization and pedagogy. "In diaspora space, the boundaries defining and confining acceptable learning break down alongside the breakdown of the legitimacy of canons of knowledge" (Edwards \& Usher, 2007: 155). Theirs is a radical call to establish more creative and flexible pedagogical practices that are not in the mould of authoritarian ones that have contributed to current global uncertainties and inequalities. According to Edwards and Usher (2007), Usher et al. (2011) and many other educationalists, the local needs to be reclaimed and re-presented within globalisation and pedagogy discourses (Bowers, 2001; Merrifield, 2010). Fenwick (2006: 9) suggests that we need to "conceptualise more open, generative and compassionate orientations" and that a revival of the Freirian notion of a pedagogy of hope is needed (Freire, 1994).

Even though it they situate their work in schools Johnson and Morris (2010) present a useful analysis of the difference and overlap between critical thinking and critical pedagogy in critical citizenship education. They summarise the ways in which critical thinking focuses on transformative learning in the individual whilst critical pedagogy explores the wider world, has 
a social and collective focus, is context driven and is explicitly political in its critique of ideology; is transformational. They note that the two areas come together in the classroom through a learner-centred, dialogic pedagogy as agreed by adult education scholars such as Brookfield $(1993,2011)$ and Burbules (2000).

Ecopedagogy provides a framework and grounding for the merging of discourses in ESD and EGC as discussed above (2.5). Misiaszek (2011, 2012, 2016, 2017), Kahn (2008) and Kahn and Kahn (2010) are authors who place ecopedagogy at the centre of their critical, dialectic approaches and it is also apparent in the work of any other authors such as Huckle and Wals (2015) and Fenwick $(2006,2009)$. Five theoretical areas are included by Misiaszek in his work on examining adult learning in north and south America, they are: sustainable development, critical race theories, feminism, media and cultural theories and globalization and neocolonialism (Misiaszek, 2012: 429).

\subsubsection{Uncomfortable learning and dialogic pedagogy}

For both teacher and learner, dealing with the issues in ESDGC can be an uncomfortable as we confront some of the worst aspect of humanity. A realistic engagement with the problems, challenges and even the traumas and tragedies of this world rather than a denial is what Huckle (2012b) and Selby and Kagawa (2011b) advocate. Instead of disempowering learners this is a transformative agenda that offers authentic hope according to authors such as Fenwick (2006), Huckle (2012b), Johnson and Morris (2010), Selby and Kagawa (2011b) and Todd $(2010,2015)$ who state that it is vital to examine and engage with difficult issues in ESD and EGC and not deny them and continue with habitual practices (Bowers, 2001; Marshall, 2014).

There are episodes in life when we feel uncomfortable, when there is a crisis, disharmony, or as Jarvis (2006a: 74, 77) calls it a 'disjuncture' that presents us with a situation that makes us reflect and ask questions. This disharmony motivates us to learn so that we can restore equilibrium in ourselves and in our lives. Todd (2010) proposes that we welcome dissonance as part of what she calls an 'agonistic' education. There is a pragmatism in Todd's work as she emphasises the need to face reality and not turn a blind eye, avoid, negate, dilute, ignore or worse, deny (Todd, 2015: 9). 
If we disavow what is 'inhuman' about us, then ESDGC cannot give an adequate response to question of violence, hate, pain, suffering, poverty, war, racism, sexism and ecological degradation, despite its own attestation to the contrary (Todd, 2015: 3). As part of this pedagogy learners and teachers are required to engage with emotions. One of these might be political anger, and White (2012) discusses how we can use this. She argues that we, in a democracy, cannot dispense with political anger and that it has a role in enabling us to protect what we value. ESDGC can find a place for political anger so that people will not feel apathetic or fearful but that they will have "a repertoire of ways of expressing democratic anger" (White, 2012: 1).

Engaging authentically with the challenges inherent in EGC is what Andreotti (2011) calls a pedagogy of 'dissensus', she places decoloniality and diversality at its core. Engaging with the issues of colonial and imperialist oppression and examining other epistemologies is essential in this vision, and it moves pluralism from its multicultural tradition to a pluralism of lived experience, as advocated by Todd (2011). 'Dissensus' is where learners are supported to "hold paradoxes and not be overwhelmed by complexity, ambiguity, conflict, uncertainty and difference" (Andreotti, 2011: 395). The geopolitics of knowledge production is emphasised by Andreotti, hers is a pedagogy that focuses on developing 'hyper-self-reflexivity' that frees us from the rational model of being human and advocates being explicitly committed to imagining a future outside the teleological Western frame. Similarly, Brookfield and Holst call for educators to undergo an ideological detoxification (Brookfield \& Holst, 2011: 201).

Agonistic situations are places where we can explore a genuine, plural 'cosmopolitic' (Todd, 2010), they provide potential for learning. In her work on teaching about conflict through citizenship education, Davies $(2004,2005)$ sees this form of classroom conflict as positive, and essential in democratic societies. Likewise, Larsson (2013) through her experiences with women learners in Sweden recognises that in a plural and diverse classroom "to act in concert within an agonistic dialogue confirms that agonistic feminism can be reconciled with a politically radical concept of popular education. In my opinion, this can challenge the order of power and, through that, reshape social structures" (Larsson, 2013: 186).

Some key works on controversy in the classroom are discussed to illustrate some of the issues that emerged from a preliminary analysis of the data relating to politics and ethics. It is acknowledged that there is a large and growing literature associated with this aspect of 
pedagogy, but within the limits of the thesis only a few key works are referred to. In her research on discussing controversial environmental issues in schools in the UK, Cotton (2006) found that teachers', whilst striving to maintain neutrality had a greater influence on classroom interaction than they thought. It is not easy for the teacher who must decide on a neutral position and risk the relativism spoken of by Gaudelli (2003) or state their views and risk being called partisan. McAvoy and Hess (2013) conducted longitudinal research with secondary-school age students in the US on deliberations about controversial political issues, they examined the teachers position and discuss how they understand high-quality classroom discussion on controversial political issues. They conclude that it is not an either/or situation regarding neutrality or stating a position, it a question of creating a "political classroom that engages students in the pedagogical practice of deliberation so that young people are provided a meaningful, challenging, and authentic democratic education". 'Political' is understood as collective decision making about how we can, and ought to live together (McAvoy \& Hess, 2013: 16).

Controversy in the classroom is the focus of studies by Hess $(2004,2009)$, Hess and Avery (2008) and Hess and Stoddard (2007) and in all these studies dialogue and discussion are identified as the most appropriate pedagogical method. Hand and Levinson (2012), in their work on discussion and the exploration of controversial issues state that questions about why dialogue is the best approach and how to facilitate it has been given little attention; this is where $\mathrm{ACL}$ can contribute as discussed above. Hand and Levinson conclude that "discussion is peculiarly conducive to appreciative understanding of the different positions in a controversy, and, second, that controversial issues are the one area of the curriculum in which teachers can engage students in discussion" (Hand \& Levinson, 2012: 626-627). Again, working in the formal school sector, Leenders, Veugelers and De Kat (2008) and Veugelers (2011) examine teachers approaches to discussing political and ethical issues. Their research found that the political was particularly challenging for teachers and that they chose to begin with discussing moral issues.

Whilst it is not possible to examine dialogue in depth, it is an essential component in critical thinking and pedagogy. A great deal is written about dialogue and discussion and how they facilitate learning (Bohm, 2013; Bohm, Factor \& Garrett, 1991; Freire, 1970a, 1973, 1994, 2004; Brookfield, 1986, 1993; 2006, 2011; Brookfield \& Preskill, 2012; Burbules, 2000; Todd, 2015; Vella, 2002); Freire placed it at the centre of his philosophy, it is a vital part of the 
process of transformation of self and society (Mezirow, 2000). Speaking, listening and sharing thoughts and feeling with one another as a dialogue with intent is part of the process of critical reflection and transformative leaning (Brookfield \& Preskill, 2012).

Bohm (2013) and Bohm, Factor and Garrett (1991) advocate more attention being given to dialogue in an age of crisis, where technology is mediating human communication. They engage with the issue of emotions such as anger and the need to examine human thought in light of global suffering, conflict and environmental destruction. A philosopher and physicist, Bohm has dedicated himself to examining the process and place of dialogue in human interaction, which he sees as essential if human beings are to communicate effectively to survive. In a book that centres on a dialogue between Martin Buber, a philosopher, and Carl Rogers a humanistic psychologist who influenced early adult educators, dialogue is seen in terms of a theory, as the basis of democracy and an activity - a praxis. It is profound and practical (Cissna, \& Anderson, 2012).

These discourses on dialogue and controversy are hopeful, they encourage teachers and learners to engage with problems. Hope is a motif in pedagogy and has been referred to in this review in connection with work by M. Mayo (1997) on the power of adult education in unsettled times and by Fenwick (2006) as an audacious expression within a plural pedagogy. Freire declared that hope is a core underpinning of education and all its processes (Freire, 2007a: 87).

\subsubsection{An ethic of care}

Related to emotions and to political motivation is the discourse of caring. It is often a missing theoretical element. Within the limitations of this thesis it is only possible to examine a few authors to introduce this essentially ethical discourse as part of a reconceptualisation of ESDGC.

In their work on global citizenship and education Schattle (2008) and Gaudelli (2003) both discuss care ethics. They recognise that it offers an alternative and more expansive way of thinking about ethical problems than the traditional, mainstream rational, logical model. It includes the affective domain and our emotive capacities in learning and acting. "Care theory acknowledges the tension between relativism and universalism yet departs from dualistic 
thought in coming to terms with moral reasoning" (Gaudelli, 2003: 130). Care theory places an emphasis on dialogue and negotiation, reflecting both the critical and relational models in pedagogy discussed above. It is context driven, situational and particular, whilst operating in a global frame that is not absolutist. "Care theory urges global teachers and students to focus on lived human problems as they are differently experienced by participants" (Gaudelli, 2003: 133).

The ethics of care emerged as a moral theory in the second half of the twentieth century; it is not solely concerned with private and domestic relationships but is a wider and more nuanced, philosophical view of caring which is relevant to public life, to institutions, social organisation, to medicine, international relations and war according to V. Held (2006: 9). Scholars such as V. Held (2006), Koehn (1998) and Noddings (2010, 2013a, 2013b) discuss care from this theoretical perspective. In a feminist analysis MacGregor (2011) links care theory to ecological citizenship and emphasises the need to politicise it. Care theory moves from caring for to include caring about.

In her work on ethics V. Held (2006) discusses our interrelatedness and our interconnection, and she relates her arguments to political discourses, to citizenship and global citizenship, making it particularly pertinent to this thesis.

I see the ethics of care from as fully a normative view as any other ethic. It addresses questions about whether and how and why we ought to engage in activities of care, questions about how such activities should be conducted and structured, and questions about the meanings of care and caring. It especially evaluates relations of care. (V. Held, 2006: 46)

Another theorist on ethic and care, Noddings (2013a) discusses this relational approach in the context of moral education. She discusses the immediate one-to-one caring and does not broach the political and wider context to the extent that Held does, she states that, "Much more must be said on caring-about" (Noddings, 2013: 12). All authors in this field recognise that we are relational beings, and nothing is done or should be considered in isolation from others. This resonates with many of the discourses in ESDGC. 


\subsection{Conclusion}

A range of different perspectives exist in ESD, EGC and ESDGC, such as those between the critical school of thought and those espousing more holistic and systemic approaches. In reviewing a wide range of literature, discourses and theories have been included that reflect the concerns in this current thesis. The breadth provides a conceptual underpinning and a basis for analysing the findings and addressing the research questions. The literature provides evidence for addressing the research question regarding the 'piecemeal' delivery and provision of ESDGC in ACL in Wales and evidence to substantiate the features described by practitioners that impeded the implementation of the ESDGC strategy. The latent contribution of ACL to ESDGC has been examined though the literature on $A C L$, its emphasis on citizenship education, collective and community approaches and the central position of social justice and critical thinking and pedagogy. These elements of ACL theory and practice are clearly aligned with the purpose of ESDGC.

Reviewing the literature on adult education clarifies and demonstrates a considerable overlap and synergy with approaches and theories pertaining to ESDGC. Some scholars in ACL, such as Jarvis, integrate a wide range of concerns from the global to the deeply personal and spiritual, discussing the false dichotomy of political and personal issues and integrating citizenship education with individual experience and local concerns. The experiential, learner-centred and transformational approaches in $\mathrm{ACL}$ can contribute to models for the theory and practice of ESDGC.

The conceptual confusion that makes EGC particularly difficult has been addressed in the literature review, and its core concept of citizenship has been outlined to provide clarity for the discussions in Chapter 8. The need for a paradigm shift, a re-appraisal of pedagogy and truly transformational approaches in both ESDGC and $A C L$ is a consistent theme in the literature, and certain elements within ESDGC in ACL such as affective learning and an ethic of care have been introduced to inform the discussions later in the thesis.

A small body of work on environmental education in adult education exists alongside a substantial literature on citizenship. However, there is not much written about ESD or global citizenship in ACL. Most of the literature directly relating to ESDGC is based on studies in schools, although there is a growing body of work in HE that has relevance to post-16 education. By bringing together the theories, traditions and philosophical underpinnings of 
adult education with the issues and discourses in ESD and EGC, the literature review contributes clarity and the field of ESDGC in post-16 education. 


\section{Chapter 3 \\ Policy Context}

\subsection{Introduction}

To position the ESDGC strategy and $A C L$ in Wales within a policy-oriented context, this chapter reviews some of the international and UK policies that have influenced the ESDGC strategy (Welsh Government, 2008a) and ACL in Wales; it gives an overview of the policy background. The intent is to provide as much policy context as possible to the case study, whilst acknowledging that the policy background is complex and shifting. It is not intended as a comprehensive policy analysis.

The review begins by looking at the international response to issues relating to ESDGC through the lens of the United Nations (UN) and the United Nations Educational, Scientific and Cultural Organisation (UNESCO). These have been significant policy drivers and influences. Following a review of the international policy context, the chapter looks at ESD and EGC as framed in educational policy in the UK and in Wales. It then examines the way in which the ESDGC strategy evolved and what it set out to achieve. A section then outlines ACL policy in Wales and includes a short sub-section on FE and $\mathrm{HE}$, where thinking and policy have influenced ESDGC in ACL. The chapter concludes with an overview of the policy context of ESDGC and ACL between 2010 and 2016. However, before reviewing policy, it undertakes a short review of literature relating to educational policy, innovation and change. This informs the discussion of the empirical findings and provides evidence and addresses the research question relating to the background or contextual features which influenced the development and implementation of the ESDGC strategy.

It is not possible to explore the wide range of literature covering all dimensions of educational policy, change and innovation. The choice of literature was guided by its general applicability to this case study: literature that provided an overview of the policy process (Trowler, 2003, Hill, 2009); literature that discusses wider ideological considerations (Ball, 1994b, 2012a, 2017); literature reviews on the introduction of innovations and change in education (Kirkland \& Sutch, 2009); and literature that examines policy in the ACL sector such as that by Coffield et al. (2007) are included. 


\subsection{Literature on policy development and implementation}

\subsubsection{Introducing change and innovation}

ESDGC can be viewed as part of policy and as an innovation that was introduced by the Welsh Government. It represented an opportunity for change, and, whilst policy analysis is not the focus of the thesis, examining some of the literature on the policy process and implementing change in educational settings provides insights to inform the research. Some of the factors described by respondents as being problematic can be identified in the policy process, and while the 'piecemeal' nature of ESDGC delivery and provision in ACL can be attributed to this in part, it is also due to the wider policy influences and the difficulties inherent in the introduction of innovation and change.

Blackmore and Lauder (2005) provide an introduction to researching policy, they state that:

Policy is more than 'official' texts produced by and on the authority of governmental or executive power. Policy has multiple dimensions within any field of activity, whether education, health or welfare. Policy could be considered to be a text, a process, a discourse, a political decision, a programme, even an outcome. (Blackmore \& Lauder, 2005: 97)

The policy process, as understood in this thesis includes multiple dimensions from ideas, and intent, communication of all forms, representation and implementation. A comprehensive account of the public policy process by Hill (2009) includes theoretical and practical considerations and covers formulation and implementation. Hill stresses throughout that "there is a need to think about the policy process as a whole" to see it as "embedded in the structures of power in society" and to be mindful that it is not always easy to generalise (Hill, 2009: 299).

Informing the policy process is an understanding of public and social policy. An edited collection examining social policy by Alcock, Haux, May and Wright (2016) includes many perspectives from these fields. The Welsh policy context is discussed by Chaney (2016) who states that "The combination of territorial politics, contrasting party ideologies and devolved elections shapes social policymaking in Wales" and "may contrast to the approach followed elsewhere in the UK" (Chaney, 2016: 176). This is discussed in the policy review below in relation to $A C L$ and ESDGC. Sustainability as an area of policy presents challenges across a 
range of domains - economic, political, moral and cultural - according to Fitzpatrick (2016); resilience in the face of new hazards is seen as the major policy driver.

Even though most of the literature on educational policy focuses on school reform and formal education, as Trowler (2003) notes, the nature of educational policy and the policy-making process are similar across sectors and domains. Policy process and the diverse local practices in implementing policy are examined by Trowler (2003), who employs a critical sociological approach, highlighting the need to look at the ideologies which drive policy-making and those who put it into practice. Trowler's analysis is useful, in that he discusses the importance of examining intent and purpose. Policy "is a statement of intention or of practice as it is perceived by policy-makers or as they would like it to be", and he sees this as limited, stating that "It is better to see policy as a process, something which is dynamic rather than static" (Trowler, 2003: 48). It is the dialogic and dynamic nature of the policy process that is crucial: the communication between actors and between the different interests and levels of influence (see Chapter 7).

Hammersley (2002) examines the relationship between research, policy and practice from a schools and formal education perspective; the focus of the work is on school and curriculum reform. Ball (2012a) also focuses on school reform in England, his analysis is more concerned with wider ideological influences on policy. Both authors provide sociological and critical perspectives. Ball notes that "Policy is both text and action, words and deeds, it is what is enacted as well as what is implemented. Policies are always incomplete insofar as they relate to or map on to the 'wild profusion' of local practice" (Ball, 1994b: 10). Like Trowler and Ball, Smith (2013) examines the ideological links between policy and purpose and argue that it is primarily the macro, ideological and systemic structures within which education operates that resists change. Ideology is understood as a framework of values, ideas and beliefs that can include ideas about the way society is and should be organised and how resources should be allocated to achieve what is desired (Trowler, 2003: 55). The current ideology, with its focus on economic growth, has its own influence:

Education is now seen as a crucial factor in ensuring economic productivity and competitiveness in the context of 'the knowledge economy'. In other words, education policy is increasingly thought about and made within the context of the 'pressures' and requirements of globalisation and within a particular of framework of political rationality. (Ball, 2017: 2) 
Behaviour change is often seen as an outcome of policy, and this normative orientation can be seen as the transmission of values (Blackmore \& Lauder, 2005).

In a comparative analysis, Hill and Hupe (2014) provide a clear description of the policy process. They examine different models and frameworks and include discourses on literacies, language, values and beliefs. The environment as an area of public policy and concern is only mentioned in connection with risks such as flood control (Hill \& Hupe, 2014: 74); however, the authors recognise that it will have increasing importance within public policy, as it impacts on the social and economic domains.

Literature on introducing innovations in education covers a broad range of contexts and approaches and only a few examples are included here to help inform this thesis and indicate areas for future research. Introducing innovations in technology-enhanced learning is a field with a rapidly expanding literature where teacher training is a key theme (Rudd, 2013). Cobo (2013), in a review of the literature discusses conditions needed to develop skills for innovation in the general population and trends within and outside formal education. Trends relevant to this thesis include: a mismatch between formal education and the challenges of an innovative society; the shift from what we learn to how we learn; changing conceptions of space-time and the emphasis on lifelong learning; and the development of soft skills. In adult education Feketene Szakos (2014) proposes that innovation-oriented adult learning theories such as the process-, biography- and change-oriented theories (which contain the elements of transformative learning theory) could be usefully employed in adult education (Feketene Szakos, 2014: 505). Indeed, examining change processes and the adoption of innovation using different theoretical framework may prove useful in informing future policy development and implementation relating to ESDGC and/or ACL.

Two literature reviews on introducing educational innovations have been examined, namely the works of Kirkland and Sutch (2009) and Nudzor (2013). Leadership is identified in both reviews as a crucial factor in the introducing and management of change. In addition, Kirkland and Sutch (2009: 18) observe that "The perception of an innovation, including how new or different it is seen to be, can be crucial to its success" and Nudzor (2013) finds that the perception of a policy as an imposition is a major barrier to the adoption and implementation of change. He warns against the imposition of change from 'outside'; the process of change 
management and the need to conduct strategic work to realise the desired outcomes for learners are emphasised.

Kirkland and Sutch (2009) provide a comprehensive discussion of teacher responses to innovations and barriers to implementing change. They focus on innovative teaching and learning practices and discuss and describe the micro, meso and macro-layers of influence in their analysis; these are usefully employed when discussing ESDGC. Teacher empowerment and teachers as change agents are a focus in Fullan's work (Fullan, 2014), and the research cited above agrees on the crucial role of enthusiastic individuals within education in moving policy forward. They recognise that successful implementation of a strategy or policy often depends on these individuals (Kirkland \& Sutch, 2009; Nudzor, 2013; Trowler, 2003).

Examining the different perceptions of policymakers and those expected to implement policy has been crucial in this case study so that intent and desired outcomes and features that are described as being barriers to implementation are better understood.

\subsubsection{Post-16 education}

Coffield, Edward, Finlay, Hodgson, Spours, Steer and Gregson (2007), in a three-year study examining the impact of policy on practice and professionals, evidence how professionals struggle to cope with national policy changes within local contexts. They describe "how managers and tutors mediate national policy and translate it (and sometimes mistranslate it) into local plans and practices" (Coffield et al., 2007: 2). They trace how education and training policy in England percolates through different levels, and how these levels interact, or fail to interact. The government model of public service reform is criticised for failing to harness the knowledge, good will and energy of staff working in the adult education sector. Another criticism is that it ignores the location of learning in the classroom, and the vital relationship between tutors and learners. The research centres on the interests of, and outcomes for, learners and finds "no evidence of the direct or simple transmission of policy into teaching practices" (Coffield et al., 2007: 736).

A different approach to examining policy implementation is adopted by Hodgson, Spours and Waring (2011), who connect the wider globalizing economic imperatives that have placed skills in the forefront of policy with the role adult education plays in the UK in supporting civic 
participation, inclusion and social justice. They highlight the differences and similarities between the diverging and converging policies in England, Wales and Scotland. Again, focusing on the UK during a period of change and uncertainty, Hodgson, Spours, Waring, Gallacher, Keep and Rees (2011) look back over a period when post-compulsory education and lifelong learning were high-profile policy areas. This was primarily in connection with skills and economic competitiveness, but also with their "role in supporting social inclusion (e.g. Leitch, 2006; Welsh Government, 2010, 2011), civic participation (e.g. Webb Review, 2007) and the development of a fairer society (The Scottish Government, 2007)" (Hodgson et al., 2011: 203). They discuss the important political juncture in $\mathbf{2 0 1 0}$ with the election of a Liberal DemocratConservative coalition government and the implications of this. Divergence between England and the other UK nations is recognised as being

underpinned by wider historical, cultural, economic and political factors in which the four countries of the UK have had different experiences of new public management, the role of local government and the balances of the public and private sectors. While England fully embraced the neoliberal reforms associated with Conservative governments during the 1980s and early 1990s and, as we have seen, largely continued by New Labour, this was not the case for Scotland and Wales. They continued along their established broadly pre-Thatcherite trajectories. Interwoven with issues of national identity, these wider historical, cultural and political factors have affected underlying policy assumptions and become a framework for policymakers in the respective countries, influencing how post-compulsory education and lifelong learning is conceptualised and even which terminology should be used. (Hodgson et al., 2011: 205)

Policy trends in Wales during this time, include the continuing importance of local authorities as providers of post-16 education and the promotion of greater sector and institutional collaboration. Concluding their study, the authors highlight uncertainty in a global context and the increasing divergence between England and the other countries (Hodson et al., 2011: 225). Specific and relevant Welsh policy studies include the work of Rees (2011), who outlines lifelong learning and adult education policy since devolution and stresses the importance of practitioner involvement in developing policies. 


\subsection{International context and background to the ESDGC strategy}

\subsubsection{Introduction to international context}

An increasing awareness of the actual and potential consequences of human action on the earth's biosphere was beginning to cause international concern during the 1960s. In response, UNESCO established the United Nations Environment Programme (UNEP) in 1972 and convened a range of international workshops, conferences and summits. These events have influenced policy developments, thinking and practice in ESD and ESDGC, particularly in Western countries, and in recent years, more globally. Some of the recommendations, reports, charters and declarations have been reviewed as background to this thesis.

This section begins by describing developments prior to the 1992 Conference on Environment and Development, also known as the Earth Summit. An examination of these earlier events shows the evolution of ideas and conceptualisations that have influenced current thinking and practice.

\subsubsection{Before Rio}

The conference on the human environment in Stockholm, Sweden in 1972, organised by UNESCO and the United Nations Environment Programme (UNEP) (UNESCO-UNEP, 1972), was a starting point for bringing global environmental problems into political and public awareness. It was the first time an integrated approach to the environment had been adopted within an international policy context. The declaration resulting from the discussions puts the 'human' firmly at the centre of environmental concerns. "Of all things in the world, people are the most precious. It is the people that propel social progress, create social wealth, develop science and technology and, through their hard work, continuously transform the human environment" (UNESCO-UNEP, 1972: Principle $5^{11}$ ). The environment was to be preserved, safeguarded and improved for people and for posterity, and science and technology and Western models of development to improve the environment are the solution.

Educational recommendations from Stockholm were taken forward and addressed in 1975 at

\footnotetext{
${ }^{11} \mathrm{http}: / /$ www.unep.org/documents.multilingual/default.asp?documentid=97\&articleid=1503
} 
the international workshop on environmental education in Belgrade, Yugoslavia. A global framework for environmental education, referred to as the Belgrade Charter (UNESCO-UNEP, 1977) proposed that the goal of environmental action as a result of education is "to improve all ecological relationships, including the relationship of humanity with nature and people with each other" (UNESCO-UNEP, 1977: 14). Environmental education is seen as part of a comprehensive lifelong education, with formal and informal education given equal priority. Citizenship and participating in processes to improve life and protect the environment are goals, and the charter recommends that ethical values are given due regard alongside the development of skills and attributes. Belgrade calls for a new global ethic (UNESCO-UNEP, 1977: 13), where environmental problems are seen as social and the environment is recognised as a political theme. This was pivotal in articulating discourses that remain central to ESD and ESDGC.

The Tbilisi Declaration (UNESCO-UNEP, 1978) from the first intergovernmental conference on environmental education in Georgia in 1977 continues the thinking from Belgrade: linking the biological to social, economic and technological issues. Environmental and development objectives are linked through the discourses of justice: "The problems of development and of the environment therefore must be approached in a spirit of solidarity and justice" (UNESCOUNEP, 1978: 67). A broad view of education in line with the vision for lifelong learning that developed as a major policy initiative in the UK in the 1980s was advocated and it was recognised as being important in helping to shape new behaviour and enable people to take action for the environment. Tbilisi was optimistic, and the environment represented "an ideal opportunity to restore to education an ethical function which it has sometimes lost" (UNESCOUNEP, 1979: 8-9). Interdependence as a central concept had entered the discourses, and since Stockholm, a broader, ecological and more integrated conceptualisation of the issues is evident.

The critical role of education in the search for environmentally sustainable modes of living had by now been established. The World Conservation Strategy (IUCN, UNEP \& WWF, 1980) produced by the International Union for Conservation of Nature and Natural Resources (IUCN), UNEP and the World Wildlife Fund (WWF), states that:

A new ethic, embracing plants and animals as well as people, is required for human societies to live in harmony with the natural world on which they depend for survival 
and well-being. The long term task of environmental education is to foster or reinforce attitudes and behaviours compatible with this new ethic. (IUCN, UNEP \& WWF, 1980: 46)

The strategy demonstrates a fundamental policy shift. It focuses on causes rather than consequences and emphasised the integration of conservation and development aims for sustainable societies. This view was then reinforced in the document Our Common Future: World Commission on Environment and Development, also known as the Brundtland Report (World Commission on Environment and Development - WCED, 1987), which emphasises the crucial role that education and teachers play in helping to bring about the social changes necessary for sustainable development (WCED, 1987: xiv). The document reflects a third world deficit model; however, it was visionary in its recognition of our moral responsibility to future generations.

\subsubsection{The Rio Earth Summit and beyond}

The Earth Summit, held in Rio de Janeiro, Brazil in 1992, alerted the world further to the complex nature of the issues underlying environmental sustainability (UN, 1992a). In total, 172 governments participated and there were over 2,000 representatives from non-governmental organisations (NGOs). Rio highlighted the concerns of nations wanting economic development, whilst acknowledging the tensions and choices between the need to protect the environment and to overcome poverty. Existing trends in 'development' were challenged as increasing numbers of people faced greater poverty and vulnerability in terms of both their livelihoods and the degradation of the environment on which they depended. Elizabeth Dowdeswell, the former executive director of UNEP, stated a vision of sustainability linked to social justice:

The Earth Summit at Rio de Janeiro saw the essential indivisibility of environment, peace and development. It also recognised that global independence could no longer be conceived only in economic terms. Alongside, there was the calculus of military parity. They were related to the instability spawned by widespread poverty, squalor, hunger, disease, illiteracy. They were connected to the degradation of the environment. They were enmeshed with inequity and injustice. (Dowdeswell, 1995: 2, cited in Tilbury et al., 2002: 2)

Agenda 21, the internationally agreed report of the Earth Summit, is a non-binding action plan which commits countries to promoting environmental sustainability (UN, 1992b). Chapter 36, 
on 'Promoting education, public awareness and training', was one of the few aspects of Agenda 21 that did not provoke contention, and both economically developed and developing countries agreed that education was critical for promoting sustainable development and increasing people's capacity to address environment and development issues. Following Agenda 21, environmental education policies and programmes around the world adopted the new vocabulary of sustainable development.

Following a six-year consultation involving experts and representatives from civil society, the Earth Charter ${ }^{12}$ was launched in 2000 . It sets out four fundamental principles for sustainable development: respect and care for the community of life; ecological integrity; social and economic justice; democracy, nonviolence, and peace. Intensifying globalization processes and the recognition of interdependence underpin the call for people to identify with the whole 'earth community' as well as with local communities. The Earth Charter's vision rests on realising a universal, shared responsibility for the present and future well-being of humanity and the living world and creating a "shared vision of basic values to provide an ethical foundation for the emerging world" (Earth Charter Commission, 2000: 1). Principle 14, on incorporating the values of the charter into education, includes both informal and formal education, and in 2003 UNESCO affirmed the intention of member states to use the Earth Charter as a tool for implementing the Decade for ESD from 2005 to 2014. It is a significant marker in the evolution of ESD and ESDGC in its holistic and ethical stance.

Ideas and conceptual understandings became more integrated and wide-ranging during the thirty years following Stockholm. The outcomes of the many summits and conferences contributed to the formulation of the eight millennium development goals, which were adopted in 2000. They set out a series of time-bound targets, with a deadline of 2015 . The goals were aimed at galvanising efforts to globally address extreme poverty whilst promoting gender equality, universal primary education and sustainable development.

In 2002, a report on the lessons learned for ESD was published (UNESCO, 2002); key messages include seeing ESD as a dynamic concept "that seeks to empower people of all ages to assume responsibility for creating a sustainable future" (UNESCO, 2002: 5), and recognising that

\footnotetext{
${ }^{12}$ http://www.unesco.org/education/tlsf/mods/theme_a/img/02_earthcharter.pdf
} 
"Lifelong learning, including adult and community education, appropriate technical and vocational education, higher education and teacher education are all vital ingredients of capacity building for a sustainable future" (UNESCO, 2002: 6). The report goes as far as to state that "sustainable development is essentially a process of learning" and that it is "perhaps more of a moral precept than a scientific concept" (UNESCO, 2002: 7).

The belief that education can foster the required values, behaviour and lifestyles and be a primary agent of transformation formed the basis for the Decade of ESD. The key objectives for the Decade were:

- facilitating networking and collaboration among stakeholders in ESD;

- fostering greater quality of teaching and learning of environmental topics;

- supporting countries in achieving their Millennium Development Goals through ESD efforts;

- providing countries with new opportunities and tools to reform education.

(UNESCO, 2005: 6)

In 2009, as part of the Decade, two significant international events took place. The UNESCO World Conference on ESD, held in Bonn, Germany and the 15th climate change conference in Copenhagen, Denmark which "became a rallying point for many civil society actors to call attention to important changes they felt were needed in global and national policies on climate change" (UK National Commission for UNESCO, 2010: 13). However, education does not feature prominently in these climate change discourses and there are warnings that "the impact of climate change activism as a primary driver for ESD should not be overstated", as this could diminish the messages and effectiveness of ESD (UK National Commission for UNESCO, 2010: 13).

Significant outcomes of the Decade of ESD include a broader understanding of TVET for sustainable development where the emphasis moved to transformation of business and community cultures towards sustainability and the development of an online resource 'Teaching and Learning for Sustainable Futures' ${ }^{13}$ which is aimed at student teachers, teachers, curriculum developers, education policy-makers, and authors of educational materials.

Successes of the Decade include raising awareness of the importance of education as an enabler for sustainable development, and galvanising pedagogical innovation. There is a

\footnotetext{
${ }^{13} \mathrm{http}: / /$ www.unesco.org/education/tlsf/
} 
recognition of the need for multiple stakeholder engagement and the importance of nonformal, vocational education and training in delivering objectives (UNESCO, 2014a: 9). There is

the need for further alignment of education and sustainable development sectors; the need for more work towards institutionalizing ESD to ensure strong political support for implementing ESD on a systemic level; and finally, the need for more research, innovation, monitoring and evaluation to develop and prove the effectiveness of ESD good practices. (UNESCO, 2014a: 10)

Global citizenship was not linked to, or promoted alongside, ESD during the Decade, and Huckle and Wals, in an analysis of the literature supporting the Decade, suggest that it "failed to acknowledge or challenge neoliberalism as a hegemonic force blocking transitions towards genuine sustainability" (Huckle \& Wals, 2015: 491). From the reviews and case studies from the Decade, it is apparent that a transformational agenda is lacking, and that the political and ethical dimensions are weak. There is no critical analysis of why unsustainable global policies and practices persist. The words 'resilience' and 'transition' are increasingly used, while 'empowerment' and 'collective action' receive scant attention (Huckle \& Wals, 2015: 500). Educators are not guided as to how to challenge existing systems and how we might change or teach for change.

\subsubsection{Conclusion}

From an anthropocentric view of the environment and narrow definitions of development to the broad ethical visions for education, we can trace the changing priorities and the ways in which problems and their solutions have been conceptualised through the lens of the UN and their partner organisations. ESDGC has been influenced by this thinking. Latterly the achievements and shortcomings of the Decade for ESD have helped to inform future directions for research, policy and pedagogy in the field. As far back as 1977, at the Tbilisi conference on environmental education, complexity and interdependence were understood as important elements. The Earth Charter continued this thinking and put ethics and universal responsibilities at the heart of its vision. It is becoming increasingly clear that ethics and concepts of interrelationships and interdependence are of central importance. The Decade of ESD did not sufficiently emphasise these and global citizenship was not a prominent discourse. It is reasonable to assume that this has contributed to conceptual confusion and non- 
engagement with EGC. Existing paradigms in education and in society were not challenged and critics point to a lack of coherent policy development in UNESCO, where the underlying ideological roots of unsustainability and inequality remain unchallenged and little guidance for pedagogy is provided.

\subsection{Education for sustainable development in the UK}

In 2005, the UK Government, the Scottish Executive, the Welsh Government and the Northern Ireland Administration agreed upon a set of shared principles to achieve the goal of living within environmental limits, and as a result, the UK sustainable development strategy, Securing the Future, was produced (UK Government, 2005a). It aligns to the UN vision and focuses on formal school education; it does not mention adult education although it does refer to professional development and work-based learning. It states that "To maintain a more competitive economy, to compete internationally and build ourselves sustainable communities, we need to improve the knowledge and skills base of everyone, including professionals and others in the workplace" (UK Government, 2005a: 39). The strategy stresses developing sustainable lifestyles and habits. Citizenship is emphasised, but global citizenship is not evident and resides in the Global Gateway, ${ }^{14}$ which is a website developed by the British Council for the Department for Education and Skills (DfES) at the UK Government. This portal was designed to help schools establish links with other countries, to enable pupils to learn more about different cultures. There is a clear divide between citizenship education and global education.

In the same year the Learning and Skills Council's (LSC) strategy for sustainable development, From Here to Sustainability, was produced and key actions for the post-16 sector are identified as: capacity building, sustainable development champions, baseline audit and influencing and persuading (LSC, 2005: 8). This is an environmentally focused strategy, and even though decision-making and participation in society are strong elements, citizenship is not mentioned. In all likelihood the separation of environment and citizenship discourses in policy percolated

\footnotetext{
${ }^{14}$ https://schoolsonline.britishcouncil.org/Global-Gateway
} 
into subsequent developments. These documents, to an extent influenced the ESDGC strategy, there are recognisable parallels and influences.

Of relevance for post-16 learning is a study entitled Learning to Last: Skills, Sustainability and Strategy, by Cohen, James and Blewitt (2002). This document laid out an agenda for ESD, focusing on the need to integrate sustainability principles and practices into all levels of post16 learning; social inclusion is one of the key discourses. Following this, the DfES published its action plan for sustainable development in education and skills, which states as its main objective that learners will develop the skills, knowledge and value base to be active citizens in creating a more sustainable society (DfES, 2003). Although citizenship was recognised as important, the global dimension was weak here.

In consultation with stakeholders in the UK, UNESCO produced a report on developments in ESD between 2008 and 2010. It underlines the challenge of articulating a common understanding of ESD across the UK (UK National Commission for UNESCO, 2010), however progress had been made: "In 2008 and 2009 there were signs of substantial progress in embedding policies and developing practices in support of ESD in the UK across a wide range of sectors" (UK National Commission for UNESCO, 2010: 8), and in 2009, Ofsted, the Government's education inspectorate in England, built sustainability into its new common inspection framework for further education and skills. As a result, inspections reported on sustainability, although performance was not graded. Best practice in the UK remains broadly undefined according to UNESCO but can correspond to any type of ESD that meets some or all of UNESCO's key characteristics (UK National Commission for UNESCO, 2010: 14-15).

The most significant changes in UK policy and regulations relating to sustainable development during the period 2008-2010 were in areas such as carbon reduction, the use of fair trade products and recycling. Momentum towards action on learning about climate change nationally and globally is noted in the UNESCO report, and is linked in the UK to the enactment of the UK Climate Change Act in 2008, which sets ambitious targets for becoming a low-carbon economy. This is having, and will continue to have, a significant impact on ESDGC, as we see the increasingly pervasive media attention on carbon reduction and action for climate change without reference to learning agendas.

A distinct lack of connection between the informal, formal, civic learning and voluntary sectors and missed opportunities for learning and for sharing resources and information were 
highlighted in the UK National Commission for UNESCO report (UK National Commission for UNESCO, 2010: 9). A dimension for further investigation that is relevant to the informal learning sector and to this thesis is

... a tendency to see change focused around what individuals and families can do, ignoring that many issues and decisions are only amenable to more concerted social action. Developing social action skills through practice in real-life contexts is a tangible example of where connection between sectors is indispensable. (UK Commission, UNESCO, 2010: 44-45)

In terms of research, the report found that "in general there is an imbalance of research activities in relation to different education sectors, with a relative paucity of research relating to ESD in the post-16 learning and skills, community and workplace sectors" (UK Commission, UNESCO, 2010: 33). Global citizenship discourses are not prominent in any of the UK documents discussed above and global citizenship education in post-16 education is not visible.

Policy in the UK changed in 2010 when a new Liberal Democrat-Conservative coalition government came into power. According to Martin, Dillon, Higgins, Peters and Scott (2013) their education policies meant that "overt, central policy support for a range of issues has been either withdrawn or reduced. Sustainable development and ESD are cases in point." (Martin et al., 2013: 1525). The Sustainable Development Commission had been the UK Government's independent adviser on sustainable development since 2000 and "worked to help decision makers and advisors embed sustainable development as the operating system of choice in the four Governments of the UK"15, but in March 2011, the Commission ceased operating.

The policy brief Education for Sustainable Development (ESD) in the UK: Current Status, Best Practice and Opportunities for the Future ${ }^{16}$ (UK National Commission for UNESCO, 2013) draws on evidence from independent experts across the UK and sets out the characteristics of best practice and an analysis of future opportunities for enhancing the core role of education and learning in sustainable development. The main conclusions are that the good practice in ESD, at all levels and in most learning contexts across the UK, is characterized by good teaching and enhanced learner outcomes. It is also linked to the professional standards and qualifications of teachers who are part of innovative communities and networks of practice. It concedes that

\footnotetext{
${ }^{15} \mathrm{http}: / /$ www.sd-commission.org.uk/

${ }^{16} \mathrm{http} / / /$ www.unesco.org.uk/wp-content/uploads/2015/03/Brief-9-ESD-March-2013.pdf
} 
developments in ESD are still relatively small in scale, mostly based on projects, and that the incorporation of good practice in all sectors is uneven. "There is no coherent view at policy or practice level about how ESD can most appropriately be experienced by learners, in a progressive sense across all age groups and how it can contribute to improved learner outcomes" (UK National Commission for UNESCO, 2013: 3-4). Another significant barrier or missed opportunity identified by the UK National Commission (2013) is the lack of synergy between formal education, community and NGOs.

Northern Ireland, Wales and England have seen a reduced emphasis on ESD, and this, according to the UK National Commission report (2013), is explained in part by ambiguity about policy in relation to education and training more generally, and about what role they might play in supporting the emerging green economy. The picture in Scotland is different; here, there is an integrated and coherent approach to sustainable development, and ESD is recognised by policy-makers and practitioners as a key enabler in the transition to a sustainable society. The Scottish Government has set targets for securing its own energy needs from renewable sources and ESD is seen as playing a strategic role in implementing these policy objectives. Scotland is the only UK nation to incorporate ESD as part of its policy for social equity and the environment. In Wales, the significant emphasis placed on sustainable development by the Welsh Government helped the development and promotion of ESDGC, but the prominence given to it in national policy has diminished in recent years.

In a consideration of ESD from an educational policy perspective, Martin et al. (2013) argue that the absence of an overarching strategic framework for sustainable development that sets out a clear vision for learning is a major barrier to progress (Martin et al., 2013: 1522). They conclude that the development of an overarching framework would result in wider adoption: "ESD would benefit from an overall strategic framework that puts it firmly at the core of the education policy agenda in all of the jurisdictions in the UK" (Martin et al., 2013: 1537).

\subsection{Citizenship education policy and education for global citizenship in the UK}

This section looks at policy related to citizenship education and emergent policies relating to global citizenship education in the UK. The discourses of citizenship are prominent in educational theory and global citizenship education has come to the fore more recently in light 
of intensifying globalization and associated accelerating trends, as illustrated by Steffen et al. (2004, 2011, 2015). As seen in Chapter 2, global citizenship is a concept and a practice, increasingly linked with the discourses of ESD (Bourn, 2014a; Ellis, 2015; Huckle \& Wals, 2015).

In 1997, the report Education for Citizenship and the Teaching of Democracy in Schools was published by the Qualifications and Curriculum Authority in England (Crick, 1998). This stressed the importance of political literacy and democracy, whilst drawing attention to the global context of citizenship education. Citizenship became a statutory subject for schools in England in 2002 and remains so for Key Stages 3 and $4^{17}$, but there is no statutory obligation to citizenship education beyond this. In Northern Ireland there is non-statutory guidance for Key Stages 3 and 4 and citizenship is also a non-statutory component of the Scottish curriculum, even though it is included in the statutory area of social sciences. In Wales citizenship education and global citizenship education are located within Y Cwricwlwm Cymreig, ESDGC and in PSE (Andrews \& Lewis, 2000). Overlap with ESDGC is seen in 'internationalism' which is a key theme in Y Cwricwlwm Cymreig (Sullivan, 2011: 78), a cross-curricular theme across all education sectors. The current Estyn Inspection Framework for $\mathrm{ACL}^{18}$ expects practitioners to promote "the development of learners' knowledge and understanding of the cultural, economic, environmental, historical and linguistic characteristics of Wales" (Estyn, 2015: 25). In their research on citizenship education in Welsh secondary schools Andrews and Lewis (2000) conclude that practitioners needed more guidance to embed it effectively into teaching and learning and that the idea of a 'Welsh' education would greatly benefit from careful attention being paid to the implementation of citizenship education. Active citizenship, global citizenship and ESDGC are also part of the Welsh Baccalaureate ${ }^{19}$ which is a qualification at Alevel.

Citizenship education in UK schools has generally been included in personal and social education (PSE) or as a cross-curricular theme. I. Davies et al. (2005: 76) state that in England, "Social fragmentation, ignorance and alienation with low participation rates and the growth of support for extremist groups such as the British National Party were influential in the

\footnotetext{
${ }^{17} \mathrm{https} / / /$ www.gov.uk/government/publications/national-curriculum-in-england-citizenshipprogrammes-of-study

${ }^{18} \mathrm{http}: / /$ www.estyn.gov.wales/sites/default/files/documents/Guidance\%20for\%20the\%20inspection\%20of\%20adul t\%20community\%20learning\%20-\%202015\%20handbook.pdf

${ }^{19} \mathrm{http}: / /$ www.welshbaccalaureate.org.uk/
} 
development of the National Curriculum for Citizenship" (I. Davies et al., 2005: 76). However, they note that even though community action was emphasised, the political literacy of the Crick report (1998) had dwindled.

Many studies have been conducted on citizenship and young people in the formal sector, including a longitudinal study by Kerr and colleagues looking at the impact of citizenship education in England (Kerr 1999a, 2003; Keating, Kerr, Benton, Mundy \& Lopes, 2010), a review of policy, research and practice by Osler and Starkey (2006) and international reviews and comparisons of citizenship education by Kerr (1999b, 1999c). In a theoretical critique of citizenship education in England and Wales Garratt and Piper (2008) draw on a range of recent empirical studies to highlight citizenship education as a means of raising pedagogical considerations for teachers and policy issues for curriculum makers and planners. Their analysis suggests that it is the traditions and histories of citizenship and citizenship education which most strongly influence the dominant models. They advocate more open conceptions that are not bound to these or to curricular requirements.

In contrast to the formal school sector, the literature on citizenship education policy in adult or post-16 education is sparse. One example of a citizenship initiative, as mentioned in Chapter 2 , is the Active Learning for Active Citizens (ALAC) project, launched in 2003, with the aim of creating a common framework and curriculum for citizenship education for adults (Blunkett, 2003: 13). This framework resulted, in England, with 'Take Part': a learning approach to help people develop the skills, confidence and knowledge to become more active in their communities and influence public policies and services. The approach was based on the critical pedagogy of Paulo Freire, which includes social and moral responsibility, community involvement and political literacy. ${ }^{20}$

A review of the policy literature reveals that definitions of citizenship are ambiguous and often simplistic. This belies the complexity and contested nature of citizenship and global citizenship as outlined in the literature review. The home nations of the UK have differing approaches to citizenship education (Andrews \& Mycock, 2007), and the linking of global citizenship education with ESD in Wales is significant.

Global education, which includes the concerns of development education and latterly of global citizenship, was not included in the 1988 UK National Curriculum but it continued to receive

${ }^{20} \mathrm{http} / / /$ www.takepart.org/manageContent.aspx?object.id=10229\&mta $\mathrm{htm}=$ home 
support, and in the early 2000s was well established with the publication of a guidance document from the Department for Education and Employment (DfEE) that went into all schools (DfEE, 2005). There is no evidence of similar initiatives in adult education. Global citizenship has gained prominence in the work of UNESCO, ${ }^{21}$ and Global First ${ }^{22}$ is an initiative by the UN secretary general, whose priorities include developing global citizenship education and expanding access to education. Global Citizenship Education: An Emerging Perspective (UNESCO, 2013) recognises the shifts that have occurred in education discourses due to globalization.

Bringing citizenship into the heart of ESD was part of the UNESCO vision following the Earth Summit: "a curriculum reoriented towards sustainability would place the notion of citizenship among its primary objectives" (UNESCO, 1997, para 68). An ethical and collaborative approach to the revision of learning objectives, content, themes, teaching and assessment was called for, and political literacy was recognised as being central to this new form of education.

Viewing education for sustainability as a contribution to a politically literate society is central to the reformulation of education and calls for a "new generation" of theorizing and practice in education and a rethinking of many familiar approaches, including within environmental education. (UNESCO, 1997, paras. 67 \& 68 cited in Huckle, 2008a: 349)

Oxfam in England produced a curriculum framework for global citizenship in 1997 and a series of guides have since been produced, mainly aimed at schools. ${ }^{23}$ According to Oxfam, a global citizen is someone who:

- Is aware of the wider world and has a sense of their own role as a world citizen;

- Respects and values diversity;

- Has an understanding of how the world works economically, politically, socially, culturally, technologically and environmentally;

- Is outraged by social injustice;

- Participates in and contributes to the community at a range of levels from local to global;

- Is willing to act to make the world a more sustainable place;

- Takes responsibility for their actions.

(Oxfam, 1997)

\footnotetext{
${ }^{21}$ http://en.unesco.org/themes/democracy-and-global-citizenship

${ }^{22} \mathrm{http}: / /$ www.globaleducationfirst.org/

${ }^{23} \mathrm{http}: / /$ www.oxfam.org.uk/education/global-citizenship/global-citizenship-guides
} 
Oxfam's work has been influential in shaping the discourses and practice of global citizenship education throughout the UK. However, this vision of a global citizen is somewhat idealised, prescriptive and possibly too all-encompassing to be useful to practitioners.

\subsection{ESDGC in Wales}

\subsubsection{The policy background}

The Welsh Government is one of only a few governments in the world to have a legal duty to sustainability (Section 79 of the Government of Wales Act, 2006 ${ }^{24}$ ). The first sustainable development scheme at the Welsh Government (which was at that time called the Welsh Assembly Government and will be referred to consistently as the Welsh Government in this thesis), was Learning to Live Differently (Welsh Government, 2000), which was later reviewed, republished and re-titled Starting to Live Differently (Welsh Government, 2004a).

The duty for sustainable development presented a significant change in the policy landscape and context within which ESD could be promoted. The Welsh Government scheme that promotes sustainable development in the exercise of the Welsh Ministers' functions is entitled One Wales, One Planet (Welsh Government, 2009). The aspiration in education is that "Sustainable development and global citizenship is firmly embedded into all levels of educational provision and lifelong learning in Wales and all schools are Eco and Fair-Trade schools. Levels of educational attainment are high" (Welsh Government, 2009: 22). School buildings, environmental assessments and environmental management systems are the main emphases throughout (EcoSchools or Eco Campus, Green Dragon, ISO14000); the global dimension is missing, and this overarching scheme does not reflect the complexity or integration discussed earlier in the Tbilisi declaration, Agenda 21 or the Earth Charter. It focuses on instrumental, practical action-orientated solutions for sustainable development. Social justice, equity and global citizenship are not linked with environmental issues and it is conceivable that this lack of conceptual integration affected later policy developments in education. $A C L$ is referred to once: "Our adult community learning policy will include support for the development of skills for individuals and communities to take a more active role in

\footnotetext{
${ }^{24} \mathrm{http} / / /$ www.legislation.gov.uk/ukpga/2006/32/contents
} 
society" (Welsh Government, 2009: 70).

Policy documents from the Welsh Government since its inception in 1998 show a progressive commitment to sustainable development, and in this favourable policy climate, a nonaffiliated, like-minded group which included the RSPB (Royal Society for the Protection of Birds), Oxfam, Cyfanfyd (The Development Education Association for Wales) and the Environmental Education Council for Wales, came together to form a group called 'Education for the Future', which successfully lobbied the Welsh Government to fulfil its obligation to sustainable development through education. As a result, the ESD panel was established as a sub-panel of the governmental sustainable development panel, and a global citizenship working group was convened jointly with the Department for International Development (DFID).

The sustainable development action plan 2004 - 2007 (Welsh Government, 2004b) identified ESDGC as one of the Welsh Government's priorities, and by 2005, Estyn, Her Majesty's inspectorate for education and training in Wales, was using the term 'education for sustainable development and global citizenship' in schools (Estyn, 2005). The Education Adviser for the RSPB in Wales was employed as the ESDGC Champion in 2007, although prior to this she had been working with the Welsh Government and was instrumental in merging the global citizenship working group and the ESD advisory panel to form the ESDGC panel. This panel had representatives from the Welsh Government, the Qualifications, Curriculum and Assessment Authority for Wales/Awdurdod Cymwysterau, Cwricwlwm ac Asesu Cymru (ACCAC), Estyn, local authorities, initial teacher training establishments, HE, the British Council, the Countryside Council for Wales, eco-schools and NGOs such as Oxfam, the RSPB and the World Wildlife Fund (WWF-UK).

As part of PSE, ACCAC published a guidance document in 2002 called Education for Sustainable Development and Global Citizenship - Why? What? How? (Welsh Government, 2002); it defines ESDGC in detail and outlines nine key concepts. Education for Global Citizenship: A Map for Curriculum Planners was a document developed by the PSE and religious education arm at ACCAC in 2003; it had the subtitle Incorporating Links to Education for Sustainable Development and Education for Race Equality. Unfortunately, it was never published.

A guidance document for global citizenship in secondary schools offers suggestions for incorporating global citizenship across all secondary school subject areas and states that it can 
be useful in post-16 education (Welsh Government, 2005b: 1); however, it is inconsistent, in that ESDGC is not referred to. The nine concepts identified and agreed in the ACCAC document are referred to in subsequent guidance documents such as A Common Understanding for the Adult and Community-Based Learning Sector (Welsh Government, 2012) and the Global Citizenship Secondary School Map (Welsh Government, 2005b), but were not included in the ESDGC strategy. The concepts are: interdependence, citizenship and stewardship, needs and right, diversity, sustainable change, quality of life, uncertainty and precaution, values and perceptions, conflict resolution (Welsh Government, 2002).

Cyfanfyd helped to raise the profile of global citizenship in the school curriculum in Wales with the publication of a booklet entitled Global Citizenship and PSE (Cyfanfyd, 2001). This was distributed to curriculum bodies, schools, local authorities and teacher training institutions in Wales. Another organisation in Wales that addresses global citizenship is the Centre for Education in World Citizenship (CEWC), which is the schools' arm of the Welsh Centre for International Affairs. Its mission is to "inspire learning and action on global issues" and two projects, 'Wales for Peace' and the 'Wales-Africa Partnership', are its main delivery vehicles.

In England, parallel initiatives were taking place, such as the publication of Developing a Global Dimension in the School Curriculum (DfES, 2005), which clearly links ESD, the global dimension and citizenship. The English document has eight similar concepts to those outlined above: global citizenship, conflict resolution, diversity, human rights, interdependence, social justice, sustainable development, values and perceptions (DfES, 2005: 8-9). In other countries in the UK, Canada, Australia, America and in many European countries, ESD and EGC were dealt with in separate policies at that time, and even though the term 'education for sustainable development and global citizenship' is long and convoluted, it encourages integration and offers possibilities for new conceptualisations and practices.

\subsubsection{ESDGC: A strategy for action and a common understanding in ACL}

Bennell and Norcliffe (2010), in their study on the development of ESDGC in Wales in the formal sector, list sources that have informed and influenced policy. These include works from the fields of global education, world studies, development education, peace education, antiracist education, environmental education, human rights education, multicultural education, futures education, and more recently, ESD and EGC. The first ESDGC strategy was produced in 
2006 and revised in 2008 (Welsh Government, 2006,2008a), it covers all education sectors: schools, youth, further education and work-based learning, higher education and adult and continuing education (as ACL was initially referred to). The strategy is intended to highlight actions for driving forward the ESDGC agenda. Five common areas are: commitment and leadership; learning and teaching; organisational management; partnerships and community; and research and monitoring. Following the publication of the strategy a suite of documents called 'Common Understandings' were then produced for each sector, aimed at supporting implementation.

Jane Davidson, the then Minister for Children, Education, Lifelong Learning and Skills, in her foreword to the 2006 strategy document made a broad statement about the fundamental importance that ESDGC was built into "our day-to-day life. It is key to us not only 'Starting to Live Differently' but to ensuring that we completely transform the mindset of future generations. (Welsh Government, 2006: i). The foreword to the 2008 version by the Minister, Jane Hutt, shows how a focus on certain issues emerged:

Climate change, poverty, conflict and consumer pressure are all part of our world today. Education for sustainable development and global citizenship (ESDGC) seeks to find ways to raise awareness and action to address the consequences of our lifestyle choices and prepare us for sustainable living in the 21st century as global citizens. (Welsh Government, 2008a: 3)

Priorities across each educational sector include evaluating ESDGC to gain a baseline against which progress can be measured, training, resourcing and mainstreaming (Welsh Government, 2008a: 10). Recommendations for the ACL sector are that supplementary guidance is developed to ensure a balance between sustainable development and global citizenship and to support the assessment of ESDGC within ACL provision. Other recommendations in post-16 education are that ESDGC is included in FE teacher training courses and other training for adult education tutors; good practice guidance is to be produced, and all institutions should be encouraged to develop a suitable environmental management system (EMS) and equivalent measures which cover all operations. All networks within the sector are encouraged to take ESDGC to their members and the sector should define relevant, common standards for ESDGC. Between 2006 and 2007 very little progress had been made in ESDGC in the ACL sector, and it was the lowest achieving education sector (Welsh Government, 2008a: 6). The 2008 strategy states that in $\mathrm{ACL}$, the immediate aim is to focus on action to raise awareness, as it recognises that provision is piecemeal (Welsh Government, 2008a: 70). 
The ESDGC strategy states that "there are similarities between ESDGC principles and adult and continuing learning approaches. These similarities may mask the 'latent' contribution that this sector may have to the incorporation of ESDGC within teaching and learning activities" (Welsh Government, 2008a: 71). This is unclear and one of the aims of this thesis is to explore this further.

Supplementary actions for the success of ESDGC include incorporating ESDGC into the strategic planning of adult education with the aim of embedding it into courses, including CPD. Incorporating ESDGC into criteria and guidelines for community funding is suggested along with the development of resources across curriculum areas, incorporating ESDGC into community development workers' training, and raising awareness amongst relevant unions and businesses as to the importance and relevance of ESDGC (Welsh Government, 2008a: 7475). None of these actions have been taken forward.

The ESDGC strategy states that once a "Common understanding develops then the pace will quicken in this sector as well" (Welsh Government, 2008a: 69). The Common Understanding for ACL (Welsh Government, 2012) was written by the National Institute for Adult and Community Education in Wales (NIACE Dysgu Cymru), the Workers Education Association (WEA) and Cyfanfyd in 2010. It is an information and guidance document for tutors, trainers, adult learners and $A C L$ providers and is intended as a starting point for integrating and consolidating ESDGC within practice. However, despite the articulation of purpose, the document does not provide comprehensive guidance for practitioners.

The suite of Common Understanding document includes: for schools ${ }^{25}$ in June 2008, Information for Teacher Trainees and New Teachers in July $2008^{26}$, a document for the FE sector in September $2008^{27}$, A Common Understanding for the youth work sector in November $2008^{28}$ and a self-assessment toolkit for work-based learning providers in January $2009^{29}$. All these documents were produced quickly, but it took until March 2012 before the Common Understanding in $A C L$ was published online. The Common Understanding documents are all

\footnotetext{
${ }^{25} \mathrm{http}: / /$ gov.wales/docs/dcells/publications/081204commonunderstschoolsen.pdf

${ }^{26} \mathrm{http}: / /$ gov.wales/docs/dcells/publications/081204infoteachertraineesen.pdf

${ }^{27} \mathrm{http}: / /$ gov.wales/docs/dcells/publications/081204furthedsectwalesen.pdf

${ }^{28} \mathrm{http}: / /$ www.learningobservatory.com/uploads/publications/1919.pdf

${ }^{29} \mathrm{http} / / /$ gov.wales/docs/dcells/publications/130814-sustainable-development-en.pdf
} 
available on the Welsh Government ESDGC website ${ }^{30}$ apart from the youth work Common Understanding, which can be found in various locations including the Learning and Skills Observatory Wales ${ }^{31}$.

Working alongside the Welsh Government to achieve the objectives of ESDGC, Estyn published Establishing a Position Statement for ESDGC, which considered the development of ESDGC in schools and FE in Wales (Estyn, 2006), and in 2008 they undertook a review of ESDGC in youth work and ACL (Estyn, 2008). The review found that many ACL providers fail to develop an integrated approach to ESDGC; Estyn felt that it was important for practitioners to understand the links between sustainable development and global citizenship (Estyn, 2008: 3), although no guidance was given as to how to realise this in practice. There was a generally a lack of understanding at all levels about the definition, purpose and benefits of ESDGC. The seven themes are emphasised in the report and examples and suggestions are given:

- Wealth and poverty - Fair Trade, sustainable procurement;

- Identity and culture - race equality, international partnerships;

- Choices and decisions - thinking about the consequences of our lifestyle decisions;

- Healthy living - health body, healthy mind;

- Natural world - take action for biodiversity, visits to countryside projects;

- Waste and consumption - management of buildings and grounds; and

- Climate change - energy use, transport choices, food miles.

(Estyn, 2008: 8)

\subsection{Lifelong learning policy in Wales and its links to ESDGC}

This section on ACL in Wales clarifies the wider policy climate within which ESDGC was introduced and it provides essential context for the case study and the following discussions.

The establishment of the ESD panel and the global citizenship working groups coincided with the publication of The Learning Country (Welsh Government, 2001), which set out the government's intentions for education in Wales until 2010. It includes commitments to realise sustainability, tackle social disadvantage, promote equality of opportunity and celebrate

30

http://gov.wales/topics/educationandskills/allsectorpolicies/europeanandinternational/sustainabledeve lop/?lang=en

${ }^{31} \mathrm{http}: / /$ www.learningobservatory.com/ 
diversity (Welsh Government, 2001: 8). ESD is referred to in this document but education for global citizenship does not appear. In The Learning Country: Vision Into Action (Welsh Government, 2005a), the strapline for the section on post-compulsory education states, "We want to strengthen the contribution of education and training to economic development. We want learning to be an everyday part of working, and non-working life, in which the interests of learners come first" (Welsh Government, 2001: 20). All mention of sustainability is relegated to its links with the economy and there is no mention of citizenship.

At the same time as the Welsh Government was promoting sustainable development, a plethora of public policy drivers were influencing the purpose and goals of adult education. $\mathrm{ACL}$ is defined by the Welsh Government in the policy statement Delivering Community Learning for Wales as "flexible learning opportunities for adults, delivered in community venues to meet local needs" (Welsh Government, 2010: 3). The statement sets out the strategic aims for $\mathrm{ACL}$ and defines the key actions for the Welsh Government:

$\mathrm{ACL}$, whilst making an important contribution to the skills agenda, is not primarily concerned with addressing national skills shortages in occupational areas identified centrally by the Welsh Assembly Government. It is about a tailored range of learning opportunities determined by local providers to meet local demand, which in the case of publicly funded programmes, ought to be targeted at those in greatest need. (Welsh Government, 2010: 4)

A consultation in 2008 proposed creating $A C L$ partnerships across Wales for the delivery of $A C L$ and the rationale and aims of $A C L$ are stated in the final policy statement as:

increased participation by those who have benefited least from education in the past or who are most at risk of not benefiting in the future; improved quality in the learning experience including increased progression to other learning opportunities or work and greater coherence in the nature and patterns of provision across the wide range of providers. (Welsh Government, 2010: 5)

The consultation document in 2008 was called Delivering Skills that Work for Wales: A New Approach to Adult Community Learning (Welsh Government, 2008c) but the action plan produced shortly after is a different document that focuses entirely on the skills agenda (Welsh Government, 2008d). Skills have become separated from community learning in policy.

The Skills and Employment Strategy and Action Plan for Wales (Welsh Government, 2008d) sets out the skills agenda and addresses poor basic skills, the high levels of young people classified as 'NEET' (not in employment, education or training), and the low levels of 
qualifications amongst the adult population in Wales (Leitch, 2006: 16). The strategy builds on the Leitch report and takes a lead from the Webb review into FE in Wales in $2007^{32}$ and recommends focusing resources on 14-19-year olds. The Webb review identifies a need for radical change in the FE sector and states that ESDGC can make a significant contribution to the changes that are called for. Funding was re-allocated from $A C L$ following the Leitch and Webb reports resulting in the loss of a range of provision. In a study on sustainable development in the learning and skills sector in England, which at that time included FE colleges, work-based learning, schools with sixth forms and ACL, Martin, Martin and Cohen (2008: 147) refer to the sector as "The poor cousin of the educational system in the UK.

Adult education, as a social institution, embodies the tension between economic growth and broader social and individual flourishing and justice. "This tension, which is still present in welfare state provision for adult education today, must be confronted if adult education policy is to contribute to societal growth in sustainable ways" (Milana, Rasmussen \& Holford, 2016: 538).

\subsection{The Welsh Context 2010-2016}

In Wales, responsibility for ESDGC moved from DCELLS to the European and international education section within the DfES in 2010. In the same year the ESDGC Champion left her post, and in 2018 ESDGC is no longer resourced or managed as a stand-alone agenda; it is now considered to be mainstreamed in education. The work outlined in One Wales, One Planet (Welsh Government, 2009) to produce another plan following on from the 2008 Strategy for ESDGC was not taken forward.

A Commissioner for Sustainable Futures was appointed in April 2011 to work with and strengthen Cynnal Cymru ${ }^{33}$ and in 2013 the Welsh Government consulted on the Sustainable Development Bill with the aim of making sustainable development a central organising principle for public bodies in Wales. During early consultation on the Bill, ESDGC stakeholders were quick to point out the absence of any mention of education as a means of supporting behaviour change for sustainable development, and they argued that "the lack of convincing

\footnotetext{
${ }^{32} \mathrm{http} / / /$ gov.wales/topics/educationandskills/publications/wagreviews/webbreview/?lang=en

${ }^{33} \mathrm{http}: / /$ www.cynnalcymru.com/
} 
evidence of the 'mainstreaming' of ESDGC thus far suggests the need for further statutory support for ESDGC" (UK National Commission for UNESCO, 2013: 10).

Wales now has a Well-being of Future Generations (Wales) Act (April 2015) ${ }^{34}$ and the Commissioner for Sustainable Futures has been replaced by a Future Generations commissioner for Wales who supports the public bodies listed in the Act as they work towards achieving its goals. The Act establishes Public Services Boards (PSBs) for each local authority area in Wales, which are tasked with improving the economic, social, environmental and cultural well-being of these areas.

Influences on the Future Generations Act include the UN sustainable development goals ${ }^{35}$ which were introduced following the adoption of the sustainable development agenda in 2015. ${ }^{36}$ These seventeen goals are broader in scope than the preceding millennium goals and place greater emphasis on ecological issues and on transforming the economy through a vision for a shared and lasting prosperity (Guardian, n.d.; Hajer, Nilsson, Raworth, Bakker, Berkhout, de Boer... \& Kok, 2015). They are seen by Le Blanc (2015) as a network that can facilitate policy integration across sectors, and this is in line with the thinking and strategic direction of the goals of the Well-being of Future Generations (Wales) Act ${ }^{37}$ (Welsh Government, 2015a). These goals are: a prosperous Wales, a resilient Wales, a healthier Wales, a more equal Wales, a Wales of cohesive communities, a Wales of vibrant culture and Welsh language and a globally responsible Wales ${ }^{38}$ (Welsh Government, 2015b: 6).

The only education or learning element is:

A prosperous Wales: An innovative, productive and low carbon society which recognises the limits of the global environment and therefore uses resources efficiently and proportionately (including acting on climate change); and which develops a skilled and well-educated population in an economy which generates wealth and provides employment opportunities, allowing people to take advantage of the wealth generated through securing decent work. (Welsh Government, 2015b: 6)

This is a functional statement: the term 'well educated' is not qualified and is linked with employment and economic growth. Between the consultation and the final Act, a seventh goal

\footnotetext{
${ }^{34} \mathrm{http} / / /$ gov.wales/topics/people-and-communities/people/future-generations-bill/?lang=en

${ }^{35} \mathrm{https}: / /$ sustainabledevelopment.un.org/?menu=1300

${ }^{36} \mathrm{http}: / /$ www.un.org/ga/search/view_doc.asp?symbol=A/69/L.85\&Lang=E

${ }^{37} \mathrm{http}: / /$ gov.wales/topics/people-and-communities/people/future-generations-bill/?lang=en

${ }^{38} \mathrm{http}: / / g o v \cdot w a l e s / d o c s / d s j l g / p u b l i c a t i o n s / 150623-g u i d e-t o-t h e-f g-a c t-e n . p d f$
} 
was added: 'A globally responsible Wales'; the goal is to become a "nation which, when doing anything to improve the economic, social, environmental and cultural well-being of Wales, takes account of whether doing such a thing may make a positive contribution to global wellbeing" (Welsh Government, 2015b: 6). This offers little guidance to practitioners in education or in other public services who are expected to implement this Act. The sectors are expected to develop their own interpretations and methods for realising the goals.

Adult Learning Wales was established in 2016, uniting two of the major ACL providers, the WEA and the YMCA College Wales. The new organisation is part of the Wales wide nonstatutory 'Adult Community Learning Wales Partnership' which was established in 2014. The partnership is developing an 'adult learning framework' that takes into account government policies such as 'Successful Futures' (Donaldson, 2015) and is instrumental in increasing integration across post-16 learning (Estyn, 2016).

\subsection{ESD/ESDGC in other post-16 sectors}

Higher Education and Further Education are discussed briefly to provide further contextual background, and to identify some of the research that has influenced the thesis, given the limited amount of work on ESDGC in ACL.

Since 2008 there have been significant developments in the HE sector relating to ESD, and the Welsh, English and Scottish Higher Education Funding Councils and the Higher Education Academy (HEA) have all enacted policies or taken action to increase engagement with ESD. As key national funding bodies for Higher Education Institutions (HEIs), they play an important role in the growth of ESD in post-16 education. The HEA has supported and promoted ESD and ESDGC and in 2014 it set up an UK-wide ESD advisory group in collaboration with the QAA (Quality Assurance Agency) to produce a guidance document (HEA/QAA, 2014).

The Higher Education Funding Council for Wales (HEFCW) allocated $£ 22,500$ to every Welsh HEI in 2008, to implement an analysis of how ESDGC was incorporated within the curriculum, and the results were published by the HEA (HEA, 2009). There was also a comprehensive review of good practice in HEls in Wales (SQW, 2009). Following a HEFCW conference on ESDGC in 2009, a tool was developed to audit ESDGC in Wales (Glover \& Peters, 2013: 209; Glover et al., 2011). Benchmarking and a baseline approach were recommended (Glover et al., 
2013; HEA, 2009: 16), echoing the intended actions of the ESDGC strategy. However, research indicates that inclusion and integration of ESDGC into the curriculum is proving to be more problematic than the inclusion of sustainability measures into estates and ESDGC in research and reflects the situation more globally in HEls (Glover \& Peters, 2013: 209).

UNESCO supported six UK Regional Centres of Expertise (RCEs) and a Welsh one was established in Swansea University in 2009. During 2009, RCE Wales published four briefing statements on its intended actions and progress and invited continuing open stakeholder input. The RCE was designed to complement existing ESDGC activity and facilitate its further development, particularly ESDGC communications, research and quality. It was intended that RCE Wales would inform ESDGC practice and policy.

Martin et al. (2008) describe the situation regarding sustainable development in the learning and skills sector in England. They conducted a survey and visited organisations looking at leadership and management, estates, courses and curriculum and community; the research concluded that policy was not being translated into practice and that the curriculum was the area that needed most work.

Cynnal Cymru, an NGO set up to raise awareness of sustainable development issues, conducted a survey of FE institutions in Wales (Thomas, 2014), and the report focused on good practice across the five common areas outlined in the ESDGC strategy. The Well-being of Future Generations Bill (Welsh Government, 2015a) provides the context for the study and discussions take place within a service delivery model. The focus is environmental, although citizenship is mentioned in the context of $Y$ Cwricwlwm Cymreig and the Welsh Baccalaureate. Details of the research and its findings on teaching and learning are unclear and receive very little coverage in the report. However, the report states that:

Generally speaking, further education colleges in Wales understand Education for Sustainable Development and do it well. At best, ESDGC is completely integrated into all courses and curricula and part of the core function of the college. At worst, it is seen by some tutors as an add-on and a box to tick. Thankfully, the latter is rare. (Thomas, 2014: 12)

This paints an optimistic picture without much evidence, and this, perhaps, warrants further examination. 


\subsection{Conclusion}

Education and lifelong learning policy are central in an international policy response to escalating and intensifying environmental degradation and global economic inequalities.

Overall, adult and informal learning is acknowledged as having a significant contribution in promoting and supporting ESD and EGC.

This chapter has outlined how thinking about the role of education evolved from the early conferences to the more recent Decade of ESD; from the holistic, integrated approach that linked environment, society and economic concerns, to Agenda 21, which raised public awareness about the issues and the role of education and lifelong learning in realising sustainable development goals. An overview of UK and Welsh policies that have been influenced by these international developments, and in turn, have influenced other policies including ESDGC has been provided.

It is not possible to include much comparative analysis in this thesis; however, the work of UNESCO presents case studies from around the world which have informed thinking in the UK on ESD and in Wales on ESDGC. Reviewing the Decade of ESD has highlighted inadequacies in UK initiatives and policies in terms of their coherence and efficacy, and some of the review findings are corroborated by the findings in this present research.

A change or trend that is evident in both lifelong learning policy and ESDGC-related policy, is the way in which the call for a 'new vision' of education, a re-thinking of its purpose, has come to the fore. This is in response to the challenges of a rapidly changing and globalised world which are driving policy imperatives. Wales decided to explicitly link global citizenship with sustainable development in ESDGC and this indicates that there was an intention to address the issues in a more integrated way. This was in line with much of the international thinking and recommendations. However, education for global citizenship does not have a policy precedent, which makes it difficult to define and conceptualise. This present thesis discusses this in the context of ACL practitioners' responses to the ESDGC strategy and seeks to clarify the concept of global citizenship and its importance in an education for sustainability.

The constantly changing policy landscape of $A C L$ has been introduced in this chapter, as this impacts on practitioners' ability to engage with innovations, new thinking and practices. The policy process, with regard to ESDGC in ACL in Wales, comes under scrutiny during the 
empirical research in this current thesis and is linked to the complex array of issues pertaining to infrastructure, ideology and purpose in ACL. Policy reflects certain aspirations of government and prevailing political ideologies, and ESDGC garnered support as part of realising sustainable development, which was supported by the Labour Government of 1997. Since then, there have been changes in government, levels of support have decreased, and the countries of the UK are adopting different approaches. There are barriers to implementing ESDGC, but sustainable development remains part of government rhetoric, even though it does not have prominence in policy, and global citizenship is becoming an increasingly familiar concept in the theory and policy rhetoric of education and lifelong learning. 


\section{Chapter 4 \\ Methodology}

\subsection{Introduction to mode of inquiry and research questions}

\subsubsection{Introducing the chapter}

This chapter focuses on the methodological approach taken to address the research questions which examine the ESDGC strategy and it implementation in the ACL sector in Wales. It begins with a brief outline of the research approach and a re-stating of the questions. This is followed by a discussion of the underpinning research paradigms and theoretical consideration, which provide a rationale for the chosen case study approach and the way in which the research questions are addressed, using evidence from all data sets in an integrated fashion.

The expedience and appropriateness of the case study design are discussed in some detail, along with issues relating to the validity, credibility and robustness of the research process and its findings. Ethics are considered before proceeding to a section which summarises, and then describes in detail, the process of conducting the research (section 4.5). This section and the reflection will adopt a first-person narrative style as opposed to the third person one that is used throughout most of the thesis to foreground the subjectivity of the processes. The data collection methods are discussed in terms of their appropriateness and their merits and limitations. Section 4.8 examines the interpretative and analytical process, with reference to theoretical perspectives, and before concluding there is a section where the researcher reflects on the process of conducting the research.

\subsubsection{Introducing the approach}

A qualitative, case study approach has been adopted to explore the 'real life' context of the development and introduction of ESDGC as an educational innovation in the ACL sector in Wales. As Miles and Huberman state: 
The emphasis is on a specific case, a focused and bounded phenomenon embedded in its context. The influences of the local context are not stripped away, but are taken into account. The possibility for understanding latent underlying, or nonobvious issues is strong. (Miles \& Huberman, 1994: 10)

In examining the policy process, formulation and implementation are considered; the process is seen as a whole, and the research seeks to present a comprehensive account. The case study approach has the potential to encapsulate and reveal complexity; this is important, as this current research is concerned that a range of voices and perspectives are represented. To this end, different methods are used, and multiple data sources facilitate a holistic understanding of the situation. Through working with different data sets over an extended period, the data are increasingly seen and understood as one body of evidence, and even though the data are broken down during the analytic process, they are then synthesised into an explanatory narrative. This maintains the integrity of the case under investigation (Cohen, Manion \& Morrison, 2011: 289).

It is axiomatic that understanding the ways in which a diverse range of practitioners interpret and engage (or choose not to engage) with the complex concepts inherent in ESDGC should involve a qualitative approach (Corbin \& Strauss, 2008; Cohen, Manion \& Morrison, 2011; Denzin \& Lincoln, 2008; Silverman, 2013). Silverman identifies two models of qualitative inquiry: naturalistic and constructivist. Naturalistic approaches are concerned with questions of 'what' is going on, and constructivist approaches are more interested in 'how' phenomena are constructed. This research began as a naturalistic inquiry, concerned with exploring and describing the situation with regard to ESDGC in ACL in Wales, and subsequently developed a more constructivist approach in order to understand how this educational initiative was being understood and engaged with. Therefore, the model adopted contains elements of both naturalistic and constructivist paradigms (Silverman 2013: 106-107).

The study uses an inductive methodology where theory is generated during the research process and where theoretical accounts, pertaining to the general features of a topic, are grounded in what people have said and in the discourses that emerge. The aim is not to attempt to encapsulate reality in one theory or in a comprehensive interpretation, but to decipher the complex and often contradictory manifestations that emerge (Hammersley, 1995: 28). Assumptions about the world, reality and the nature of social phenomena influence research, the questions we ask and how we do it (Denzin \& Lincoln, 2005; Sayer, 2000; 
Silverman, 2013). In this current study, these assumptions can be summarised in the following way:

Fig. 4.1 A series of related assumptions (Adapted from Waring, 2012: 16)

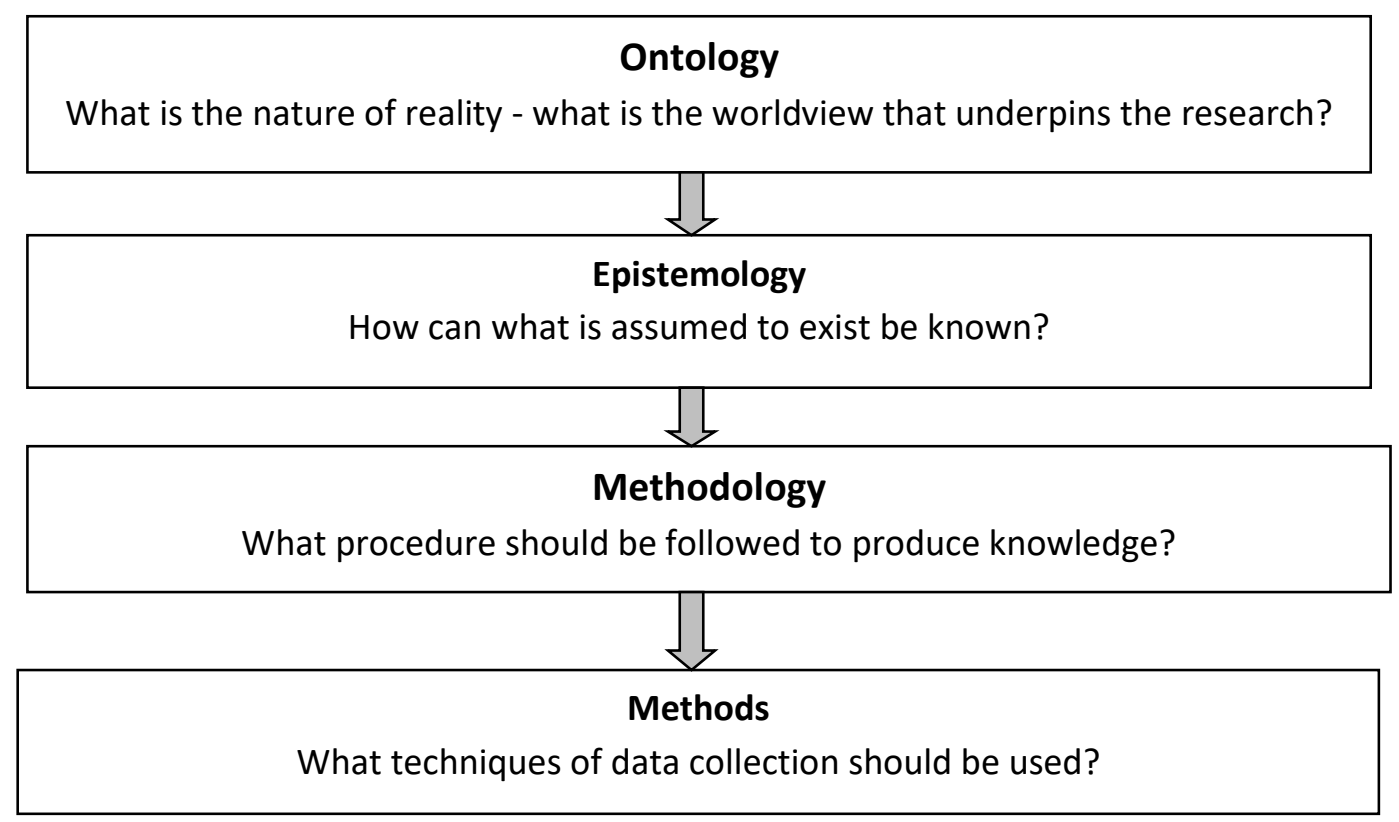

Ontological assumptions are examined in the discussion on research paradigms (section 4.2), and linked to this, and underlying the methodological approach, is an epistemology that assumes that ways of knowing are manifold and are not limited to logical, rational means. Knowledge is intellectual, cognitive and conceptual and it is embodied, tacit and felt. Knowledge is negotiated in the social world and the process of gaining knowledge is often unstructured, opportunistic, and serendipitous, as is research. However, through a systematic, transparent and sustained approach, we can articulate and communicate our rationale, decisions, the research process, findings, insights, explanations and understandings. No a priori scheme or theoretical framework was employed, as this was an authentic exploration of a complex case without judgement, and authentic accounts of respondents contribute to addressing the research questions. 


\subsubsection{Research questions}

1) What were the background and contextual features which influenced the development and implementation of the ESDGC strategy?

2) What were the features described by respondents which subsequently contributed to the 'piecemeal' delivery and provision of ESDGC in ACL in Wales?

3) From the literature and from the data, can we distinguish the 'latent' contribution of $A C L$ to ESDGC, and how this contributes to an understanding of implementation processes in translating policy to practice?

4) How can features emerging from the research assist in identifying some of the difficulties surrounding the implementation of EGC? Can these inform a reconceptualisation of ESDGC more aligned to the translation of policy into practice in the future?

The background and contextual features of the ESDGC strategy were discussed in Chapter 3. The international, national and more local Welsh policy drivers help us understand why and how the ESDGC strategy evolved. Through consulting with a range of stakeholders from policymakers to classroom tutors, features contributing to the 'piecemeal' ad hoc and inconsistent provision of ESDGC in ACL (Welsh Government, 2008a; Estyn, 2008) are described and the data analysed, and findings discussed. The 'latent' contribution of ACL to ESDGC is examined and explained through the words of the research respondents considered in the context of the literature which demonstrates theoretical congruence. The synergies and areas of conceptual confusion indicate possibilities for a re-conceptualisation of ESDGC.

Given the adoption of the case study design, these questions were explored using a number of different methods, including a review of policy, a broad literature review, in-depth interviews with those involved at the strategic or policy level, questionnaires and interviews with managers in the $A C L$ sector, a questionnaire distributed to $A C L$ tutors across Wales, focus groups and also observations and notes taken during teaching sessions.

\subsection{Theoretical and conceptual lenses}

There are several foundations on which different kinds of empirical research are constructed, including the scientific, positivistic, naturalistic/interpretive and constructivist. Each rests upon 
different conceptions of social reality, and indeed reality (Sayer, 2000). Different theories, such as critical theory or feminism, can inform questions, methods and analysis, but locating this work within one research paradigm or theoretical framework is not possible because the study emanates from, and is informed by, different disciplines, discourses and canons, as understood by the researcher. This is often the case in education, which is itself informed by different disciplines (Cohen, et al., 2011). ESDGC is also linked to multiple bodies of knowledge and therefore the territory under examination is complex. To understand the purpose, aims and rationale for the research approach, some guiding paradigms, theories and perspectives are outlined

The thesis draws on theories that are particularly pertinent to $\mathrm{ACL}$, such as critical theory, which is concerned with ideology critique and social change, and is inextricably linked with, and must involve, praxis: informed and committed action to change the world (Usher et al., 2011: 189). ESDGC and emancipatory ACL both embody within their aims the notion of democratic participation and social justice with a desire to change the world: therefore, a critical approach aligns with this (Grey, 2013: 27). Some scholars state that critical theory is explicitly normative, entailing a prescriptive view of what those living in a social democracy should do (Brookfield \& Horst, 2011; Cohen et al., 2011: 31). The researcher does not, however, presume to know exactly what behaviours and mindsets should prevail and adopts a more plural, contingent and practical approach, whilst maintaining an explicitly political and emancipatory orientation. A systemic, holistic or ecological view of interrelatedness also informs the thesis, and this is linked to various discourses in the discussions in Chapter 8 , where a re-conceptualisation of ESDGC is discussed.

The positivist paradigm of science, which purports that there is one objective reality, knowable through experimental methods, observation and measurement, is clearly not appropriate for the questions addressed in this research. A positivist philosophy uses the hypotheticodeductive method, which formulates a hypothesis that can be falsified or corroborated through testing, in order to deduce generalisations that point to a 'truth'. This qualitative research study, in contrast, uses an inductive and abductive reasoning and hypotheses emerge from the analysis and interpretation of the empirical data. Inductive reasoning, based on valid, credible data, provides conclusions that are probable, having made generalisations from the data, and abductive reasoning, which is a form of induction, provides the best possible explanation(s) based on the evidence available (Reichertz, 2007, 2014; Thomas, 2010). 
An interpretative paradigm runs through the study, as it seeks to understand aspects of the world of human experience (Cohen et al., 2011: 17) as does a constructivist view that our reality is linguistically constructed (Gorski, 2013). The positivist paradigm, which purports that outside our human subjectivity there is one unifying universe, also has a bearing on the current thesis. At first glance, this appears contradictory, but critical realism offers a philosophical system that accommodates this perspective and aligns with the chosen case study design (Easton, 2010: 119; Gorski, 2013; Miles \& Huberman, 1994).

Critical realism [CR] is emerging as a viable philosophical paradigm for conducting social science research, CR-based research methodologies offer researchers new opportunities to investigate complex organizational phenomena in a holistic manner. (Wynn \& Williams, 2012: 797)

'Objectivity', for critical realists, is an ideal that researchers attempt to attain through systematic research techniques. The extent to which objectivity is attained is evaluated through the community of scholars and other stakeholders, such as policymakers. 'Truth', as such, is negotiated through dialogue. This provides opportunities for discovery (emergent knowledge) as opposed to operating by testing a priori hypotheses.

A discussion of the intricacies of a critical realist philosophy cannot be undertaken within the limitations of this thesis. However, certain aspects that resonate with the research design and data analysis are outlined to clarify the researcher's assumptions. Constructivists claim that we each construct different realities. The critical realist philosophy contends that there is reality and that the way we perceive and experience this depends, in part, on our beliefs and expectations, which are socially constructed and mediated. Our worldviews are influenced and affected by our context, experiences, cultures and our awareness or consciousness: we cannot totally separate ourselves from what we assume, believe or know. Critical realism admits an inherent subjectivity in the production of knowledge, and in this respect is in line with the constructivist position (Grey, 2013: 26). As a philosophy and approach to social research, critical realism can include both naturalistic and constructivist research paradigms and is closely aligned with the researcher's view; it assumes a transcendental realist ontology, an eclectic realist/interpretivist epistemology and a generally emancipatory axiology (Easton, 2010: 119). 
Critical realism offers an overarching philosophy and methodological approach that accommodates within it the complexities and shifting theoretical terrain of critical and holistic approaches that characterise this case study. The value of critical realism is in its recognition of complexity and of open and interdependent, interacting systems. It provides this thesis with a philosophical positioning that allows the inclusion of different theoretical approaches. The realism resonates with a call to examine all aspects of ESDGC including uncomfortable and disturbing aspects of human behaviour and its consequences. The urgency for and implications of an' eyes wide open' approach is discussed later in the thesis (8.5.3).

Critical realism is an approach to case study research (Easton, 2010) and not, as such, an influence on choice of methods, data collection or mode of analysis; it is compatible with a wide range of methods (Sayer, 2000: 19) and it is aligned with what can be termed an 'ecological ethos'. Critical realism provides the best philosophical framework within which to conduct this current case study research. Reality cannot be expressed or captured directly in words and concepts, we can only point to it and describe our perceptions and interpretations of it as best we can. Critical realism offers a mirror that allows the reader to see more clearly how the researcher has interpreted this corner of reality and compare this to other interpretations and constructions in order to compare and make generalisations.

Causality, in the wider context of our previous knowledge and beliefs is contingent. Causal relationships rely on assumptions based on reason, experience and evidence, and these contribute to an abductive reasoning and to the best explanations. The breadth and depth of data contributes to the robustness of conclusions and generalisations within the acceptance of the systemic (open and nested) approach supported by critical realism. A fundamental tenet of critical realism is that we can use causal language to describe the world.

Since all philosophical positions rely on assumptions, they can only be ultimately judged pragmatically. Not in the limited sense used by philosophical pragmatism but in terms of our beliefs so that they result in better explanations. One powerful pragmatic argument in favour of critical realism is that it is performative (Easton, 2010: 119).

There are different versions of critical realism. Sayer (1992) sets out eight key assumptions that clarify the researcher's position: 
1. The world exists independently of our knowledge of it.

2. Our knowledge of the world is fallible and theory-laden. Concepts of truth and falsity fail to provide a coherent view of the relationship between knowledge and its object. Nevertheless, knowledge is not immune to empirical check and its effectiveness in informing and explaining successful material practice is not mere accident.

3. Knowledge develops neither wholly continuously, as the steady accumulation of facts within a stable conceptual framework, nor discontinuously, through simultaneous and universal changes in concepts.

4. There is necessity in the world; objects-whether natural or social-necessarily have particular powers or ways of acting and particular susceptibilities.

5. The world is differentiated and stratified, consisting not only of events, but objects, including structures, which have powers and liabilities capable of generating events. These structures may be present even where, as in the social world and much of the natural world, they do not generate regular patterns of events.

6. Social phenomena such as actions, texts and institutions are concept dependent. We not only have to explain their production and material effects but to understand, read or interpret what they mean. Although they have to be interpreted by starting from the researcher's own frames of meaning, by and large they exist regardless of researchers' interpretation of them. A qualified version of 1 therefore applies to the social world. In view of $4-6$, the methods of social science and natural science have both differences and similarities.

7. Science or the production of any kind of knowledge is a social practice. For better or worse (not just worse) the conditions and social relations of the production of knowledge influence its content. Knowledge is also largely-though not exclusivelylinguistic, and the nature of language and the way we communicate are not incidental to what is known and communicated. Awareness of these relationships is vital in evaluating knowledge.

8. Social science must be critical of its object. In order to be able to explain and understand social phenomena we have to evaluate them critically.

(Sayer, 1992: 5)

\section{An illustration of critical realist ontology}

Let us look at a natural phenomenon. Grass grows, and we can observe this; we can measure it and understand it in terms of chemical interplay, energy exchange and matter, we can regard it as a miracle or we can simply see it as grass growing. There are perspectives on, interpretations of and various understandings and experiences of the phenomena, but the grass grows anyway. This underpins a critical realist view that it is misleading to speak of an empirical world, as the world, and reality should not be conflated with our experience of it (Bhaskar, 2013; Sayer, 2000). 
Congruent with, and part of, a critical realist philosophy is a pragmatic approach primarily concerned with finding solutions to problems as opposed to seeking ultimate knowledge or truth. Pragmatists focus not on whether a proposition fits a particular ontology, but on whether it suits a purpose and is capable of creating action (Dewey, 1938b; Rorty, 1998). Contributing to the practical domain of education is one reason for conducting this research and it therefore has a strong pragmatic element. It endorses the view that the point is to initiate and maintain important conversations and not to seek objective truth (Rorty, 1979: 377). The pragmatic and plural approach of this case study challenges binary distinctions or dualism and points to an approach that is "conceptually cautious and more reflexive about both its implicit philosophy and methodology and its social and political coordinates" (Sayer, 2000: 6). Complexity theory lends itself to this educational case study (Davis \& Sumara, 2009): it acknowledges that there is "multiplicity of simultaneously interacting variables" (Radford, 2008: 510) and there is no recourse to the simple cause-and-effect model (Cohen et al., 2011: 28).

One way of framing the researcher's conceptual lens is by considering it as an ecological view. This takes into account complexity, paradox and contingency; it holds that everything is impermanent, and that the world is composed of open systems (Bhaskar, 1998), and is itself an open system. "The world is composed of open systems that are nested within, and have nested within themselves, other open systems" (Gerrits \& Verweij, 2013: 169); and systems, although bounded, interact with other open systems, resulting in change. Ellis (2013: 59) states that "A critical realist (CR) perspective offers ontological (What is real?), epistemological (What can we know?) and axiological (What do we value?) bases as a foundation for an ecological humanism".

This study does not purport to use grounded theory per se, however, the mode of inquiry does contain elements that are similar to grounded theory (Charmaz, 2014), as it employs an emergent method, "inductive, indeterminate, and open-ended ... It begins with the empirical world and builds an inductive understanding of it as events unfold and knowledge accrues" Charmaz (2008: 155). Traditionally, grounded theory aims to generate theories from the data that account for the data (Charmaz, 2008: 157; Thornberg, 2012) but this current thesis does not set out to generate theory; rather, it endeavours to generate explanatory hypotheses based on empirical data and on examining documentary evidence and literature. A contentious area in grounded theory is that of the literature review. It was believed that it was best not to 
review any of the literature in the substantive area under study beforehand, because this could colour the analysis of the data (Glaser, 1992: 31). However, in the present study, an initial and broad literature review was conducted before embarking on the empirical research; this contextualises the case, particularly through providing a chronology of conceptual thinking and policy developments. Corbin and Strauss (2008), Thornberg (2012) and a growing body of researchers argue for using the extant literature in this way, engaging proactively with it from the beginning of the research process.

\subsection{A Policy case study}

\subsubsection{Using case studies}

The case study design provides a holistic framework for an intensive exploration of a unique case, explored from multiple perspectives (Cohen et al., 2011: 167; Simons, 2009; Thomas, 2011: 512; Timmons \& Cairns, 2012; Villarreal Larrinaga, 2017; Yin, 2009). “Policy process studies are likely to be case studies, using qualitative methods" (Hill, 1997: 25), because case studies can provide detailed, human-scale data to support and fuse theory and practice. This is useful for informing policy (Cohen et al., 2011: 291) and "in the context of policy-making, which often seeks certainty, comparison and conclusiveness, case study research is important precisely because it studies the particular in-depth, and often yields outcomes that are inconclusive" (Simons, 2009: 167).

Case studies are suitable when the boundaries between phenomenon and context are not always evident or clear (Yin, 2009: 18). The case of ESDGC in ACL is influenced by, and interacts with, international policy, an academic literature and practice across different sectors, and this is in accord with the critical realist approach discussed above.

Simons offers a useful and comprehensive definition of case study research:

Case study is an in-depth exploration from multiple perspectives of the complexity and uniqueness of a particular project, policy, institution, programme or system in a 'real life' context. It is research-based, inclusive of different methods and is evidence-led. The primary purpose is to generate in-depth understanding of a specific topic (as in a thesis), programme, policy, institution or system to generate knowledge and/or inform policy development, professional practice and civil or community action. (Simons, 2009: 21) 
According to Merriam (1988: 16, cited in Simons, 2009: 20), case studies rely heavily on inductive reasoning in handling multiple data sources. However, Thomas (2010) proposes that the case study approach can find legitimacy in the "experiential knowledge of phronesis rather than the generalising power of induction and theory in explanation and prediction"(Thomas, 2010: 575). Phronesis, with its emphasis on practical intelligence and virtuous behaviour, resonates with the normative issues in $A C L$ and ESDGC as well as the pragmatism inherent in this exploration of policy implementation.

Yin (2009) proposes the prior development of theoretical propositions in case study design, in line with grounded theory, but I concur with Thomas's view that "Because of both the contingency of social life and the necessary limitations on the kind and quantity of confirmatory evidence that can be disclosed, theory, in any kind of technical sense, is unattainable" (Thomas, 2010: 577). This does not mean that explanations are not forthcoming or that discussing differing perspectives and judgements is not undertaken. As Villarreal Larrinaga says, "Wanting to use case study research therefore means forgetting about the blacks and whites (accept or reject) and opting instead for the full palette of colours. This is the reality faced by the researcher; a hybrid one, with a multitude of shades and nuances" (Villarreal Larrinaga, 2017: 150).

\subsubsection{Rigour}

There are many aspects of, and approaches to, rigour in qualitative research. The language used includes the terms: validity, credibility, dependability, conformability, quality and reliability (Cohen et al., 2011; Houghton, Casey, Shaw \& Murphy, 2013: 13; Silverman, 2013). Rigour is achieved through ensuring transparency and detail when describing the research rationale and process as well as clarity about interpretative judgements. Validity is based upon the truth of the premises of a thesis or argument and the use of logic to form conclusions or propose explanations. Huberman and Miles (2002: 38) and Kreber (2010) propose the concept of 'authenticity' in preference to validity, reliability or trustworthiness, and see it as a characteristic of both qualitative research and the researcher (Bush, 2007: 91). Striving towards authenticity "can suggest new possibilities for theorizing about and improving upon our practice in adult and higher education" (Kreber, 2010: 195), and to this end the research 
process, which is not always straightforward, is described as clearly as possible (Halpin \& Troyna, 1994: 5-6; Seidman, 2013).

Many have recognised how research, including choice of approach and methods, is influenced to some extent by the researcher's beliefs and values, which include understandings of moral, philosophical and political issues (Silverman, 2001: 270). Through providing some context in Chapter 1 and describing and discussing foundational paradigms (4.2), the researcher's bias or pre-conceptions can be better understood in the context of the overall thesis, and, because they cannot be transcended or ignored, they are "put to work" (Usher et al., 2011: 184) and become part of the fabric of the case study.

Being a practitioner who conducts research is often the case in educational research (Usher et al., 2011), and the researcher was known to some of the research participants, particularly those being interviewed. The researcher has worked in ACL and in ESDGC-related fields and developed professional and personal credibility, and this probably contributed to access being granted easily and willingly on all occasions, and to the establishment of trust and rapport. Developing respectful professional relationships throughout the research process was vital (Anderson \& Kanuka, 2003) and Gunzenhauer stresses that the "quality of qualitative research reflects the quality of relation developed between the researcher and researched as 'knowing subjects'" (Gunzenhauer, 2006: 621). At the same time, it is recognised that familiarity can bias responses, and this was considered during the interviewing and data analysis. The researcher's employment status is illustrated alongside the data collection chronology in Figure 4.2 for clarity. 


\begin{tabular}{|c|c|c|c|c|c|c|c|c|}
\hline \multicolumn{9}{|c|}{ Fig 4.2 Empirical Data Collection - Chronology and Employment Status } \\
\hline \multirow[b]{2}{*}{ Quarters } & \multicolumn{4}{|c|}{2008} & \multicolumn{4}{|c|}{2009} \\
\hline & 1 & 2 & 3 & 4 & 1 & 2 & 3 & 4 \\
\hline & & & & \multicolumn{2}{|c|}{ Literature review 1} & & & \\
\hline & & & & & Mapping the case & & & \\
\hline & & & & & \multicolumn{3}{|c|}{7 in-depth interviews } & \\
\hline & & & & & & & & Visiti \\
\hline & & & & & & & & Managers qu \\
\hline & & & & & & & & \\
\hline & & & & & & & & \\
\hline & & & & & & & & \\
\hline & \multicolumn{4}{|c|}{ Project Manager in ACL } & & & & \\
\hline & & & & & \multicolumn{4}{|c|}{ Independent Consultant } \\
\hline & & & & & & & & \\
\hline & & & & & & & & \\
\hline \multicolumn{9}{|c|}{ PhD Research } \\
\hline \multicolumn{9}{|c|}{ Welsh Gov commission and PhD data collection } \\
\hline \multicolumn{9}{|c|}{ Analysis - PhD \& Welsh Gov report } \\
\hline \multicolumn{6}{|c|}{ Employment status } & & & \\
\hline
\end{tabular}


The breadth of data from a range of individuals and groups contributes to the robustness of the case study through enabling triangulation (Cohen et al., 2011: 195). The validation of data through triangulation was accomplished through using different data collection methods with different groups of respondents this allowed the triangulation, the crosschecking and referencing the different data sources and data sets to evaluate the extent to which the evidence converged. It was a process of constant comparison and iterative categorization (See 4.8). Providing as much relevant context as possible provides additional rigour, although it is recognised that a complete historical context cannot always be included. Chapter 3 provides a description and rudimentary analysis of policy relating to ESDGC and $A C L$, and the Welsh context situates the case study under investigation, thus enabling a fuller consideration of generalisability.

\subsubsection{Generalisability}

There is considerable debate amongst researchers as to the possibility or necessity of generalisations in case studies. "In sociological and educational research, knowledge is concerned not with generalisations, predictions and control but with interpretation, meaning and illumination" according to Usher et al. (1997: 181); Gomm, Hammersley and Foster (2009a: 5) also question if generalisability is necessary or appropriate in case study research and Hammersley states:

Research conclusions typically take the form of empirical generalisations about a whole population of cases, or theories about a particular type of phenomenon. From a practitioner point of view, the problem with empirical generalisations is that their relationship to the particular cases that are of concern is, at most, only probabilistic ... A substantial element of contingency therefore surrounds the value for practice of both empirical generalisations and theoretical knowledge. (Hammersley, 2002: 44)

Stake $(1995,2000)$ refers to 'naturalistic generalisations', where the reader decides as to whether the case or aspects of the case are applicable to other cases. "Naturalistic generalisations are conclusion arrived at through personal engagement in life's affairs or by vicarious experience" (Stake, 1995: 85) and it is important to establish empathetic understanding for the reader. 'Thick' or in-depth descriptions of context enable other researchers to detect similarities and differences between data and make reasoned 
judgements about developing a working hypothesis to apply in other situations. In other words, naturalistic generalisations are made as the reader recognises differences and similarities with other cases (Stake, 1978, 1995, 2009; Thomas, 2010: 580).

As this is a specific case, set in a specific location during a particular window of time, against a particular backdrop of social and economic conditions and circumstances, the entire case, findings and conclusions might not be transferable, replicable or generalisable. However, one might take aspects, events or certain mechanisms and find that they contain elements that are relevant to and comparable with other situations and cases (Timmons \& Cairns, 2010: 3). Stake, states that there can be more than one form of generalisation taking place (Stake, 1995). For example, process generalisations are possible because the process of developing and introducing an educational innovation is applicable in other and varied contexts (Simons, 2009: 166).

It is within an understanding of usability of findings that Simons suggests different ways of generalising in, or from, case study research. These include: naturalistic generalisation, process generalisation and generalisations made through gaining universal insights arrived at through in-depth particularization. Simons feels that instead of searching for generality in in-depth case studies, we should "try to capture the essence of the particular in a way we all recognize" (Simons, 2009: 167). It is important to remain open to the tensions and paradox that can arise between the universal and the particular, and through reexamination, we can eventually come to realise both the significance of the unique instance or circumstance and the universal understanding, which can then be incorporated into a wider body of knowledge and compared with other cases.

Thomas feels that our expectations should be moderate concerning the generalisations that can emerge from social research (Thomas, 2010: 576). This recognises the limits of induction in social science generally, and the failure to simultaneously acknowledge the significance of abduction, which seems to be the appropriate inferential form for case study, as it provides "heuristics - ways of analyzing complexity that may not provide watertight guarantees of success in providing for explanation or predication but are unpretentious in their assumptions of fallibility and provisionality" (Thomas, 2010: 577). This is congruent with critical realism. The 'truth' cannot be guaranteed, but the current research provides credibility through aiming to be as authentic as possible, describing the research process honestly and systematically and through findings that are 'beyond reasonable doubt'. Generalisation is discussed further in the conclusion (Chapter 9). 


\subsection{Ethical considerations}

Ethics is a vitally important domain and a central factor in all research. The principles underpinning the British Educational Research Association guidelines (2011) are: respect for the person, knowledge, democratic values, quality and academic freedom, and the researcher's conduct should be guided by responsibility to participants, sponsors, the community of academic researchers, and to educational professionals, policymakers and the public (British Educational Research Association, 2011: 4-5). These principles have guided the current research and encompass the range of activities undertaken and the intent.

Ethical considerations linked to the purpose of the research "cannot be value free or politically neutral in this fundamental sense" (Hammersley, 1995: 110) and the subjectivity of the researcher is acknowledged, although objectivity is strived for on all occasions, and bias discussed where appropriate. As well as addressing procedural ethics and ethics concerning purpose, method and reporting (Cohen et al., 2011: 75-76), Walker reminds us that our professional responsibility as educators involves not just pointing to the problem and its roots, but that "we ought to connect such research to practical attempts to improve higher (or 'adult') education" (Walker, 2006: 130). This is part of the intent of this current thesis.

The researcher is bilingual - her mother-tongue is Welsh - and this enabled the research to be conducted bilingually. All questionnaires were offered in Welsh and English and all interviewees were given the option of conducting their interviews in Welsh. Focus group participants were offered the choice of conducting discussions in Welsh, and in North Wales some people took up this offer. Enabling people to communicate in their language of choice adds to the authenticity of responses; it ensures equality of opportunity, respects a bilingual culture and complies with the Welsh Language $\mathrm{Act}^{39}$.

Written, informed consent was obtained from the seven participants at the strategic level prior to conducting in-depth face-to-face interviews. They were informed that they were free to withdraw at any point without prejudice (See Appendix A). Ethical considerations are particularly important when using interviews as a research method, and obtaining informed consent protects the researcher, as it reduces the liability of the researcher and

${ }^{39}$ https://www.legislation.gov.uk/ukpga/1993/38/contents 
ensures participants' rights (Bell, 2010: 46; Cohen et al., 2011: 77). The seven policy interviewees were chosen specifically because of their roles and professional positions; most were chosen from the ESDGC panel. There are a limited number of people in this group, and because of this, and their specific professional roles, these people could be easily identified. Anonymity was therefore an important consideration.

Conducting interviews with a specific person is often central to studies that examine policy; this contrasts with research where the respondents represent a general population, such as managers and tutors in $\mathrm{ACL}$, and where all responses are anonymous (Walford, 2011). "Academic educational research on the powerful may be unlike any other forms of educational research in that confidentiality may not be able to be assured" (Cohen et al., 2007: 128) and quotations at times could be attributable. This makes anonymity difficult, even though it makes statements relevant and meaningful (Fitz \& Halpin, 1994). Interviewees were made aware of these issues and every effort has been made to preserve anonymity without compromising the research or creating anodyne descriptions (Cohen et al., 2011: 93). Some quotes, when they refer to pragmatic points, will possibly be attributable, but this occurs only when the issue to which the quote relates is not of a contentious nature. Apart from this, anonymity has been preserved though the use of writing devices which minimise the recognition of individuals. These seven interviewees are not assigned pseudonyms: they are identified as part of this group using terms such as 'policy level interviewee' or 'member of ESDGC panel', and at times quotes are attributed generally. The sex of respondents has been changed occasionally and these techniques are part of the endeavour to convey meaning without alluding to people's identity. The potency of the data might be diluted to an extent through this censorship, which was necessary in order to respect individuals' positions.

In 2009 I was commissioned by the Department for Children, Education, Lifelong Learning and Skills (DCELLS) at the Welsh Government to conduct research into the support needs of the ACL sector for embedding ESDGC; the executive summary is in Appendix B. Permission was obtained from the Welsh Government to include additional questions into the research tools for the commissioned study (See Appendix C). They were assured that this would not be onerous for respondents or detract from the purpose and validity of their research study. To this end, questions were brief and most included an open-ended option, so that people could choose their level of response. All questionnaires, and the interviews with managers, were kept as brief as possible to minimise intrusion. The researcher met 
with people at times and in places that were convenient to them and made phone calls through prior arrangement via email. She was always aware of maintaining respectful relationships and providing clarity about the purpose of the research and its subsequent use and dissemination. This quote captures many of the elements considered in this study:

All research involving participation by human subjects, whether conducted in physical settings, virtual settings, or both, is inescapably intrusive to a greater or lesser extent. Participants' routines and, indeed, to some extent their lives, are changed from what they otherwise would have been because of the researcher's intrusion into their routines. Obtaining informed consent does not obviate intrusion; it simply gives the researchers permission to intrude. (Lankshear \& Knobel, 2004: 3)

All participants in the Welsh Government study were informed that some responses would be used as part of a PhD thesis. Participation was voluntary, and confidentiality and anonymity assured. There were separate research questions for the PhD that were not part of the Welsh Government research: for example, specific questions on hopes and fears for the ESDGC strategy and ESDGC in ACL. Data from these questions did not form part of the Welsh Government report.

Huberman and Miles (2002: 47) state that "Capturing social complexity and servicing political utility can run counter to each other", and the literature on educational policy alludes to tensions that can arise during the research (Haplin \& Troyna, 1994; Trowler, 1998; Hammersley, 2002a; Walford, 2011). This was, however, mitigated, because there was recognition amongst all those involved in the research, including the Welsh Government, of the mutual benefits in identifying features inhibiting the implementation of the ESDGC strategy. Many people have contributed to this study: people gave of their time, they shared their views and thoughts, and the data is accorded due respect through using it as the basis and starting point for further inquiry that can hopefully contribute to policy, theory and practice in some measure. 


\subsection{Research process - overview and summary}

The research is predicated on the findings from qualitative data obtained from three groups:

- Those developing policy and strategy for ESDGC in Wales

- Managers in ACL in Wales

- Tutors in ACL in Wales

After conducting a broad literature review, people who were involved at the strategic level in $A C L$ and ESDGC were identified and seven in-depth interviews conducted. These interviews with key informants highlighted issues from the perspective of those seeking to communicate strategic messages and influence practice. Shortly after the first analysis of these interview transcripts, I began work on the Welsh Government commissioned study. This work presented an opportunity to engage with a wide range and number of $\mathrm{ACL}$ practitioners across Wales. It was important to gain the views of as many stakeholders as possible, from heads of services, managers and programme developers to ACL tutors whose practice is located in the classroom with learners. Delivering ESDGC awareness sessions to adult education tutors across Wales during this time also afforded opportunities to observe and explore issues.

In summary, the research began with a broad literature review followed by seven in-depth interviews with those involved in developing the ESDGC strategy. Then, having analysed these interview transcripts, I visited some of the ACL strategic partnership across Wales. Here, managers representing the different sectors delivering $A C L$ meet to share information and plan delivery. I contacted and gained the trust of members of the partnerships and through them was able to distribute questionnaires to $\mathrm{ACL}$ managers and tutors across Wales. At the same time as the questionnaire to managers was being distributed, I arranged interviews with a sample of managers in ACL. Once the data in its entirety had undergone an initial analysis and broad themes or categories had been identified, two focus groups were conducted with a mix of practitioners, one in South and one in North Wales. Another literature review was conducted following further analysis of the data.

Due to a number of different circumstances, including the commission from the Welsh Government and changes in supervision in different academic disciplines, the trajectory of this thesis has not been a linear one. Describing the process and the rationale and decisions 
taken is challenging and it is hoped that employing a range of diagrams, tables and charts will bring some clarity to a 'messy', if rewarding, process.

Fig. 4.3 Summary of the research process

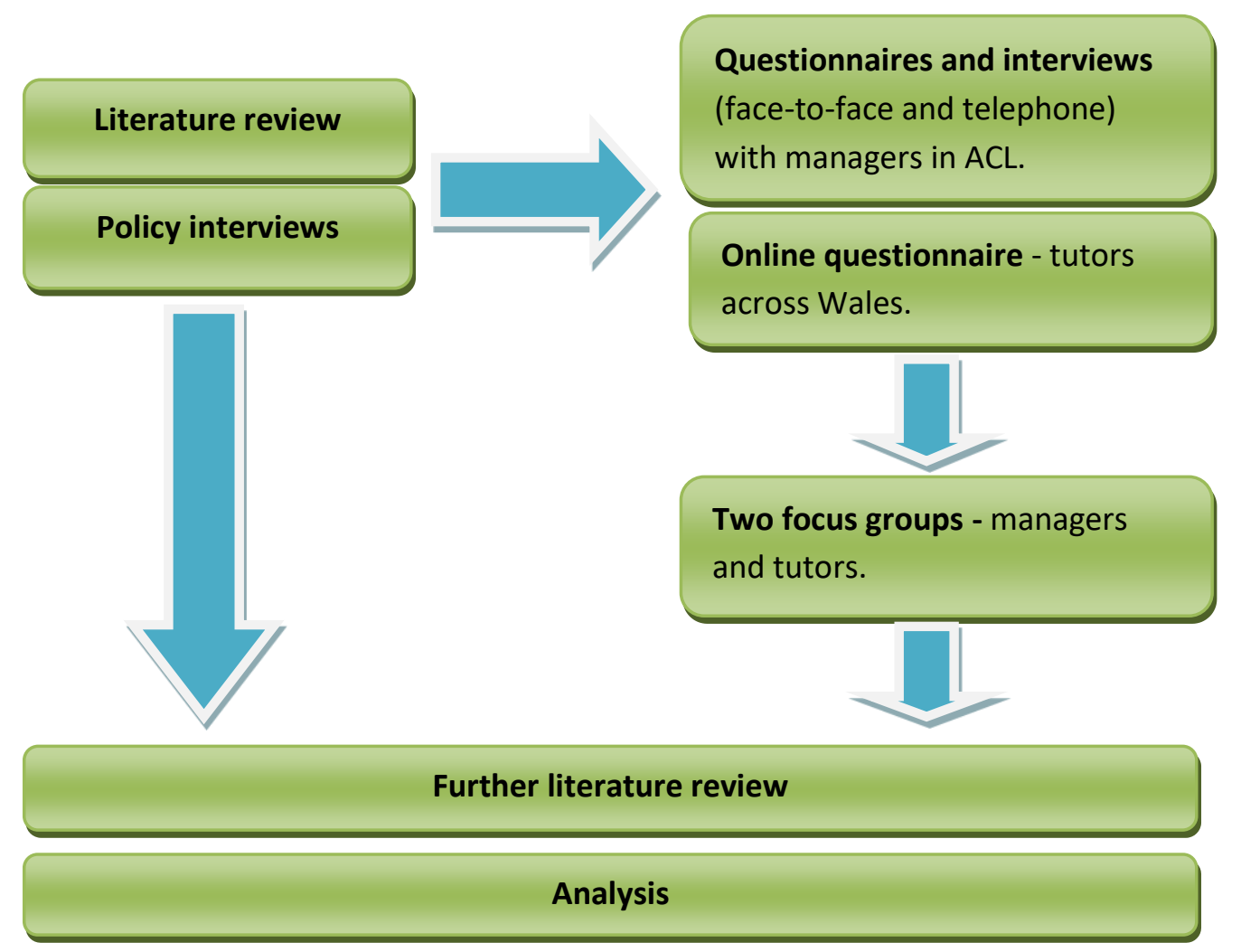

\subsection{Data collection and methods}

\subsubsection{Introduction}

The ESDGC Champion at the Welsh Government was supportive of the research for this $\mathrm{PhD}$, which would ultimately contribute to the field (see Appendix C). It was agreed that the PhD questions would not interfere with the commissioned study, but conversely, would enhance it. I made a choice to reach and elicit responses from a large number and crosssection of people working in $\mathrm{ACL}$ in Wales, to obtain data from as many practitioners as possible; this meant that some considered compromises were made. The table below summarises the research process and methods used: 
Table 4.1 Methods used, and data collected.

\begin{tabular}{|c|c|c|}
\hline Method & Action & Outcomes \\
\hline Three pilot interviews & $\begin{array}{l}\text { Three people from different } \\
\text { sectors delivering ESDGC. }\end{array}$ & $\begin{array}{l}\text { Three interviews - broad issues } \\
\text { identified for interview } \\
\text { schedule. }\end{array}$ \\
\hline In-depth interviews & $\begin{array}{l}\text { Contacted those who were linked } \\
\text { to developing the ESDGC strategy } \\
\text { and who were involved across } \\
\text { sectors and/ or specifically with } \\
\text { the ACL sector. }\end{array}$ & $\begin{array}{l}\text { Seven interviews conducted } \\
\text { and transcribed verbatim. }\end{array}$ \\
\hline Desk Research & $\begin{array}{l}\text { Reading policy and strategy } \\
\text { documents. }\end{array}$ & $\begin{array}{l}\text { Background on policy and } \\
\text { practice. }\end{array}$ \\
\hline $\begin{array}{l}\text { Notes from meeting with } \\
\text { ACL Strategic Partnerships } \\
\text { in Wales } \\
\text { (Appendix D: example of } \\
\text { data) }\end{array}$ & $\begin{array}{l}\text { Partnerships contacted, and } \\
\text { meetings attended. Some single- } \\
\text { county, some multiple-county } \\
\text { partnerships. Background and } \\
\text { aims of research presented; main } \\
\text { research questions discussed and } \\
\text { recorded. }\end{array}$ & $\begin{array}{l}\text { Five partnerships visited. The } \\
\text { findings from these informed } \\
\text { the questionnaires. }\end{array}$ \\
\hline \multicolumn{3}{|l|}{ Questionnaires } \\
\hline $\begin{array}{l}\text { Manager questionnaire } \\
\text { (Appendix E: example of } \\
\text { questionnaire; Appendix } \\
\text { F: sample of analysis } \\
\text { matrix) }\end{array}$ & $\begin{array}{l}\text { Questionnaires sent out through } \\
\text { the partnerships via email. }\end{array}$ & $\begin{array}{l}\text { A slow but steady response - } \\
\text { senior and middle managers } \\
\text { and officers. Thirty-one } \\
\text { completed. }\end{array}$ \\
\hline Tutor questionnaire & $\begin{array}{l}\text { Sent out through the } \\
\text { partnerships via email. }\end{array}$ & $\begin{array}{l}\text { Very little response ( } 2 \text { ). } \\
\text { Decision to send out an online } \\
\text { survey. }\end{array}$ \\
\hline $\begin{array}{l}\text { Tutor online questionnaire } \\
\text { (Appendix G: Sample, } \\
\text { summary of responses) }\end{array}$ & $\begin{array}{l}\text { A pdf explaining the research sent } \\
\text { out via the ACL partnerships and } \\
\text { through NIACE Dysgu Cymru and } \\
\text { the WEA with the link to online } \\
\text { questionnaire. }\end{array}$ & $\begin{array}{l}\text { The online questionnaire } \\
\text { replicated the first } \\
\text { questionnaire with some } \\
\text { refinements to wording and } \\
\text { layout to improve readability. } \\
\text { Response - } \mathbf{2 6 2} \text {. }\end{array}$ \\
\hline $\begin{array}{l}\text { Manager online } \\
\text { questionnaire }\end{array}$ & $\begin{array}{l}\text { This was sent out via the } \\
\text { partnerships. A copy of the email } \\
\text { questionnaire. }\end{array}$ & Nineteen completed \\
\hline \multicolumn{3}{|l|}{ Other Methods } \\
\hline $\begin{array}{l}\text { Interviewing Managers in } \\
\mathrm{ACL} \\
\text { (Appendix } \mathrm{H} \text { : example of } \\
\text { data) }\end{array}$ & $\begin{array}{l}\text { More face-to-face interviews with } \\
\text { managers in all sectors were } \\
\text { conducted and telephone } \\
\text { interviews. }\end{array}$ & $\begin{array}{l}\text { The interviews ensured a } \\
\text { geographic and sector } \\
\text { representation and allowed } \\
\text { some issues to be explored in } \\
\text { depth. Fourteen in total. }\end{array}$ \\
\hline $\begin{array}{l}\text { Notes from tutor training } \\
\text { (Appendix I: example of } \\
\text { data) }\end{array}$ & $\begin{array}{l}\text { At ESDGC awareness training } \\
\text { sessions run by the researcher, } \\
\text { participants were asked the basic } \\
\text { questions regarding support } \\
\text { needs. }\end{array}$ & $\begin{array}{l}\text { Observations and notes were } \\
\text { taken, and participants were } \\
\text { given paper/notebooks to feed } \\
\text { in quick responses. Over } 100 \\
\text { short responses from ACL } \\
\text { tutors across Wales. }\end{array}$ \\
\hline $\begin{array}{l}\text { Notes from meetings and } \\
\text { events attended } \\
\text { (Appendix J: example of } \\
\text { data) }\end{array}$ & $\begin{array}{l}\text { The researcher attended } \\
\text { practitioner meetings and } \\
\text { training. }\end{array}$ & $\begin{array}{l}\text { Set up through initial contacts } \\
\text { at conferences, training, and } \\
\text { partnerships. Tutors and } \\
\text { officers/development workers }\end{array}$ \\
\hline
\end{tabular}




\begin{tabular}{|l|l|l|}
\hline & & $\begin{array}{l}\text { and managers in attendance. } \\
\text { Four in total. }\end{array}$ \\
\hline $\begin{array}{l}\text { Focus groups } \\
\text { (Appendix K: example of } \\
\text { data) }\end{array}$ & $\begin{array}{l}\text { One in South Wales and one in } \\
\text { North Wales. Information sent } \\
\text { out through ACL partnerships, } \\
\text { NIACE and WEA. These took place } \\
\text { in February 2010, towards the } \\
\text { end of the empirical research. }\end{array}$ & $\begin{array}{l}\text { Focus group discussions } \\
\text { stimulated by using findings so } \\
\text { far. Twenty-three at each } \\
\text { event: forty-six participants in } \\
\text { total. }\end{array}$ \\
\hline
\end{tabular}

Using different methods with the different groups with a common research aim was important in order to be able to formulate as complete a picture of the case as possible (Kvale \& Brinkmann, 2009: 143) and resulted in different data sets with different formats, including short written texts in questionnaires, short telephone interview notes, long indepth interview transcripts, questionnaire responses, and notes from meetings and teaching.

\section{Table 4.2 Summary of methods employed}

These methods are in approximate chronological order. A more detailed account follows.

\begin{tabular}{|c|c|c|}
\hline Methods & $\begin{array}{l}\text { Responses } \\
\text { /numbers }\end{array}$ & Rationale/description \\
\hline $\begin{array}{l}\text { Semi-structured, face-to-face pilot } \\
\text { interviews }\end{array}$ & 3 & $\begin{array}{l}\text { Conducted in order to outline the main } \\
\text { concerns and issues for the policy } \\
\text { interviews. }\end{array}$ \\
\hline $\begin{array}{l}\text { In-depth face-to-face interviews with } \\
\text { policymakers }\end{array}$ & 7 & $\begin{array}{l}\text { These were semi-structured interviews with } \\
\text { those closest to policy development in } \\
\text { ESDGC and } A C L \text { in Wales. }\end{array}$ \\
\hline $\begin{array}{l}\text { Meetings with ACL strategic } \\
\text { partnerships in Wales }\end{array}$ & 5 & $\begin{array}{l}\text { Some were single county partnerships and } \\
\text { others were larger, three or five county } \\
\text { partnerships. }\end{array}$ \\
\hline $\begin{array}{l}\text { Semi-structured interviews with } \\
\text { managers in } A C L\end{array}$ & 13 & $\begin{array}{l}\text { These were a mix of telephone and face-to } \\
\text { face interviews. }\end{array}$ \\
\hline Questionnaires to managers & 50 & 31 responses by email and 19 online \\
\hline $\begin{array}{l}\text { An online questionnaire was sent to } \\
\text { tutors }\end{array}$ & 262 & This was sent via the ACL partnerships \\
\hline $\begin{array}{l}\text { Focus groups with a range of } \\
\text { practitioners }\end{array}$ & 2 & $\begin{array}{l}\text { One in North and one in South Wales. These } \\
\text { were conducted towards the end of the } \\
\text { study. } 46 \text { participants in total. }\end{array}$ \\
\hline $\begin{array}{l}\text { Notes from attending meetings and } \\
\text { workshops with groups of practitioners }\end{array}$ & 4 & $\begin{array}{l}\text { This included notes from a discussion at a } \\
\text { NIACE Dysgu Cymru conference workshop. }\end{array}$ \\
\hline Notes from teaching sessions & & $\begin{array}{l}\text { Teaching ESDGC awareness to ACL tutors } \\
\text { throughout Wales, including ESOL tutors, } \\
\text { Welsh for adults, arts and general groups of } \\
\text { tutors. }\end{array}$ \\
\hline
\end{tabular}




\subsubsection{Interviewing}

\subsubsection{Introduction}

Interviewing is a powerful way to gain insights into an issue and understand people who are involved in complex social practices such as education (Seidman, 2013: 7). During all interviews, minimizing the researcher's effect was accomplished through stating clearly the purpose of the research and keeping the sharing of personal experience and conversation to a minimum, whilst recognising that the interview is a form of dialogue (Mishler, 1991). The technique of active listening was employed where the researcher pays conscious attention to everything about the person and seeks to understand the meaning conveyed (Denzin \& Lincoln, 2005, 2008; Gillham, 2005: 29, 31; Seidman, 2013; Silverman, 2013). It included giving occasional feedback, summaries and encouragement. Open-ended questions were used wherever possible, as these do not require a 'yes' or 'no' answer and allow respondents to express a range of views and thoughts. All interviews used a semistructured format which allowed unexpected results to emerge (Gillham, 2005: 47) and enabled respondents to direct the interview to an extent.

\subsubsection{Pilot or preliminary interviews - Policy level}

Whilst delivering ESDGC training to adult education tutors in Wales, and from an initial review of the literature, issues were identified for exploration. To verify the relevance of these ideas, to check assumptions and to test questions for an interview schedule, pilot interviews were conducted. Three people were contacted on the basis that they worked in different sectors. They were informed that these interviews were intended to cover broad issues. Interviewees were:

A. Chief Executive of a national NGO involved in delivering ESDGC.

B. Senior Manager in an FE college with responsibility for ACL.

C. Head of an environmental NGO delivering ESDGC training and courses to different groups from children and youth groups to teachers and adults.

$A$ and $B$ were involved in strategy development and these two interviews lasted about 45 minutes; the interview with $\mathrm{C}$ lasted 20 minutes. Interviews were recorded and transcribed verbatim. The interviews began with one key question: "What do you think the main issues in ESDGC in ACL in Wales are?" The interviews were semi-structured and informal, designed to allow respondents to talk about what was important and relevant to them (Merriam, 2009: 89; Gillham, 2005: 46). 


\subsubsection{Seven in-depth, face-to face policy interviews}

Interviews were conducted with:

1. The Head of ESDGC at the Welsh Government, the ESDGC Champion.

2. Chief Estyn inspector for $A C L$ with responsibility for ESDGC.

3. A representative for further education (FE) on the panel who also had responsibility for ACL and is the chair of Colegau Cymru's (the association of FE colleges in Wales) ESDGC group.

4. A representative for the Welsh Local Government Association (WLGA) which represents the interests of local government and promotes local democracy in Wales. It represents the 22 local authorities in Wales. She was also head of ACL in a local authority.

5. The director of NIACE Dysgu Cymru (National Institute of Adult and Community Education in Wales).

6. Head of Cyfanfyd, the Development Education Association in Wales. A voluntary sector, membership organisation, promoting ESDGC.

7. An officer at the WEA (Workers Education Association) with responsibility for ESDGC.

The selection of those involved with the ESDGC panel in Wales with an interest in or representing the $A C L$ sector was achieved through purposeful sampling (Patton, 1990: 169; Silverman, 2014: 60). Walford (2011) notes that access can be difficult where a policy initiative is controversial and contested and he cites reports that show that those promoting or implementing the initiative may resist scrutiny. This was not the case in this research study and the policy level respondents granted access willingly.

It is important to recognise issues connected to interviewing people in 'powerful' positions (Cohen et al., 2011: 166, 170 - 174): "Elite" interviewing is one way of describing the interviews conducted with those at this senior level (Ball, 1994a). The research deals with key issues relating to policy and might deal with sensitive concerns specific to this group of interviewees (Cohen et al., 2011: 172). It was important to remain sensitive to the fact that respondents were possibly reflecting the policy agenda in their answers, or were being politically pragmatic, in that they were there to do a job and were not overly concerned with research or with discussing conceptualisations. These people are familiar with being questioned and with being listened to, and this can lead to their responding to research questions in similar ways, replying with standard answers or not answering the specific questions (Walford, 2011). However, respondents understood the purpose of research, and this, despite the possibility of 'stock' responses, meant that they understood its relevance and import. 
Interviewees were known to the researcher on a professional basis and a new relationship - a research relationship - therefore had to be established prior to and during interviews. An equal relationship was presumed on the part of the researcher: a non-hierarchical one where the participant was at the centre (Trier-Bieniek, 2012: 632). Establishing trust is crucial to obtaining good data, and, along with curiosity and naturalness, is a key attribute of a successful researcher (Woods, 1986 cited in Cohen et al., 2011: 410). Interviews were conducted in respondents' workplaces or at a neutral meeting place. They lasted between one and two hours; notes were taken, and they were digitally recorded and immediately transcribed verbatim. Authentic behaviour of the interviewees was noted: gestures such as 'tuts' and sighs and the rolling of eyes. Each person was asked the same questions in a similar order so that all interviews covered the same ground. The uniformity enabled the interview sessions to remain focused, reduce bias and increase the comparability of transcripts for analysis.

\subsubsection{Interviewing managers}

In total, thirteen interviews were conducted with ACL managers. There were three face-toface interviews and ten telephone interviews. Four interviews were conducted in Welsh. Sectors represented are:

- Voluntary sector 3

- Higher Education 5

- Local Authorities 3

- Further Education 1

- Accreditation body 1

Total 13

Interviews lasted between 20 and 45 minutes. Notes were taken and then written up and included into a matrix of themes, which were cross-referenced with the policy interviews.

\section{Telephone Interviewing}

Use of the telephone as a method for interviewing was chosen, not to save the researcher time but in response to managers who stated that they were busy and that a telephone interview was possible, whereas arranging a face-to-face interview would be problematic, if not impossible. Interviews were always arranged by email and the area of questioning was outlined beforehand. This form of telephone interviewing is participant-centred (TrierBieniek, 2012), and it allowed access to a range of managers in ACL. 
The qualitative telephone interview has been described by some as a good alternative, but not as a primary method for data collection (Trier-Bieniek, 2012). There are different arguments for and against this method (Cohen et al., 2011: 439), such as the differences in rapport when communicating on the telephone, as visual clues and cues to meaning are not available. However, rapport was developed and often facilitated by previous communication via email or previous meetings. Another difference between the face-toface and telephone interview is brevity, as the telephone interview can be more direct and succinct (Irvine, Drew \& Sainsbury, 2013: 100). Most research studies on the use of telephones in interviewing have been on quantitative research and there is not a great deal of evidence on the reliability and validity of qualitative telephone interviewing (Irvine, 2011; Sturges \& Hanrahan, 2004; Trier-Bieniek, 2012). However, research by Sturges and Hanrahan (2004) found no significant difference in the quality of data obtained between face-to-face and telephone interview methods.

\subsubsection{Questionnaires}

\subsubsection{Introduction}

Good practice in questionnaire design includes piloting to ensure that the questionnaire is understood by the respondents and provides valid data (Cohen, 2011: 402). This was done with colleagues in adult education settings and staff at the university. A section for general comments was included after almost every question so that people had every opportunity to respond fully.

\subsubsection{Managers' Questionnaire}

The questionnaire was emailed to managers across Wales through the ACL Partnerships and an online version was also distributed. It followed the same basic schedule used in the interviews. Managers included: heads of education at local authorities, development officers, programme managers in all sectors, community education officers at local authorities, and senior and operational managers in further and higher education.

Nineteen online questionnaires and $\mathbf{3 1}$ email questionnaires were returned, giving a total of 50 responses. Sectors represented were as follows:

- Voluntary Sector 6

- Higher Education 11

- Local Authorities 16

- Further Education 17

Total $\mathbf{5 0}$




\subsubsection{Tutors' questionnaire}

An email outlining the purpose of the research and containing a link to an online questionnaire was sent to all ACL partnerships, and their members were asked to distribute it to all tutors. The online survey software 'Survey Monkey' was used; it is a web-based resource that the researcher had used many times professionally. It has a clear, userfriendly interface.

There are conflicting views amongst researchers in social science as to the benefits of using online questionnaires. Kelly Harper and Landau (2008) write about the different standpoints taken by researchers using different modes of enquiry, and they discuss research carried out to examine the difference between pen and paper, face-to-face and electronic data gathering. The end results show little difference between methods, "with no appreciable reduction in information content", as long as the researcher has used a good questionnaire design with appropriate questions to elicit the best responses (Kelly et al., 2008: 139). I was conscious, when designing questionnaires, not to overburden practitioners, but in retrospect I could have asked more questions because tutors, in particular, were happy to be consulted, as this so rarely happens. I was, perhaps, being too cautious.

Various techniques can be used to help increase responses to questionnaires or surveys including networking as identified by Fowler (2009: 60). This was taking place through visits to the $\mathrm{ACL}$ strategic partnerships and contact with $\mathrm{ACL}$ managers throughout Wales as part of the research and because of teaching ESDGC awareness.

All questionnaires were offered in Welsh or English.

\section{There were 262 responses (226 in English and 36 in Welsh).}

There is no database of adult education tutors in Wales and each sector and institution employs part-time tutors on short-term contracts. It is not possible to say exactly how many tutors received the questionnaire. From the scant information available, it is estimated that 262 is between a quarter and a third of tutors in ACL in Wales and the 50 managers represent a similar proportion. 


\subsubsection{Other data collection methods}

\subsubsection{Meetings with $\mathrm{ACL}$ partnerships}

The ACL strategic partnerships are supported by the Welsh Government, and members represent all those organisations and institutions delivering $A C L$ in Wales (local authority, $\mathrm{FE}, \mathrm{HE}$ and voluntary sector). When visiting a partnership, I gave a brief presentation on ESDGC, which included the purpose of the Welsh Government research and the PhD, and those in attendance were asked for their views and thoughts about the ESDGC strategy, including their hopes and fears regarding implementation, and the challenges for embedding it in policy and practice. Time was limited, and it was not possible to obtain detailed or in-depth responses from these meetings. The information derived was used to supplement and add validity to the findings from the interviews, questionnaires and focus groups. Partnership meetings attended were as follows:

- South West Wales and Mid Wales Partnership - Bridgend, Carmarthenshire, Ceredigion, Neath Port Talbot, Pembrokeshire, Powys.

- South East Wales Partnership - Cardiff, Blaenau Gwent, Merthyr Tydfil, Rhondda Cynon Taff, Vale of Glamorgan.

- Merthyr

- North East Wales - Conwy \& Denbighshire

- Interview with the Chair of the Cardiff Partnership

Visiting the partnerships established contacts with ACL managers. These direct contacts were useful in enabling further access to practitioners.

\subsubsection{Focus groups}

Two focus group sessions were conducted: one in North and one in South Wales. Invitations were sent out and those who attended were a mix of managers, tutors and development workers from across the different sectors delivering ACL. There were twentythree people in each group, and because the groups were large, a colleague worked alongside the researcher acting as a scribe, helping record discussions and capture data.

Focus groups are a series of discussions occurring in a specific, controlled setting and they took place after all other data had been collected and after a significant amount of data sorting, iterative categorisation and analysis had been done. Emerging issues were used as starting points for some discussions. The focus groups were conducted in the following way: 
- Clarifying purpose of the focus group

- Introductions and icebreaker

- Presentation. ESDGC in ACL and the research so far

- Discussions 'support needs', 'hopes and fears'

- Ranking exercise - nine statements from the research findings

- Discussions about priorities and key areas for development

- Everyone was given a notebook to record thoughts and ideas, and to offer suggestions; these were left behind at the end of the day.

One activity that was used to facilitate participation and discussions on the key issues was a diamond ranking exercise ${ }^{40}$. This presented the preliminary research findings in the form of nine statements which participants were asked to rank in a diamond pattern. This 'diamond ranking' is a research and teaching tool and technique; people work in small groups and negotiate the order of the statements to arrive at a consensus (Clark, 2012).

\section{Fig. 4.4 Diamond ranking}

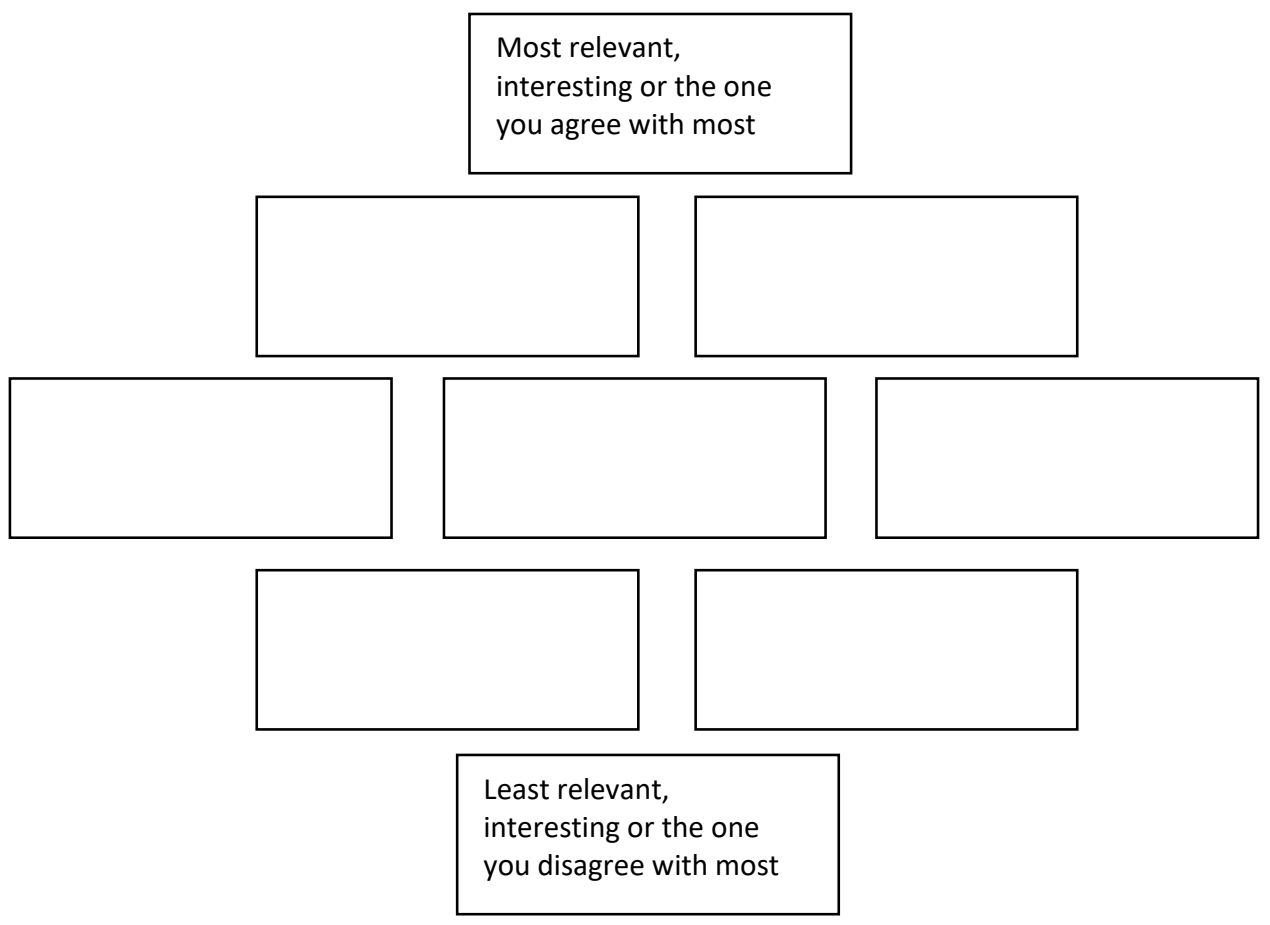

A relaxed atmosphere was created during the focus groups to support the participants in expressing themselves honestly. To ensure that everyone had the opportunity to contribute, participants worked in small groups and recorded their thoughts and discussion

\footnotetext{
${ }^{40}$ Diamond ranking technique -

http://www.academia.edu/1197745/Using Diamond Ranking activities as a visual methods rese arch tool and http://teachingtechniques.boston.ac.uk/diamond nine and ranking.html
} 
points on flip charts and post-its. Each person contributed to recording the discussions and participants moved around: this ensured that no voices dominated. A range of activities and the mixing of people and groups facilitated a dynamic that encouraged a range of perspectives so that normative discourses would not obscure any controversial issues that arose (Smithson, 2000: 103-4). What distinguishes focus groups from the other modes of inquiry is the interaction between participants; the data is collectively generated, and this is recognised during the analysis (Vicsek, 2007). The format generated a great deal of discussion covering the same substantive areas as the interviews and questionnaires with managers and tutors.

\section{Fig. 4.5 An example of a recording method from the focus groups}

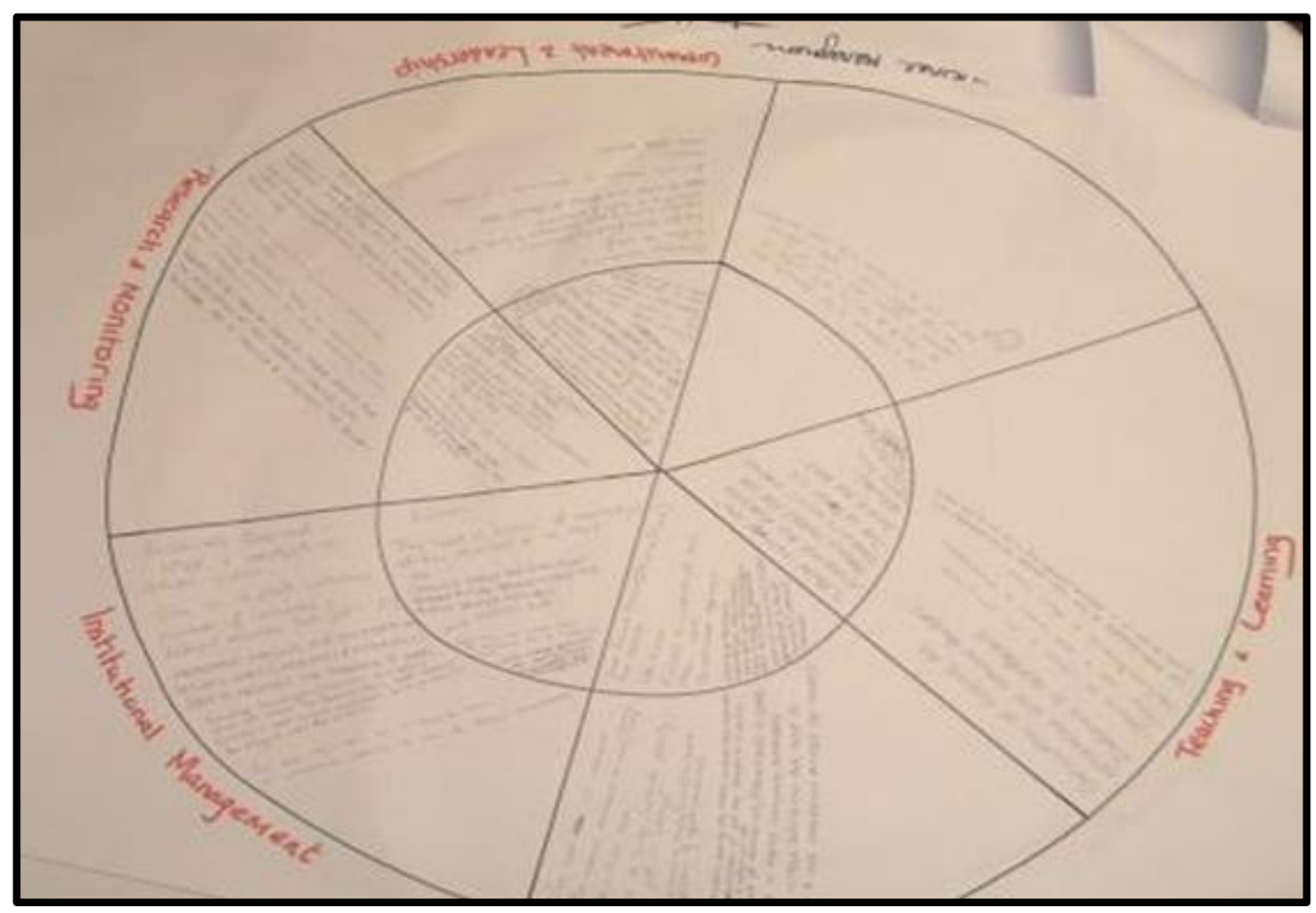

\subsubsection{Other data sources}

Teaching ESDGC awareness sessions to ACL tutors throughout Wales offered opportunities to observe, take notes and ask questions. The data gathered were in the form of notes and provided supplementary data. I also kept notes from conferences and meetings attended. Again, these notes have been referred to as part of triangulation and not as substantive evidence. 


\subsection{Analysis}

\subsubsection{Introduction}

The purpose of this section is to elucidate the systematic, mechanical, creative and sometimes serendipitous aspects of analysis through describing the different phases and procedures that were undertaken. It begins by clarifying the approach taken in line with the theoretical underpinning discussed earlier, and then describes the process of analysis, which is not linear and sometimes appears chaotic, as the data is 'mined' and interpreted for meaning, explanations, insights and understandings. The reasoning is inductive, abductive and at times deductive, as I seek to understand and explain emergent findings (Charmaz, 2008: 157; Reichertz, 2007, 2014; Thomas, 2010).

"There is no particular moment when data analysis begins. Analysis is a matter of giving meaning to first impressions as well as to final compilations" (Stake, 1995: 71). All aspects of the case study involved interpretation and analysis which is an iterative process with different and overlapping phases as re-readings and iterative categorisation (Neal, 2016) expose layers of meaning and interconnections within and between the data sets. Examples of data from the different sets are provided in the appendices. The approach to organising and presenting the data was though clustering data around themes. Comparison across respondent groups and data sets were possible using this approach (Cohen et al., 2011: 551); however, the analysis remained responsive to issues that emerged from certain individuals, or factors relating to educational sector or professional roles. No one source of evidence answers the research questions: they are only fully addressed through combining and triangulating data from a range of actors (See Table 4.3). A complex interplay of concord and discord provides the understandings and allows the researcher to draw conclusions.

\subsubsection{Answering the questions: uncovering, discovering and making sense}

Theories, as suppositions or system of ideas intended as explanations based on general principles, were not proposed prior to conducting this case study research, and overarching theories are not generated from the data. The aim is to contribute to 'practical wisdom' as opposed to theory or to identifying causal events, in line with phronesis (Thomas, 2010). 
Many unseen factors have exerted influence on ESDGC in ACL in Wales and accordingly the analysis uses a systemic, critical realist approach, which recognises that contingent conditions act upon structures and mechanisms and influence effects (Sayer, 2000: 15).

Selectivity is endemic in research, extending to data collection and analysis, and judgements were made, and decisions taken with regard to the emerging themes - which to analyse beyond initial categorisation. A key research question is concerned with examining why ESDGC delivery in ACL in Wales was patchy, inconsistent and ad hoc. This includes identifying barriers to the successful implementation of the ESDGC strategy and the research has focused on this rather than examining good practice. Policymakers' and practitioners' descriptions enable an understanding of the policy process and how this relates to the needs, hopes and concerns of practitioners, thereby addressing key themes that are evidenced and discussed in Chapters 5 and 6 . The findings are expressed as themes and sub-themes: these form the headings and sub-headings of the sections.

\subsubsection{The phases of analysis}

\subsubsection{Introduction}

Transcribing the initial seven interviews was the first stage of analysis. The process provided fresh perspectives, and insights emerged during the re-listening and transcription, which included reference to memos and notes taken during the interviews. An initial analysis of the seven policy interviews identified broad themes, which were categorised and refined iteratively as new information was collected from the other, different groups of respondents (Neal, 2016). This process was repeated with all data sets. In-depth analysis of interviews and questionnaire data was done prior to the focus groups and the data from other sources, as described above was then introduced and woven into the analysis which had established substantive themes.

The analogy of producing a fabric might be used: the data, cleaned, carded, and spun in the analysis, represent the longitudinal threads, the warp; the discussions, including theories and concepts, become the weft that moves through the data and gradually builds up and creates the fabric. The loom is therefore what already exists: the ESDGC strategy, existing practice and the literature and knowledge relating to ESDGC. 
Specialist qualitative data analysis software (such as NVivo or NUDIST) was not employed, the analysis was instead carried out using word processing software, Excel spreadsheets, paper and coloured pens. There were three iterative processes:

1) Data reduction through coding, categorisation and identifying themes and patterns;

2) Triangulation and displaying data; and

3) Conclusion drawing, through re-conceptualising and theorizing

(Miles \& Huberman, 1994).

The procedure is non-linear and can be visualised in the diagram below.

Fig 4.6 Components of Data Analysis: Interactive Model

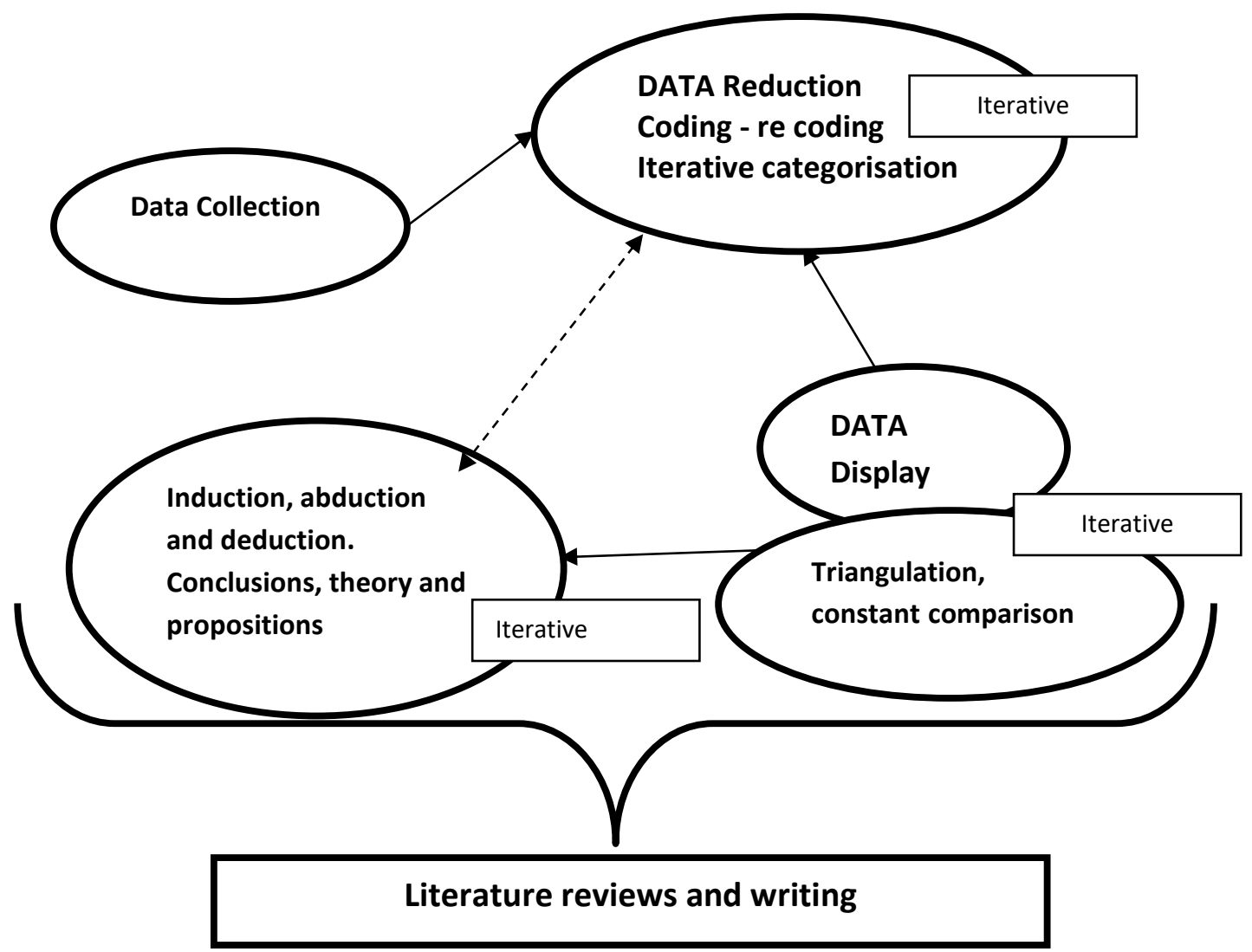

4.7.3.2 Data reduction - Iterative categorisation, codes and themes

From years of maintaining close contact with the data, I was able to re-visit the analysis many times and interrogate the different data sets and combinations thereof. I immersed myself in the data over a prolonged period to develop a deep familiarisation or intimacy 
with all content. The data was ordered (Neal, 2016: 1097) and thematically coded and categorised to reduce, organise and create meaning. Appendix $F$ is a sample of data from the managers' questionnaire organised into a matrix for analysis. Each wave of data collection was accompanied by a corresponding exercise in condensation through further categorisation and analysis (Miles \& Huberman, 1994: 56). The different data sets and the way in which they relate to the research questions are shown in Table 4.3 below; however, no one data set answers one questions, it is the aggregation that provides the evidence.

\section{Table 4.3 Data sources and how they contribute to addressing the research questions}

- Addressed directly - The data source provides evidence to address the question directly.

- Partly addressed - Insights are gained from the aggregated data from this source that contribute to addressing the question. Some respondents within that group address it.

- A limited extent - Some insights are provided from this data source

\begin{tabular}{|c|c|}
\hline Data Source and Respondents & Questions Addressed \\
\hline Review of policy & $\begin{array}{l}\text { Question 1- addressed directly } \\
\text { Question } 3 \text { - a limited extent } \\
\text { Question } 4 \text { - a limited extent }\end{array}$ \\
\hline Literature review & $\begin{array}{l}\text { Question 1- a limited extent } \\
\text { Question 3 - addressed directly } \\
\text { Question 4-partly addressed }\end{array}$ \\
\hline $\begin{array}{l}\text { In-depth interview transcripts - those } \\
\text { involved in developing policy }\end{array}$ & $\begin{array}{l}\text { Question } 1 \text { - partly addressed } \\
\text { Question } 2 \text { - addressed directly } \\
\text { Question } 3 \text { - addressed directly } \\
\text { Question4 - partly addressed }\end{array}$ \\
\hline Interview transcripts - managers & $\begin{array}{l}\text { Question } 2 \text { - addressed directly } \\
\text { Question } 3 \text { - a limited extent } \\
\text { Question } 4 \text { - partly addressed }\end{array}$ \\
\hline Questionnaire - managers & $\begin{array}{l}\text { Question } 2 \text { - addressed directly } \\
\text { Question } 3 \text { - partly addressed } \\
\text { Question } 4 \text { - partly addressed }\end{array}$ \\
\hline Online questionnaire - tutors & $\begin{array}{l}\text { Question } 2 \text { - addressed directly } \\
\text { Question } 3 \text { - a limited extent } \\
\text { Question } 4 \text { - partly addressed }\end{array}$ \\
\hline $\begin{array}{l}\text { Focus groups - strategic and } \\
\text { operational managers and tutors }\end{array}$ & $\begin{array}{l}\text { Question } 2 \text { - addressed directly } \\
\text { Question } 3 \text { - a limited extent } \\
\text { Question } 4 \text { - partly addressed }\end{array}$ \\
\hline $\begin{array}{l}\text { Notes from ACL partnership } \\
\text { meetings - strategic managers }\end{array}$ & $\begin{array}{l}\text { Question } 2 \text { - addressed directly } \\
\text { Question } 3 \text { - a limited extent } \\
\text { Question4 - partly addressed }\end{array}$ \\
\hline Notes from teaching - tutors & $\begin{array}{l}\text { Question } 2 \text { - addressed directly } \\
\text { Question } 3 \text { - a limited extent } \\
\text { Question } 4 \text { - partly addressed }\end{array}$ \\
\hline $\begin{array}{l}\text { Notes from meetings - strategic and } \\
\text { operational managers and tutors }\end{array}$ & $\begin{array}{l}\text { Question } 2 \text { - addressed directly } \\
\text { Question } 3 \text { - a limited extent } \\
\text { Question } 4 \text { - partly addressed }\end{array}$ \\
\hline
\end{tabular}


The use of themes, categories and codes to ascribe meaning to text allowed me to identify patterns and create relationships within and between data sets. Longhand notes were used predominantly, and these, alongside the codes, helped categorise data. As well as a systematic approach, a certain amount of artistic sensibility helps to make meaning from, and sense of, data. "When you think about how we gain insights from artists, poets, novelists, it is when we recognize something in what they have said or portrayed which communicates an essential 'truth' about the human condition or social context of the times" (Simons, 2009: 167).

A more focused analysis followed the identification of broad categories and themes, and sub-categories were added as the data were more minutely scrutinized. The iterative process moved between the data and literature over several cycles, identifying recurring themes, patterns and gaps. The gaps were identified as topics that people avoided talking about, hurried over, omitted to speak about/mention or where very little was said (Silverman, 2013). The themes and codes ascribed to the data are related to discourses and possible explanations that address the research questions. See Appendix $L$ for examples of initial categorisation/coding from the different data sets.

Some examples of the initial broad themes:

- Policy process - perceptions of

- Representation and inclusion in policy process

- Vision - communication

- $\mathrm{ACL}$ approach and theory - latent contribution

- Strategic and operational barriers

- Hopes

- Fears, concerns, cynicism and pessimism

- Tutor autonomy

- EGC and EGC/ESD balance

- Global citizenship education

- Policy-practice gap

- Learner autonomy

- Community development, local focus

- Sector-specific issues (FE, HE, Voluntary sector and local authorities)

- Pedagogy

These are descriptive, core themes; the next sub-set of themes clustered these as patterns began to emerge. Further categories were then used which were more interpretative or inferential. During the final wave of data collection (the focus groups), the data did not reveal any completely new themes, and this reaffirms the categorisations and analysis thus far. 


\subsubsection{Triangulation and working with the data}

Multiple sources of evidence are used in this case study and they are converged in a triangulating fashion (Yin, 2009: 18). This brings clarity to large amounts of data: it reaffirms the use of categories and allows for the discarding of some themes/issues that do not address the research questions or are peripheral.

The ultimate power of field research lies in the researchers' emerging map of what is happening and why. So any method that will force more differentiation and integration of that map, while remaining flexible, is a good idea. Coding, working through iterative cycles of induction and deduction to power the analysis, can accomplish these goals. (Miles \& Huberman, 1994: 65)

Comparison of the data sets began immediately following the transcription and initial coding of the first interviews, and the first tranche of notes from ACL partnership meetings. As each wave of data was collected, the process was repeated. Because the data from the different data sets were different in their style, the codes did not always match. However, through continuous triangulation, inference, induction and abduction, the relationships within and between data sets became clear.

Tables 4.4 show some examples of how themes and categories emerged from iterative categorization and triangulation.

Tables 4.4 (a, b, c, d) - Examples of themes

Table 4.4 a Policy interviews, ACL partnerships \& manager data

\begin{tabular}{|l|l|l|l|}
\hline 1st level Themes & $\begin{array}{l}\text { 2nd level } \\
\text { categories }\end{array}$ & policy level interviews & $\begin{array}{l}\text { Managers - including ACL } \\
\text { partnerships }\end{array}$ \\
\hline Concern & Tutors' autonomy & $\begin{array}{l}\text { Three mentioned this - } \\
\text { potential barrier } \\
\text { One - not an issue }\end{array}$ & $\begin{array}{l}\text { Most recognised this - } \\
\text { particularly operational } \\
\text { managers }\end{array}$ \\
\hline Resources & $\begin{array}{l}\text { Foluntary sector - cynical } \\
\text { about resources being } \\
\text { Govailable. Champion } \\
\text { concerned for future } \\
\text { funding. }\end{array}$ & $\begin{array}{l}\text { Many cynical and } \\
\text { pessimistic that resources } \\
\text { would be available for } \\
\text { implementation. }\end{array}$ \\
\hline
\end{tabular}


Table 4.4 $b$ Managers \& tutors

\begin{tabular}{|l|l|l|l|}
\hline 1st level Themes & 2nd level categories & Managers & Tutors \\
\hline Concern & Tutor autonomy & $\begin{array}{l}\text { Most recognised this - } \\
\text { particularly } \\
\text { operational managers }\end{array}$ & $\begin{array}{l}\text { Many - very concerned } \\
\text { political indoctrination - } \\
\text { imposed agenda }\end{array}$ \\
\hline Burden & $\begin{array}{l}\text { Additional } \\
\text { bureaucratic } \\
\text { paperwork }\end{array}$ & $\begin{array}{l}\text { Most recognised this } \\
\text { many and tick-box - }\end{array}$ \\
\hline
\end{tabular}

Table $4.4 c$ Tutors \& policy interviews

\begin{tabular}{|l|l|l|}
\hline Themes & Tutors & 7 policy level interviews \\
\hline Burden - tick-box & $\begin{array}{l}\text { Work and pay conditions } \\
\text { Lack of consultation with } \\
\text { practitioners on the issues }\end{array}$ & $\begin{array}{l}\text { Possibility of tick-box - without } \\
\text { substance, without changing } \\
\text { minds - long term }\end{array}$ \\
\hline $\begin{array}{l}\text { Welsh Government leading } \\
\text { agenda }\end{array}$ & $\begin{array}{l}\text { Many very critical - hypocrisy - } \\
\text { imposition of ideology - } \\
\text { preaching }\end{array}$ & $\begin{array}{l}\text { Voluntary sector - concern re: } \\
\text { lack of critical review and } \\
\text { reflection } \\
\text { A need to move ahead - drive } \\
\text { agenda }\end{array}$ \\
\hline
\end{tabular}

Table 4.4 $d$ Different sectors - managers - emerging issues

\begin{tabular}{|l|l|l|l|}
\hline Local Authority & FE & HE & Voluntary Sector \\
\hline Quality - consistency & Training - quality - & Communication - not & Social justice agenda \\
Community - & Consistency across & being kept informed & Stressing methods \\
resources & sectors & Ecological courses & Inclusion - follow-up - \\
Resources, guidance & Tutors - support & recruiting ... & \\
$\begin{array}{l}\text { and training - for all - } \\
\text { staff. }\end{array}$ & issues & & \\
$\begin{array}{l}\text { Capacity. Sharing } \\
\text { good practice Learner } \\
\text { autonomy .... }\end{array}$ & & & \\
\hline
\end{tabular}

Segments of the data were then clustered for a final layer of analysis and comparison. The analysis deepened, and the focus sharpened as repeatable regularities emerged: it is a form of distillation.

\subsubsection{Explanatory hypotheses: insights, understandings, conclusions}

Congruent with an emergent inquiry the analysis remained on-going throughout the different phases of data collection and was concurrent with a literature review that informed the discussions (Corbin \& Strauss, 2008). The interpretation and attribution of meaning was of itself a learning process (Cohen et al., 2007: 167) and it continued throughout the writing of the thesis. 
A gap between 2010 and 2015, when the data were not engaged with due to changes in supervision and a different approach (See 4.9 below), might at first appear to be a problem, but the distance engendered new perspectives as the data were re-read and re-analysed. During the process of writing, a number of summaries were re-shaped many times, and even though "more than one story can be derived from data" (Corbin \& Strauss, 2008: 50), through repeated analysis distinct themes and conceptual patterns emerged to create a narrative.

Inductive and abductive inferences were used to infer the best possible and probable explanations relating to the research questions. This is in line with propositions put forward by Thornberg and Charmaz (2014) and Reichertz (2013), who endorse moving between induction and abduction: "Abduction means selecting or constructing a hypothesis that explains a particular empirical case or set of data better than any other candidate hypotheses, as a provisional hypothesis and a worthy candidate for further investigation" (Thornberg \& Charmaz, 2014: 155). Abduction attempts, as far as possible, to begin its observations without presuppositions and, above all, without theories.

Yet abduction is not the product of uninformed guessing or a god-given ability to recognize what is right, but is rather a matter of absorbing (the greatest possible amount of) environmental data, which are then (albeit subconsciously) interpreted and used to arrive at a meaningful conclusion. (Reichertz, 2013: 127)

Whilst conducting the empirical research, conceptual confusion became apparent as respondents at all levels, from policymakers to tutors, said or intimated that they were unclear about what ESDGC was and what the constituent concepts meant. Exploring this became the focus for further investigation and another literature review. After all, it is practitioners' understanding of the concepts of sustainable development and global citizenship "that will shape their pedagogical practices in ESD" (Stevenson, 2006: 279). Given that ESDGC can be related to, and is relevant to, all aspects of life, from the biological material world to the realms of philosophy, politics, cultural practices and spirituality (Blewitt, 2008: 28), gaining conceptual clarity to provide a rationale for developing theory and practice becomes a daunting task. ESDGC includes addressing normative questions: it is therefore apposite to engage with literature on the philosophical, moral and political underpinnings of ESDGC to discuss a re-conceptualisation. 


\subsection{Reporting and style}

The style chosen for the writing of this thesis is predominantly in the formal third person; however, there are occasions when the researcher uses the first person. This approach is taken when context that involves the researcher is being described and discussed; this allows for a more fluent reading. It is hoped that the style can bring to life the people behind the data and their hopes and concerns for this educational innovation. The subjectivity in this interpretive approach is reflected in the style of the findings chapters.

As was discussed in relation to ethics, the evidence from the seven policy level interviews is reported in a manner that, whilst it at times might appear vague, is designed to preserve the anonymity of these people, who might be easily distinguished from their professional roles. Managers from across all sectors delivering ACL are distinguished as 'Senior Managers' (those who work at a strategic level) and 'Operational Managers' (those who organise programmes and courses and have a developmental role). It was decided that this separation could offer insights; however, no added value was gained by distinguishing individuals. Where it added to the relevance and import of the evidence, managers' institutional affiliation has been reported. In this respect, anonymity is assured. Although they work across different sectors, tutors locate their practice in the classroom and their professional experience, working conditions and practices are broadly similar, and they are identified as 'Tutor'. Individual tutors have not been identified because no pattern or trends emerged across the different subject areas, types of employment or employers. In addition, some tutors taught for many institutions and across sectors delivering $A C L$, and this made it impossible to attach significance to an individual identifier.

It was decided, with advice from research supervisors, that quotes would be made readable in order that the narrative would flow. Most of the pauses that were illustrated in the transcription process by ... and the 'ums' have not been reported, apart from when they convey meaning. Spelling mistakes in the questionnaire have been corrected and formatting standardised for ease of reading. It is the meaning that is important, and this is preserved and presented honestly. 


\subsection{Reflection on the research process}

It is prudent to explain some of the circumstantial challenges encountered during the research process, particularly issues linked to supervision. Changes in supervision had a significant influence and bearing on methodology, and inevitably disrupted the overall research process.

Table 4.5 Supervision

\begin{tabular}{|c|c|c|}
\hline Year & Time frame & Supervision \\
\hline 2008 & $\begin{array}{l}\text { October } 2008 \text { - } \\
\text { Summer } 2009\end{array}$ & Supervisor in the School of the Environment and Society \\
\hline \multicolumn{3}{|l|}{2009} \\
\hline 2010 & \multirow{4}{*}{$\begin{array}{l}\text { October } 2010 \text { - } \\
\text { February } 2013\end{array}$} & \multirow{4}{*}{$\begin{array}{l}\text { Supervisor in the Department of Politics and Cultural Studies } \\
\text { - moral philosophy - global citizenship }\end{array}$} \\
\hline 2011 & & \\
\hline 2012 & & \\
\hline 2013 & & \\
\hline 2014 & \multirow{2}{*}{$\begin{array}{l}\text { August } 2014 \text { - } \\
\text { October } 2015\end{array}$} & \multirow{2}{*}{$\begin{array}{l}\text { Supervisor in the Department of Politics and Cultural Studies } \\
\text { - global citizenship - policy studies }\end{array}$} \\
\hline 2015 & & \\
\hline 2016 & \multirow{2}{*}{$\begin{array}{l}\text { January } 2016- \\
2018\end{array}$} & \multirow[t]{2}{*}{ Supervisors in the Geography Department } \\
\hline 2017 & & \\
\hline
\end{tabular}

My first supervisor, based in the School of the Environment and Society, was a biologist with an interest in sustainability. He retired before the end of the first year of research. I continued with my research and after some months without supervision, a member of staff in the Department of Politics and Cultural Studies became my supervisor. His interest was in the conceptualisation of global citizenship and the moral and ideological underpinnings of the concept. The original research proposal envisioned two stages of data collection: the first to identify broad themes and the second phase to focus on the emerging issues. However, a second stage of empirical research was put to one side as I was encouraged to pursue a conceptual thesis. Unfortunately, this supervisor became ill and was absent for most of 2013. At the same time, my mother became critically ill and I was involved in caring for her until she died in December that year.

In August 2014, supervision was transferred to a member of staff in the same department: a political scientist who had published in the area of global citizenship. His interest was in policy, and whilst I was interest in analysing policy and the policy process, I did not want this to be the sole focus of the thesis. In January 2016, I met Professor David Clarke, Head of Geography at Swansea University, who agreed to be my supervisor. I also had a second 
supervisor, Dr Keith Halfacree, and I am grateful to them both for their guidance, advice and support.

Whilst the research process has not been smooth, I gained insights into the different ways in which disciplines conceptualised and conducted research and was introduced to a new body of literature that enabled me to develop perspectives and insights I would not otherwise have had. Without these, the conceptual confusion would not have been addressed as fully.

\subsection{Conclusion}

This methodology chapter has provided a detailed description of the paradigms and conceptual lenses that informed and underpinned the research, as well as a detailed description of the research process: including data methods, collection and the analytic process. The rationale for choosing a case study design, and the decision to include multiple perspectives and different data collection methods for different groups of respondents has been discussed. These were appropriate techniques for exploring the situation in ESDGC in ACL in Wales and addressing the aims of the case study. A qualitative methodology that combines different methods and data sources provides the most credible, plausible and generalisable results.

Everything in this thesis is context, and through including rather than excluding themes in the findings as full a picture as possible is presented to the reader. Selectivity extends from data collection to analysis and to the inclusion and exclusion of themes and data; therefore, not every finding has been discussed. Judgements have been made and decisions taken about the emerging themes that were analysed beyond the initial stages of categorisation. Even though certain peripheral themes are discarded, an inclusive approach is adopted so that the research questions can be fully addressed.

To recap on and summarise the questions before the findings are presented and discussed in the following two chapters: they involve identifying the background features which influenced the development of the policy of ESDGC in Wales and explaining reasons for the 'piecemeal' delivery and provision of ESDGC in ACL, as described by the research respondents. Another question focuses on EGC and why it was neglected and finally, a question addresses the 'latent' contribution of ACL to ESDGC and how can this contribute 
to a re-conceptualisation so that ESDGC can be better understood and made relevant for policy and practice in ACL. This last question is fully examined and discussed in Chapter 8. No one section or chapter and no one data source answers any one question: the pieces of the case study jigsaw come together through the thesis. The discussions and conclusions bring the research questions together into explanations based on the analysis of the findings, the policy context and the literature reviews. 


\section{Chapter 5 \\ Findings: $\mathrm{ACL}$ and Policy Context}

\subsection{Introduction}

The principal aim of this chapter is to provide context through the use of the empirical findings and to explore themes relating to policy. Previous chapters have described and discussed the international and national policy context and the literature has provided the conceptual context for ACL and ESDGC. This adds to the validity of the findings, enables them to be better understood and allows generalisations to be made where appropriate. Using evidence from the empirical research - the words of practitioners and policymakers the situation in Wales regarding policy and provision affecting ESDGC in ACL is further explained and described in this chapter and in Chapter 6. Each heading and sub-heading represents a theme that emerged from the analysis of data.

Throughout the chapter, the research questions 'What were the background features which influenced the development and implementation of the ESDGC strategy?' and 'What were the features described by respondents which subsequently contributed to the 'piecemeal' delivery and provision of ESDGC in ACL? 'are addressed as context and findings are integrated. The question relating to ACL's 'latent' contribution to ESDGC is also addressed throughout the different sections. This chapter contributes to an overall understanding as insights are cumulatively gained and explanations postulated.

A brief description of the research respondent groups begins the chapter and provides a synopsis and follow-on from the methodology chapter. The next section (5.3) looks at the $\mathrm{ACL}$ sector in Wales at the time the research, as described by managers and tutors. Challenges faced by the sector are discussed in terms of overarching policy, and priorities and the delivery infrastructure of $A C L$ in Wales is described. A summary of the responses from the different educational sectors delivering $A C L$ gives an indication of the specific issues relating to ESDGC in each of these sectors and the range of approaches and provision.

Issues relating to policy are then discussed in section 5.4 which focuses on the macro, policy level. Data from the seven-in-depth interviews feature prominently, as these respondents and senior managers in ACL address strategic issues relating to policy. The 
development of the ESDGC strategy is described from the perspective of the different respondents and the themes of representation, consultation and communication emerge and are examined.

The hopes that people expressed for ESDGC and the strategy are looked in section 5.5, and this is followed by an examination of the fears and resistance that people described (section 5.6); these fears and concerns represent potential barriers to the implementation of the ESDGC strategy. The final theme in this chapter is that of the wider policy landscape in Wales and the way in which respondents highlight the fact that the ESDGC strategy was not linked with other policy imperatives, particularly community development. This includes a discussion on global citizenship in relation to local agendas and ties in with the fourth research question on features which illustrate difficulties associated with implementing EGC.

The themes used to structure the two findings chapters are similar to those identified by Kirkland and Sutch (2009) in their review of the literature on the introduction and adoption of innovations in the schools' sector. The authors discuss the macro, meso and micro layers of influence, and these are usefully employed when discussing ESDGC.

Macro level factors and layers of influence: these include the lead from government, national policy, structures, including inspection, and funding criteria. Global influences have been examined in the policy chapter.

Meso level factors and layers of influence: these include institutional culture, support, infrastructure, management, and locally communicated strategic vision and direction.

Micro level factors and layers of influence: these are concerned with the issues directly relevant to those expected to implement the innovation, such as their capacity to implement it and their perceptions of the strategy and dispositions towards it.

\subsection{Research respondents}

Seven in-depth interviews with those involved in developing policy in ESDGC in ACL were conducted initially with the following key informants:

- Head of ESDGC at the Welsh Government, the ESDGC Champion.

- Chief Estyn inspector for ACL with responsibility for ESDGC.

- Representative for further education on the ESDGC panel who also had responsibility for $\mathrm{ACL}$ and was the chair of Colegau Cymru's (the association of FE colleges in Wales) ESDGC group. 
- Representative for the Welsh Local Government Association (WLGA), which represents the interests of local government and promotes local democracy in Wales. It represents the 22 local authorities in Wales. This interviewee was also head of $A C L$ in a local authority.

- The Director of NIACE Dysgu Cymru (National Institute of Adult and Community Education in Wales).

- The Director of Cyfanfyd, the Development Education Association for Wales: a voluntary sector, membership organisation, promoting ESDGC.

- An officer at the Workers Education Association (WEA) with responsibility for ESDGC, whose response was informed by a discussion with the head of the WEA prior to the interview.

As discussed in the previous chapter, the anonymity of these respondents is preserved though using various writing techniques and different identifiers such as 'Policy level interviewee' or 'Member of ESDGC panel', for example.

The graphs below provide a profile of the manager and tutor populations that responded to the questionnaires.

Fig 5.1 How managers identified themselves - Questionnaires (numbers)

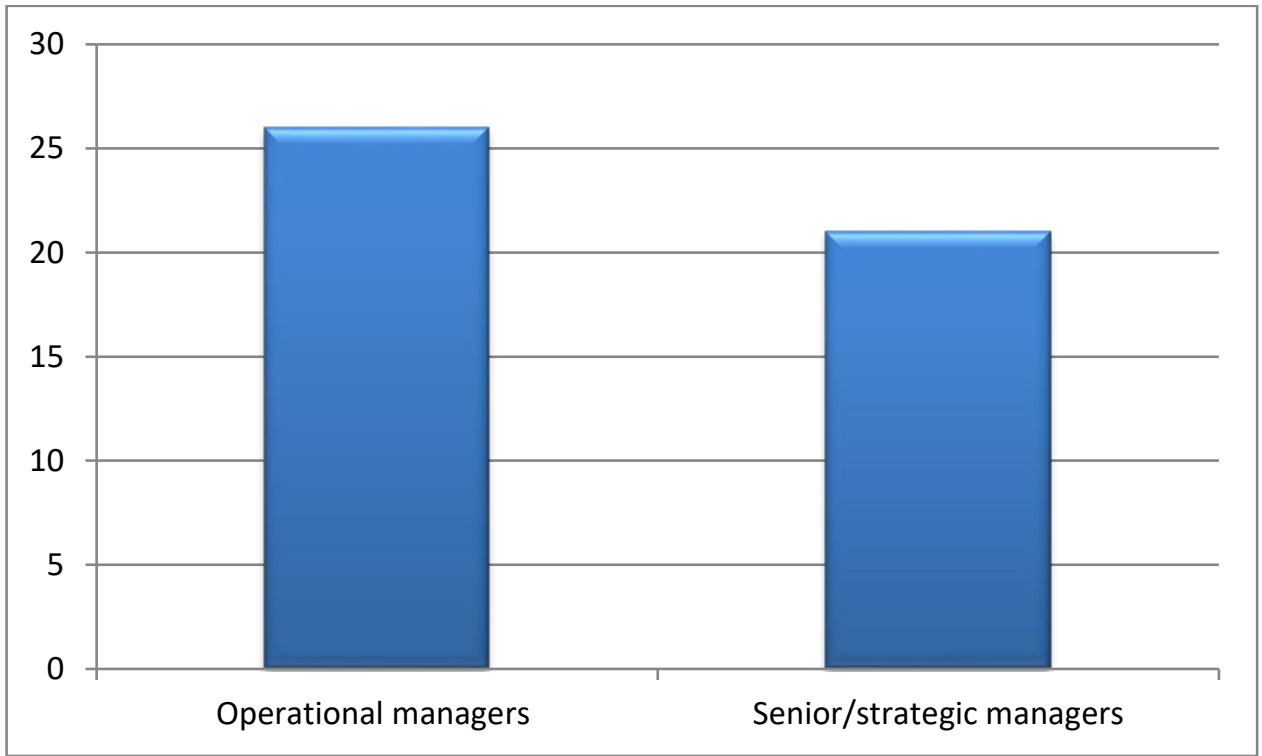


Fig. 5.2 How managers identified themselves - Interviews (numbers)

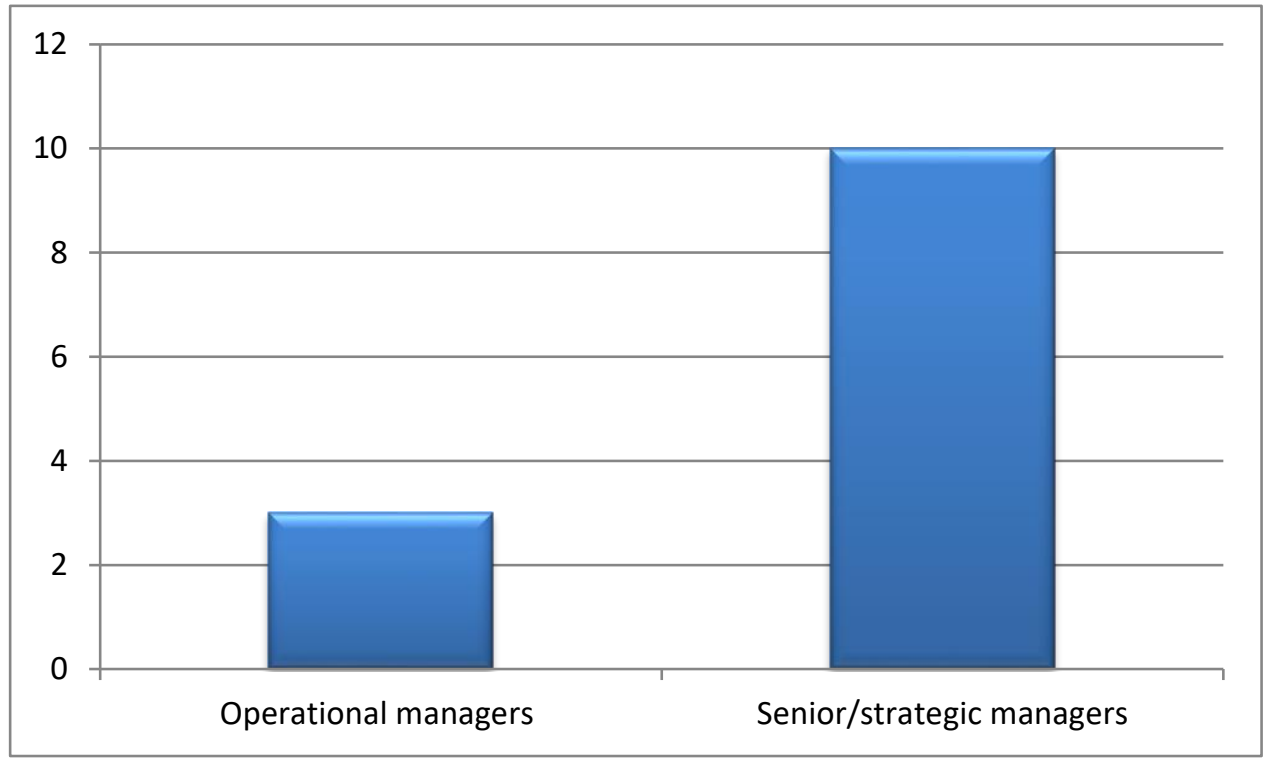

Fig 5.3 The sectors where managers worked - Questionnaire

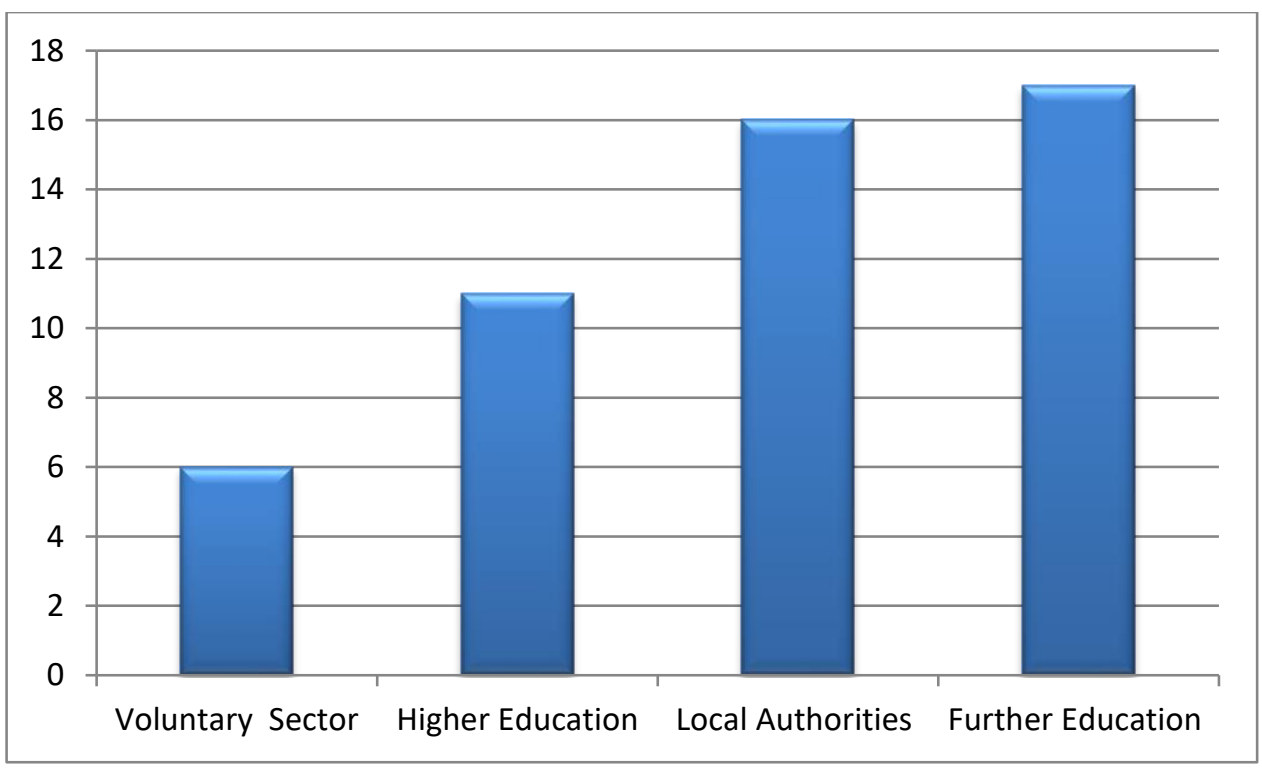


Fig 5.4 The sectors where managers worked - Interviews

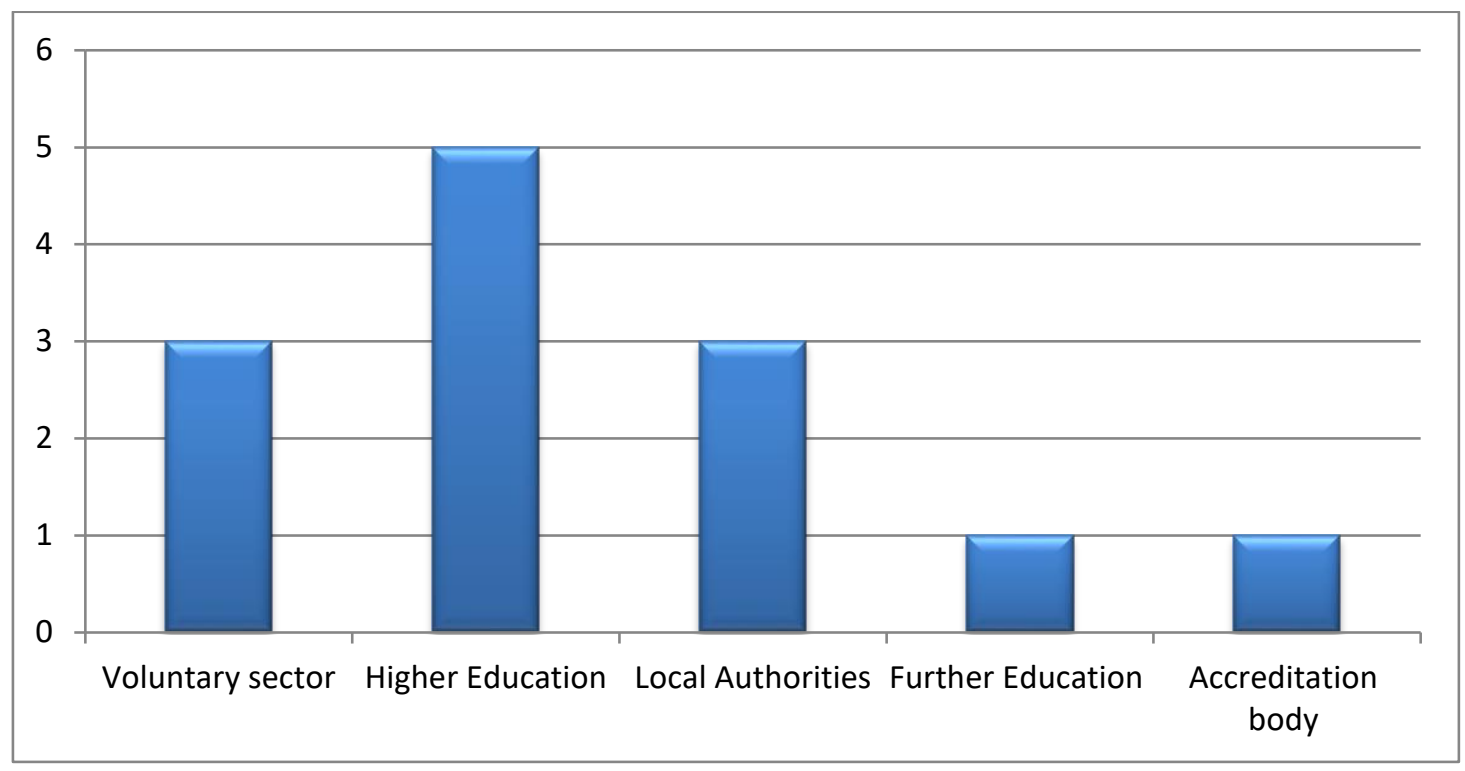

Fig. 5.5 How tutors identified themselves (294*)

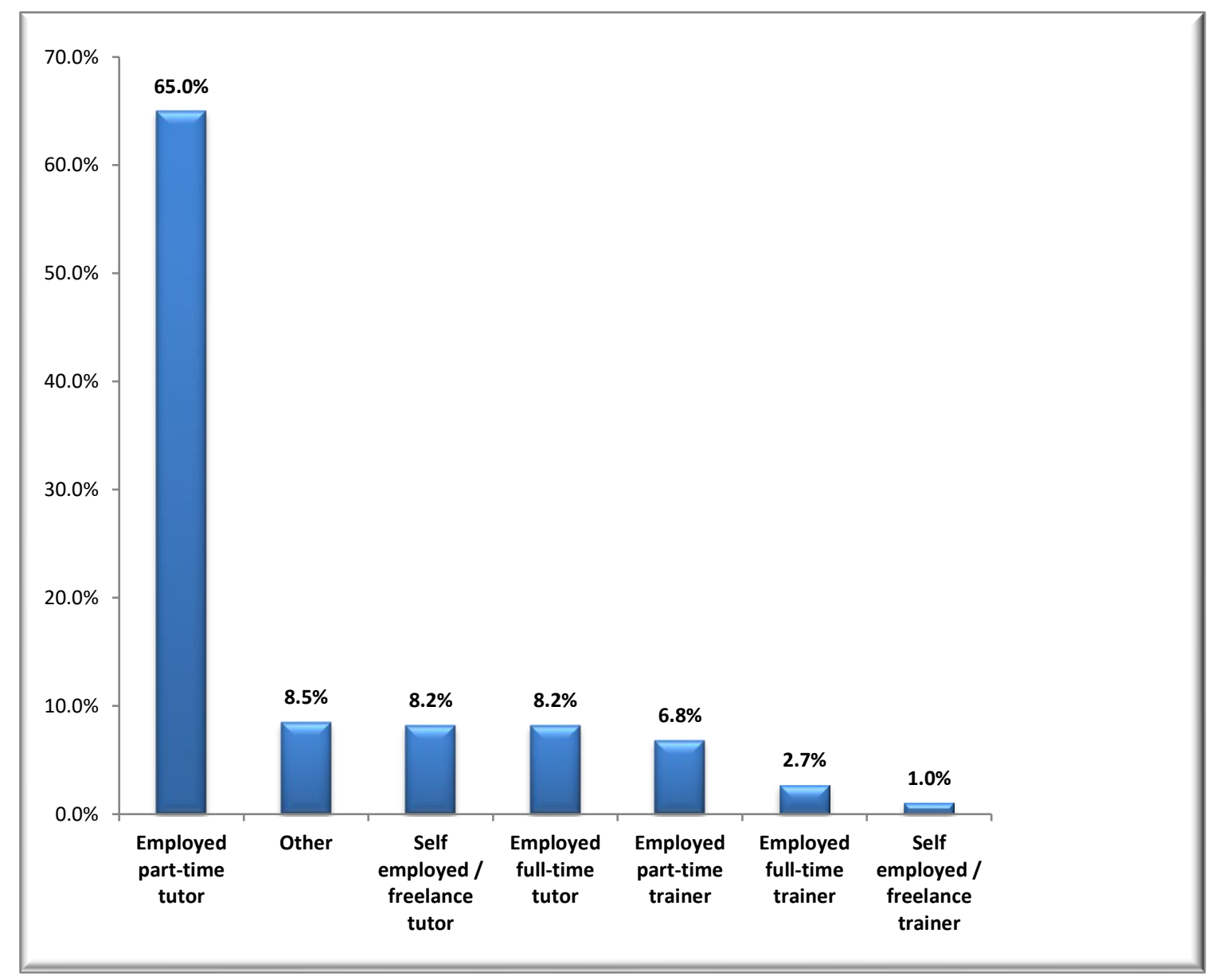

*250 respondents answered this question and were able to select more than one option resulting in 294 responses collected. 
The $8.5 \%$ representing the 'other' category in Figure 5.5 above, included a diverse array of roles including dual roles such as tutor and IT co-ordinator, and there were four development officers who also delivered classes/training. Some tutors highlighted other unpaid roles that they undertook, such as an anti-bullying champion role, and four tutors stated that they worked on a voluntary basis. Many stated that they had other paid jobs or roles, and these included secondary school teacher, engineer and PGCE student.

Nearly $\mathbf{7 2} \%$ of tutors/trainers were employed on a part-time basis, with $9 \%$ being selfemployed and $11 \%$ employed on a full-time basis.

Fig. 5.6 Who tutors work with/for (442*)

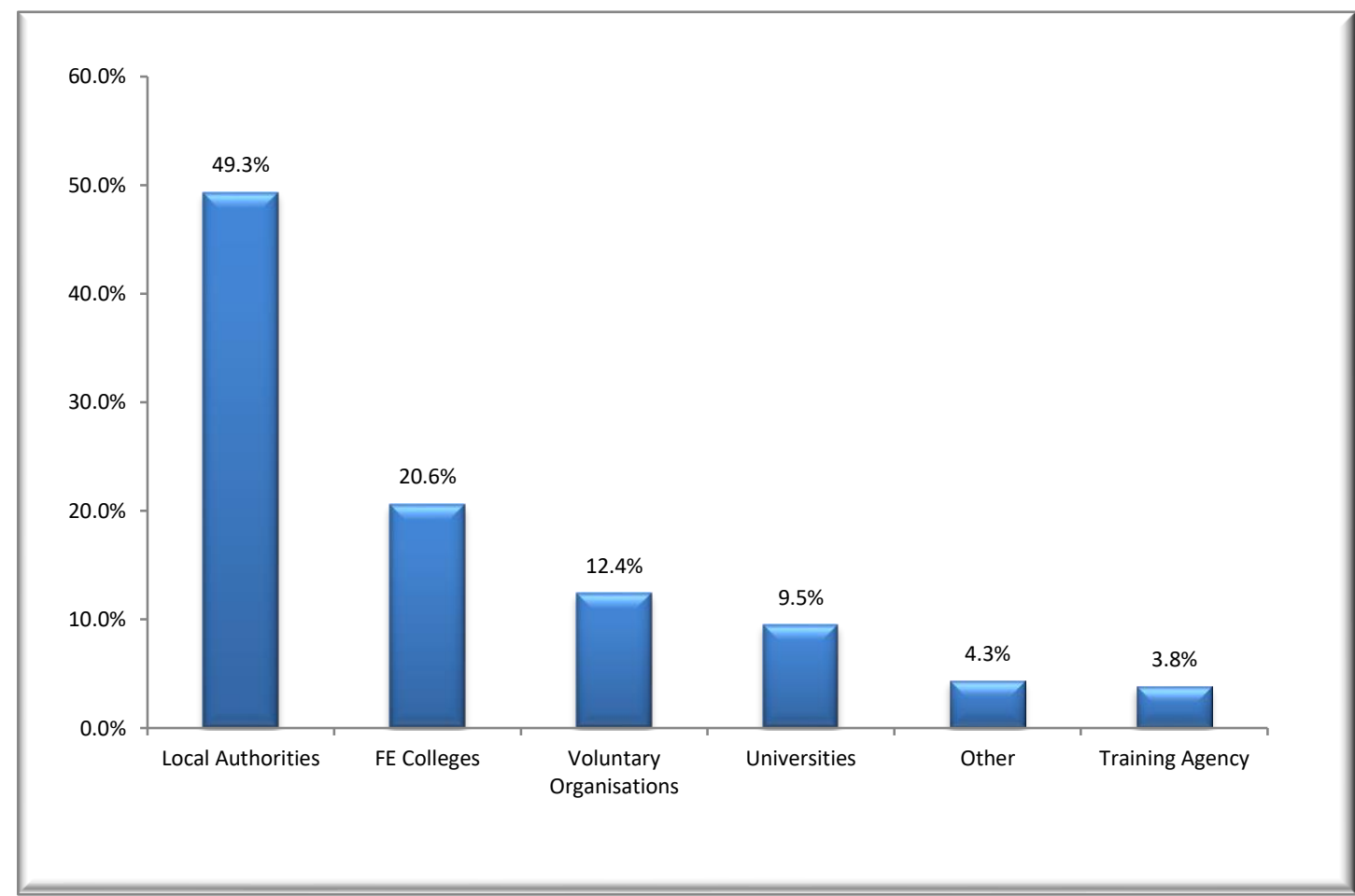

*258 respondents answered this question and were able to select more than one option resulting in 442 responses collected.

The 'other' category in Figure 5.6 above, included 6th form private school, freelance language school, Communities First and the health service. 
Fig. 5.7 Curriculum areas that tutors teach/train (352*)

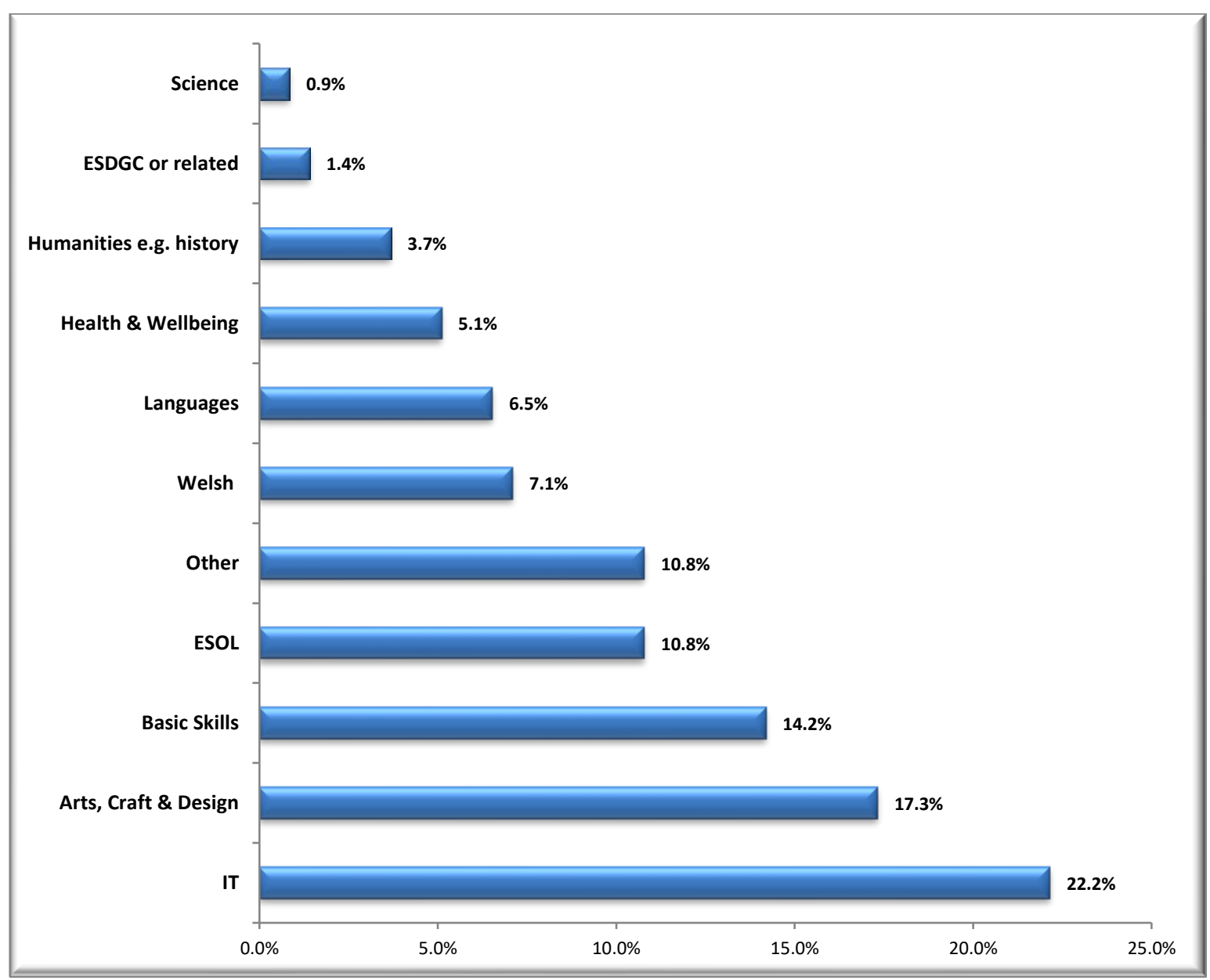

*242 respondents answered this question and were able to select more than one option resulting in 352 responses collected.

The curriculum areas are those used by the local authorities and FE colleges. However, tutors identified many other subject areas that did not fit easily or obviously into these categories. Many teach in more than one curriculum area. The 'other' category included: absorption curriculum for asylum seekers, refugees and other immigrants, yoga, business administration, first aid, fitness and dance, food and hygiene, health and safety, food technology, creative writing, facilitation skills to voluntary groups, personal development, confidence, sugar-craft and cake decorating and 'land-based' topics. Three people taught trade union studies, three worked with youth, three taught music, two taught cookery, and two taught gardening.

Tutors were asked if they taught or ran any ESDGC-related courses and 23 people took the opportunity to state that they were incorporating ESDGC into their lessons. These included $\mathrm{IT}$, business studies, Welsh for adults and youth work. Two tutors stated that their work 
involved international dimensions and they related this to global citizenship, and two tutors said they advised or helped others to deliver ESDGC and embed it into their work.

$66 \%$ of tutors had heard of ESDGC and this was closely aligned to the $70 \%$ who said they had undergone some form of training in ESDGC (see 6.4).

\subsection{The ACL sector in Wales}

\subsubsection{Challenges for the ACL sector - a Cinderella service}

It is worth recalling the policy and funding issues faced by the ACL sector in the period 2008-2016. Whilst it is not possible to give a comprehensive account of the strategic and physical delivery infrastructure of $A C L$, a summary of responses from the different sectors delivering ACL provides background and context for the discussions that follow.

Adult Education practitioners were, in the words of a director of lifelong learning in a local authority, "Used to being the poor relation. It's a Cinderella service, non-statutory. Puts you at a disadvantage anyway". The ACL sector has never received the level of funding that the statutory and formal sectors receive. However, it has been variously supported and promoted by different political parties and differing political agendas and economic policies. At the time of the research, the sector was experiencing budget cuts as a consequence of several influences including the Webb review in FE (2007), which recommended directing spending towards provision for 14-19-year olds and the global imperative for economic growth and re-skilling. The financial constraints and policy changes impacted on the sector's ability to respond to new initiatives. An interviewee at policy level said:

The ACL sector in Wales is going through a torrid time: it is being decimated. As well as ESF (European Social Fund) funding ending and a lot of work going, other things are happening too. The Assembly is focusing on the skills agenda. We've seen a $20 \%$ drop in ACL learners in the last two years. ACL providers and centres are closing.

Concerns were expressed at all levels about the limitations and restrictions imposed on ACL by funding cuts and changing government priorities and the impact this was having on the sector's ability to engage with, and deliver, ESDGC. 
Changes in the policy landscape were affecting ACL provision, and this was remarked upon many times in the interviews at the macro, policy level of influence and by strategic managers at the meso layer. Funding was being directed at vocational courses, and classes seen as 'leisure' were not being funded. Practitioners, particularly strategic level managers, complained about political agendas that were constraining ACL and the sector's capacity to engage with a broader range of issues through innovations such as ESDGC. One of the Policy level interviewees said that "ACL has lost the issue-based learning, the sort of critical thinking style, because the funding doesn't enable that to happen as much. Some are still doing it, but not much really."

The strategic ACL partnerships were being established as I embarked on the empirical research; this was in line with a directive from the Welsh Government. All sectors were represented on the partnerships and their remit was to co-ordinate and strategically plan ACL provision in their regions, and to provide evidence and intelligence to inform and influence policy. Each ACL partnership is autonomous, responding to regional needs. Priorities and approaches differ depending on the membership and representation. The discussions at the five ACL partnerships visited varied greatly, from a distinct lack of interest at some, to enthusiasm and practical engagement in others. One senior manager who was coordinating a partnership said:

We are focusing on equality and diversity in our strategic plan. This is the focus and there is only so much you can do. Actually, ESDGC is there (in the plan) but only a sentence. We have not addressed it! There were not many places to include ESDGC. It was Estyn that gave clear guidelines for this. It is about equality of opportunity and the diverse communities of Cardiff. We are multicultural, and yes, I suppose we can make links with global citizenship through this, but we are not linking it to ESDGC. (Senior Manager)

This comment highlights several issues: the pressure practitioners are under to deliver various policies, the separation between policies and issues and possibly the perception of ESDGC as a predominantly 'green' or 'eco' initiative. Global citizenship, and the way in which equality and diversity are embodied in the concept, was not seen as an opportunity.

In south east Wales, the partnership had a higher representation from $\mathrm{HE}$, and possibly as a result, the discussions focused on infrastructure and policy issues. This ACL partnership acknowledged that the way in which ACL provision is organised and delivered across statutory and voluntary sectors poses challenges for policymakers and they concluded that the diffuse and fragmented nature of $A C L$ was one of the main reasons why ESDGC had not been embedded effectively: "It is an artificial, civil service way of dividing things out" 
according to one senior manager. Members of that partnership suggested adopting a post16 approach, and the chair commented that

Dividing it into sectors is perhaps not the best way to organise ESDGC. Why not have a post-16 approach? Then it would be easier sharing resources and good practice and systems. Why can't we have a more joined-up and efficient approach? (Senior Manager)

Another senior manager commented that difficulties arose because of having to negotiate between different Welsh Government approaches, policies and documents within post-16 learning.

There is too much disconnection between the policies and strategies. In my own college, DCELLS are expecting us to develop separate approaches to ESDGC for WBL, for FE and for ACL work. There should be one integrated approach. There is also not enough attention to how learners will develop their ESDGC skills as they move between educational sectors. (Senior Manager)

Senior managers across all sectors felt that ESDGC needed to be recognised as a priority within institutions and organisations at a senior executive level if it was to become embedded in practice and policy. However, whilst meeting with the ACL partnerships, it was apparent that ESDGC was not part of their plans, there was no lead from the Welsh Government and no imperative to embed ESDGC into planning priorities. The head of a lifelong learning service in a local authority felt strongly that if ESDGC was built into the service plans of institutions, then it was more likely to become integrated,

Let's have ESDGC as a core principle, at the beginning of everyone's plans: the service plan describes, it spells out what the priorities are, what we want to achieve across the service in the county over the coming academic year and how we will go about using the resources, e.g. targeting Communities First. There is no guidance on this [for ESDGC]. (Senior Manager)

Initial thoughts about ESDGC were about recycling and running energy-efficient buildings, but $\mathrm{ACL}$ is not located in one institution or in a building. A great deal of provision takes place in community venues, and therefore, providers are not always in control or able to influence the running of buildings where courses are delivered. This issue was mentioned in a policy level interview:

Initial thoughts about what' sustainable development education' was all about, about recycling, putting switches off, running buildings efficiently. These were the initial ideas about what it was all about, and a lot of $A C L$ is not in a building they own, they do not have control over; not something they can use with their students. 
Practitioners were, however, taking the initiative. For example, a community centre in the Vale of Glamorgan had Fairtrade coffee machines installed and a Carmarthen centre was purchasing fair trade beverages; they prided themselves in their fair trade policies and procurement practices. Some centres were working on reducing paper use and on lessening their carbon footprint: "This is a 'green' centre. Paper cups instead of polystyrene. It is more expensive, so to do all we want, or could do, would be too expensive. We don't have the budget, we do what we can" (Operational Manager). Unfortunately, when asked about how they were linking these developments with learning it was apparent that this was not happening in any of the centres visited. Wider issues and learning opportunities were being missed. For example, fair trade was not being explained to centre users and the issues associated with paper and polystyrene and waste and consumption were not explored with learners.

The ACL sector has a complex infrastructure which was not fully comprehended by those developing policy at the Welsh Government. I was told by a member of the ESDGC panel that "The civil servants at DCELLS who are supporting this have no idea about the ACL sector and how it is structured", and this situation gave rise to difficulties and continued tensions. In the ACL sector, a particular constraint and challenge was the employment terms and conditions of tutors across all sectors; the majority of tutors are employed on a part-time basis and paid an hourly rate. Higher education does offer some part-time contracts, but they are far and few between. Tutors' employment terms have a considerable impact on their ability to dedicate time to ESDGC and to researching new curriculum. Most tutors must undertake continuing professional development (CPD) and develop new courses and programmes in their own time. "The fact that tutors are not employed full-time, paid by the hour and have no job security is a big issue. How can we expect them to attend training?" (Senior Manager). Whereas those working in ACL saw this as a problem, it was not recognised as being of significance by those at policy level in the Welsh Government. The point was made that "WAG just does not get it. They just don't understand the situation in $\mathrm{ACL}$ that tutors are generally not full-time employees like teachers" (Operational Manager).

Each of the educational sectors delivering ACL has strengths and weaknesses and expressed different concerns about ESDGC and its implementation. Each sector has slightly different priorities and approaches, and they were able to engage with ESDGC in different ways and to varying degrees. For example, $\mathrm{HE}$ and FE deliver undergraduate and 
postgraduate courses but also deliver $\mathrm{ACL}$, community development and some youth work courses on campuses and in community venues. NGOs each have their own remit, expertise and approaches to delivering ESDGC, including delivery through personal development, global education and development education, whilst local authority and FE provision has a broad curriculum (See Fig. 5.7) and is delivered in community venues. The following sub-sections summarise the specific issues and priorities in the different sectors based on responses from managers and from the discussions at ACL partnership meetings.

\subsubsection{The voluntary sector}

Three voluntary sector organisations working in ACL in Wales engaged substantially with the ESDGC strategy: Cyfanfyd, NIACE Dysgu Cymru and the WEA. All three are membership organisations. About $20-25 \%$ of Cyfanfyd's work is in ACL and the WEA and NIACE Dysgu Cymru both work exclusively in ACL. These three organisations collaborated in producing the Common Understanding for ACL (Welsh Government, 2012). NGOs felt that they had not been adequately involved in developing the ESDGC strategy, given that some had been working in this field for many years. "The strategy has left out the voluntary sector. Such a missed opportunity" (Senior Manager in a Local Authority). This is an ironic situation, when considering that the initial drive for ESDGC came from NGOs, from the RSPB and Oxfam. Another person in a policy level interviews said:

The voluntary sector has been side-lined, even though they have a lot of the expertise, especially in the global aspect. Not many people know about this, not many people working in this field and there is a lack of expertise in this area. It is complicated in ACL, and ESDGC is a big and complex thing, there is not a lot of expertise around, I am optimistic though.

Cyfanfyd, as an umbrella organisation for development education in Wales, has considerable expertise in ESDGC. Cyfanfyd staff were critical of the approach the Welsh Government had taken to developing and implementing policy and critical of the ESDGC strategy itself and the way concepts were being communicated. It was delivering training to practitioners across education sectors and had been leading on development and global education in Wales since 1991.

The WEA has a long tradition of adult education and its approach to adult learning is summed up by an interviewee as follows: "student-centred, getting students to think for themselves, responsible for their own learning and own actions" (WEA). This reflects a self- 
directed, empowerment model of adult education (Brookfield, 1986; Brookfileld \& Holst, 2011; Knowles, 1980; Knowles et al., 2014; Merriam, 2001) and is discussed in Chapter 8. The WEA merged with the YMCA Wales Community College to become 'Adult Learning Wales' in 2016; it is the largest provider of adult community learning in Wales.

At the time of the research, the WEA were actively delivering ESDGC training and courses and were collaborating with Cyfanfyd on developing practitioner networks and with Agored Cymru on developing ESDGC units and accreditation. Agored Cymru (previously the Open College Network) is an awarding body which offers 'Credit and Qualification Framework ${ }^{411}$ approved qualifications. A senior officer at Agored with responsibility for ESDGC was interviewed and spoke of three areas of activity. They were supporting the development of units and qualifications in practical subjects such as traditional building: "We have people wanting to do traditional building, lime rendering, practical things. This is more artistic, more practical, about skills, doing something useful" (Agored officer). They had an ESDGC tick-box for those developing units to ensure that ESDGC was embedded in module outlines and they were accrediting training courses run by other organisations such as Cyfanfyd and the WEA. ESDGC was one of NIACE Dysgu Cymru's strategic priorities, but they were not taking a lead in this area because they felt that they did not have the background or expertise. NIACE Dysgu Cymru had identified key priorities, one of them being ESDGC. However, basic skills was taking priority as the focus of policy and curriculum developments. They confessed that they had not done as much as they would have liked to in connection with ESDGC.

The different approaches taken by the formal and informal sectors were highlighted repeatedly by some policy level interviewees. One respondent said: "Whilst the environmental sustainability agenda is widely promoted, there is limited promotion of the specific ESDGC policies and strategies outside mainstream formal education". The perception of respondents from the voluntary sector was that those working at the Welsh Government had very little knowledge or understanding about the work they did, and consequently the voluntary sector felt that their expertise and experience was being ignored, undervalued and underused. A senior manager with a strategic role said:

The voluntary sector provides energy and innovation. We are being eroded, we are too awkward. A missed opportunity. The voluntary sector for 20-30 years has been

41

http://gov.wales/topics/educationandskills/qualificationsinwales/creditqualificationsframework/?la ng=en 
working in this area: they drove the whole agenda. What we have is very skilled people, a lot of whom we are losing, or we've lost, people who've worked in this area, people who are ... you know, development studies degrees with lots of teaching experience, and that whole expertise is being ignored.

The voluntary sector has always had a pivotal role in ACL; it is a fundamental part of the policy and delivery infrastructure. ACL has its roots in the voluntary sector where it was primarily delivered through Sunday schools in the 19th century and through the WEA in the 20th century before becoming part of statutory provision.

Following the publication of the ESDGC strategy, each education sector produced a Common Understanding document, intended to provide starting points and good practice examples for use at a local level, "because each sector is holding such different ideas" (Policy level interviewee). In the ACL sector, Cyfanfyd, NIACE and the WEA organised a consultation event with practitioners across the $\mathrm{ACL}$ sector in Wales and together wrote the draft document. They felt that the Common Understanding had to bridge a conceptual gap and provide a more theoretical outline of principles and ethos which was missing from the ESDGC strategy document. They wanted to underline the traditions of citizenship studies, international solidarity, radical activism, class struggle and learner empowerment in adult education; they were concerned that the interpretation of ESDGC had been 'shallow' and wanted to imbue the Common Understanding in ACL with more depth and a critical underpinning.

In contrast, and in opposition to this, the Welsh Government wanted a uniform suite of documents to be produced across all the education sectors. The document produced by the ACL sector was deemed to be too political and theoretical, and the Welsh Government did not feel that it was in line with the other sectors. In order for it to be published it required editing, and parts of it were rewritten with the final agreement of the organisations that produced it. One Policy level respondent commented "It is not what they [Welsh Government] want to hear; they [WEA, NIACE and Cyfanfyd] did get the views of the sector, they did not just go away and write it".

The suite of Common Understanding documents for schools, Teacher Trainees and New Teachers, FE, the youth work sector and work-based learning providers were produced quickly, but the Common Understanding in ACL was not published online until 2012 (Welsh Government, 2012). It contains an explanation of ESDGC and examples for teaching and learning, but no guidance had been available for ACL practitioners until 2012. Even though 
there are examples for embedding ESDGC into different subjects, there is not much practical guidance and information in the document.

Tensions were apparent between the Welsh Government and some people and organisations in the voluntary sector.

"We have argued ..."

"They just don't get it ..."

"They are difficult ..."

Cyfanfyd, who were experienced in delivering ESDGC, did not welcome being told what ESDGC was, and saw their role as a critical friend to the Welsh Government. There were comments on the irony that government was not open to criticism when so much emphasis was placed on developing critical thinking skills.

We are not unsupportive, but it is not healthy if we all take the government line in ESDGC or anything else. We regard ourselves, in terms of ESDGC, as a critical friend of the Assembly. We have been involved in developing the original strategy and feeding into various developments in ESDGC; but we do think that there are some aspects of it that need further development. Some of it needs to be re-emphasised, reviewed and revisited. (Senior Manager)

This person went on to speak about the lack of social justice discourses in ESDGC. Some of the tensions resulted from this, the lack of flexibility in reviewing the existing strategy and those developing policy failing to recognise how the voluntary sector in Wales had been delivering ESDGC before the term was coined. The sector felt marginalised and this created on-going difficulties with communication between government and the voluntary sector delivering ESDGC.

\subsubsection{Local authorities, further and higher education}

FE and local authorities employed about $70 \%$ of all $A C L$ tutors in Wales at the time of the research, and many tutors work for both colleges and local authorities. They often worked together and meet regularly, at conferences such as those organised by NIACE Dysgu Cymru or Agored, for example. There was a consistency across their provision and practice, and they shared similar concerns. The main concern that emerged from research with managers and tutors in these sectors highlighted the added burden and bureaucracy that delivering ESDGC represented for practitioners and a perceived lack of momentum by the Welsh Government in moving the agenda forward. 
FE and local authorities stressed the need for consistency and guidance on quality issues, and for them, social inclusion and the community development agenda were important. Ensuring that ESDGC was relevant and meaningful for all learners was a concern raised many times by senior and operational managers in these sectors: "What does ESDGC mean to people living on an estate? Let's start working with community regeneration" (Senior Manager). Community development and its relevance to ESDGC in ACL is examined as part of the findings in Chapter 6.

Senior and strategic managers in local authorities emphasised the need for consistency and communication between national and local government; their responses were often policy orientated: "I think it [ESDGC]should be a core principle of the service plan along with quality assurance" (Senior Manager). Local authority officers and development workers expressed most strongly a concern for the importance of embedding ESDGC, and they highlighted the good work that was already taking place. Some FE colleges were embedding ESDGC into their institutional plans. There was a level of enthusiasm for ESDGC from managers in $\mathrm{FE}$, and local authorities, there was more optimism than in the other sectors.

Gaining access to managers in HE during the research was problematic, and interviews that were conducted were brief, with very little discussion or questioning. Only a few individuals were taking an interest in ESDGC in $\mathrm{HE}$ departments delivering $\mathrm{ACL}$, and this tended to be primarily in sustainable development related curriculum. The ESDGC panel member for HE was also the lead in the UNESCO Regional Centre of Expertise (RCE) in ESDGC based at Swansea University. He was not available to take part in this research and it was not possible to find out about any work relevant to $A C L$ that had taken place in and through the RCE.

Some practitioners in HE institutions spoke about established courses such as geology, botany, garden design, conservation management and ecology as the obvious places to integrate ESDGC into the curriculum, but they did not give examples where this had been done. They reported that courses linked to ESDGC were not recruiting learners: "We've had to be more specific - more general environmental issues courses did not recruit" (Senior Manager), and there was an example of a 'sustainable development' course at one university not recruiting any learners. Some other institutions however, reported that certain courses were recruiting well, "We run courses like 'conservation', 'the edible landscape' and 'permaculture', these go down well, we work with the country park" (Senior 
Manager). Most of the responses were linked to environmental issues and sustainable development. Another university had obtained a DFID mini grant to work with TUC learning reps and the community, and they felt that this was having a positive response and impact. However, no details were forthcoming, as they had only just begun the project.

It did not appear that the integrated ESDGC message was being heard or implemented across the HE sector. A few keen individuals were developing work on ESDGC but there was not a great deal of evidence in HE of ESDGC being delivered in ACL. It was patchy, and one head of department said, "I am not getting the message, and it is an important area, nobody has talked to me before about this". The provision and delivery of ESDGC in ACL in $\mathrm{HE}$ appeared to be 'piecemeal'; communication and promotion of ESDGC amongst $\mathrm{ACL}$ practitioners appeared inconsistent and patchy.

\subsection{Policy}

\subsubsection{The process of developing the ESDGC strategy - actors and levers}

The process of developing the ESDGC strategy prepared the ground and established a foundation for its subsequent implementation. Through focusing on the process of developing the ESDGC strategy, certain factors that respondents describe are highlighted and provide insights into the reasons why the provision and delivery of ESDGC in ACL was 'piecemeal'. The hopes and fears of practitioners are discussed and practitioners' perceptions during the introduction of ESDGC are evidenced through the data. This section introduces some of the key individuals and organisations involved in developing the strategy, who represented, or were involved with, the ACL sector. It discusses the 'sticks' and 'carrots' for implementation as described by the respondents.

The ESDGC Champion played a central role in creating and promoting the ESDGC Strategy. Along with Oxfam Cymru, she had, in her role as the RSPB education adviser in Wales lobbied the Welsh Government to take their responsibility for sustainable development into the domain of education. The lobbying was successful and resulted in her official appointment in $2006 / 2007$, although she had been working alongside the Welsh Government since 2004. An ESDGC panel was tasked with overseeing the development of the strategy and I was told that the first strategy was a distillation of their thoughts and 
that "The driver for ESDGC came from the environmental lobby getting together with development educators": the impetus came from the environmental sector and not, primarily from educationalists. Initially there were no teachers involved in the process.

Producing a strategy without delay was important. The Champion wanted to develop momentum and acknowledged that the original panel had been comprised of keen individuals who had "Moved things forward. The decision was made to go with the energy at the beginning". Some people on the ESDGC panel felt that "people would not have come together or paid attention if there was not a strategy or action plan", and so producing this became the primary focus.

The speed of the policy process was a concern, one person at the policy level said, "It's been done too quickly" and they added:

What is the rush? Need a longer term, 10 years, not have people bidding against each other for work. It has to be longer term and more of a whole approach but there is not the will in government. They do not see the point, and the Champion is pushing it through quickly. It will look good, but ....

Another person at the policy level commented:

It [the strategy] was put together quite quickly, the champion drove it. There was a consultation, but it was a bit late for ACL.

One enthusiastic comment that demonstrated support for the Welsh Government's approach and recognised the potential of ESDGC was this one from a senior manager in an FE college

Good work by WAG on this, they moved it on quickly. The strategy has raised the profile across the board; opened it up, opened up opportunities for practitioners' institutions and curriculum. In twenty years, I have never had the opportunity to incorporate global issues into teaching or the college in any way. (Senior Manager)

I was told that the formal sector owned the ESDGC agenda. Initially schools were the focus and "They could immediately see how this could be included into the curriculum" (Member of ESDGC panel). At first, this was through the environmental curriculum - the eco-school agenda. The ESDGC Champion spoke of how ESDGC was relevant to young people and to their future. It was not until the consultation on the draft ESDGC strategy in 2005 that the ACL sector was included, and it appeared from the interviews that they had not been previously considered. There did not seem to be an awareness of the ACL sector and the role it was playing and could play in developing work in ESDGC and delivering government objectives. 
Estyn were key players in the development and delivery of the ESDGC strategy. There was an Estyn representative on the panel during the development of the strategy and this person fed-back to a senior inspector who had overall responsibility for ESDGC and ACL at Estyn. The Welsh Government had been offering advice to Estyn, who did not have expertise in ESDGC. I was told that they had been signposted to documents and policies, and to books, manuals and guidance. Many of those interviewed at the policy level confirmed this situation.

Whilst ESDGC is not a statutory requirement. It is a major strategic initiative from the Welsh Government and is included in the Estyn common inspection framework. Funding from government to education providers is dependent on a successful inspection and is therefore a significant policy lever for embedding ESDGC into practice. HE is the only sector delivering $A C L$ that is not inspected by Estyn. It is, however, influenced by the Higher Education Funding Council Wales (HEFCW) and the Higher Education Academy (HEA), who also offer guidance on policy and practice. ESDGC is not, however, linked to funding in HE.

The possibility that "it could become Estyn's version of ESDGC" was a concern expressed by some senior managers, and Estyn as the arbiter of good practice and the body setting standards for ESDGC in ACL was called into question by a senior manager in the voluntary sector, who said: "Saying that Estyn inspectors, who don't know anything about it, are now the gatekeepers in Wales: this is ridiculous".

For FE and local authorities, another policy lever came directly from the Welsh Government, who, from 2008 to 2010, required them to make returns in their strategic plans on activities relating to ESDGC.

FE colleges required to report on what they are doing. The stick is Estyn inspecting. DCELLS and Assembly asking for it to be reported on, so we had that kind of driver and they were the drivers that I use internally in the college and in the sector as well. You can go to college principles and senior management teams and say, 'we need this, we are doing this for these reasons' and you can put in all the kind of principles and philosophical reasons you like - and some college principals were doing stuff, but others are doing it because they've got to. That is the reality of it; it's still a way in though. (Policy level interviewee)

This senior manager from FE understands the realities in that sector; how, due to many reasons including personalities, communication and college priorities there will be differences in the way ESDGC is embedded. 
Positive feedback on the process of developing the ESDGC strategy was rare. From the evidence obtained from practitioners, most were unaware of the process and it was only a few senior managers and those who were directly involved that commented. The speed of the process and the lack of expertise in ESDGC at a policy level were problematic.

It [the strategy] was put together quite quickly - the Champion drove it. There was a consultation, but it was a bit late for $\mathrm{ACL}$ and the voluntary sector, which has been side-lined, even though they have a lot of the expertise, especially in the global aspect. Not many people know about this. No experience. It is complicated. (Senior Manager)

\subsubsection{Representation, consultation and communication}

A lack of representation on the ESDGC panel emerged as a significant concern amongst $A C L$ managers across all sectors. Initially there was no representation from ACL. Black and Minority Ethnic (BME) or other minority groups were not represented either. Representation was a contentious issue.

In their research on ESDGC in the schools' sector, Bennell and Norcliffe (2010) also found unease regarding this. Their research confirmed the view that the initial appointments to the subsidiary panels, and to the main ESDGC panel, were somewhat arbitrary. During the period of years over which the policy developed, the panel did become more strategic, but continued to lack representation, particularly from BME groups and practitioners (Norcliffe \& Bennell, 2010: 11-12). In interview, four people commented on this, saying "No black people on panels and committees. No faith groups". Practitioners in the voluntary sector felt that this was a significant omission and it is likely that a more diverse representation on the ESDGC panel would have made a difference to the strategy and its implementation. A senior manager said: "I bang the drum for $\mathrm{ACL}$ and for the voluntary sector in particular, and what about Communities First and community development? All that work." The gaps in representation created a certain amount of antagonism from those working with groups and communities whose concerns were not included or articulated and whose work was not being considered.

It was, however, acknowledged that there were "difficulties associated with having representation at a national, strategic level from all the diverse groups in the voluntary sector that could have an interest in ESDGC" (Senior Manager), but there had not been a wide consultation or continued communication with the $\mathrm{ACL}$ sector in order to discuss and 
address the issue of the weak and limited representation by the ACL sector in ESDGC's strategic development.

The ESDGC Champion struggled to find effective points and lines of communication in the ACL sector. I was told that the Welsh Government found it difficult to get representation from $A C L$ on the ESDGC panel and it was not easy for them to identify individuals and organisations to work with. This was due to the disparate nature of the ACL sector and a lack of awareness among those working on ESDGC in the Welsh Government. An interviewee at policy level commented that "The concepts of ACL seem alien to those we are dealing with in DCELLS". They did not understand the different delivery models in the $\mathrm{ACL}$ sector and they were not conversant with its ethos and traditions.

"There is no one policy for adult education" (Policy level interviewee), this and the fragmented and sometimes nebulous nature of the ACL sector made it difficult for those working at policy level. It was "difficult to find appropriate individuals to join in the initial discussions, because of the low awareness about the whole agenda (in $\mathrm{ACL}$ )". There is no one body representing $A C L$ and it was apparent that this caused difficulties for policy development, dissemination and implementation.

In 2005 we had to formalize the strategy and tried to engage with the relevant people in each sector. This is when ACL came on board, but even then, when we were writing the strategy it was hard to find national players in ACL. There aren't, weren't as clear cut co-ordinating organisations. Sustainable development was not on their agendas. NIACE? Not really; Community Learning Wales? Not really. (Policy level interviewee)

Eventually, Community Learning Wales, which was a body representing ACL in local authorities, nominated the head of a local authority lifelong learning service to represent $\mathrm{ACL}$ in the statutory sector. This person did not think that the sector was adequately represented in this way though, saying:

I feel I've failed on the panel. Perhaps someone else ought to represent ACL, but $A C L$ hasn't got the same resources as other sectors and we are different, it is difficult. I bang the drum for $A C L$, but I keep saying to the Champion 'I do not represent the whole of ACL. What about Communities First, community development, the voluntary sector? Need to bring this all together. (Policy level interviewee)

It was impossible for one person to represent $\mathrm{ACL}$ across $\mathrm{FE}, \mathrm{HE}$, local authorities and the voluntary sector, but, from what research respondents said, the ESDGC panel had a particularly narrow and limited representation from ACL. 
During the consultation on the draft ESDGC strategy in 2005, it became apparent to $A C L$ practitioners that they had not been involved in deliberations: in the words of a senior manager: "The original ESDGC strategy was not going to have an ACL sector input". During the interviews, respondents recounted the way in which practitioners from the voluntary sector approached the ESDGC Champion and met with her. As a result of this meeting, new members were incorporated onto the panel, including some people who, if not representing ACL, had some links with it. These included the chair of Cyfanfyd (who retired before this research was conducted) and a representative from FE who was also responsible for county-wide $A C L$ provision. Others joined later, but representation for $A C L$ was weak and their role and the role of the panel was unclear, as indicated by this comment:

You know I get confused about why I am round the table. What am I supposed to be doing? What's my role? How do we $[\mathrm{ACL}]$ fit in? How can we disseminate? If I am sat round the table and don't know what I'm supposed to be doing, then how are other people supposed to know? (Policy level interviewee)

A substantial amount of ESDGC in the ACL sector was being delivered by NGOs, but "The voluntary sector was not included in the policy process, I don't think", according to one of the policy level interviewees. This led to tensions between the Welsh Government and practitioners in the sector: as a senior manager said during interview "WAG did not listen, to anyone, to the voluntary sector in particular perhaps". The ACL sector had been marginalized in the policy process and the voluntary sector had been particularly marginalized: "Well, I really think that what the ESDGC strategy hasn't done is ... what's been left out is the voluntary sector, particularly on a national basis, the national organisations that have been working with people and communities on these issues" (Senior Manager).

Lack of involvement at the strategic, policy level meant that the $A C L$ sector was the slowest to begin addressing ESDGC. The strategy suggested that "initial actions within the sector must focus on raising awareness at both a strategic level and through training to all course planners and tutors" (Welsh Government, 2008a: 71), but unfortunately, this was done in an ad hoc manner, without a coherent, strategic approach. Different organisations adopted different approaches, and there was no guidance from the Welsh Government.

ACL tutors commented on unfamiliar language and lack of clarity in the ESDGC strategy. The language used in the strategy was familiar to those who had worked in areas related to ESDGC, but it was not easy for practitioners "Acronyms like ESDGC and even the 
convoluted term in full are very obscure. Read George Orwell's 'Politics and the English Language' and let's have some straight clear language and not elitist, political jargon" (Tutor).

Comments such as "Have never heard of ESDGC" and "I know nothing about it" were common amongst tutors and reflected a lack of communication with practitioners at the micro level. Many said they did not know exactly what was expected of them and they wanted clarification regarding the Welsh Government and Estyn requirements. It was not until the Welsh Government commissioned a research study into $\mathrm{ACL}$ support needs in 2009 (Appendix A), that ACL tutors were consulted about this initiative. A tutor commented, "How on earth are we supposed to teach this? Does anyone know? We certainly have not been informed" and another said "I would like to know about how ESDGC policies are being developed. No one has come to my classroom to ask me about what practical issues they need to think about in developing the policies". It was not only tutors who had not heard about the strategy; one senior manager said: "We have heard so little about it. Who is communicating?" and a senior manager in HE stated that he had not heard about ESDGC.

\subsubsection{Conclusion - summary of policy issues}

This process of enacting a strategy for ESDGC in Wales was done swiftly and efficiently. However, from the evidence from interviews at the policy level and from the data obtained from ACL managers and tutors, it was evident that many elements were not duly considered. The ACL sector and the groups with which they worked were not involved in initial deliberations and the sector was not adequately represented in the policy process. If there had not been overtures from the $\mathrm{ACL}$ sector to the ESDGC panel during the consultation process, the sector might not have been included. $\mathrm{ACL}$ was a late arrival in the development of ESDGC and this did not stand the sector in good stead for implementing the strategy and embedding ESDGC into their practice; they were disadvantaged from the beginning.

A lack of clear communication between the Welsh Government and the sector was due to several factors. The two main ones that emerged from analysing the data were the complex and disparate nature of the sector and a lack of knowledge and understanding about ACL at the macro level, on the ESDGC panel and in the Welsh Government. 
This section has shown how factors affecting successful implementation in the ACL sector were present during the process of developing and producing the ESDGC strategy. A lack of representation, consultation and communication represent, to an extent, barriers to the implementation of the strategy in $\mathrm{ACL}$, and the issues are particularly acute in relation to the voluntary sector, where a great deal of expertise in ESDGC resides. Respondents at a policy level and senior, strategic managers felt that as far as ACL was concerned, the policy process had been piecemeal, leading to piecemeal engagement by practitioners and consequently piecemeal delivery.

\subsection{Hopes for the ESDGC strategy}

This section focuses exclusively on practitioners' hopes and aspirations for ESDGC. Whilst delivering ESDGC awareness training to adult education tutors, I found that approximately one-third of tutors were resistant to ESDGC, seeing it as an added burden and resenting the imposition of this agenda from government. Another third would comply and try to do what was required and the remaining third were enthusiastic, feeling that it was important.

Despite the many dissenting and disgruntled voices, there was idealism and hope about ESDGC. One senior manager said, "This is a great idea and we are well advised to take it seriously", and this sentiment was echoed many times. "I think the message is getting through now, that this is not going to go away. We are not just doing it to tick a box, because your future generations, our future generations depend on us taking some action" (Policy level interviewee). The responses from managers, both senior and operational, indicated that stakeholders in $A C L$, including tutors and learners, were generally in favour of ESDGC being embedded into policy and practice "Learners and tutors are actively supportive of ESDGC in their local areas" (Operational Manager) and managers felt strongly that "Goodwill should be supported through investment and actions" (Operational Manager). They were optimistic that ESDGC could be incorporated or embedded into nearly all courses if there was investment and support for practitioners.

There is a great deal of good will for this, for what ESDGC represents. It could be good. So much more needs to be done though. Where is the investment? Some tutors are keen, but others aren't sure what it is and need training. (Senior Manager) 
There was an emphasis on the need to bring policy and practice in line if ESDGC was to be successfully implemented "I hope that it is given time and that it is automatically included in curriculum and in the authority's policies - there needs to be a closer link between the two" (Senior Manager).

The hope that ESDGC would contribute to behaviour and lifestyle changes was also evident amongst managers who said that they hoped ESDGC would provide "Understanding and changing behaviour in communities through ACL provision" (Operational Manager) and a senior manager hoped for "Continued improvement and awareness of the ways ESDGC can become part of the individuals lifestyle through ACL". Managers stressed their hopes for change and some saw $\mathrm{ACL}$ as having a strong role bringing about change: one senior, strategic manager noted "ACL is seen as a key stakeholder for change in public attitude to areas such as ESDGC".

Tutors and managers alike hoped for continued momentum for, and investment in, ESDGC, and many hoped that everyone, all tutors, managers and services could take on board ESDGC's aims. Ten tutors described the purpose of ESDGC as a 'raising of consciousness and awareness'. Tutors' hopes can be expressed under three main themes. The first is the hope that ESDGC would be seamlessly embedded into ACL policy and practice; the second is that ESDGC could and would contribute to a better world for future generations and the third is that it could help to raise awareness or consciousness. These are discussed in section 6.2, relating more to practice.

Those tutors who were doing work that they considered to be part of ESDGC, such as a community singing group, spoke of the positive knock-on effects of their work:

My work relates massively to the concept of global citizenship, as within my classes, self-generating small communities are created where people become motivated to be together and make every effort to do so in a fun and relaxed manner. They develop their "community" skills within the safe haven of the community singing workshop and this will hopefully have a positive knock-on effect with the way they deal with community issues within their own locality. (Tutor)

In opposition to these positive hopes, three tutors hoped that the Welsh Government and Estyn would desist from promoting ESDGC; their hopes were for an end to it!

An operational manager expressed optimism about the $\mathrm{ACL}$ sector collaborating to deliver the ESDGC strategy: "My hope is that the sector will work to make the values and principles underlying ESDGC a reality and that the sector will work together to allow ESDGC to 
develop naturally" (Operational Manager). Unfortunately, this approach was not visible and $A C L$ providers, although coming together in the $A C L$ strategic partnerships, were not prioritising collaboration on ESDGC.

Amongst policy level interviewees, it was envisaged that $\mathrm{ACL}$ centres and institutions would, as part of ESDGC, endeavour to use fewer resources alongside incorporating it into the curriculum. Practical action on sustainable development was seen as a good starting point and recycling as something everyone could do immediately. The optimism was about changes in behaviour and lifestyles. The ESDGC Champion and Estyn mentioned this approach many times.

Estyn promoted optimism and a certainty: "ESDGC is there for the foreseeable future in Estyn's plans". The Welsh Government saw the publication of the LLUK professional standards (LLUK, 2009) as a way forward in ACL. The professional standards were developed to provide a framework for tutors and other practitioners in post-16 education, and some policy level interviewees were optimistic that this would contribute to developing momentum for ESDGC in the ACL sector.

\subsection{Fears and resistance}

\subsubsection{Introduction}

This section highlights issues that practitioners and policymakers have described as concerns, which generally express themselves as fears, cynicism, resentment, resistance, doubts, pessimism and confusion. Responses point towards, and indicate, features that were inhibiting the implementation of the ESDGC strategy, beginning with the process of developing the strategy. This section addresses the research question on the background features influencing the development and implementation of the ESDGC strategy and the research question relating to the 'piecemeal' delivery of ESDGC in ACL is directly addressed.

A certain level of cynicism pervaded the ACL sector's responses to the ESDGC strategy, and there was a certain amount of resistance to ESDGC. One senior manager in a telephone interview commented that ESDGC was "A waste of time" but did discuss the strategy briefly. The strategy was being implemented by "some keen individuals" in this person's institution but no details were forthcoming. The head of one local authority ACL service 
would not engage at all with ESDGC; in a telephone interview he said that he did not see that it had any relevance and I was not invited to attend the ACL partnership meeting for that county. However, managers and tutors in this authority were sent information about the research and I received responses from them; the responses were consistent with those from other local authorities.

Tutors who did not believe that ESDGC should be part of the curriculum stated this strongly

"I hope that this will be removed from the curriculum"

"Gobeition bod Estyn a'r Cynulliad yn gwneud Ilai o ffwdan amdano yn y dyfodol" (Hope that Estyn and the Assembly make less of a fuss of it in the future)

"Gobeithiaf na fydd yn treiddio'n ddyfnach i'r sector. Hoffwn weld diwedd ar y fath wastraff arian" (I hope that this will not penetrate further into the sector. I would like to see an end to this waste of money).

\subsubsection{Cynicism and pessimism}

Practitioners had experienced the introduction of other initiatives which had not received continuing, longer-term investment and were, therefore, not effective. These innovations include Y Cwricwlwm Cymreig ${ }^{42}$, Entrepreneurship, IT, Equal Opportunities and Diversity. As a result of past experiences, practitioners exhibited a level of disillusionment with the Welsh Government. A tutor commented "This is just a tick-box exercise again - as with Cwricwlwm Cymreig - it will have a spurt of energy behind it, then gone, and we will not be supported".

The director of NIACE Dysgu Cymru summed up a feeling that many practitioners expressed, "People are cynical about Welsh Government producing a strategy and not following through, but not cynical about the agenda". Tutors were the most cynical, but managers also expressed pessimism. A candid remark from a manager was "Hopes? Don't have any. Pretty pessimistic" and a tutor flatly said "There is no hope!" and "Idealistic" and "impractical" was how some other tutors viewed the strategy; "It is more of a dream than a hope at the moment. I can always hope, but my expectations are low" (Tutor). Many thought ESDGC would be forgotten as other priorities and initiatives came forward from government; a senior manager was concerned that "After a year or two, it will not be as much of a priority, and slips away, just as other initiatives have in the past". From the

${ }^{42}$ http://learning.gov.wales/docs/learningwales/news/130424-cwricwlwm-cymreig-report-en.pdf 
outset, practitioners were sceptical about the long-term commitment of the Welsh Government: "it becomes a tick-box exercise and something else comes along before it has a chance to embed" (Operational Manager).

Lots of effort in the strategy, then nothing. So that probably adds to the perception that it is a hot topic, then probably ditched and move on to something else, because this has happened in the past. The danger with this, and anything, is that when you integrate it, more generally in policy terms, this is the aspiration, but sometimes things get lost, so it ends up being nobody's responsibility. It has happened with bilingualism. (Policy level interviewee)

Even supportive voices were tinged with scepticism and/or frustration.

This will come and go, just like a lot of stuff that comes out from government: it's a trend. Don't get me wrong, it's good, we all need to live more sustainably and become more aware of global issues but.... come on, who is going to take it forward? (Tutor)

At one ACL partnership meeting it was observed that "ESDGC is seen by many in the sector as 'flavour of the month'. Now we are already on to 'Learner Voice' which is the next Estyn priority" (Senior Manager). This point was echoed by several people at all levels who were aware that Estyn was shifting its focus, and it was likely that ESDGC would not, in the near future, receive the same emphasis or level of support. People understood that "ESDGC is an initiative that needs to be embedded, but as with all new initiatives it needs time for tutors and learners to consolidate the concepts and to adopt it fully" (Operational Manager), and practitioners commented that "This should be a long-term strategy" (Tutor).

A token gesture and a tick-box exercise to satisfy external requirements was a common perception amongst tutors, and policymakers were aware that managers and tutors could be doing ESDGC simply to comply with Estyn requirements without any understanding or enthusiasm. Despite this some wanted to do it justice:

Although it is obviously an essential element in current day teaching, it has to be presented to both tutors and students in a cohesive and persuasive manner, so that it is not viewed as some add-on element or as a box that has to be ticked. (Tutor)

Perceived hypocrisy on the part of the Welsh Government was one cause of resistance, and during teaching sessions, many tutors expressed concern that the Welsh Government was not acting in line with its sustainable development operating principle. Importing cheap South American beef for school meals instead of buying Welsh beef was one example given by a tutor, and another said: 
My College has very low green credentials (too much paperwork and duplication!). My hopes and expectations for the $\mathrm{ACL}$ sector are low, as they are with our society as a whole. Reduce emissions by 2050 ? Must be joking. We are a consumer society and economic growth at all costs seems to be a universal panacea. (Tutor)

This comment addresses macro political and economic issues and the need for a paradigm change if ESDGC is to succeed. This is addressed further in the discussion chapters ( $7 \& 8)$.

Some managers commented on and criticised the ESDGC strategy for taking an 'easy fix' approach, using recycling, gardens, fair trade and international exchanges as easy options. There was a fear that ESDGC could be "tokenistic", as one manager put it and "clumsy and counterproductive if done in this way". The more challenging approach that integrated concepts of sustainable development and global citizenship and that addressed political and ethical issues was not promoted.

ESDGC, if addressed fully, ultimately challenges the status quo and asks us to examine our assumptions, social values and norms "ESDGC is about changing the whole educational paradigm. It is impossible to do it, to teach it in an educational system that is against all that ESDGC stands for. It is silly". This statement was made by the director of an environmentally focused NGO working across all education sectors. Several practitioners working in ESDGC-related areas expressed this view, that there was a need to critically examine the education system and its values and challenge the status quo.

\subsubsection{ESDGC as an imposed agenda - practitioners' perceptions}

A factor in the resistance to ESDGC was that $A C L$ practitioners perceived it as an imposed political agenda albeit well-intentioned. As one tutor expressed it,"[lt is the] unacceptability of preaching about and imposing such an agenda"; this was a recurring theme. Some respondents, particularly from the voluntary sector, expressed unease that the Welsh Government was driving ESDGC in Wales. Tutors across sectors also expressed this unease:

Governments should not tell us what we should know. This is not healthy democracy. This is the Welsh Assembly banging on about something again, a political agenda. They are imposing it on us because they have to. How many really believe it? We don't have the time to do what we have to do now, let alone this as well. (Tutor) 
Both managers and tutors expressed the view that ESDGC had been imposed on them by a government that did not fully appreciate their situation and had not considered how it was going to be delivered in ACL. These are typical comments.

It is sometimes difficult enough for students to admit to the need for basic skills: it then seems unfair for educational bodies to insist on using the opportunity to preach to them about the government's latest favourite topic, no matter how worthy the subject may be. (Tutor)

and

Please don't burden us with more paperwork for these badly paid non-accredited courses that people come to for social reasons. How will more jargon and paper shuffling help anyone except those who are paid to create acronyms?" (Tutor)

The fact that the government was leading, and that Estyn had a strong influence on ESDGC was a concern expressed by heads of organisations, managers and tutors alike. "An imposition of someone's agenda without much explanation" (Tutor) and "Government propaganda" (Tutor) were comments in this vein. One senior manager in interview said, "When we talk on a UK level, there are some who are shocked that it has become a government agenda in Wales and that the government is controlling the agenda, and I see this as problematic".

Two people at the policy level said in interview that they felt that the policy would not succeed in the longer term without a continual feedback and review mechanism, but there was no sense that there were long term plans for this to take place.

It's a bit like women's education. You have to keep revisiting it. You can't say ' we've just ticked the box'; it is an evolving process. You will get new people on board and you know. Why do we need it? Got to keep asking. Women have got equality, so we don't need to be doing that anymore? It is critical thinking again. (Policy level interview)

There was a view amongst NGOs that the government was not open to criticism or to reviewing the strategy. NGOs working in ESDGC-related areas wanted to be more closely involved at a strategic level and wanted a dialogue with the Welsh Government. However, those developing the ESDGC strategy did not see this as a priority. 


\subsubsection{Learner and tutor autonomy}

A concern for learner autonomy and learner needs was frequently expressed by practitioners, particularly tutors. This issue overlaps with the perception of ESDGC as an imposed political agenda. People pay for and attend adult education classes to learn about a subject; they attended for a variety of reasons, and ESDGC was seen as impinging on the rights of learners. "ACL courses are seen as something people choose to do and they do not want this imposition. We would like support in managing this learner autonomy issue" (Senior Manager). Another manager commented that "adult learners, they have chosen to use their time and money in a particular way. There is enough of a challenge engaging learners anyway" (Operational Manager), and the introduction of ESDGC without consultation, was perceived as undermining the efforts of the sector to recruit adult learners, many of whom were wary of the educational system, having been failed by it and in need of accessible and supported routes back into learning.

Managers were concerned that "ESDGC is imposed on the sector and that the 'rights' of adults to attend an ACL class for their own purposes is compromised by artificially imposing ESDGC on the curriculum" (Senior Manager). A tutor put it this way: "it is another method of government interfering in the real education, i.e. giving people the information and abilities to make their own decisions and decide their own directions" (Tutor). The following comment covers the issues of learner autonomy and the linked perception of ESDGC as an imposed political agenda:

A balance must be struck to recognise that adult learners are more concerned with learning and should not be deterred from doing this because of side issues (measures) that are not important to them as individuals. Learning must be enjoyable and productive and ESDGC should be part of this process without becoming too much of a political issue. (Tutor)

An important point was made by a senior manager, who commented that:

The social interaction, and meeting friends, and getting out, and all that kind of benefit is what a lot of $A C L$ is about, so, the danger is that you impose ESDGC on them, and say 'now you have to learn about the seven ESDGC themes'.

These views highlight the fact that practitioners could not see the relevance of ESDGC and how it could contribute to, rather than detract from, learning. They saw it as an add-on and as extra work, and a tutor made the following point: 
We need support, not extra work. At present I have to include ESDGC, Welsh Language and culture and Basic Skills into an IT class. The difficulty I face is selling these 'extras' to fee-paying learners, as they see this as using their IT time for something that they would not have agreed to and don't want to pay for.

Some tutors wanted to be able to embed ESDGC unobtrusively, seamlessly and meaningfully so that it would not detract from learners' purpose for attending courses, but they did not feel confident or supported to be able to do this.

Although they might be open to it and agree with it, it's that challenge of getting it into their courses in a meaningful way, which doesn't get in the way of their main goal in terms of coming on a course. (Tutor)

The resistance that ESDGC engendered was partly because tutors felt that the issues were being 'pushed' or 'forced' onto them and onto learners. This perception is illustrated in the following comment:

I feel as if I am teaching learners to suck eggs, the majority of whom are mature responsible adults and who are equally capable of researching information on recycling or global citizenship. Learners want to come to class to learn about IT, not about climate change, which is being pushed at every available opportunity until we are at the point of ESDGC overload. (Tutor)

The perception of ESDGC as an imposed agenda also caused tutors to feel as if their professional autonomy was being undermined and even under threat: "Let tutors do their job, teaching the subjects they signed up for" (Tutor). They wanted to be "trusted to respond to students' needs" (Tutor). One comment from a tutor makes a very strong point regarding professional autonomy.

The premise that the autonomy of teachers to decide what appropriate content is, is disappearing and being dictated according to a very political agenda. This development is scary and fascist, reducing the ability/right of individuals to think for themselves. We are supposed to educate people in order for them to be able to learn, think and come to conclusions of their own accord rather than dictate. (Tutor)

Tutors, in the main, wanted to be left alone to teach their subjects; they wanted to be supported and trusted by their employers to do the best for learners. They felt that their professionalism was compromised.

I am sorry to disappoint, but I just like teaching people to paint and draw and I am not interested in any of the political aspects/tutor developments/etc. I also run a successful business in my own studio, both painting and teaching, and all this extra stuff just puts me off teaching for the community ed. sector, although it is a job that I love. (Tutor) 
A few tutors spoke about the importance of the issues, but many others could not see the relevance of ESDGC and thought it was detracting from what they wanted to teach and what people were there to learn.

I do not see it as my role to incorporate ESDGC into teaching a group of ladies, mostly senior citizens, who have come to learn a craft which they enjoy as a hobby. I have discussed your document with both of my classes and they all see it as highly inappropriate for them. (Tutor)

In the focus groups, where there was a range of people in different roles within $A C L$, including senior and operational managers, development officers and some tutors. The discussions on learner entitlement and autonomy split the groups 50:50 with one half feeling that ESDGC was important enough to be imposed. The imposition, however, came with extra work, which practitioners were not always happy about.

\subsubsection{An added burden?}

As well as seeing ESDGC as an imposed agenda, practitioners at all levels across all sectors commented on the added burden it represented. This included the bureaucracy and the additional preparation and learning involved, particularly for tutors. "Wish it was not imposed on us. I am too busy as it is" (Tutor) and "Concerned that it will add to my already strained schedule for the sake of more jargon and bureaucracy!" (Tutor) were typical comments. Managers recognised and acknowledged this added burden on overworked tutors; the challenge was "How to translate policy into practice without it becoming a burden but being a positive thing to do" (Operational Manager). Managers were concerned that "Part-time tutors are already stretched and have minimal preparation time and will need to condense more information into a short course" (Operational Manager).

The other cross-cutting themes that must be embedded along with ESDGC into schemes of work in ACL represent added work for tutors "As with the inclusion of Welsh cultural content that was an outcome of a recent Estyn inspection, my anxiety is finding time to locate appropriate content and revisit existing resources to incorporate new material" (Tutor). Another tutor expressed the same concern "To address all of the cross-cutting themes, of which ESDGC is one, in the short time available for most adult courses, well it can feel like a tall order" (Tutor). 
Tutors certainly felt overburdened and had little incentive to take on the extra work: "Too much is expected of tutors who, in return, have no financial or job security" (Tutor). Changes in $\mathrm{ACL}$ meant that tutors were being forced by the current framework to accredit 'leisure' classes, and this added to their work and something learners resented: "Students already resent OCNs [Open College Network credits] for what they perceive as a leisure class and that anything extra which takes time away from their chosen focus [ceramics] will also be resented" (Tutor). There were other directives and initiatives from government such as basic skills and health and safety that also had to be incorporated into their schemes of work, along with the cross-cutting themes.

Not having the time necessary to embed ESDGC was an issue for tutors. Supportive tutors wanted to be in a position to research and explore the possibilities for ESDGC and embed it into their lessons, but "Already have severe time restraints to deliver curriculum as it stands" (Tutor). As one senior manager said: "Tutors feel stressed trying to catch up with everything. The joy of teaching is going!"

The time for $\mathrm{ACL}$ classes is minimal; the curriculum is being packed with skills and wider issues that many part-time tutors have difficulty keeping up with; integrating these components is a step further. We need funded time for training staff, and further time for tutors to prepare teaching resources. (Senior Manager)

In addition to the need for time and support to embed ESDGC, some tutors felt that a great deal of knowledge and new skills were needed: "It requires a lot of skill on the part of a tutor to integrate all of the themes in one short session, maintain ILPs (Individual Learning Plans) and still deliver the core" (Tutor). This perception, coupled to the lack of support and resources available to them, contributed to a lack of confidence amongst practitioners. This is among the findings discussed in Chapter 6.

\subsubsection{Conclusion - summarising hopes and fears}

From resistance to faint pessimism, the fears and concerns of ACL practitioners were often linked to the belief that the ESDGC strategy was not supported by long-term resource allocation and that it was a tick-box exercise. Other initiatives and cross-cutting themes had been introduced and subsequently not received support or become fully embedded in practice. The jaded outlook of practitioners was therefore understandable. 
ESDGC was frequently perceived as an imposed political agenda and an added bureaucratic burden on overworked, part-time tutors. Practitioners across the sector expressed a concern for learner autonomy, which was a one of the main points of contention amongst tutors and some managers. Tutors felt their professional autonomy was threatened, as they had not been consulted or involved in deliberations about policy or translating it into practice; this left practitioners feeling disempowered and disillusioned, lacking confidence and direction.

Managers expressed concerns at a more strategic level than tutors, pointing out the need to incorporate ESDGC into institutional and national policies and strategies. Overall, managers were more optimistic, possibly reflecting their professional, managerial and leadership roles and their relative proximity to more strategic, policy issues. They also expressed more confidence in being able to take the agenda forward (See Fig. 6.3), again, this could be because of their professional roles and their access to documentation and information on ESDGC which was not readily accessible for most tutors.

Concerns and fears for ESDGC outweighed hopes; they underline the features that were contributing to the 'piecemeal' delivery and provision of ESDGC in ACL and point to where things need to change and inform future developments.

\subsection{Wider policy issues - lack of strategic integration}

ESDGC has relevance to, and overlaps with, many other priorities of government, including health, poverty, civic participation, carbon reduction, resource efficiency and environmental protection and enhancement. Even though 'poverty' and 'health' are key themes in ESDGC and tackling poverty and health and well-being are both strategic priorities for the Welsh Government, they were not linked.

Communities First ${ }^{43}$ is a key Welsh Government programme aimed at tackling poverty. It provides funding for lead delivery bodies within local authority areas to narrow the economic, education/skills and health gaps between the most deprived and more affluent areas in Wales. Learning is one of the three strategic objectives, which are expressed as: prosperous, learning and healthy communities. The programme works with eligible communities: those that that have the highest ranking in the Welsh Index of Multiple

${ }^{43} \mathrm{http} / / /$ gov.wales/topics/people-and-communities/communities/communitiesfirst/?lang=en 
Deprivation. ${ }^{44}$ "Many projects going on in Communities First areas could be seen as good ESDGC, and we are not making the links or harnessing that. No talk of it on the panel at all" (Member of ESDGC panel). There were no representatives from community groups or from anyone working in community development on the ESDGC panel. The links were not made, even though community development and sustainable development have overlapping and integrated agendas (UK, Government, 2005; Tilbury \& Wortman, 2004, 2008; Warburton, 2013).

Some senior managers commented on the significance of community development organisations and the importance of working with them to achieve the goals of the ESDGC strategy "Communities First is involved in ACL. Some of the learning is informal, some is engagement, and some is formal. I think Communities First needs to have training and support if we are expected to do anything programme wide" (Senior Manager). Another local authority manager asked, "What does ESDGC mean to people living on an estate, Penlan [one of the poorer areas in Swansea] for example?" and a tutor said that "Some learners might think this is a middle-class issue, it's all right for you. Some people have more important things to think about, day-to-day concerns. But this is an issue for everyone" (Tutor).

The focus groups discussed ESDGC in the community and felt that "local people should be involved, local communities, local activities, links to community business and social enterprise should be made. Use everyday resources in classroom such as local newspapers. It must be organic development, local democracy" (Focus Group Discussion). Opportunities for different organisations to work together were identified in the focus groups, such as links with and between organisations such as Oxfam, community farms and community growing projects. The perceived lack of support at the macro level for creating links between ESDGC and community and local agenda was reflected in this comment: "Paying attention to people at the local level, to cultural differences that matter and shape community and its future. Government don't really want this" (Tutor).

One of the ACL partnerships in the South Wales valleys included representatives from community development organisations, and at the meeting with this partnership the lack of communication and coherence between community development, $A C L$ and ESDGC was discussed. There was a consensus that the integration of community development and

\footnotetext{
${ }^{44} \mathrm{http}: / / g o v . w a l e s / s t a t i s t i c s-a n d-r e s e a r c h /$ welsh-index-multiple-deprivation/?lang=en
} 
ESDGC needed to be addressed. Community practitioners felt that "Community development should be incorporated into ESDGC and vice versa" (Community Learning Officer). The chair of this ACL partnership commented that "ESDGC is most obvious in 'community development' and 'active citizenship' themes" (Senior Manager). Community representatives said that they had not been informed or consulted about ESDGC but would have welcomed involvement, as they could see its relevance to their work. "Right now, it is very vague for organizations like Communities First, who are not $\mathrm{ACL}$ providers but involved in $\mathrm{ACL}$ " (Community Learning Officer).

ACL has traditionally worked with those 'furthest from the labour market', 'hard to reach individuals and communities' and people facing multiple deprivation, to use only some of the policy terms. It is a sector that knows how to engage with people and how to make learning relevant and interesting so that people embark on learning journeys. ACL had traditionally provided 'stepping stones' back into learning and education for people and ESDGC could be part of this empowerment agenda. This is the view taken by many community practitioners in $\mathrm{ACL}$ and community development.

My hope is to have proper recognition and support for the importance of involvement with the outdoors, food production and environmental issues in engaging 'hard-to-reach' members of our communities in education. The moraleboost such training results in is often the key first step towards further selfdevelopment and improved, usually highly productive, community involvement. (Tutor)

Working with communities was crucial for the success of ESDGC according to many practitioners, "A raised awareness and sharing of information in the community will contribute to making a difference" (Senior Manager), and another senior manager said that "Communities would be a good place to start working on ESDGC". Community development and ACL practitioners were disappointed about the disjuncture between ESDGC and community development, which was seen as short-sighted. I was informed that "ESDGC and citizenship were removed from the Communities Firsts remit/terms of reference, from the vision framework" (Senior Manager).

Community development, we are not really harnessing that in the panel at all, and there are lots of projects that are going on in Community First areas that could be considered really good ESDGC activities. The Bryncynon strategy where they are converting oils into sort of bio fuels and ... well there's no way as far as I can see that that information is getting fed either way. Community development is engaging with harder to reach communities and looking at empowering people. (Policy level interviewee) 
One HE institution was working with community leaders and the TUC on embedding ESDGC, but this was the only example of a formal link with community development outside the voluntary sector.

A great deal of $\mathrm{ACL}$ takes place in communities, and community development is part of the ethos of $A C L$, but those developing the ESDGC strategy did not consult with, or include, people working in community development. NIACE Dysgu Cymru's director said: "We support the intention completely. If it was linked more closely to other strategies it would have a greater chance of success".

Those working in Welsh Government on the ESDGC strategy have no background in adult education, they do not seem to know anything about it at all, nor the community development work linked with lifelong learning. Surprised, I think, to find out that we did have a different take on it. (Policy level interviewee)

The TUC representative, in their interview said they were "keen on environmental impact and supported fair trade" but had not considered ESDGC. There were many areas of their work that aligned with ESDGC, particularly their international solidarity work, but they had not engaged with ESDGC and vice versa. This is an example of how the ESDGC strategy created a narrow view that excluded rather than created an inclusive, plural platform for change and transformation.

\subsection{Conclusion}

Practitioners' hopes and fears, their perceptions of ESDGC, the strategy and the policy process have been examined in this chapter, and features inhibiting the implementation of the ESDGC strategy in ACL in Wales have become apparent in the emerging themes. Certain features of the policy process contributed to a lack of engagement, and ACL practitioners and policymakers have described factors contributing to resistance or antipathy towards the ESDGC strategy. This evidence makes it possible to understand the varied reasons for the piecemeal provision and delivery of ESDGC from different perspectives.

Difficulties were evident from the inception of the policy process. What emerges is a picture of policy development that was hurried and lacked appropriate representation. A lack of communication between the policy level and the $\mathrm{ACL}$ sector stemmed, in part, from this initial lack of representation on the ESDGC panel, and from the fact that those developing the strategy did not fully understand $\mathrm{ACL}$ or the sector: this led to it being 
overlooked and to continuing difficulties. Some NGOs delivering ESDGC, felt particularly aggrieved, as many years of delivering ESDGC related work and expertise was not utilised.

The complex and fragmented nature of $\mathrm{ACL}$ infrastructure posed problems for policymakers, for policy development and implementation. As a senior manager said, "it's complicated, very complicated". A view from government which reflects a certain unease is: "The ACL sector is awkward". ACL is delivered by different institutions with different priorities and approaches, creating challenges for policymakers and for practitioners alike. Without a sector-wide strategic approach it was difficult to move the agenda forward.

In my own college Welsh Government are expecting us to develop separate approaches to ESDGC for WBL, for FE and for ACL work. There should be one integrated approach. There is not enough attention to how learners will develop their ESDGC skills as they move between educational sectors. (Senior Manager)

There was no clear sense of who was taking the ESDGC agenda forward. The ACL partnerships could have potentially offered strategic direction and support, but ESDGC was not part of their remit. Inclusion in local authority service plans would have potentially made a difference through giving it statutory leverage as mentioned by senior managers. A tutor also commented: "Angen i sefydliau a mudiadau arwain y ffordd" (Institutions and organisations need to lead the way). ESDGC was not being integrated into the ACL policy infrastructure. This demonstrates either an oversight on the part of the Welsh Government or that ESDGC was not a wider or long-term priority. Changing policy directives and funding cuts to the liberal curriculum in favour of the skills agenda exacerbated the situation and made it difficult for the ACL sector to fully engage with ESDGC.

Tutors expressed resentment towards what they perceived as the imposition of a political agenda and an added bureaucratic burden, when they were already overstretched to deliver accreditation. The perception of ESDGC as a tick-box exercise was evident amongst tutors and they were concerned for learner autonomy. These issues were not well understood by those in the Welsh Government seeking to implement ESDGC.

The perception of practitioners was connected to their experience of other cross-cutting themes that had previously been introduced, with the expectation that they would be embedded into practice. However, there had been very little follow-up and support for these and therefore practitioners, particularly tutors, were not optimistic about ESDGC being supported in the longer term. These perceptions and their significance in translating policy into practice are discussed further in Chapter 7. 
Although training for community development practitioners was mentioned as a future action in the ESDGC strategy (Welsh Government, 2008a: 75), they were not included in deliberations. This meant that adults engaging with $\mathrm{ACL}$ through community groups did not encounter ESDGC and the separation of community development and sustainable development at a strategic, policy level, impacted on practice and delivery. Failing to explicitly link strategic government priorities with ESDGC was reinforcing a separation between local and global concerns, and possibly contributed to the view that sustainability was about environmental issues and that development was a concept applied to other countries.

Adult education has the potential, through its reach, to influence many people: An operational manager in a local authority said, "We reach 2,000 adults on a weekly basis. We can have a big impact, a powerful impact on families, children and communities. We reach all sectors of communities, top professionals and the homeless". One can see immediately that there is the potential for a great deal of learning in line with the aims of ESDGC. Adults are able to exert influence in different spheres of life, as citizens, consumers, professionals and as parents: "If you want a cultural shift, well even if you influence schools, children, you still need to reach the parents. It is the home that the messages get to children and young people" (Senior Manager). The ESDGC Champion saw the potential of influencing adults and she could see the challenges of engaging adults. This statement from the policy level interviews illustrates this point: "The excitement in $A C L$ is that you have adults who are buying things, investing, spending money, living lives, making decisions. The challenge is that you are working with people who have set opinions and set lifestyles and choices". This statement does not allow for the transformative potential of adult learning where change is possible, and its affects are felt in families and communities.

It is true to say that the ACL sector did have a limited awareness of ESDGC, and the piecemeal delivery was in part because the sector became involved later in the policy process. Having said this, there were many groups and individuals that were and had been delivering ESDGC for many years, albeit in the guise of environmental education, development education, global education or peace studies for example and as part of good adult education.

The ESDGC Strategy refers to the similarities between ESDGC principles and adult and continuing learning approaches which may mask the 'latent' contribution of ACL. (Welsh Government, 2008: 70-71). One of the key areas for this latent potential has been 
described in this chapter as research respondents made the links with community development. This and other synergies between ESDGC and ACL are discussed in Chapter 8. 


\section{Chapter 6 \\ Practice, Practitioners and the Policy-Practice Gap}

\subsection{Introduction}

The primary concern of this chapter is the domain of practice and operational issues. There is overlap with the findings in the previous chapter because policy, to a large extent, dictates and directs practice. The features described by ACL practitioners that contribute to the piecemeal delivery and provision of ESDGC in the ACL sector become more apparent.

The first section examines the hopes practitioners expressed, followed by a description of the practical and operational features that respondents identified as being barriers to implementing the ESDGC strategy. Respondents' own words are used as illustrations and evidence. The situation in $\mathrm{ACL}$ is then discussed in terms of an identified policy-practice gap. Section 6.5 then examines conceptual confusion which provides evidence, when combined with insights from the literature review, that addresses the question on EGC being problematic in comparison to ESD. The chapter highlights more of the latent potential of ACL to ESDGC and concludes by looking at pedagogy, this then informs the discussion and re-conceptualisation of ESDGC in Chapter 8.

\subsection{Hopes for ESDGC - practice}

This section on hope for ESDGC is a relatively short one, as fears and concerns elicited longer and more nuanced responses. Hopes were often related to providing good teaching and learning experiences and tutors often spoke of hopes in terms of learner experience:

My hopes and expectations are towards my students: to raise awareness in a positive and constructive way, to enable and not to paralyze, to demonstrate and encourage responsibility within the close community and our global community. I want to set achievable targets and to make positive changes. (Tutor)

Many tutors wanted to make a positive difference, to raise awareness amongst learners, and particularly to help decrease carbon emissions and explore issues of identity and globalization. One tutor hoped that "knowledge of ESDGC issues will motivate ACL staff and learners to develop initiatives to help people in the Third World" (Tutor). This displays the 
deficit model and the concept of development as being linked to 'other' and 'different' people and cultures.

Some tutors expressed the hope of a better world for their children and grandchildren "I want to become more aware and secure the future for generations" (Tutor) and they commented on how they hoped ESDGC would contribute to a healthier, better and cleaner environment. They often wanted to "educate on the wider social/economic/environmental issues" (Tutor).

A number of practitioners saw how ESDGC could, potentially, contribute to a good general education. The comments below are examples of tutors' hopes.

"My hope is that ESDGC will be delivered seamlessly."

"My hope is for a better and healthier environment to live in."

"A greater understanding of what ESDGC is, and its implementation."

"My hope is that people will become more aware - and secure the future for generations."

"For awareness to be raised and for all tutors to include it within their working practice."

Two tutors expressed the view that they "would like to see this contributing to a broadening of learning and teaching experiences" and about half the tutors in the research hoped that ESDGC would become "a real 'live' topic and be completely integrated" (Tutor). One commented "I would like to make it an integral part of the courses I teach without it becoming the main focus" (Tutor). Supportive tutors wanted ESDGC to be embedded and taught "in an enjoyable way without it being forced into the curriculum" (Tutor). The hope was juxtaposed with the concern that ESDGC should not be forced or shoehorned into the curriculum and that it should be delivered seamlessly. One said, "It would be nice to have a group designed for coming up with and developing creative ideas for how different things could be included in a curriculum for ESDGC" (Tutor). The Common Understanding document went some way to providing this, but not enough to enable tutors to confidently and seamlessly embed ESDGC into their subjects.

Questions about anxieties and concerns elicited more in-depth responses than hopes and expectations, but optimism was apparent in the examples given by some tutors of activities that they were undertaking ( 23 in the questionnaire). These included the following: "I integrate ESDGC into my classes by encouraging my students to think carefully before printing anything"; "I undertake writing exercises for the Pembrokeshire Portal with an 
ESDGC theme"; "I have taught classes and run workshops about using recycled materials in art and craft", and an ESOL tutor commented:

Since I work with people with many different backgrounds from all over the world and introduce them to everything they need to fend for themselves and continue to improve by themselves here in Wales (and the UK as a whole) after they have left my hands it seems that I am involved in Education for Sustainable Development and Global Citizenship. (Tutor).

Managers' hopes were expressed slightly differently to those of tutors. They were more straightforward in that they were concerned with either policy or practice and hopes and fears were more closely linked. Hence many of the managers' hopes are integrated into the other themes within this chapter. Some examples include:

"A hope for improvement and consistency in the delivery of ESDGC" (Operational Manager).

"Financial support and resources developed for tutors across programme areas and direction given to managers" (Senior Manager).

"Hope that it will be embedded into the sector, but I fear that it becomes tokenistic" (Senior Manager).

\subsection{Practical and operational features}

\subsubsection{Lack of support and guidance for practitioners}

No matter how important tutors felt ESDGC was there was a recognition that to implement the strategy, support mechanisms, guidance and resources were necessary:

This is about very important issues, significant to all our lives; it will be a shame if we do not have the resources to ensure it is taken forward. I believe embedding it is what we are supposed to do. How can we do this without help and guidance? (Tutor)

Both managers and tutors felt an acute lack of practical and strategic support for implementing ESDGC, expressed from their different professional and practical perspectives.

ACL managers felt sure that without investment from government, a deeper level of commitment from both full and part-time staff was not going to happen: "The policy/strategy is sound. The implementation is compromised by a lack of appropriate 
resources. It is a huge agenda, and we don't have the resources - particularly time - to do it justice" (Operational Manager). According to most practitioners, time and funding for staff development were the main enabling priorities. One of the policy level interviewees said, "Again it is because ACL does not have the resources, more than any other sector, it is on the periphery, other sectors have more resources to put into ESDGC delivery" and a senior manager at policy level said

So DCELLS and ESTYN gave ESDGC a high profile, but no resource or no kind of any real guidance about requirements, so there is a huge variety of responses - in effort and in resources - that go into it across the sector.

A tutor highlighted the issues of time and training: "We need the time to be able to develop this, it takes a lot of effort to embed new curriculum. We have not had training and no resources available to give us time or training". Not having the time to learn about ESDGC and to prepare lessons was a persistent complaint, and managers, who were aware of the workload of tutors and their pay conditions, wanted to be able to support them: "The tutor has a lot of work to do, so we need to make it easy for them" (Senior Manager). Managers wanted to effect change but were keenly aware of the need for resources to embed ESDGC.

Many tutors expressed the need for reassurance from the institutions they worked for regarding the integration of ESDGC into the fabric of $A C L$ in the long-term. They wanted "A greater sense of this being the way forward and not just a trend" and "to feel confident that I can have the support of my employer/s" (Tutor). Managers in turn needed commitment from institutional heads. One senior manager said, "It needs to come from the top, from the Vice Chancellor" and another said: "It needs to be tackled from the top, by senior management in institutions" (Senior Manager).

The lack of resources available to support the embedding of ESDGC was a recurring theme throughout the research: "tackling the largest issues on the planet on a shoestring" as one senior manager expressed it. The head of an NGO and chair of an ACL partnership stressed the need for incentives: "We need to incentivise in order for the sector to implement this worthwhile but complex initiative" and other managers also made this point stating "It has mainly been sticks, Estyn inspection. We have not had many incentives given for doing it other than this really" (ESDGC panel member in interview). 
Tutors were asked what they wanted or needed to embed ESDGC and develop their professional practice. They commented on the dearth of guidance and resources available, "Where is the guidance on how to do it in the classroom?" (Senior Manager). As mentioned earlier, the guidance document $A$ Common Understanding in ACL (Welsh Government, 2012), which was intended to provide guidance and give a unified understanding of ESDGC and its implementation, was not available at the time of the research. Cyfanfyd had produced a short booklet with case studies across all sectors providing ACL: colleges, Communities First and organisations such as the Centre for Alternative Technology (Cyfanfyd, 2008). The examples provide inspiration and ideas, they span all areas of lifelong learning and include community development, ESOL and postgraduate courses, but the publication was not a comprehensive guidance document.

The scope of ESDGC and the enormity of the issues created anxiety amongst tutors, who said, "Where to start?" and "How do small communities change within this big world?". This is an important issue and encapsulates many of the themes discussed in this thesis; it is re-visited in Chapter 8.

Typical requests from tutors were: "I would like more information passed down to me as a tutor, explaining exactly what is required, and maybe ideas how to embed it into a family history lesson" and "ideas for how it can be introduced into my subject areas". Guidance, information, practical examples, general ideas, an overview of what was involved, and the sharing of good practice were some of the things tutors wanted. In short, they wanted "More of everything!" (Tutor).

In this vacuum, tutors worried that they were not teaching ESDGC well: "I got by last year by guess work, and a little help from the office where I work" (Tutor).

I am concerned that I will not be able to keep up to date with current thinking or that I will make mistakes. I didn't realise that batteries needed to be recycled separately. My learners now leave all their batteries with me; this is increasing my workload as I have to take them to the tip. (Tutor)

Managers realised that tutors were unsure about ESDGC, and as one operational manager said "Underpinning it is self-confidence. It is so huge, and you can't know everything. This is a major difficulty with it, tutors are afraid". Managers were also apprehensive and needed guidance “Managers in the sector don't know anything about ESDGC. They get frightened off by it" (Senior Manager). The whole ACL sector recognised a need for guidance to direct the development and delivery of ESDGC. 
Teaching and other resources were in short supply, "Resources? This would be a good idea! We have not seen any yet - are some being developed?" (Tutor). Practitioners needed resources to embed ESDGC into specific subject areas such as mathematics, family history or pottery. The need for subject specific guidance and resources was a strong message from tutors. "Teaching resources are needed badly; anything that would help familiarise students. One sheet or a pack, anything would be better than nothing explaining what it is, where to begin" (Tutor); "Would be good to have models, a suite of good practice guides" (Senior Manager). Unfortunately, there were very few suitable resources available.

Personnel to take ESDGC forward were a resource that many people felt would be of great benefit: "A champion attached to each ACL board to promote and support initiatives provide inspiration and suggest resources" (Operational Manager).

I think that each provider should have a member of staff with designated responsibility for ESDGC and hours allocated for that purpose. This would be the person to attend network meetings and bring back ideas/good practice that could be adopted by management and implemented locally. (Senior Manager)

Initial action in the $\mathrm{ACL}$ sector was meant to focus on raising awareness (Welsh Government, 2008a: 11, 71) but this phase was not consistently implemented. A few people and organisations were however, taking the initiative. For example, 'Welsh for Adults' had instigated a series of ESDGC awareness training sessions for tutors and the WEA had likewise organised workshops for tutors across Wales. This provision was, however, patchy, and there was no strategic approach across the sector. A senior manager in interview said, "It was a missed stage" and a manager in the voluntary sector said:

A leaflet or something like this; the first thing they will get is the Common Understanding Document. We will recommend a flyer or something like that. So, people will get the Common Understanding Document and tutors will not read it. Managers might but there are loads of part-time tutors. It is these that you want to get on board. You have to translate to people on the ground. (Operational Manager)

Managers concerned that this awareness raising was not done suggested solutions such as offering "briefing for senior managers working outside mainstream formal education on ESDGC. This would be very useful, just a briefing. We are extremely busy with many agendas" (Senior Manager). Another senior manager said it would be beneficial if there were briefings for all levels of staff: "Operational managers, programme managers, tutors, everyone". 
The ESDGC strategy promised a "coherent set of quality criteria which will be the focus for action" in the short-term (Welsh Government, 2008a: 11) and quality was an issue that managers in FE and local authorities were particularly concerned with, probably because of Estyn inspection criteria. The Welsh Government stated that they were interested in identifying best practice, but this was contested by those who called for a focus on 'good' practice instead of 'best' practice. Three of the seven people interviewed at policy level made this point. Quality and consistency were among the main concerns of senior managers across the ACL sector. "Quality concerns me deeply" said one senior manager, and another said "What about quality? Who is the arbiter of quality? Who says what is good practice or best practice? Some people have just come into this without much background and set up as experts. It's disheartening" (Senior Manager).

\subsubsection{Training issues and expertise}

Training was needed at all levels, from awareness raising to training for senior managers: "I need to help tutors be more ESDGC aware in their course and lesson planning. I need training too" (Operational Manager). Another manager echoed this "Senior management should have training too! Not just tutors. Many managers do not know what it is or how to do it" (Operational Manager). Some managers wanted to "know how to inspire tutors and learners and show that ESDGC is relevant to their lives and classes: craft, special needs, dancing classes, etc." (Operational Manager) and "Even administrative staff should be made aware and have some sort of training " (Operational Manager). Without training practitioners lacked confidence and could not effectively embed ESDGC into their practice.

Tutors' terms of employment frequently prohibited them from attending training: "In adult education we are paid hourly. How can we be expected to pick this up and run with it? We do not get paid to attend training, and I am not sure my employers would deliver good training anyway" (Tutor), and it was feared that "Tutors won't attend training because they are not paid" (Manager). Tutors needed support to work through the complex concepts, issues, new ways of working, new content and new knowledge: "They are comfortable with their subject, but this is another body of knowledge" (Senior Manager). Anxieties regarding their levels of knowledge and lack of information on topics relevant to ESDGC inhibited tutors. 
Scientists don't always get it right, and I am aware that I don't want to enforce or pass on information that is not helpful or even wrong. I also don't want to instil unnecessary anxieties or concerns. As teachers, we have responsibilities towards our students, and I would not want to mislead them. (Tutor)

Tutors asked "where is the training going to come from and how will it be supported?" (Tutor). There was no strategic training programme even though some individual consultants and organisations such as Cyfanfyd and the WEA were offering training. "Is there a coordinated and systematic approach to training from WAG? No, but we need this. It will be key to the success of this policy. If tutors are not supported, then how can it be implemented in the classroom?" (Operational Manager). A senior manager said "CPD resources needed, and training, training, training" (Policy level interview).

\section{Fig. 6.1 Training received by tutors}

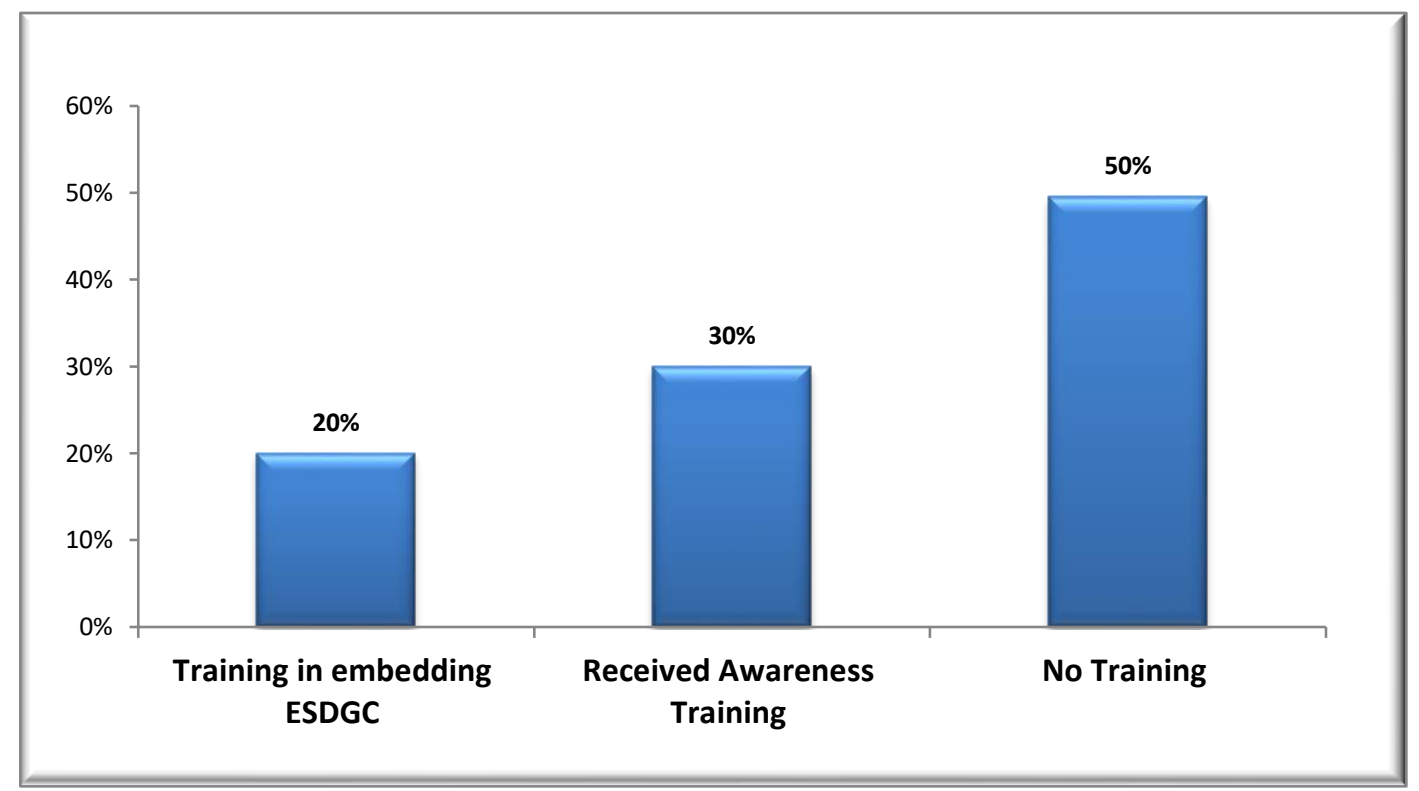

Of those tutors who responded to the research, 30\% had received awareness training and $20 \%$ had received training in embedding ESDGC. Nearly $50 \%$ of tutors had not received any training. Two years after the publication of the strategy this was a relatively low proportion.

The proportion of tutors who had attended training corresponds almost exactly with the graph below which indicates tutors' confidence levels regarding ESDGC. 
Fig. 6.2 Tutor confidence levels to take ESDGC forward in their work

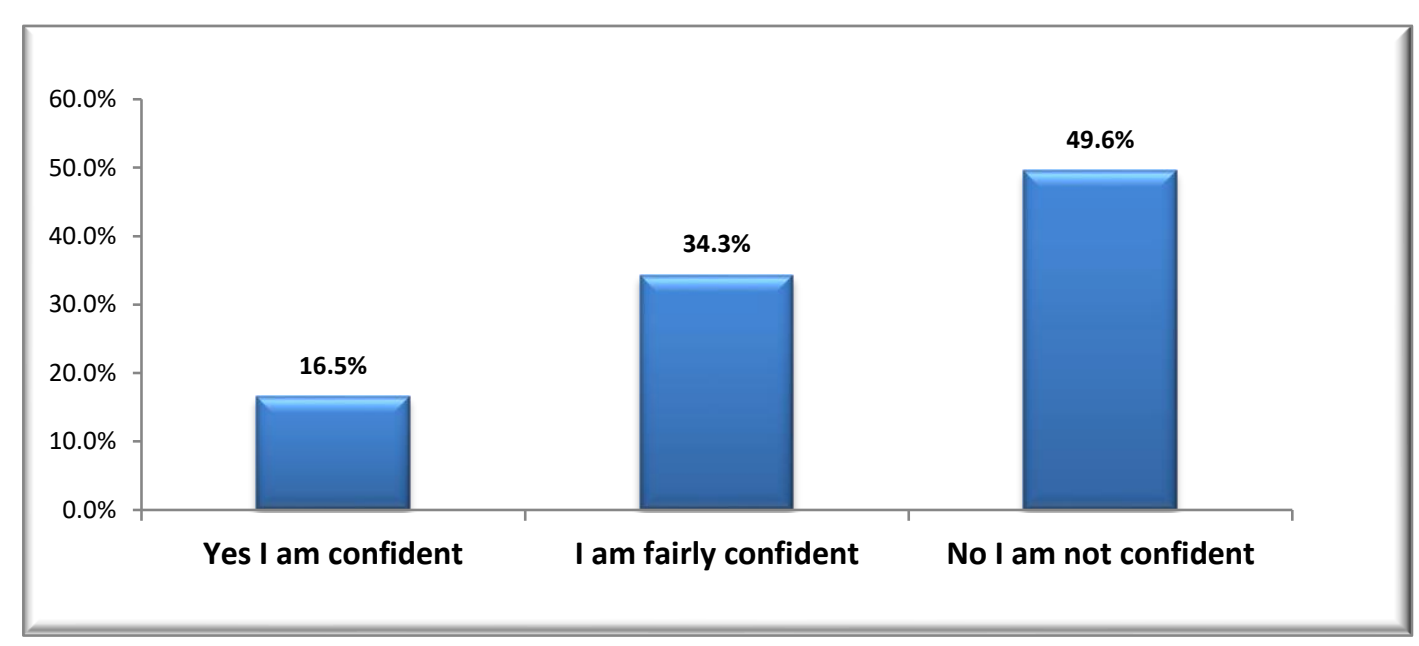

Training and CPD were priorities for practitioners. However, nobody knew who was going to organise and deliver this; there was no strategic delivery plan.

Tutors expressed the need for clarification about Welsh Government and Estyn expectations: "I am not sure what is expected of me" (Tutor), and an operational manager asked, "What is expected in ACL delivery and the administrative aspects of ESDGC?" Clear directives and guidance were not forthcoming, and practitioners floundered.

Managers also wanted guidance, training, and to have access to resources for themselves and for tutors in their institutions; however, they were more confident than tutors to take ESDGC forward, as the graph below shows. The data also shows that they felt more confident in understanding the issues. 
Fig 6.3. Managers' levels of confidence to take ESDGC forward - Questionnaires

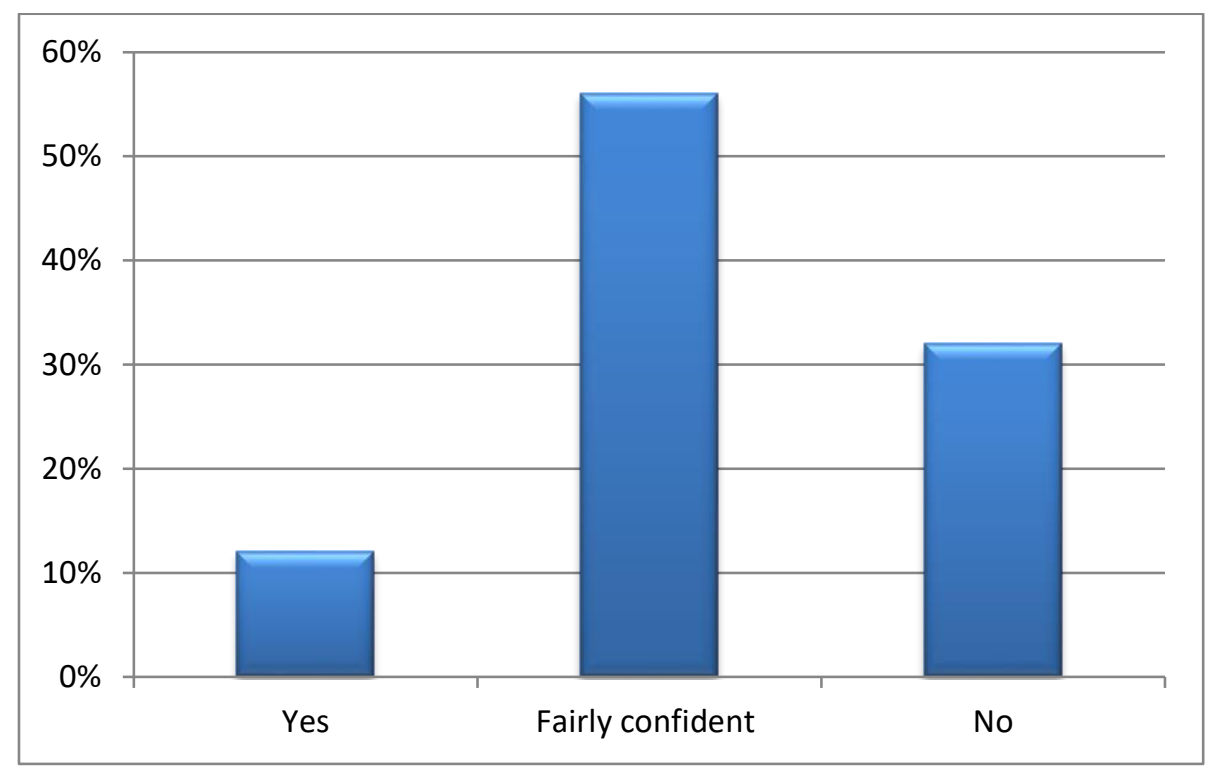

\subsection{A policy-practice gap}

Some of the frustrations of $A C L$ practitioners is expressed in the following quote, which refers to the lack of resources, the perceived tokenism and the lack of follow-up already discussed.

A great deal is already being achieved, but if it is going to be an 'integral' part of $A C L$, then we need funding for that. But far from having appropriate funding to do it properly, ACL is facing serious cuts. So, it will be a case of 'this is important, so do it, but there will be no funding for it!' So how is it supposed to be done? Déjà vu! (Senior Manager)

The lack of investment indicated a gap between the rhetoric of policy and practical support for implementation this was responsible for a great deal of the cynicism and pessimism encountered during this research. One thing that exacerbated the policy-practice gap was the late publication of the $A C L$ Common Understanding, which was written in 2009 but not available online until 2012 (Welsh Government, 2012). Two years after the publication of the ESDGC strategy a relatively high proportion of ACL tutors were still unaware of it, as indicated in Figure 6.4 below. 
Fig. 6.4 Tutor responses to the question 'Have you heard about Education for Sustainable Development and Global Citizenship?'

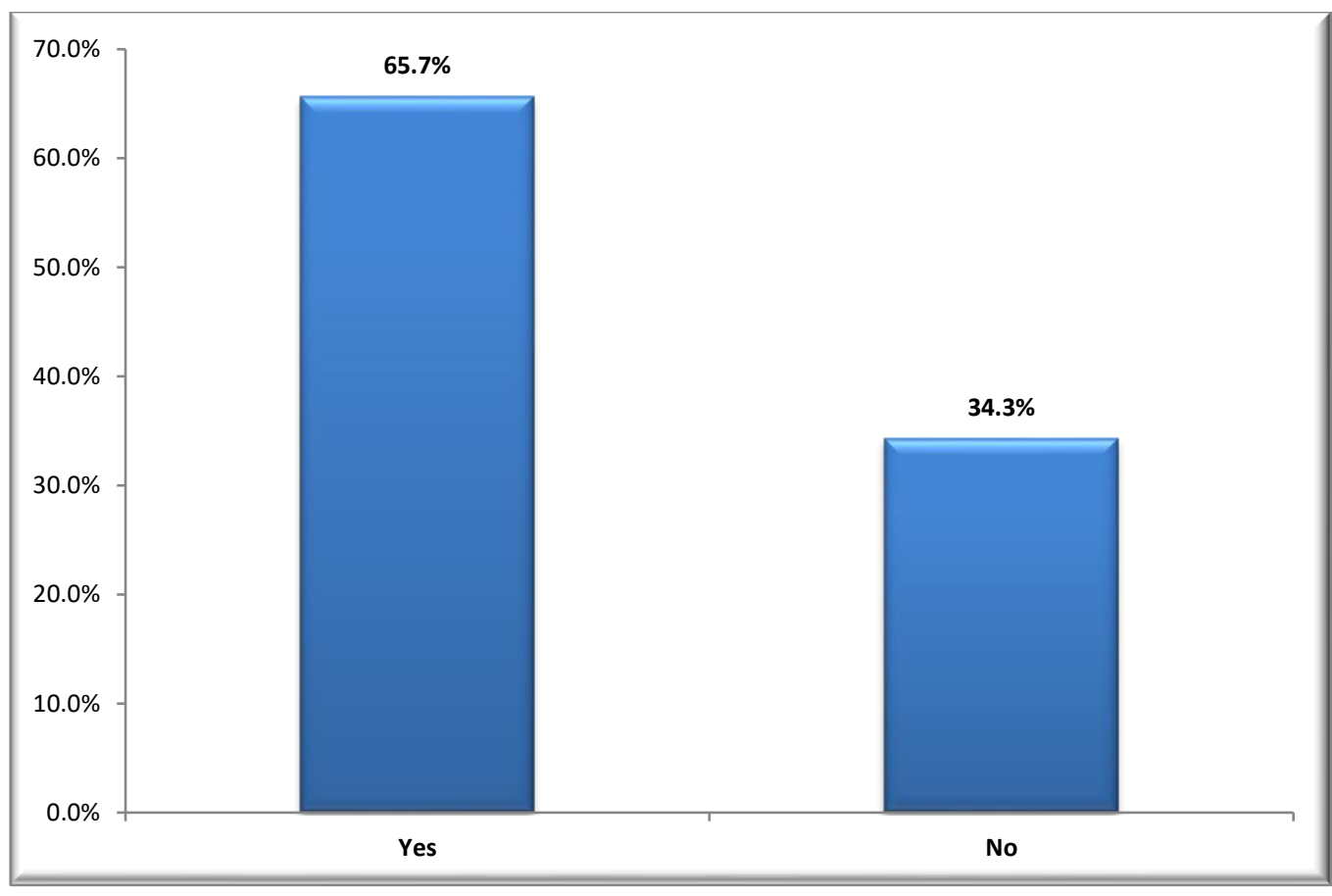

Whilst managers supported ESDGC many saw the strategy as unrealistic "Welsh

Government policy looks good, but it is not there on the ground. So, it looks good, people say 'great' but it is not a realistic vision" (Senior Manager). Tutors also commented in this vein "However grand and ambitious the ideas, it's the 'how do we do it' bit and the support of this. This is not coming out from Welsh Government" (Tutor).

You've got your policies, and this does not always translate down into passion or practice... One of the big problems is that things come from policy level and people develop policy without really thinking about the practice, some not having much experience of practice, and it's the gap between policy and practice. This, I think, is the problem. (Senior Manager)

A senior manager said, "We need a policy in the county", and then added "But not sure how valuable this is without the practicalities". Another said, "This innovation is overdue and very necessary but needs to be given time commensurate with the amount of work needed for successful implementation" (Senior Manager). Practitioners did not expect that resources and support would be forthcoming "It is all well and good having a strategy, but will we have some back-up? support, resources?" (Tutor); "Must have resources and money for tutor training! But I don't suppose there will be any funding will there?" (Operational Manager). A senior manager said "A statement is OK but what does it mean in 
practice? Practical things that we can do at a service level and also that the individual can do in the classroom. This is what is needed" (Senior Manager).

Despite the consensus that ESDGC is not a discrete subject area and should ideally be embedded into all areas of the curriculum, people were unclear about what 'embedding' meant or how to do it. "Tutors need to know specifically how to embed ESDGC into their subject" (Senior Manager). Practitioners wanted an infrastructure to facilitate communication, share resources and develop quality in ESDGC, which "has to be institutional and at classroom level. Walking the walk and talking the talk" (Senior Manager). The next step in the strategy for ESDGC in ACL was to develop networks and communities of practice, but there was no funding available to take this forward.

Practitioners interpreted this lack of investment in ESDGC as a lack of commitment from the Welsh Government, and the focus groups identified the lack of money to support the strategy as the main impediment to implementation. "There is no investment in ESDGC in $A C L$, so how do they expect us to do it?" (Senior Manager). "If you can't afford to implement why do strategy? You raise people's expectations" (Policy level interviewee). A senior manager from HE commented:

We need money to enable us to train our tutors, paying them to attend training and also giving some financial incentive to the university. This is an enormous culture change; however, this must be backed up with resources or it is empty. The money is not there.

The future did not look secure for ESDGC. The following interview comment by a member of the ESDGC panel in Welsh Government illustrates how the delivery and realisation of the ESDGC strategy was not a priority:

Suddenly it's gone around a corner and hit a brick wall. There is nobody in Welsh Government who sees ESDGC as their business. Is it Department of Environment, Sustainability and Housing's responsibility now? There is an acceptance that everyone's got to deliver carbon reduction, but it is just a bit ... kind of ... no one is holding the baby. It is exhausting!

In 2010 climate change was becoming a priority with government and resources were being channelled towards climate change research and action, eclipsing ESDGC as an initiative, "The important thing is that people have to be personally committed. It is seen as a political priority, but when emphasis shifts, possibly to climate change, which it could, then inevitably some will be more committed than others" (Policy level interviewee). 
Given the lack of momentum from government, the lack of available funding for the foreseeable future, a lack of expertise in ESDGC in the ACL sector resulting in few training opportunities, and a lack of resources, practitioners faced considerable challenges to implementing the ESDGC strategy.

Despite the goodwill encountered, the lack of direction and support illustrate a policypractice gap which led to much of the cynicism and resistance encountered. Managers were not as forthright or as 'vocal' as tutors in expressing their disquiet but there was, even amongst senior managers, an awareness that it would take personal, institutional and government commitment to make this strategy a success and they were pessimistic about the provision of adequate or long-term support for ESDGC.

\subsection{Conceptual confusion - purpose and perceptions}

\subsubsection{Introduction}

This section examines different perceptions of ESDGC, which was understood and articulated in different ways by all groups of research respondents. The question as to why EGC was particularly problematic is addressed, and the difficulties that arise in addressing ethical and political issues are explored. This leads into, and overlaps with a section which focuses on pedagogy, the 'how to' referred to by practitioners and policymakers (section $6.6)$.

In interview, an Estyn inspector stressed the need to understand why ESDGC was important, and why we were doing it "More people need to know why in my opinion. It is the why". This person was the only research participant to articulate this point. This is significant, given the concerns and resistance discussed above, and the fact that many practitioners were unsure about why they were being asked to embed ESDGC into their practice and could not see its relevance for learners.

Some tutors who were optimistic and supportive of ESDGC said they saw it as an opportunity to "make learners more aware" (Tutor) and thought ESDGC could potentially help to "improve my students' knowledge of all things" (Tutor). Another wanted to have "The ability to be able to prevent my students from buying the Sun and watching trash TV" (Tutor). According to several tutors, ESDGC has the potential to contribute to a better 
world and a healthier environment. They could see the latent potential. Focus group participants said, "A clear definition is needed" and this was related to the need for a clearly articulated vision and purpose for ESDGC that would motivate and incentivise practitioners.

For the ESDGC Champion, eco-efficiency and behaviour change were part of the purpose or hoped for outcome of the strategy. "How you live your life is the main thing" was one comment made, and much of the thinking at the Welsh Government was about people reducing their carbon footprint through activities such as recycling and making choices in favour of more ecological lifestyles. One senior manager in FE was enthusiastic about courses that promoted this, such as permaculture and solar power. She said:

They [courses such as permaculture and green /renewable energy] relate to sustainability: they are good. I think there's a huge opportunity out there, an area that people are thinking about - it is an opportunity to engage potential learners on courses and give people the skills that will make the change in people's lifestyles, habits.

Only practitioners already working in ESDGC in the voluntary sector mentioned social justice, equality and race as important issues. They believed that these could be explored through $\mathrm{ACL}$ because its practice was underpinned by theories of learner empowerment and inclusivity within a social justice model. "The aims and ethos probably more closely aligned with the ACL sector, social justice and the sustainable agenda. It is strong in ACL" (Policy level interviewee), and this strongly points to the latent contribution of $A C L$ to ESDGC through citizenship and social justice discourses.

\subsubsection{Themes, concepts and different approaches}

There was a degree of confusion and controversy about the use of the themes and concepts in ESDGC. The seven themes are based on those identified by UNESCO as part of the Decade of ESD: wealth and poverty, identity and culture, choices and decisions, health, the natural environment, consumption and waste and climate change. The Estyn (2006) report on schools stated that the nine 'key concepts' that were first used were too abstract for teachers and that the themes were more practical (Welsh Government, 2008b: 50). Estyn, in their review of ESDGC in the ACL sectors (Estyn, 2008), use the themes as the model for ESDGC delivery (Estyn, 2008: 16). The model was devised by Estyn and the ESDGC Champion. A senior manager in interview stated that "I think there's a consensus 
across most of the sectors, that when we talk about ESDGC, we are talking about those seven themes, but there is a debate between the themes and the principles (sic)" (he meant the concepts). A criticism expressed by practitioners was that the themes were put across in an authoritative way by the Welsh Government and Estyn, "not allowing for, or encouraging people to be flexible in their approach" (Senior Manager in an NGO). Tutors corroborated the perception that the themes encompassed ESDGC, as they often spoke of them, but the concepts were not mentioned. One senior manager repeated that the themes were enough "We've now defined what ESDGC is through the seven themes".

This same senior manager referred to ESDGC as "an issue", "a theme" and "a subject area" in the same interview; he also said, "Climate change and poverty is what it's all about!" which reflects the priorities of Oxfam at that time. Another view expressed by someone in the voluntary sector was that:

You don't talk about ESDGC, you talk about critical thinking. You could teach a class about soap operas and people might want to come along. There's lots in it about critical thinking and consumerism and media influences and there are themes relating to ESDGC all the time.

These comments illustrate very different approaches to teaching and learning in ESDGC, from a pragmatic and operational point of view to a more critical, reflective approach.

\subsubsection{Global citizenship}

Research respondents often used the term 'environmental issues' when talking about ESDGC, and a key finding of the Estyn report (2008) was that people were embedding ESD into their practice more than EGC and the two were not being integrated. A senior manager said: "People are not making the connections - recycling with global issues - not generally - the balance is in favour of sustainable development". Sustainability and environmental issues were easier for practitioners to understand: "Most people, tutors and managers, take the easy route: the green, eco-issues. Much more information on them and more straightforward isn't it? Global citizenship is a bit abstract: how are we supposed to make sense of it let alone teach it?" (Operational Manager).

Some policymakers, when asked about global citizenship and its integration with sustainable development, gave answers that were evasive: "I don't have them separate in my head" (Policy level interviewee). Global citizenship for many managers and for some of 
the policymakers included international links and student exchanges, with some referring to multiculturalism as a celebration of other cultures. Links with groups in developing countries, sending aid, money or clothes to refugee camps were perceived as education for global citizenship. These approaches were, as one senior manager who was promoting ESDGC positively put it, "'Neat' ways of making global connections", but they demonstrated a limited and superficial approach that did not fully explore or address the concept of global citizenship or encourage critical thinking. One senior manager was concerned that "People will not buy into ESDGC at a deeper level than recycling" (Senior Manager).

Lengthy comments relating to global citizenship were made by tutors responding to the questionnaire. They illustrate a certain amount of confusion but also a great deal of interest and even passion, and a desire to engage with the issues. Tutors felt strongly about Welsh culture, identity, historical perspectives, the causes and consequences of globalization and our ability to live together in peace. Some tutors wanted to include globalization as part of their lessons and comments that illustrate this include "By embedding ESDGC into information technology lessons, people are learning what human development and globalization means or could mean for them and their own communities" (Tutor) and "I hope this will continue to be promoted and I will most certainly utilise it in my sessions to make students more open minded of global factors that have affected history both past and present in local areas" (Tutor).

These comments exhibit insights into some of the issues in EGC, but many tutors said they did not understand what global citizenship was and wanted guidance on how to integrate it into their subjects: "Global citizenship is a phrase I don't really understand. My only possible suggested link to pottery is the universality of making pots from clay" (Tutor). Practitioners wanted "more information about the global citizenship aspect please" (Tutor) and educating people for global citizenship was not understood by the majority of tutors, "Preparing people to be global citizens in the $21^{\text {st }}$ century - what the hell does this mean?" (Tutor). Some tutors were cautious about global citizenship, as exemplified in the following quote:

[we could include] instilling a sense of value for our own ancient European (and amazing Welsh) traditions to those who come to live here as well as some PR for the indigenous population to help us understand the advantages there are in exposure to non-European traditions without fear of our own identity being drowned out. (Tutor) 
The links between local and global issues, between community development and sustainable development, between global citizenship and local participation were not being made. Cyfanfyd saw their role as promoting the global perspective in ESDGC and their officers were among the few who commented on global, social injustice and on the disjuncture between ESD and EGC. "There is still a problem, definitely. Some people who are very environmentally based don't have a global perspective to their work" (Policy level interviewee).

The director of an environmentally focused organisation said "[The Welsh Government/ policymakers] could ditch the global citizenship, but I do see why it has to be there. People don't know what it is though, even people who say they do and are working in this area". The following comment highlights the political nature of global citizenship, a degree of cynicism, and emphasises the way in which this was not realised "Global citizenship could be about power relationships, but it was just embraced as an aspirational term. There is an urgent need to look at it critically" (Senior Manager).

The Welsh Government, uniquely among nations, decided to link ESD with EGC; this was an opportunity to explicitly link ecological issues with citizenship in a globalised world. However, "Many aspects need further development, there are blind spots. You can see there is an emphasis on the green agenda, on environmental issues" (Operational Manager). A senior manager commented that "Most tutors keep sustainable development and global citizenship separate - they do not know".

\subsubsection{Broaching ethics and politics in ESDGC}

Global citizenship and sustainable development are concepts that are inherently ethical and political, as normative questions about how we should or ought to live are addressed. Tutors were uneasy about this, and there was a concern about bias and indoctrination; one tutor felt that there was a "Power imbalance. ESDGC teaching can/could be insidious, brainwashing. You are the tutor, with the power to change ways of thinking etc." (Tutor). Another tutor said, "I am concerned that deliverers will miss the point and incorporate their own agendas into the classes which might damage the point and/or fail to supply learners with what they really need for harmonious interaction in society" (Tutor). The following comment was made in the focus group discussions addressing the issue of politics and ethics: 
It can often be seen as very political, and it is a big ask of tutors to teach this [without training, guidance and resources]. Tutors will hold beliefs and biases. It can be a danger; a danger of tutors preaching a particular message that they sign up to or blocking information on other points of view. (Tutor - Focus Group Discussion)

From the evidence provided by the data and from my own teaching experience, tutors did not find it easy to discuss issues that explicitly deal with politics and ethics in the classroom. During teaching an ESDGC awareness session in a HE institution, a senior manager and head of department said that "fundamentally ESDGC is about moral education". He said this was a difficult but worthwhile area to explore and there was a consensus in the class discussion that ethics should not be ignored and was a fruitful starting point for discussions.

Three people at policy interview level, from three different professional perspectives, spoke of ESDGC as having a political dimension that was proving to be problematic for practitioners. The Estyn inspector acknowledged that ESDGC was fundamentally about politics ("with a small p") and said "it is a difficult area for tutors". Another respondent at policy level said it was important to be able to 'depersonalise' issues in the classroom.

Tutors expressed concerns about ESDGC being political: "Learning must be enjoyable and productive and ESDGC should be part of this process without becoming too much of a political issue" (Tutor). This is a complex area for tutors. Skill and sensitivity are needed to facilitate classroom discussions and a level of commitment stemming from a sense of purpose.

Voluntary sector practitioners emphasised the need to put social justice at the centre of ESDGC. The WEA said they employed a "rights-based approach to ESDGC" and one of the policy level interviewees expressed strong views regarding the inclusion of justice and equality discourses and race issues: "Unless you have justice nothing will happen. The 'greenwash', the green capitalism will continue, and you will always have the marginalised groups".

Community cohesion, race equality and social justice are important things we need to look at. This silo-ing of ESDGC away from race equality and community cohesion and the fact that ESDGC has not taken on board equalities and not taken on board community cohesion. A missed opportunity. (Senior Manager in the voluntary sector)

In both focus groups, the lack of engagement with social justice and black and southern perspectives, and the lack of representation from BME groups on the ESDGC panel raised 
concerns: "Nobody on that panel that has any perspective on this. Working with race etc. has been omitted. This is a glaring omission, but nobody talks about it. Is it too uncomfortable?" (Focus Group Discussion).

Practitioners in the voluntary sector felt that an easy approach had been encouraged in ESDGC - one that focused on environmental issues: "It is more tangible, it is easier to look at environmental issues rather that looking at ourselves in the world" (Operational Manager). Current and controversial issues such as war and Islamophobia were avoided, however it was recognised that it is difficult for untrained and unsupported tutors to facilitate discussions about these issues.

An easier, softer approach is often taken, and issues such as Islamophobia, which people are concerned about are ignored such as young girls having hijabs pulled. Well, they say 'Oh, this is equality and bullying, not ESDGC'. The themes, they don't have conflict, it was taken out. Learners want to talk about this, I find. We find this on our training events. Government wants you to take their view, I suppose. (Operational Manager in the voluntary sector)

Adopting a different, more philosophical approach to ESDGC was suggested by two senior managers. One spoke in interview of 'Philosophy for Children'45

Critical thinking: Estyn is looking at this I think. One of the things I'd like to do, this philosophy with children, this burrowing down. What l'd like to do is train the tutors on that methodology so we're not just thinking about. Well, what do we talk about here? It's about opening up discussions, so it can, so we can engage learners to start thinking for themselves and finding answers. (Senior Manager)

ESDGC encompasses fundamental ethical and political questions, but people shied away from these and did not recognise them as educational and learning opportunities.

Practitioners were not encouraged or supported to pursue a deeper line of inquiry that could potentially develop transferable and ultimately more interesting, useful and transformative learning. A senior manager in HE said "it is all about philosophy, isn't it? Perhaps we should take this approach".

ESDGC is done in such a surface way. People have not got the confidence to make the connections. People with experience and expertise can make those connections, but what we are presented with is: you must do this and that and the other, here are the seven themes, follow them and that's it! This can be so limiting unless the practitioner has got the expertise and training to tease out all the connections. (Operational Manager)

${ }^{45}$ http://p4c.com/ 


\subsubsection{Conclusion - conceptual coherence}

The divide between, and the integration of, global citizenship and sustainable development was not explicitly addressed in the research questions. However, from what practitioners and policymakers spoke about, it appears that ESDGC was not being conceptualised or delivered in an integrated or holistic manner; environmental, sustainable development discourses dominated. Some respondents at the policy level and managers in the voluntary sector spoke of social justice in connection with ESDGC but these discourses were not prominent ones. People were not making the connections between social justice and the environment.

It is recognised that the purpose of ESDGC is difficult to articulate: "The grey areas! It is such a huge topic, too complex to get the whole picture" (Tutor) and there is a consensus in the literature that sustainable development and global citizenship are complex concepts, and definitions are all-encompassing, broad, and some might say vague. The broad scope of ESDGC and the lack of a unitary definition allow for different perspectives and plural discourses, but notwithstanding, it is important to clarify purpose and communicate a vision. However, a vision for ESDGC in ACL was not articulated or communicated and many people did not know what ESDGC was or see its relevance. There was a marked difference in the way various people perceived and understood it. Specifically, EGC caused confusion.

One Factor which impeded the embedding of ESDGC in teaching and learning is that tutors do not want to, are afraid to, and lack the confidence to tackle what they perceive as controversial issues for fear of appearing partisan, learners becoming emotional or conflicts arising in the classroom. Tutors did not feel able to facilitate discussions in the classroom that were potentially controversial and uncomfortable, covering emotive and challenging subjects.

It is tricky. Some of the issues can cause people to get het-up; they're contentious. Talking about race issues for example, slavery, immigrants, the middle east, women's issues, global corporations, apartheid, south Africa, oil and pollution, power and corruption and on and on. It is difficult and a lot for us as practitioners to take on. (Focus Group Discussion)

The ESDGC themes did not contain 'conflict' and the Welsh Government did not demonstrate an interest in including and looking at issues such as racism or war within the framework of ESDGC. It was, in the words of a policy level interviewee: "Too political". A 
reluctance to engage with controversial issues at all levels was evident and consequently EGC was 'neglected' in favour of ESD.

\subsection{Pedagogy - teaching and learning}

Two main issues associated with teaching and learning were described by participants in the research: the idea that ESDGC cannot be forced into the curriculum and the omission of pedagogical discourses in the ESDGC strategy and its communication to the sector. These and other key issues emerging from the analysis of the data are described here.

ACL learners do not fall into neat categories. The curriculum is diverse and peoples' motivations or reasons for learning are varied: therefore, tutors need considerable guidance as to how to embed ESDGC in a way that is appropriate, relevant and meaningful to their subject and to learners. One senior manager said that ESDGC has limits and "it is right that learners and tutors feel confident enough to say that they think it is not relevant here, giving people a chance to opt out" (Senior Manager), and an operational manager said that "Globalization or poverty are not necessarily going to lend themselves to all topics". Having no guidance or training, however, left tutors ill-equipped to make judgments. The goal was to embed ESDGC at all levels and it was acknowledged that it should not be forced. "You've got the institutional embedding in your policies procurement, procedures etc. In the class I think it's about ... well, what you can't do is force it" (Senior Manager). The head of lifelong learning in a local authority commented that "in a two-hour sugarcraft session, which of the concepts can we incorporate? We would not do this - it can't be forced".

A comment from a voluntary sector manager was that "ESDGC is not the starting point with learners. Nobody will turn up for this. Start where people are, looking at what issues are important to them, what people are interested in, what concerns them in their lives" (Operational Manager). This relates closely to issues of relevance and is based on one of the theoretical foundations of adult education, namely experiential learning: beginning with the experiences of learners.

Pedagogy was not included in the ESDGC strategy. A series of steps was suggested from initial awareness and conceptual understanding to behaviour change, but there was no guidance as to how this could be done. "There should've been some sort of awareness 
raising at the beginning. How can tutors be expected to know what it is? They haven't got the time to do a lot of research" (Operational Manager).

The LLUK professional standards in ACL that followed the publication of the strategy aimed to "unpack the competencies" needed to develop ESDGC (LLUK, 2009: 3) and provide a framework for practitioners but offered very little guidance on how to teach ESDGC. "The policy documents say very little about methodology" (Policy level interviewee) and a member of the ESDGC panel said that pedagogy had not been discussed on the ESDGC panel "Oh no, no, not at all, not at all. Method is not discussed on the panel". A manager in an NGO said "There are two levels: organisations and learning and organisations and fair trade, energy efficiency etc. This [the latter] is quite straightforward but learning and teaching, not so straightforward" (Operational Manager).

There was a reluctance to talk about teaching methods or pedagogy by some of the policy level interviewees. The subject was evaded and skirted around. There were comments such as "My personal and professional belief is that it's not about content, it's about setting people up to think and review". An explanation of critical thinking and how to facilitate this with learners through discussion and dialogue was not included in the strategy and the Common Understanding in $A C L$ was meant to provide guidance for practitioners. Although it had examples and provided some theoretical background, the document did not fully address the 'how to', and the LLUK professional standards (LLUK, 2009), whilst advocating discussion and dialogue gave no guidance or examples for practitioners.

Many practitioners thought ESDGC required a certain amount of scientific knowledge, and this left them feeling disempowered. For many, the scope of ESDGC prevented them from broaching it: it was overwhelming, and they did not know where to begin. They were also pessimistic about being able to influence positive change: "Sometimes there is too much doom and gloom, it can switch people off, as they think we will not be able to rectify the problem, so we may as well carry on as we are if it's going to happen anyway" (Tutor). Given the breadth of ESDGC, a curriculum is impossible to define, and method is possibly more important than content, as one senior manager in the voluntary sector said: "It is as much about method as content. It is different to the formal sector where the emphasis is on curriculum. There is a different approach."

Positive attitudes to teaching and learning amongst practitioners were reflected in statements such as "I can see the possibility of engaging more learners, as ESDGC could 
introduce a new approach to learning" (Tutor), and many practitioners expressed enthusiasm but felt unable to take it forward without support,

It is about good practice now, not policy. That has been done. We need to look at the how to do it now and we need resources for this and a linked-up approach across the adult education sector. There is a lot of good work going on, I think, and we could share what we are doing, but this is not easy, very difficult in fact. (Operational Manager)

New ways of working were needed, and "Not all tutors will feel confident to do this delivery, and interpretation of ESDGC. Training is needed to enable us in the sector to really think about this and to embed it meaningfully" (Operational Manager). A senior manager felt that "Tutors don't only need training in ESDGC awareness; they need training in how to be facilitators. They need to be able to encourage critical thinking and respond to a group with possibly very different views". This raises important issues for the ACL sector, for the Welsh Government in respect to ACL and ESDGC and possibly for the post-16 educational sector.

\subsection{Conclusion}

This conclusion brings together the themes from both findings chapters, relating to policy and practice and to conceptual confusion.

Tutors' hopes for ESDGC reflected practical aspirations that ESDGC would be seamlessly embedded into practice and would contribute to enhanced learning experiences. They also expressed hopes for an ecologically sustainable, peaceful and harmonious world, and a raised awareness amongst learners and practitioners of the issues embodied in ESDGC. Managers hopes overall, related to practical implementation from a more policy and strategic orientated; they hoped the sector could share resources and expertise and they recognised the need for ESDGC to be embedded in policy at all levels if it was to succeed. The concerns described by all groups of respondents were more complex and ranged from mild pessimism to outright resistance. It is these negative responses that can help us understand the ad hoc implementation of the ESDGC strategy and why provision and delivery of ESDGC in ACL is 'piecemeal'. There are lessons to be learned in terms of developing, delivering and implementing such an educational innovation as ESDGC to fulfil the hopes described above. 
Lack of representation, consultation and inadequate communication during the process of developing the strategy alienated tutors and left managers in a position where they were unsure of how best to support tutors to embed and deliver ESDGC. The initial focus during policy development was initially on schools; the formal sector was more accessible and straightforward, and results could be more immediately realised and potentially measured. Other sectors followed, but $A C L$ was not included until shortly before the final consultation in 2005. A lack of representation and participation in the policy process immediately alienated the ACL sector and the communities it worked with.

Conduits for communication between the Welsh Government and ACL sector were inadequate for many reasons, including structural and strategic issues. The underlying ethos and philosophy of ACL was not understood by some developing policy at the Welsh Government and this contributed to difficulties. The shifting policy purpose of ACL and the lack of a single and unifying framework or policy caused difficulties, and the ESDGC Champion and the sector struggled to find common ground. Tensions were apparent between those who did not have a background in ESDGC but were driving the agenda, and those who had been working in ESDGC for many years in the voluntary sector. Their experience and expertise were not fully utilised in assisting the government to take the agenda forward.

Managers and tutors needed training, guidance, and resources; they were essential if ESDGC was to be implemented successfully. Without them, people lacked confidence, motivation and any incentive to embed ESDGC. Without investment in the means to implement the strategy tutors became cynical and managers, whose role it is to support and empower tutors to translate the strategy into practicable words and actions, were unsure how best to proceed.

The absence of long-term commitment by government in the ESDGC agenda contributed to negative responses by tutors and managers. According to many ACL managers, ESDGC needed embedding at a strategic level, with strong and explicit leadership from heads of service and institutions. Without this, the outcome was that ESDGC was only visible in pockets where there were enthusiastic individuals or groups. If the Welsh Government had encouraged ESDGC to be included in regional and local policy, this would have demonstrated long-term commitment and given it a stronger strategic position. 
Without a shared or clearly communicated vision, and with ambiguous and mixed messages regarding themes and concepts being communicated from the policy level and the meso level from managers, then tutors at the micro level were disadvantaged. They had difficulty identifying starting points and practical ways to embed ESDGC into teaching and learning. ESDGC was perceived by some practitioners as an ideal and an aspiration of government, and for many, even if they were well disposed towards its aims, it was perceived as an unwelcome ideological imposition and an added bureaucratic burden. Many tutors did not see its relevance or understand its purpose. A conceptual confusion and inconsistency regarding ESDGC was apparent amongst all groups of respondents.

Conceptually, combining EGC with ESD was ambitious and even enlightened, but global citizenship and EGC were not understood and there was a high level of general misunderstanding. It was not linked to active citizenship, local agendas, diversity, community development or sustainable development and not linked to the Welsh Governments' priorities in tackling poverty and promoting health and well-being. The consequences of separating awareness and engagement from education and learning, and the synergy and potential of linking community development discourses with ESDGC are discussed in Chapter 8 and in the conclusion (Chapter 9).

Pedagogy was left to practitioners, and a lack of reference to it or to learning outcomes probably contributed to misunderstandings about ESDGC. Lifestyle and behaviour changes were envisaged as immediate outcomes and not seen as a result of long-term, sustained educational intervention based on learning theories and developing a practice that empowered practitioners and learners. Political and ethical discourses were not encouraged. Respondents recognised that discussing potentially controversial and emotive issues in a classroom was challenging, and they were not confident to take this forward. However, tutors did want to explore issues of identity, culture and globalization, but they were not supported. There were managers in the voluntary sector who were including values education, social justice and what were perceived as difficult issues into ESDGC, but those developing policy did not support this approach and most practitioners avoided it.

Chapter 3 has provided a policy context which addresses the research question on the background features which influenced the development and implementation of the ESDGC strategy. Chapters 5 and 6 , through using the evidence from practitioners in the ACL sector in Wales, and those involved in developing the ESDGC strategy, have identified features which subsequently contributed to the 'piecemeal' delivery and provision of ESDGC in ACL. 
Chapter 6 has, through using the empirical data, highlighted problematic features associated with EGC.

Throughout the two findings chapters, research respondents alluded to the' latent' contribution of $A C L$ to ESDGC through its more critical approach, links with community and an emphasis on teaching methods for example; these points were particularly stressed by voluntary sector practitioners. Chapter 8 addresses the question of the 'latent' contribution of $A C L$ to ESDGC, the potential and the possibilities. It does this through expanding the discussion on EGC and examining theoretical congruence; this also further illuminates the features associated with 'piecemeal' provision. Before this discussion, Chapter (7) takes up the themes relating to policy and the policy process and examines them through the lens of literature on implementing policy, change and innovation in education. 


\section{Chapter 7 \\ Discussion: Policy into Practice}

\subsection{Introduction}

This is the first of two discussion chapters, which set the research findings in a wider context, relating them to the literature reviewed in Chapters 2 and 3 and to the policy background and context described in Chapter 3. Features influencing the implementation of the ESDGC strategy are identified throughout the findings, and from the data - from what people have said - it is possible to posit explanations for, and gain an understanding of, why ESDGC did not become consistently embedded in ACL in Wales.

This chapter begins with a section on policy development and implementation, discussed in relation to, and contextualised by, the research findings. It considers layers of influence, policy levers, representation and communication, and the disjuncture between policy and practice is addressed. Within these discussions and throughout the chapter the research question on features contributing to the 'piecemeal 'delivery of ESDGC is addressed. A section discusses the articulation of vision in ESDGC and purpose behaviour and paradigm change are discussed. Finally, a focus on community approaches in relation to ESDGC identifies features from the findings that indicate some of the missed opportunities to engage people through ACL with ESDGC. The discussions in this chapter contextualise the synergy between ESDGC and ACL which is a theme developed in Chapter 8.

\subsection{Policy}

\subsubsection{Policy process}

Policy encompasses all aspects from initial ideas to implementation, and for successful implementation, policy development in education requires continual discussion, review and evaluation. It is a "process, something which is dynamic rather than static" (Trowler, 2003: 48), with the dynamism coming from several sources, from the different layers of influence. These are the policy actors and policy subjects referred to by Ball (2015: 467) who deserve to be the focus of policy studies. 
The intention to embed ESDGC across all education sectors in Wales was ambitious, and not everyone encountered during the research was supportive of the strategy and its aims. Some, from heads of service to tutors, were vehemently opposed to this directive, on which they had not been consulted. There had been a consultation process, but the inclusion of the ACL sector was an afterthought. This reflects the 'reduction' of education and ESDGC to an issue primarily of relevance to young people. Not being fully included in the policy process coloured the sectors' perceptions of, and response to, the ESDGC Strategy; the findings demonstrated that many ACL tutors did not identify as stakeholders, they perceived ESDGC as an imposed agenda: "I don't feel comfortable teaching ESDGC. It is incorporated into lessons because I have to, and not because I want to" (Tutor). Managers in the voluntary sector commented that BME and other minority communities were not included, to the detriment of ESDGC. The Champion and the ESDGC panel had a job to do - to produce a strategy and implement a government policy; this was done quickly and efficiently. However, many issues and many perspectives were not considered, and certain assumptions were made and promoted as values (Blackmore \& Lauder, 2005: 100).

Kirkland and Sutch (2009: 18) observe that "The perception of an innovation can be crucial to its success", and the perceptions of the research respondents underline some of the more problematic features associated with implementing the ESDGC strategy. There are of course wider policy influences, but this section addresses the case study and research findings. Anticipating potential barriers when introducing change or innovation is an important aspect of successful change management. However, due to a lack of representation on the ESDGC panel and a lack of understanding or knowledge of the $\mathrm{ACL}$ sector amongst those developing policy, this was not possible and contributed to patchy and 'piecemeal' development of ESDGC in the ACL sector. Policy studies acknowledge that introducing an innovation and trying to implement change will usually involve "conflict among those who make policy, as well as those who put it into practice, about what the important issues or problems for policy are and about the desired goals" (Trowler, 2003: 49). However, some of the tensions could have been avoided if there had been better representation from, and dialogue with, the ACL sector, especially those working in ESDGCrelated areas in the voluntary sector. Trowler sees policy development and implementation as a coding and decoding process as illustrated below. 


\section{Policy Encoding Process}

\section{Policy Decoding Process}

Transmission to implementers. From the macro to the meso level

A great deal of activity happens here - publication and dissemination of documents for example

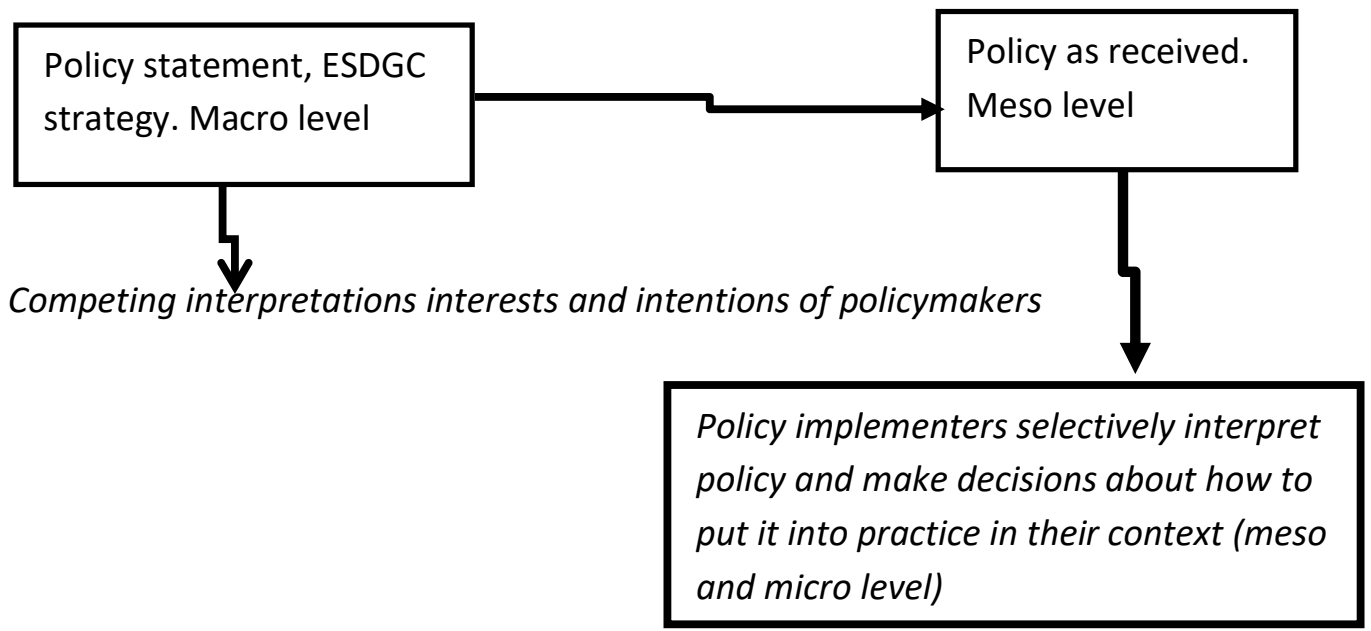

This diagram represents the policy process as observed in this research. It closely aligns with Trowler's model, illustrating how ESDGC was informed by various, sometimes competing interests and interpretations and how these were then transmitted through the different layers of influence. Those involved in developing the ESDGC strategy represent the macro layer; the managers at the meso layer of influence were responsible for putting structures and practical support in place within organisations and institutions for the implementation of the strategy, and for communicating key messages to tutors at the micro level.

Many innovations in education, including lifelong learning, are driven by policy, rather than the innovations driving policy. ESDGC is a case in point, following on, as it did, from the Welsh Government's commitment to sustainable development. ESD is also seen by some such as Rost (2004: 6-8, cited in Bourn, 2014a: 21) and Jickling and Wals (2008) as a response to, and an expression of, international political will. 
Sometimes policy follows innovation; at other times innovation follows policy. Many trends in education seem policy-driven, rather than innovation-driven. Trends such as lifelong learning and competence-based education are inspired by national and international policies (and corresponding economic incentives). Environmental education is no different. The conversion from environmental education to education for sustainable development may be seen as a policy-driven transition. (Jickling \& Wals, 2008: 5)

The empirical research found that communication between the different layers was limited. Inflexibility and a top-down approach, which practitioners perceived as an imposed policy agenda, characterised the process. Jickling and Wals (2008:11) refer to this as the 'Big Brother' approach to ESD. Many ACL tutors viewed ESDGC as an imposed government agenda and an added bureaucratic burden, and even if they were sympathetic to it, many responded with suspicion and antagonism. Jickling and Wals $(2008,2012)$ warn of this, as policymakers and practitioners in the field of ESD/ESDGC enthusiastically, and often with good intent, seek to impose values and ideologies. Perhaps, as one senior manager put it, there was "a mismatch between what people are interested in and what policy says they should be interested in". Perceptions of a policy as an imposition can be a major barrier to the adoption and implementation of change in education, as demonstrated by Nudzor (2013).

Other models of ESD identified by Jickling and Wals include the 'feel good' version, which promotes fair trade and celebrates multiculturalism, for example: this was often encountered in the research. The other is the 'enabling thought and action' model based on a critical empowerment model. This model involves practitioners in dialogue and decision making and is a heuristic "Inspired by socio-constructivist and transformative views about education and actively engaged citizens, it points to possibilities beyond sustainable development" (Jickling \& Wals, 2008: 17). This empowerment model is congruent with and characterises theoretical approaches in $\mathrm{ACL}$ discussed in this thesis.

\subsubsection{Roles, communication and representation}

Leadership is a crucial factor in introducing change (Fullan, 2014; Nudzor, 2013). Strong leadership can mitigate against the perception of the imposition of change from 'outside', which Nudzor warns against. According to the literature on change management in education, a great deal of strategic work should be conducted prior to and during the 
introduction of an innovation to realise the desired outcomes for learners. There had been work prior to publication of the strategy, some of which is outlined in Chapter 3, but the research observed that continued communication and strategic action was limited.

Up until 2010, when the ESDGC Champion left, the lead from government was strong in the formal sector. The Champion had a great deal of drive to produce the strategy, and the influence of the minister at the time, Jane Davidson in ensuring that there was a strategy for ESDGC cannot be underestimated. "The role of the ESDGC Champion, seconded from RSPB, once appointed, was recognised as being of particular importance, especially her personal attributes of skills, enthusiasm and tenacity" (Norcliffe \& Bennell, 2010: 11). The crucial role of enthusiastic individuals in moving $\mathrm{ACL}$ policy forward is recognised by many authors, including Coffield et al. (2007), and they stress how the successful implementation of a strategy or policy often depends on them.

Even though managers were supportive of ESDGC, several expressed that they did not have the expertise to support tutors. However, managers did not confess to the need for training as much as tutors, possibly because of their senior, more strategic professional roles. People and organisations with experience and expertise in ESDGC were in short supply throughout the ACL sector in Wales and there is a need to build up a base of knowledge and support for practitioners. Managers, as well as having insufficient information and knowledge about ESDGC, also lacked the statutory leverage to be able to fully support tutors. Tutors thought that stronger strategic leadership was needed: "Institutions should lead the way" (Tutor) and one tutor summed up the relationship between the meso and the mico layers thus: "If educators were software and institutions were hardware, then the software is running in 'safe-mode' because the hardware does not currently meet the specifications to run the full version of the software".

Estyn, with representation on the ESDGC panel, played a large part in communicating messages about ESDGC. They influenced and guided practitioners, exerting considerable influence at both meso and micro level. Institutions and individual practitioners, to some extent, had to respond to Estyn's inspection framework requirements and this was a significant lever for action on ESDGC. It was, in the words of practitioners, the 'stick', and there was a feeling that there was a need for more 'carrots' to incentivise and motivate. Studies on the impact of policy levers on educational providers suggest that institutions will respond to levers in order to secure funding (Coffield, 2007; Hodgson, et al., 2011). In 2010 
Estyn changed its priority to the 'Learner Voice' and ESDGC became side-lined. It did not disappear, and remains part of the Estyn inspection framework, but it was no longer being promoted or supported and practitioners reacted to this with cynicism. They had seen this situation before with other initiatives that had not been given the time and resources to become embedded into practice.

Managers in the statutory sector were more reticent in their criticism of Estyn and of the Welsh Government than tutors; they were quietly complying. This possibly demonstrated their allegiance to institutions and the necessity to comply with statutory requirements. Providers wanted to be seen to be doing the government's bidding in the hope that this secured favour, which could in turn secure funding (Hodgson et al., 2011: 29). However, there was the recognition that because of this, ESDGC was being approached as a tick-box exercise:

What some providers are doing now, they have a checklist and you've got to have done some bilingualism, if relevant, some IT and use smart board, key skills and then tick, oh an ESDGC box. That's the danger: Estyn won't give you a grade 1 unless you put ESDGC in. (Senior Manager)

Torres (2013) examines relations between actors at community, institutional and national level and their roles in legitimising policy through their influencing power. He concurs with the assertion that "At the core of successful innovation is the relationship between the innovation, the capacity and disposition of the innovator, and the environment in which the innovation occurs" (Kirkland \& Sutch, 2009: 3). The iterative relationships and communication between macro, meso and micro layers, which can be visualised in figures 7.1 and 7.2 are at the centre of this. They were underdeveloped in the case of ESDGC in $\mathrm{ACL}$ in Wales. 
Fig. 7.2 Layers of influence and lines of communication

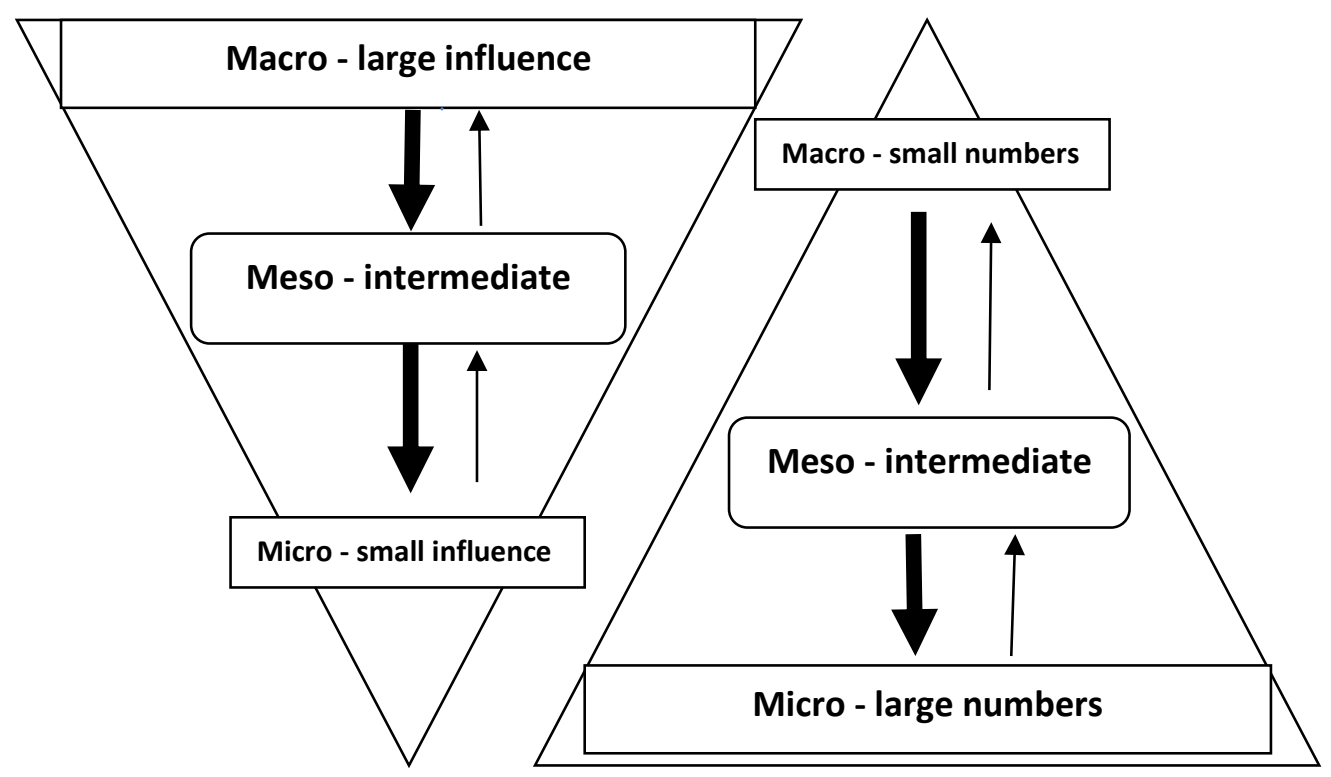

It is becoming widely understood that end-user involvement and innovation are crucial in developing new practices and approaches (Hill \& Hupe, 2014; Trowler, 2003; von Hippel, 2005). Without this involvement, practitioners become disengaged from policy aims, or even resist them, as this study has confirmed. One of the findings of a literature review by Murphy on the social pillar of sustainable development was that "The underlying premise [here] is that if people are involved in decision making, they are more likely to support environmental reform" (Murphy, 2012: 24). However, this current research found that tutors, overall, felt like passive recipients of the ESDGC strategy. Many in the ACL sector felt disengaged from ESDGC, having been marginalised during the policy process. Rees (2011), in his work on lifelong learning policy in Wales, suggests that those who are required to deliver policy objectives in education are often the least involved in its development. Another factor inhibiting communication and translation of policy to those who are intended to implement it is the obfuscating language of ESDGC. Tutors commented several times on jargon and a manager said: "I know you've got to call it something... to encompass that breadth, but, honestly, people don't know what it all means. The terminology is off putting".

If tutors and managers had been involved in the policy process, and if there had been communication and consultation, there might have been more 'buy-in' from the sector. Tutors were not included in deliberations during strategy development and it appears that the majority had not been consulted within their institutions and organisations. It is 
therefore not surprising that they were resistant to ESDGC.

\subsubsection{Disjuncture: a policy-practice gap}

Discord between actors at the policy macro layer and some individuals and organisations at the meso layer, particularly in the voluntary sector can be viewed as a dichotomy of social action, after Habermas: "Social action can be either success-oriented strategic action or understanding oriented communicative action" (Torres, 2013: 7). The former was the orientation largely taken by the ESDGC Champion, and the latter approach was the predominant one adopted by voluntary sector practitioners working in ACL and ESDGC.

They spoke of a values orientation, political and ethical communicative action and the need to involve tutors, learners and minority groups in a learner-centred approach to realise individual and community learning outcomes.

The current research found that there was a lack of understanding between those at a policy level and the ACL sector, particularly the voluntary sector, even though NGOs had strongly influenced the development of the ESDGC strategy. "The ACL sector is awkward" was one comment reflecting a view from government. The UK Commission for UNESCO, in their review of ESD in the UK, corroborated this situation: the review found that there was a distinct lack of connection between the formal and the informal, civic learning and voluntary sectors.

There is a lack of connection, and hence little realised potential for synergy, between learning experiences in formal education and what might be learnt through community involvement and third sector capacity building. In addition, there are tensions between activities that emphasise campaigning/activism/awareness-raising behaviour change, and those favouring learning and an exploration of the subtleties, complexities and uncertainties inherent in sustainability. As yet few opportunities have been created to explore this area. (UK Commission for UNESCO, 2010: 9)

The report highlighted the missed opportunities for learning and for sharing resources across sectors and organisations. Information and collaboration and partnership working were strong recommendations for the future (UK Commission for UNESCO, 2010: 8). Managers in ACL in Wales across all sectors noted that an integrated post-16 approach might be a solution to confusion and piecemeal delivery in the ACL sector. This would involve collaboration, sharing and mutual learning across $\mathrm{FE}, \mathrm{HE}$, local authorities, the 
voluntary sector and possibly work-based learning, and entail collaboratively developing strategies and sharing experiences and expertise in the process.

Martin et al. (2008), in their research on embedding of ESD in the learning and skills sector in England - which at that time included FE colleges, work-based learning and ACL - found that policy was not translating into practice. This is very much in line with the findings in this present research. Lack of capacity within the ACL sector was a contributing factor. Funding cuts following the Leitch Report in 2006, subsequent policy directives where ACL became more aligned with the economic agenda (Edwards \& Usher, 2007) and 'austerity' measures introduced in 2010/2011 all contributed to this. Traditional classes or those seen as 'liberal' education or 'leisure' were not being funded, despite the evidence of the contribution of adult learning to well-being and social capital (Feinstein et al., 2003). ACL is a sector that has always suffered from a lack of investment. One research respondent called it the "Cinderella sector". Without the prospect of long-term funding for ACL and for ESDGC, the policy-practice gap became wider and practitioners became despondent. Some ACL practitioners were aware of the situation and managers and tutors accross sectors expressed the view that for the ESDGC strategy to sussceed, it required investment. "It is about making a difference, isn't it? Are the policies alone going to make a difference? No!" (Operational Manager).

ACL Practitioners had seen other innovations from the Welsh Government come and go, such as the cross-curricular 'Cwricwlwm Cymreig' ${ }^{146}$ which displays some similarities to ESDGC, in that it remains as part of the Estyn inspection framework for ACL but there is little guidance for practitioners or statutory support available. Without guidance, how were practitioners meant to embed new concepts and content, often unrelated to their subjects, into their practice? Managers and tutors said that practitioners across the sector needed training, guidance and resources to be able to embed ESDGC into teaching and learning, but resources to support implementation were not forthcoming.

Most ACL tutors are paid an hourly rate and very little funding is available for them to access training. A similar situation was found in the formal sector, where funding was not available to free up teachers' time to participate in training. A lack of time was put forward as one of the reasons why teachers in schools were less involved in ESDGC (Bennell \& Northcliffe, 2010). For a policy like this to succeed, CPD is essential, and the production of

\footnotetext{
${ }^{46} \mathrm{http} / / /$ learning.gov.wales/resources/browse-all/the-cwricwlwm-cymreig-final-report/?lang=en
} 
the Lifelong Learning UK Framework for Professional Standards (LLUK, 2009) was a recognition of this. Unfortunately, LLUK was dissolved in 2011 and the framework is not being used. A systematic approach to training ACL managers and tutors was not visible: "Is there a coordinated and systematic approach to training from WAG? No, but we need this. It will be key to the success of this policy. If tutors are not supported, then how can it be implemented in the classroom?" (Operational Manager).

The UK Government's sustainable development strategy reiterates and stresses the importance of government leading by example (UK Government, 2005) but a divide between policy and practice was apparent in the way government conducted its business. ACL practitioners commented on this: "How dare the Assembly be so hypocritical? They can do more for sustainable development than we can, and they import Argentinean beef to feed schoolchildren!" (Tutor). Another comment was:

The office has taken it on quite well: people sourcing through green sources, you know. So, the organisation supports it, we are a good company in that sense, practicing what we preach. Welsh Government flying here there and everywhere. It's hypocrisy. (Agored Officer)

There was a need for an explicit lead and commitment from government, from institutions and heads of service. Without this, the outcome was that ESDGC became, as Trowler (2003: 81) found, "restricted to a small group of enthusiastic innovators" and change stalled.

Many managers and tutors saw the potential of ESDGC but felt that "it is not a realistic vision... it is not there on the ground" (Senior Manager). Practice had not been duly considered: "The 'how do we do it' bit and the support of this is not coming out from Welsh Government" (Operational Manager). The possibilities to engage learners and provide a springboard for new approaches was recognised by some, but unfortunately managers and tutors said that they did not know how ESDGC could be translated into classroom practice. Practitioners with experience in ESDGC mentioned several times that it was "More about content than methods". An emphasis on appropriate pedagogy and on learning outcomes might have offered some direction to practitioners in the absence of resources.

A lack of investment and long-term commitment, coupled with a lack of capacity, meant that policy could not be translated into practice. For long-term commitment, the inclusion of ESDGC at a strategic level within ACL was needed. It needed to be embedded in the $A C L$ partnerships remit and in strategy at all levels: this would, in the words of a senior 
manager, "unlock the participation of people, the involvement of tutors and trainers and learners and everyone else. So, as the directors of education sign up, then others will".

\subsection{Vision}

\subsubsection{Purpose - a vision for change}

According to many educators, including Jarvis (2007), O'Sullivan (1999) and Sterling (2013), a coherent vision for change and transformation is vital for promoting a future-facing education, and if an education policy is to succeed, it is important to develop a clear shared vision (Trowler, 2003: 81). How we perceive change guides the nature of change, and it is the clear articulation of purpose that will guide the content and practice of educational change,

The teleological character of education provides us with one important reason for suggesting that questions about 'what works' - that is questions about the effectiveness of educational actions-are always secondary to questions of purpose. It is only when we have provided an answer to what we hope to achieve that we can begin to ask questions about the ways in which we might be able to achieve such outcomes. (Biesta, 2010: 500)

A strong emphasis on explicitly shared values and vision within organisations, at the meso layer, is one of the characteristics identified by Martin et al. (2008) for embedding ESD in post-16 education, and it is largely agreed that clarity of purpose helps to guide and create educational change (Biesta, 2010; Trowler, 2003: 81; Twining et al., 2013: 230). The Future Generations Act in Wales reinforces the need to develop shared visions for the future: this is essential if we are to navigate difficult situations and create new ways of living and working together for ecologically sustainable and thriving futures.

Current global trends such as climate change, the instability of socio-economic structures and increasing individual and social anxiety are escalating (Auth et al., 2015; Steffen et al., 2011, 2015), and it seems apposite to include a futures perspective into ESDGC. Balanced and integrated with an understanding of history, a futures perspective allows learners to express their hopes and fears (Hicks, 2001b); it can clarify purpose and bring realism to visions for the future. This can be an antidote to the individual and collective pessimism 
that can all too easily creep in, as seen in the empirical data where some $A C L$ practitioners expressed a cynical resignation to current situations.

The findings demonstrated that the purpose of ESDGC was not articulated clearly and a coherent vision for ESDGC was not communicated. This situation left practitioners floundering and feeling disempowered; it constitutes a barrier to implementing the ESDGC strategy, as illustrated by the following quote:

If people understood what it was, if tutors really understood its purpose, why? What it is trying to achieve? If they had it explained to them better, they would be more likely to be behind it, to see its relevance. Now, they just don't see the point and not a lot of incentive for them. (Operational Manager)

The different perceptions of ESDGC and its purpose among policymakers and practitioners alike are not surprising given the lack of a shared vision and clearly articulated purpose. Other factors contributing to this confusion include the diverse range of ideologies and intentions, informed by different disciplines and bodies of knowledge found in the literature on ESD and EGC and the ambiguous definitions in ESDGC. Whilst these definitions are deliberately all-encompassing to provide flexibility and a broad canvas for practitioners to work with, they have diluted and divided the intention of the strategy. If concepts are not understood, then policymakers can, as a solution to the problem of ambiguity, draft guidance in a way that could still be unclear (Trowler, 2003: 129). Some respondents felt that this was the case with the Common Understanding in ACL: "I don't think it does the job it was meant to do" (Policy level interview).

Without purpose, vision, adequate training or guidance, people literally did not know where to begin, and the seven themes which are noted on the Welsh Government website ${ }^{47}$ were not enough to guide practitioners. The idea that "ESDGC is built around seven themes" is debatable, and during the research it was evident that the nine concepts identified in the early days of policy development (Welsh Government, 2002) - were not being engaged with. Estyn (2008) suggested that these concepts were abstract and did not help teachers and learners to understand what ESDGC was about; however, they potentially provide a robust framework for ESDGC, especially if used alongside the themes. In a recent report for schools (Estyn, 2014), the seven themes are referred to as concepts and the original nine are not mentioned. Likewise, in a work-based learning publication (National Training Federation Wales, n.d.), the concepts have disappeared.

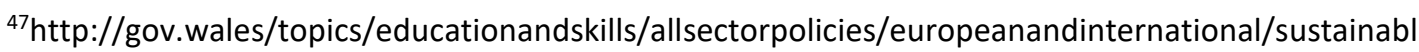
edevelop/?lang=en [Accessed 26/4/2016]
} 
People have not got the confidence to make the connections. People with experience and expertise can make those connections but what we are presented with is: you must do this and that and the other, here are the seven themes, follow them and that's it! This can be so limiting unless the practitioner has got the expertise and training to tease out all the connections. (Operational Manager)

No clear picture emerged of the conceptual thinking underpinning the ESDGC strategy, and the perception held by many practitioners, particularly tutors, was that ESDGC was concerned with 'eco' or 'green' issues. ESDGC was not seen as an integrated whole, and a separation between ESD and EGC was apparent. This corroborates the findings of Estyn (2008) and Huckle and Wals (2015). The concepts of global citizenship and education for global citizenship were not well understood and were often misunderstood. There was a need for clarity and guidance on the meaning and relevance of global citizenship to learners' lives. This resonates with the research findings of Andrews and Lewis (2000) in the formal schools' sector in Wales; they concluded that teachers needed guidance, particularly on how to teach the more political aspects of citizenship and how to develop political literacy. A senior ACL manager, the chair of an ACL strategic partnership said that the partnership was focusing on equality and diversity, but it was not engaging with ESDGC. The connections were not made, demonstrating how fragmented the concepts are in people's thinking.

Adults, unlike children, choose to attend courses and often pay for them. Learner autonomy is fundamental. This significant difference between ACL and the formal sector was not recognised at the macro level and even though the ESDGC Champion understood that adults had the potential to implement and influence change through exercising consumer choice, the emphasis was on influencing children: "they are the future" (Policy level interviewee). Adults are considered to be citizens, whereas children and young people are considered neophyte citizens who can be more easily influenced (Callan, 1997). A professor of lifelong learning during interview emphasised that the most important socializing influence on children was the family, and particularly parents; the best place to start is where each new generation acquires its moral anchoring - at home in the family (Etzioni, 1991: 45):

If you want a cultural shift, well even if you influence schools, children, you still need to reach the parents. It is the home that the messages get to children and young people. Parents are the direct agents of socialisation! They put the messages to children. There is no reaching out to parents in ESDGC or the family as a learning 
unit. Research on the wider benefits of learning shows that parents bolster children; they are much more influenced by parents than school. (Senior Manager)

Social structures and networks of family and community were largely ignored by those developing the ESDGC strategy and a choice was made at the Welsh Government to concentrate on formal education and initially on schools.

In summary, the purpose of ESDGC was not clearly articulated and practitioners responded with a range of perceptions: "It's [ESDGC] so big, vast, it is about everything. Covers so much. Where do you start? How are tutors supposed to know?" (Focus group comment). A response that emphasised the importance of being clear about the purpose of ESDGC was:

It is about seeing the gains. There is a gain! So that people see the point, that they can see that they gain personally, not doing this just because you are told to. If people know the gains, they are more likely to do something. (Agored Officer)

\subsubsection{Behaviour change or paradigm change?}

Behaviour change towards more sustainable lifestyles is part of the purpose of ESDGC. Proenvironmental consciousness and behaviour is a well-researched area and it is a complex matter, and how this is understood and defined varies, depending upon values and assumptions. Ideological blind spots may prevent certain perspectives from being explored (Kollmuss \& Agyeman, 2002: 256). In the 1960s and 1970s, 'outcomes' became the focus of learning, and those outcomes were predominantly about behaviour change. Today this is being revisited, not only with skills and vocational outcomes, but also because ESD and ESDGC emphasise behaviour change to mitigate, prepare for and cope with climate change. Educational theorists, however, are more concerned with changes in the ways in which people understand, experience, or conceptualize themselves and the world around them to learn for behaviour change and sustainable development (Clover et al., 2013; Delors, 1996; Jarvis, 2006b, 2008b; Kollmuss \& Agyeman, 2002).

Behaviour change has a body of literature associated with it in psychology, organisational management and education. It is complex, and the policy process leading to it requires a considered, staged and cyclical approach (Hill, 2009; Trowler, 2003). There is a fine line between telling learners how to live their lives and asking them to question and look critically at how they live their lives and how and why they behave in certain ways. Jickling and Wals echo the thoughts of some respondents when they say that "forceful promotion 
of ESD has, at times, been damaging and divisive, whether this was intended or not" (Jickling \& Wals, 2012: 56). Missionary zeal, or an overly zealous approach by those driving the agenda and those working in ESDGC, was referred to by practitioners in ACL. As one senior manager observed, "they are often organisation with a strong environmental view or global view and giving that view only". People will not listen if they feel they are being preached at, and this was the experience of Fagan (2013), who worked on sustainable development with communities in the Hebrides.

Improved learning outcomes are often the goal of educational innovations; however, they did not appear to be the prime concern in the ESDGC strategy. This, according to Jickling and Wals, (2012: 50), is not how it should be, and Sterling emphasises the need to focus on deeper learning in ESD (Sterling, 2008; 2011a). It is not unreasonable to assume that the lack of intermediate and recognisable learning outcomes in ESDGC contributed to tutors' perception of ESDGC being dictatorial; they resented its authoritarian implications. Several tutors stated that they hoped, through ESDGC, to 'raise the consciousness of learners' (5.5) illustrating a view that is not merely concerned with behaviour change. Possibly not enough consideration was given to the importance of changing the thinking, and subsequently the behaviour, of those implementing the strategy, namely the tutors. Expecting tutors to develop new curricula and approaches to teaching and learning requires a long-term plan, a strategic vision supported by senior managers and a continued momentum at a policy level (Coffield et al., 2007).

The need for a new educational paradigm is frequently stated in the literature, for example by Bhola and Gomez (2008), Bowers (2017), Jucker (2002), Orr (1994) and Sterling (2003, $2010 \mathrm{~b})$, to name but a few. The change needed to promote and facilitate sustainable development and global citizenship involves more than learning about recycling or buying fair trade goods. Even though these actions are important, ESDGC encompasses much more.

It is a rethink about how we are as human beings and what does make you feel human and connected. It could be a very radical thing, a revolution. Economic growth and ESDGC, you can't have both. It does not mean more necessarily. Just have to be smarter, not slavishly adhering to what we have done in the past. It takes a lot of intelligence. (Agored Officer)

Unfortunately, a transformational vision for ESDGC that critically engaged learners in exploring values and attitudes, connecting local agendas to global concerns and examining 
the wider socio-economic frameworks, was not articulated or communicated widely. The emphasis was on practical action for sustainable development.

A criticism levelled at the Welsh Government and Estyn's approach by senior ACL professionals referred to superficial, action orientated starting points which were not taken any further. The strategy document does not have a reading list, and, when asked about the conceptual basis and the thinking behind it, those at a policy level were vague, saying it had been "Pulled together" by reading and drawing on people's knowledge. Old paradigms are at the root of the unsustainable conditions in which we find ourselves in according to many authors, including Sterling (2011: 19). The individualistic, behaviour-change model reflects a view that does not, ultimately, challenge dominant global patterns of power, politics and economic structures that give rise to unsustainable development (Huckle \& Wals, 2015).

\subsection{Community}

According to Porritt, "Perhaps the most striking of all the insights is the conclusion that sustainable development and community participation must go hand in hand" (Foreword in Warburton, 2013: xi). He, like me, cannot be persuaded that politicians have fully grasped and understood what sustainable development is and how it is linked to local and community development. Even though Agenda 21 includes a section on community, and many references are made to community participation (UN-UNEP, 1992), communitydriven and community-embedded sustainable development are not high on political agendas.

Traditionally, community development has had two main objectives, to tackle poverty and deprivation and to increase the political participation of excluded groups. Localism, democratic empowerment and greater self-reliance form the basis of community development practice and these principles are congruent with $\mathrm{ACL}$ learning theory, as discussed in Chapter 8. UNEP's original thinking on ESD included these elements (UN-UNEP, 1992), but they were not obvious in ESDGC. Tackling poverty and child poverty are priorities for national and local government in Wales, and poverty is a core theme in ESDGC. Nonetheless, when poverty was encountered in ESDGC, this was usually associated with 'Third World' issues. Links between poverty and everyday life were not made. With a 
focus on the global - on globalizing processes, the global economy and international competitiveness - more local concerns and agendas are overlooked in the rhetoric of policy and in practice associated with ESDGC, ultimately reflecting an impoverished conceptualisation of globalization itself.

Burningham and Thrush (2001), in their research with disadvantaged communities in the UK on perceptions of, and engagement with, global environmental issues, found that people experiencing difficulties in their lives and trying to make ends meet often conceptualised the issues as being too distant (either geographically or temporally), arguing that priority should be given to immediate problems. This issue of being 'too distant' is a central challenge for sustainability and for ESDGC. ESDGC clearly needs to be brought close to home, related to peoples' everyday lives and community concerns. The recognition of the deep interrelationship between the local and global is at the heart of sustainable development (Blewitt, 2008: 2) and many ACL practitioners, both managers and tutors in this current research understood the importance of integrating local and global development and wanted to make the issues relevant to people living in disadvantaged communities.

Community development and lifelong learning have long been acknowledged as connected policy discourses (Moreland \& Lovett, 1997), but in Wales, community development initiatives and practitioners were not communicated with, or involved in developing the ESDGC strategy. Yet, community development organisations, when consulted as part of this research, immediately saw links with their ethos and practice. For example, a manager quoted Securing the future, the UK strategy for sustainable development: "'joined-up solutions to locally identified problems, working in partnership to tackle economic, social and environmental issues' and thus meeting the Millennium Development Goals" (UK Government, 2005: 9), and an ACL tutor commented "Paying attention to people at the local level, to cultural differences that matter and shape community and its future government don't really want this" (Tutor). This again, points to the 'one-size-fits-all' approach with a formal sector perspective not being well-received. A homogenous ESDGC did not promote or support a local and plural vision and the Common Understanding document did not go far enough in enabling ACL practitioners to take this forward.

Some managers were supporting local-level innovations and good practice in ESDGC. This approach, according to Coffield et al. (2007), recognises that the practice of creating 
solutions in local situations and at an individual level can lead to transformational learning that ultimately supports government-led innovation. Emphasising the need to support community-based practices for sustainability, Tilbury and Wortman (2008: 83) state that: "Realigning existing funding opportunities, building the capacity of facilitators and supporting more innovative and participatory approaches to community education are needed if existing education programs are to make a significant contribution to sustainability practice". Partnership is an essential part of the ESDGC strategy and the point was made during the focus groups about the need for ACL providers to work with NGO's and a diverse range of groups and organisations. Highlighting partnership working aligns with UNESCO's recommendations (UNESCO, 2014a), and non-formal community education is often cited as being crucial in raising awareness, building partnerships, and influencing action to engage people in working towards sustainability, "The most successful programs involve partnerships with other agencies and community representatives, but are initiated by the community" (Tilbury \& Wortman, 2008: 88).

A systemic approach where environment, economy and society are linked permeates the literature associated with ESDGC but was not encouraged or supported at a local level. Securing the Future (UK Government, 2005) includes a chapter called: 'From local to global: creating sustainable communities and a fairer world', but the recommendations for action separate local and global issues (Bourn, 2005: 16). The joined-up approach was not there, and the same scenario was seen in ESDGC in Wales.

Learning is a powerful agent for change within the critical, empowerment model in ACL (Freire, 1970a; McGivney, 1999; Moreland \& Lovett, 1997; Torres, 2013); however, separating community engagement from $\mathrm{ACL}$ meant that many community organisations in Wales did not engage with ESDGC. It was a missed opportunity. Cynnal Cymru/ Sustain Wales ${ }^{48}$ were tasked by the Welsh Government to engage with communities on sustainability; they were given the public awareness remit.

The other part of the task, that community involvement, volunteering, raising awareness ... we came to an agreement with Cynnal Cymru that this would be their area, they would do the general, public awareness raising, getting people revved up about it. That was the arrangement we came to. We do anything that was education - policy, strategies, organisations, learning settings - and they would do

${ }^{48}$ http://www.cynnalcymru.com/ 
general public awareness, campaigns. There is overlap, especially in adult and community-based learning. (Policy level interviewee)

However, the work of Cynnal Cymru is predominantly environmental and their projects do not have a significant learning focus.

Sustainable communities are a key priority in Securing the Future (UK Government, 2005), which emphasises helping people to make better choices. However, this is primarily about behaviour change and developing sustainable lifestyles and habits. It is likely that this strategy influenced ESDGC. Making assumptions about how we should live can easily alienate people, and this was discernible in the responses of practitioners who resented, what they perceived as the 'preaching' tone in ESDGC. Devaluing local knowledge and promoting certain lifestyles will alienate people from the message because the issues and ideas are not seen as relevant or connected to their lives and immediate concerns (Bowers, 2001, 2017; Burningham \& Thrush, 2001). "If ordinary people do not care about development being sustainable, and change their attitudes and behaviour, any amount of policy programmes will fail" (Warburton, 2013: 28). Challenging current paradigms requires an understanding on the part of educators about how people can be marginalized through preaching about behaviour change and individual responsibility at the expense of community and social learning and deeper understandings of systemic issues.

The separation between community and sustainable development and the low profile of EGC and its links with local agendas helps to explain the lack of emphasis on a social, collective or community dimension in ESDGC. In this context, it is worth discussing the tension between the liberal individualism of Knowles $(1973,1980)$ and Nussbaum (1997), for example, and the collective and relational approaches of many theorists in $\mathrm{ACL}$ and ESDGC (Annette \& Mayo, 2010; Bowers, 2001; English \& P. Mayo, 2012; Sterling, 2009, 2010a; Wals, 2009). The view of humans as independent and autonomous or completely self-interested is disputed by many, and V. Held (2006), in proposing a new approach to ethics, highlights the relational nature and interdependence of humans, in opposition to the view in liberalism where the flourishing of the individual takes precedence, analytically and normatively, over the flourishing of any group (V. Held, 2006: 13). Liberal traditions focus on individual development, sometimes at the expense of situating the individual within a geographical location, a landscape, a community and within the 'big picture' of an interconnected world. 
"[Lifelong learning] is a public and personal human activity, rather than private or individualistic. One of the features of the education system is the paucity of a language for learning as process and participative experience" (Crick \& Wilson, 2005: 359). This is what $A C L$ can bring to ESDGC, social, intergenerational and community-based learning approaches that redress the emphasis on the autonomous, rational individual through an underpinning collective dimension. This is fundamental to a worldview with an ecological ethos and is in line with the purpose of transformational models of ACL (Jarvis, 2008b), and indeed with the concepts inherent in ESDGC (Sterling, 2003, 2010a; Wals, 2009). Relational models (Helne \& Hirvilammi, 2015) and empowerment models (Jickling \& Wals, 2008) are other expressions that encompass the collective dimension in ACL and ESDGC.

The disconnect between community development and $\mathrm{ACL}$ and the separation of public awareness from learning arguably contributed to the neglect of citizenship discourses: without personal and local starting points the global becomes an abstraction. This was a missed opportunity, as the aims, objectives and processes of ESDGC and community development have many similarities and there is potentially a great deal of synergy. Community and sustainable development both have a critical social justice orientation (English \& P. Mayo, 2012: 135) and it is here where the latent potential can be realised through adopting new approaches.

\subsection{Conclusion}

This chapter, building on the findings in the previous two chapters, has shown how the process of developing the ESDGC strategy impacted on the ACL sector and its perceptions of ESDGC and the strategy. Much of the negativity reported by ACL practitioners stemmed from the lack of consultation, representation and communication between the layers of influence, and a policy-practice gap was exemplified by the lack of long-term support and commitment from the Welsh Government. Practitioners were disempowered by these features.

Whilst discussing issues within the global frame of reference, many authors, including Agyeman (2005a, 2005b), Elliot (2012) and Warburton (2013) argue that sustainability can only be realised by reducing inequality and poverty in specific localities through participatory, appropriate and flexible policy creation and through local politics and 
citizenship. A participatory policy process was not observed in this case study, it was not a flexible or dialogic process.

Vision and a clear purpose were not communicated, despite the forward thinking of the Welsh Government in its integration of ESD and EGC. In ACL, one of the most glaring omissions was the links to community and community development: the separation of learning and community engagement was not in keeping with the theory and practice of $\mathrm{ACL}$ and probably contributed to the sector's lack of engagement with ESDGC. In the literature, democracy and a critical citizenship are envisaged as the route towards change and towards sustainable development. In ACL, citizenship in all its guises, from active citizenship to inclusive citizenship, is not only a discourse: it is part of the underpinning philosophy. "The links between adult education and active citizenship are clear - there is abundant evidence" says Field (2006: 167). This theme is developed in the next chapter.

The analysis of the findings and the discussions in this chapter have highlighted features contributing to the 'piecemeal' provision and delivery of ESDGC in $\mathrm{ACL}$, and the section on community has begun to demonstrate where the latent contribution of ACL to ESDGC lies. The following chapter further explores the congruence between ESDGC and ACL through an examination of learning theory. 


\section{Chapter 8 \\ Discussion: Synergy and Future Approaches}

\subsection{Introduction}

Moving beyond the policy process and its associated features, this chapter examines the synergies between ESDGC and ACL and the potential therein for a new approach and pedagogy. Themes from the findings are brought together with theories in $A C L$ to highlight the 'latent' contribution of ACL to ESDGC. Bringing the complexity of ESDGC together with the theories and approaches within ACL presents possibilities in both forms of education. Through this, features described by respondents which contributed to the 'piecemeal' delivery and provision of ESDGC in ACL in Wales are addressed.

An examination of the transformational purpose and theory of ACL which has relevance to ESDGC provides the basis for a discussion of the re-framing or re-conceptualisation of ESDGC. This rests on an examination of the conceptual basis of EGC which underpins explanations as to why EGC was problematic. An appropriate pedagogy is then discussed in the final part of this chapter.

Whilst it touches on all research questions, this chapter specifically addresses the following two:

From the literature and from the data, can we distinguish the 'latent' contribution of ACL to ESDGC, and how this contributes to an understanding of implementation processes in translating policy to practice?

How can features emerging from the research assist in identifying some of the difficulties surrounding the implementation of EGC? Can these inform a reconceptualisation of ESDGC more aligned to the translation of policy into practice in the future?

\subsection{ACL and ESDGC: synergy in purpose}

The Common Understanding in ACL document (Welsh Government, 2012) states that the basic principles of good adult education are the same as those of good ESDGC: to foster critical thinking, debate and discussions and create citizens who participate in the 
democratic process. This quotation from the document outlines elements that provide synergy between $A C L$ and ESDGC:

ACL and ESDGC share a common goal of empowering individuals and facilitating their development as active and aware citizens recognizing the needs of learners to engage independently and critically with the processes and networks developing as a result of global change. (Welsh Government, 2012: 7)

$A C L$, within an empowerment model, is by its very nature transformative for the individual, and can, through collective approaches, transform society. Learners are empowered to participate in communities or in decision making, for example through personal transformation in conjunction with, and connected to, addressing the structural and ideological problems which underlie social injustice. A transformational $A C L$ approach "helps to move the problem being ascribed to individuals and their problematic behaviour to a more critical and therefore useful socio-political understanding of forces or circumstances" (Clover et al., 2013: 5) that influence our lives and the environment, both local and global. This suggests a strong synergy with ESDGC and is clearly part of the 'latent' contribution of $A C L$ to ESDGC.

"Public policy affecting learning through the life course has been on something of a roller coaster over the last 15 years" (Tuckett, cited Schuller \& Watson, 2009: xi) as it continues to respond to trends such as intensifying globalization, changing demographics, advances in technology and changing political, economic and social agendas. These changing policy priorities and directives, which include education, have adversely affected the ACL sector's ability to respond to the ESDGC strategy.

In the early 21st century, as job tenure has decreased, and temporary employment has grown, adult education has adopted a role in enabling people to adapt to portfolio careers (OECD, 2003). On the one hand, this fluidity and flexibility can be appealing; however, on the other hand it means increasing insecurity and instability for many (Bauman, 2013), and adult education is often part of a series of coping mechanisms in the face of unpredictable and unsettling change. The UNESCO report of 1972 on Lifelong Learning (Faure, 1972) emphasised adapting to change, but this was revised in 1996 in light of intensifying globalization and inequalities, and learning to adapt was replaced with a strong emphasis on learning in order to be able to proactively direct, or re-direct, change for human wellbeing and development (Delors et al., 1996). This emphasis is echoed by Usher et al. (2011) and others in that "Learning to adapt to change is not enough of itself, it is learning to change, to proactively direct or re-direct change for human well-being and development 
that is the critical challenge" (Torres, 2003: 34). This points to further synergies between $A C L$ and the stated principles of ESDGC found in the definitions (1.2).

Democracy and citizenship are key discourses in adult education (Annette, 2009a, 2009b; Biesta, 2011; Dewey, 1916; Jarvis, 2008b), and Martin (2003) argues that the dominant discourse of lifelong learning is a political rather than an educational one. I contend that these discourses and purposes are inseparable, and that adult education, as an instrument for social change, can deliver different policies and educational outcomes, such as those embodied in ESDGC. Many research participants commented that the purpose and ideology of ACL was compatible with ESDGC referring to social justice and traditions of community engagement, active citizenship and empowerment that were once at the core of adult education.

In ACL years ago, there were Miners' Institutes, reading rooms. They are now Bingo halls: it's not the same. The critical learning was there. We put on what people expect from adult education now - sugar craft, embroidery and all the rest - and find it difficult to fund issue-based courses. We do things like local and family history, where you can tease out the issues, but not much. (Senior Manager)

Since beginning this research in 2008, the ACL sector's ability to engage with ESDGC and realise its potential has been constrained because of the increasing emphasis on qualifications and skills for employment and the decrease in emancipatory and transformational learning. This was recognised by many research respondents as an underlying reason for the 'piecemeal' engagement and delivery.

One aspect of the 'latent' contribution of ACL referred to in the ESDGC strategy is the critical approach at the centre of an education that realises adulthood (Brookfield, 2001). Critical approaches are prevalent in EDS, for example in the work of Fien (2000) and Huckle (1993, 2008a, 2010, 2012b), and they are central in EGC (Andreotti, 2006, 2011; L. Davies, 2006; Ellis, 2015). Critical thinking as an aim, as well as a skill to be acquired, is central to ESDGC, but critical pedagogy or transformational learning was not emphasised. The following section examines transformational approaches to learning to further understand the contribution that $\mathrm{ACL}$ theory and practice can make to ESDGC. 


\subsection{Transformational approaches in ACL and ESDGC}

\subsubsection{Introduction}

"Historically, adult education has adopted a critical stance towards, almost a mistrust of, theory, and has instead valorised practice and experience" (Usher et al., 2011: 172). ACL theory is, according to Brookfield (1995: 1), weak and lacks one coherent, publicly stated rationale which its practitioners can believe in and work within. The research found that this contributed to problems, not only within the ACL sector, but also for policymakers seeking to communicate ideas and strategy. However, despite its lack of a single unifying theory, there are elements within the transformative/transformational discourses of $\mathrm{ACL}$ that are pertinent to ESDGC.

Some scholars in fields related to ESDGC often refer to adult education theories, theorists and practices when discussing pedagogy. Bourne (2014b), for example, draws on critical adult educationalists such as Brookfield, Friere, Jarvis and Mezirow in his work on pedagogy in development education, and many scholars such as Clover et al. (2013) and Sterling (2011a) highlight the transformative potential of ESD/ESDGC. Transformational adult education clearly has a great deal to contribute to ESDGC, which in turn can provide a renewed sense of purpose for ACL.

Overall, transformative learning changes the individual and transformational learning's goal is to critique and change society, so that it becomes more equitable. It challenges the norms and hegemony that create discrimination and inequality. As a prominent adult education theorist and practitioner, Brookfield has questioned transformative learning for focusing on gaining deeper understandings of assumptions, but not putting enough emphasis on changing teaching practice and on radical personal and social transformation (Brookfield, 2000). Therefore, transformative learning must be part of a wider transformational learning that adopts collective and social approaches. The process, according to many authors, begins with the life experiences and concerns of learners (Fenwick, 2001; Freire, 1970a; Jordi, 2010; Kaufmann, 2010; Kolb, 1984; Mezirow, 2000) and moves through cycles of connecting abstract ideas and global issues with the personal and local through critical reflection and dialogue.

Clover et al. (2013) and others (Edwards \& Usher, 2007; Merriam et al., 2012; Mezirow, 
1981; Sterling, 2011a; UNESCO, 2014b ${ }^{49}$ ) recognise that transformation is achieved through a learner-centred approach which includes learners' experiences and uses methods and discourses that empower both learner and tutor. Mayo (2010: 55) and others in adult education firmly believe that learning should be driven by the needs and aspirations of learners. Dewey, arguably the most influential thinker on education in the twentieth century, put experiential learning at the centre of his learning theory (Dewey, 1938a). This is not only related to learning experiences as part of the curriculum, it is learning that begins with the learners' lived experience. This learning theory features in most ACL discourses (Kolb, 1984), and even though experiential learning was present in the professional standards for ESDGC in ACL (LLUK, 2009: 22), it was not promoted widely, and it was not how tutors and managers in ACL were approaching ESDGC. They were struggling to find starting points and to create relevance: "Don't know where to go to find out how to do this. What's the relevance to people in Cardiff's lives?" (Senior Manager).

Two orientations within a transformational paradigm are considered in the following sections: 'critical' and 'holistic'. These are chosen for their prevalence in the discourses and literature of both $A C L$ and ESDGC. This thesis suggests combining them to create a more expansive theoretical framework for delivering learning outcomes in and through ESDGC where transformational learning is recognised as being 'whole-person' learning.

\subsubsection{Transformational, critical approaches}

Discourses in transformative and transformational learning are based on critical thinking which allows us to recognise falsehoods, distortions, misperceptions and misinformation (Brookfield, 1993); "Through transformative learning we are freed from uncritical acceptance of others' purposes, values and beliefs" (Merriam et al., 2012: 133). Critical pedagogy takes this further through ideology critique, where dominant ideologies and the assumptions, ways of thinking and behaviours associated with them are examined. It involves critically questioning why there is distortion and falsehood, who is responsible for creating this, and how to act for social justice. New perspectives and meanings are cocreated through critical reflection and dialogue.

\footnotetext{
${ }^{49} \mathrm{https} / / /$ sustainabledevelopment.un.org/content/documents/1674unescoroadmap.pdf
} 
Johnson and Morris (2010), within a framework for critical citizenship education, provide a useful diagrammatic representation of the relationship between critical thinking and pedagogy (Fig. 8.1).

Fig. 8.1 Intersections between critical thinking and critical pedagogy (Johnson and Morris, 2010: 80)

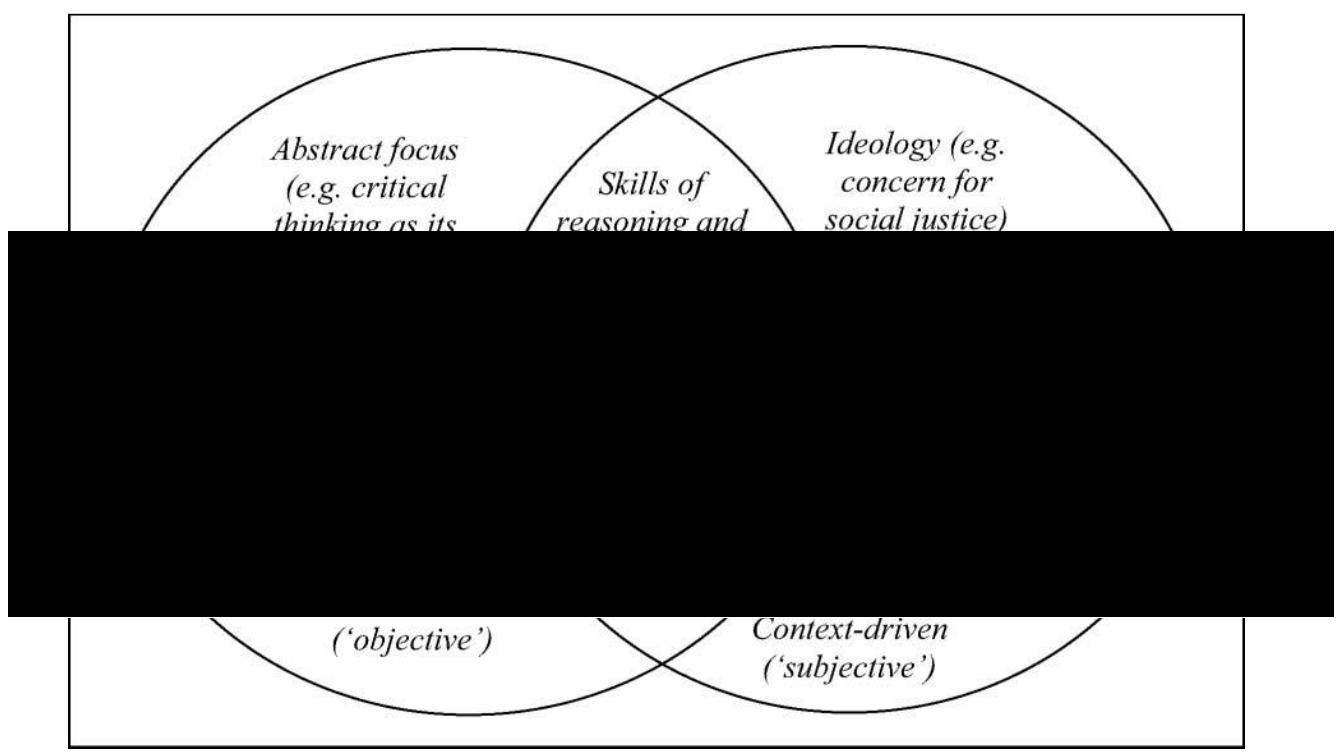

However, to separate critical thinking from critical pedagogy is a false distinction, and for teaching and learning to be transformational they need to be integrated (Burbules, 2000).

Critical thinking skills are essential in ESDGC but remain largely abstract and technical; 'critical', in this sense, easily becomes a buzzword without a precise meaning (Johnson \& Morris, 2010: 78). In ESDGC in Wales, critical thinking and not critical pedagogy was emphasised, and as a result, the practical and context-dependent orientation of critical pedagogy was not used. The local, learner-centred and experiential approaches advocated in the literature (Brookfield, 2001; Johnson \& Morris, 2010) were not emphasised. The Common Understanding in ACL did, however, address this through emphasising participation, active learning and the contribution that the learner's experience and knowledge can bring to the process (Welsh Government, 2012: 7). The guidance also advocated critical approaches but at the time of the research ACL practitioners did not have access to this document.

Espousing critical thinking is not useful for many adult educators who are not familiar with critical pedagogy or with ESDGC and the 'how to' was not obvious in the strategy 
document. For many practitioners critical thinking remained an abstract ideal, unrelated to day-to-day lives. However, as noted previously, Brookfield has demystified critical thinking through using dialogue and discussion as teaching and learning tools and methods. Critical pedagogy, according to Brookfield (2001: 21) "Springs from the desire to extend democratic socialist values and processes, to create a world in which a commitment to the common good is the foundation of individual well-being and adult development". The literature in both $A C L$ and ESDGC identify the central role that this form of pedagogy can play in helping to create a more socially just and ecologically sustainable world.

Educating for sustainability requires developing not only critical understanding of complex concepts, but also the thinking skills necessary to analyse vested interests to recognise and challenge bias, to analyse decision-making processes and to be able to discuss solutions and prospects for change. (Fien \& Tilbury, 1998: 23)

The collective and relational nature of all learning is recognised to the extent that the wider transformation of organisations and society occurs as individuals work together. Freire's (1970a) emancipatory model is one of transformative learning for systemic change (Kaufmann, 2010; M. Mayo, 1997) and, significantly, Freire wrote in his last book that "Ecology has gained tremendous importance at the end of this century. It must be present in any educational practice of a radical, critical, and liberating nature" (Freire, 2004: 7). ESDGC contains within it the realisation of Freire's vision. It is potentially radical and transformational.

According to Ellis (2015), it is important to remain critical of all approaches, including critical ones. Bowers (2005) has questioned transformative learning theory which is, he contends, consistent and continuous with Western idealism and values that problematise a deficit model of third world poverty. ESDGC failed to fully consider communal approaches, and the ways of knowing, cultural beliefs and practices of learners, who are not a homogenous group. The emancipation of the individual is legitimate, in that going outside one's own world view is enlightening. However, to dismiss local knowledge and traditions and to relegate them to a low-status outside education has proved to be complicit with the destructive model of unsustainable development (Bowers \& Apffel-Marglin, 2005; Eidoo et al., 2011).

In ESDGC, adult educators are called on to include forms of knowledge that are not part of the traditional canon. The voices of those without recourse to expression in the political 
mainstream, both locally and globally, must be included and listened to. In the present research, local concerns and voices were not prominent in ESDGC. ACL has a tradition of engaging with disadvantaged and socially excluded groups and communities. A critical approach rooted in place, in culture and connecting the individual to community and to the global frame can support the aims of ESDGC, however, many ACL practitioners in Wales noted that community development approaches were missing, and this was recognised as a characteristic of $A C L$ that could contribute to meaningful learning. In contrast, the formal sector influence and an individualistic, behaviour change model on the ESDGC strategy were to the fore.

Some practitioners working in the community asked, "What does it mean for community development practice?" (Focus Group), and in interview an operational manager said:

How do you get them out of their house to take part in their community? Then it's thinking about how you can develop that so that they can see themselves in the wider world. What you do in your community does have an impact on the wider world. I suppose it's for learners and practitioners; how they can be actively engaged and working in their community. (Operational Manager)

Critical transformational learning can provide an underpinning theory and practice for realising the goals of ESDGC. Its purpose it to transform consciousness, both individually and collectively (Freire, 1970a, 1972; Merriam et al., 2012; Mezirow 1983, 1990) and such change is at the heart of ESDGC. "Conscious action and the development of strategies for development and change of any type, let alone conscious strategies for development and transformation and social justice, require women and men with critical consciousness" (M. Mayo, 1997: 3). Exploiting the synergy between ACL and critical approaches in ESDGC can contribute to a truly transformational agenda for change.

\subsubsection{Holistic approaches}

'Holistic' is a contentious term and concept, often maligned and described as 'woolly'. It is frequently misunderstood and taken to mean 'everything' instead of the whole incorporated into its parts; Sterling echoes my thoughts that "It is difficult to articulate an understanding of the world that is fundamentally holistic" (Sterling, 2010: 214). In this subsection, a holistic approach is considered in relation to ESDGC, so that it can be 
incorporated into the dominant theoretical model in adult education and learning, which is a critical one:

Our field's [adult education] preoccupation with critical discourses, critical theory and postfoundational challenges to knowledge has in many ways been very beneficial. Yet, it has also resulted in exclusionary practises such as deciding that the only worthy knowledge is found under the rubric of criticality. (English, 2005: 3)

The literature on ESD and ESDGC contains many references to a 'holistic' approach (Bonnett, 2009; Orr, 1994; Scott \& Gough, 2003; Sterling, 2001, 2003, 2004a). The philosophies that distinguish holistic educational approaches centre on the belief that education involves more than moulding people into roles such as worker, professional or citizen. Holistic education does not narrowly define human possibility and it is based on the premise that each person finds identity, meaning, and purpose in life through connections to others, to community and the natural world. It is an ecological model. There is no prescribed curriculum, as it is responsive and flexible and learning is experiential. The whole person is considered, including the intellectual, emotional, physical, social, spiritual and aesthetic dimensions. It is acknowledged that this holistic ideal is difficult to translate into practice within an educational system and paradigm that fragments and compartmentalises knowledge, and where learning context and content are stratified and delineated.

Holistic education recognises that the affective domain is as important as cognitive learning. The affective domain includes examining values, attitudes and beliefs and encompasses feelings and emotions. It is emotions and feelings that we are discussing here; they do not have prominence in the discourses of ESD and EGC even though feelings and emotions are recognised as being inseparable from the cognitive in learning theory (Jarvis, 2006a: 18). Emotions and feelings are part of the way we perceive and process information, the way in which we store, retrieve and use it; they are part of the way we learn (Heron, 1992). In addressing complex and often emotive issues in ESDGC, they can expand the possibilities for learning (Dirkx, 2001, 2006; Larsson, 2000; Orr, 1994; Shephard, 2008; Taylor, 2008) through developing communication and empathic skills and emotional intelligence.

Education in a globalized world is increasingly putting emphasis on the importance of values, attitudes and communication skills as a critical complement to cognitive knowledge and skills. The education community is also paying increasing attention to the relevance of education in understanding and resolving social, political, 
cultural and global issues. This includes the role of education in supporting peace, human rights, equity, acceptance of diversity, and sustainable development.

(UNESCO, 2013: 1)

Emotions and feelings are deeply interrelated and are part of a holistic adult education which "underscores the importance of attending to emotions and feelings in contexts, interactions, and relationships" (Dirkx, 2001: 68). Affective learning enables the development of higher-order skills in line with Bloom's taxonomy of learning objectives (Anderson et al., 2001). Higher-order thinking is the ability to move from simply remembering to analyse, evaluate and create and to communicate learning effectively; higher-order learning builds on previous learning and involves the interplay of thoughts and feelings. Without the affective domain there is a lacuna.

The spiritual dimension is increasingly seen as an important element in adult education and social change by authors such as Cranton and Taylor (2012), English (2013), Fenwick and English (2004) and Tisdell (2003, 2011a, 2011b). This is not an esoteric vision: it is fundamentally about purpose and how we make meaning in and of our lives (Tisdell, 2003: 31). It can be articulated through the lens of humanistic and personal development (MacKeracher, 2004), the purpose of which is to foster self-understanding and selfknowledge. Spirituality is enmeshed in culture: it is not something rarefied and otherworldly. It is an important aspect in our global interconnectedness as referred to by O'Sullivan (1999) and interdependence is a key concept in ESDGC.

Learning from affective responses within a critical and transformational approach can be a powerful process, and through making connections with lived experience, we can develop a deeper understanding of the seemingly abstract issues in ESDGC. The following section proposes an approach that puts global citizenship at the heart of an education for sustainable development, and that informs a learner-centred pedagogy that brings critical and holistic approaches together. It is intended to contribute to a theoretical framework that can be more closely aligned with ACL theory and practice. 


\subsection{Re-conceptualising ESDGC as ecological global citizenship education}

\subsubsection{Education for Global Citizenship at the centre}

The Welsh Government added EGC to ESD, however, a proposed re-conceptualisation informed by the literature, the findings and previous discussions, foregrounds EGC in an ecologically grounded pedagogy. Using the term 'ecological global citizenship education' and not describing it as an education for ecological global citizenship provides a less normative concept that is more open and inclusive. It is not perfect by any means. Ellis's $(2013,2015)$ term 'global citizenship as sustainable development' captures the meaning, although it does not fully convey an ecological model which includes critical and holistic approaches proposed here, in what is simply, one theoretical model for what must remain a dynamic work in progress.

EGC did not receive the same attention as ESD in ESDGC and this began during the policy process, which was driven, and led, by practitioners with backgrounds in environmental education. This contributed to misunderstandings of the concept of global citizenship, and a 'thin' approach to EGC dominated: one that focused on multiculturalism, international exchanges and fundraising, for example (L. Davies, 2006: 6). The quote below reflects the findings in this current research and articulates the imperative to clarify concepts and link discourses:

My sense is that citizenship educators are not over interested in 'global citizenship' per se except as a small part of what they might do. My sense also is that those promoting global citizenship do not necessarily have a detailed knowledge of or wider interest in the field of citizenship. (Ellis, 2015: 216)

It is important to understand the concept of citizenship before we can fully comprehend the discourses of EGC, according to Gaudelli (2003) and Schattle $(2008,2012)$. Hence, there are sections in the literature review on citizenship and citizenship education in ACL that help explain the latent contribution of ACL to ESDGC through its traditions of citizenship education and civic learning (Fryer, 2010; Jarvis, 2008b; M. Mayo \& Annette, 2010).

One reason for an apparent and relative neglect of EGC is that until recently, most of the literature on ESD has marginalised global citizenship discourses and they were not prominent during the Decade of ESD (Huckle \& Wals, 2015: 496). Tutors included in the current research frequently said they did not know what global citizenship was or how to 
do it, and yet strong views were expressed (See 6.6). It is an emotive subject (Ellis, 2015, Tully, 2014).

Notions of global citizenship appeared abstract to $A C L$ practitioners, as links were not made between the experiences of learners, local agendas, community development and ESDGC, as discussed in the previous chapter. It is understood that, at times, it is necessary to abstract to an extent, inasmuch as everything outside our immediate experience is, in a certain sense, imagined by us (Gerzon, 2010). However, the issues can be made relevant through experiential and self-directed learning approaches. This current research found that many ACL practitioners lacked confidence and the skills needed to be able to make the connections between local and global issues and the abstract and concrete in order to facilitate learning. This was evident in responses from tutors and managers.

The central importance of global citizenship in ESD is recognised by many authors; for example, Ellis $(2013,2015)$ sees critical global education and citizenship as sustainable development. Huckle (1996, 2001a, 2001b, 2014,2015) emphasises its central role in a critical approach and Huckle and Wals (2015) discuss the importance of highlighting it due to the 'business as usual' outcome of the UN Decade of ESD.

If key causes of the global crisis are the prevailing geopolitical order and lack of global governance, together with a lack of 'civic pedagogy', as the authors of TEWN [The Education we Need for the World we Want] maintain, then global citizenship education should lie at the heart of an international initiative on ESD, such as DESD. This premise leads us to suggest combining the emerging theory and practice of sustainability or sustainable citizenship with that of ecopedagogy and global citizenship education. (Huckle \& Wals, 2015: 493)

Global citizenship is, as Gerzon (2010: $x x$ ) says, "both an ' inside' and an 'outside' job because the inner work of raising our awareness enables us to act in the world in more effective, transformative ways".

Citizenship as a core concept in ACL has become marginalised in the current ideological climate in the UK. However, global citizenship can find expression through adopting an approach that includes elements of the radical traditions and theories of $A C L$, and $A C L$, can through the inclusion of ESDGC re-purposes itself, as Blewitt (2004b) proposes, in line with sustainable development goals. The synergy between $A C L$ and ESDGC points to a way forward where community development and sustainable development are linked and where local and global citizenship become synonymous. 
The Venn diagram below presents a useful visualisation of the proposition, where ecology, politics and ethics are interlocking domains instead of the economic, social and environmental as traditionally seen in association with ESDGC. Even though this is not fully adequate, it represents an accessible model for teaching and learning in ACL.

Before considering elements of this education, it is necessary to clarify what we mean by global citizenship and what it means to be a global citizen.

\subsubsection{What is global citizenship?}

The concept of global citizenship is dynamic, multifaceted and contested, and, as seen in the literature, it is variously understood and influenced by traditions of citizenship. Examples include 'cosmopolitanism', as Kant conceptualised it and 'development' or progress in Marxist terms which are both based on Eurocentric values, norms and masculine frames of reference. Different and multiple discourses, such as de-colonial, ecological and feminist ones are now more prevalent in the literature and their inclusion can create a plural, dynamic and inclusive notion of global citizenship. The current discourses and daily practice of citizenship exclude many disadvantaged and marginalised groups of people (Lister, 2003; Pattie et al., 2004).

The language used in public discourses is not familiar to those who are disempowered though poverty and various levels of illiteracy, for example, and who cannot make their voices heard. ACL addresses the issue of social exclusion through engaging with communities using tried and tested participatory methods and critical pedagogical models that empower learners. ESDGC can potentially provide the context for more relevant citizenship and global citizenship education even though political and ethical discourses, which are inherent in citizenship, posed problems for some ACL practitioners. This was recognised at the policy level "it can be difficult for tutors. It is political with a small ' $p$ '” (Policy level interviewee) and a tutor stated: "It can often be seen as very political and it is a big ask of tutors". However, there were some who recognised the ethical dimension and welcomed this, "Fundamentally ESDGC is about moral education" (Senior Manager).

Through the realisation that we share one biosphere and that we have a shared vulnerability (O'Neil, 2000), the need for an ecological, ethical, political and global perspective linked to sustainable development has come to the fore. Some people think 
they are global citizens, others do not, and many others have not considered or even heard of the concept. Given the contested nature of citizenship, it is inevitable that there is debate as to what constitutes global citizenship. From the literature, there are effectively two main ways of looking at this:

1. There are parameters to be a global citizen; you are one through membership. In this approach, one is or is not a member of the global community. This is a political community and would be defined by governance, legislation, an ethical code, or codes of conduct, for example. In this model there is a point when we say that someone is, or is not, a global citizen.

2. We are all global citizens by the very dint of being human. A global citizen is a member of the human race.

The first definition is in keeping with the traditional definition of citizenship (Marshall, 1950: 28-9), and is usually linked to a nation-state. The second, inclusive, definition is used here: it embodies an ecological, interconnected, interdependent ethos which underpins the core elements of citizenship as outlined in the literature review: participation, rights, responsibilities (duties/obligations) and identity (Williams \& Humphrys, 2003: 4).

One of the main objections to the use of the word 'citizenship' in a global context is that it has traditionally been linked with a polity and there is no global polity. Global governance is not broached in this thesis, and global citizenship, as understood here, is framed by ethical and political dimensions and discourses (Hayden, 2005: 3). It is a particular 'frame of mind' in the first instance, redolent of Bonnett's (2002) idea in connection with ESD, and it is the examination and actualization of these mind-sets, or transformations, that is the challenge for educators.

Global citizenship is not a new idea but defining what it means remains problematic. In the context of ESDGC, Dobson (2003a) and Huckle (2001a, 2001b, 2015) have put forward a notion of global environmental or ecological citizenship where responsibilities come to the fore as a counterbalance to the liberal emphasis on rights (Callan, 1997; Dobson, 2003a; Dower, 2007, 2010; Valencia, 2005). Ecological global citizenship balances rights with an emphasis on individual and collective responsibilities or duties. These duties, within the global frame, are often non-reciprocal and fall primarily on those who occupy unsustainable amounts of ecological space vis-à-vis those in need. Obligations are also extended towards future generations, as we have a responsibility to ensure a healthy planet for them to inherit (Dowdeswell, 1995; UN, 1987; Welsh Government, 2015a). 
A discourse of responsibility and concern for other human beings and other forms of life is the realm of ethics, or moral philosophy, and it is worth engaging with this field of study to enhance understandings in ESDGC. Research by Leenders et al. (2008) and Veugelers (2011) found that when teaching citizenship and global citizenship, beginning with moral or ethical issues and moving to the political was easier for teachers. Pertinent arguments include the proposition put forward by Singer (2004: 4), who states that the value of the life of an innocent human being does not vary according to nationality, and Rorty (1989: 190), who claims that we have a moral obligation to feel a sense of solidarity with all other human beings. He puts aside notions of rational and universal moral deliberations and focuses on the shared vulnerability and the common, human recognition of suffering as the basis for solidarity. As he puts it: "We have obligations to human beings simply as such", and this creates, what Rorty sees as "a more expansive sense of solidarity than we presently have" (Rorty, 1989: 196). Solidarity entails seeing difference as less important (tribe, race etc.), and thinking of people who are different from ourselves as included in the range of ' $u s^{\prime}$ (Rorty, 1989: 92). This, however, does not mean that we do not recognise and value difference, which is important to identity and to a plural vision for citizenship; nor does it promote a bland cultural relativism (Brookfield \& Holst, 2011; Gaudelli, 2003; Veugelers, 2011).

'Identity' is not being examined in this thesis; however, its relationship to a plural vision for a pedagogy for global citizenship education is important (Todd, 2011, 2015). "A radical conception of plurality is needed in order both to re-imagine the boundaries of democratic education and to address more fully the political aspects of conflict that plurality gives rise to" (Todd, 2011: 101). This vision focuses on individuals within unique contexts, with unique narratives and experiences as part of, and not separate from, the collective and plural visions for global citizenship. This aligns with experiential learning and with the transformational model in ACL discussed above.

\subsubsection{The discourses of care - ethical starting points}

Caring about human and non-human life and the lives of those not yet born is linked to both political and ethical discourses. However, care theory and discourses are not prominent in ESDGC or in $\mathrm{ACL}$, even though there is a recognition that it is in the common interest to care about each other's self-development as well as one's own, because our own flourishing depends, in a vital sense, on the flourishing of others (Buber, 1958; 
Brookfield \& Preskill, 2012; Freire, 1970a). Schattle (2008) and Gaudelli (2003), in their work on global citizenship and education, discuss care theory; there are those who think it can play an important part in a framework for ecological global citizenship education.

Why should we care about the environment? Why should we care about anything or anybody? These are fundamental questions that are worth considering. We probably do care for our family and friends, but what about people we don't know, people who live in another country or on the other side of the world, or future generations, plants, animals? Care, of some form, takes place from the minute we draw breath. There are different forms of caring. There is the immediate caring 'for', which is the initial form of caring that we experience, and as we mature, we can, by extension, learn to care 'about' (Noddings, 2002: 22). This 'caring-about' includes all aspects of life: the political and personal, private and public. Care is political and ethical.

Caring-about is an important aspect of justice and takes caring into the public realm. "The ethics of care provides a way of thinking about and evaluating both the more immediate and the more distant human relations with which to develop morally acceptable societies" (V. Held, 2006: 43), and Held hopes that her arguments will "apply also to what we may come to think of as global citizenship" (V. Held, 2006: 159). Justice is closely linked to an ethic of care, but whereas justice seeks a fair solution between competing interests, the ethics of care seeks interconnections and focuses on relationships and interdependencies (V. Held, 2006: 15). There is a need for both orientations and the dominant social justice model in both ACL and ESDGC might be balanced with care discourses.

According to many authors, most people are alienated from ethical discourses which have traditionally been concerned with abstract norms, even though moral reality includes feelings, emotions and embodied experience (Koehn, 1998; Singer, 2004, 2011; Rorty, 1989; Todd, 2010, 2011). "Dominant moral theories tend to interpret moral problems as if they were conflicts between egotistical individual interests on the one hand, and the universal moral principle on the other" (V. Held, 2006: 10), whereas real life involves a complex web of relationships and interdependencies and our individual interests are intertwined with the well-being of others. Interdependence as a central concept in ESDGC highlights the pertinence of this. 
Some research respondents acknowledged that:

These issues, they are about morality, aren't they? They are looking at how we live our lives and how we make choices, based on morals. Sort of a philosophical approach, I suppose - interesting. One could approach it this way and begin by looking at ethics and suchlike. (Senior Manager)

At the heart of ethical problems lies the need to understanding relationships, because "ethics are fundamentally about social situations" (Jarvis, 2008b: 134). This is in accord with social, systemic and relational learning in ESD and EGC, and indeed relational learning has emerged as a means of expressing what has been missing in education (Jarvis 2008a: 170; Sterling, 2010a).

Care discourses can foster inclusion through making public issues more immediate and relevant (V.Held, 2006; Koehn, 1998; Noddings, 2010, 2013a, 2013b) and they can inform a pedagogy that includes both holistic and critical transformational learning approaches. There were great expectations following the Earth Summit in 1992 (UN, 1992a), but Agenda 21, whilst raising awareness in education of the global sustainable development agenda, has not ignited a passion amongst $A C L$ educators. The literature highlights the need for new pedagogies, for new forms of education in the light of globalization, and care theory has the potential to integrate and connect ecological, political and ethical issues and inspire new perspectives.

\subsubsection{Ecological, relational approaches}

The commitment to rationalism, the ill effects of an unbridled belief in science and the myth of universality are taking their toll on life on this planet (English \& P. Mayo, 2012: 57); our rational thinking is destructive, and so perhaps relational thinking is worth trying. We live in relation, we learn in relation, we are a part of the earth and in relation to it: the relational is an ecological ethos which Helne and Hirvilammi (2015) argue is vital for our well-being and for sustainable development. As Sterling states this view is "Associated with an emergent, yet fragile, 'postmodern ecological worldview'"' (Sterling, 2013b: 43).

Focusing on the individual has not resulted in a paradigm shift towards more sustainable living, or demonstrated far-reaching learning outcomes (Huckle \& Wals, 2015); therefore, a more collective and democratic form of learning is advocated. Collective learning and action for sustainability is often under-emphasised (Cotton et al., 2016) and the present 
research found that it was not a strong discourse in ESDGC in Wales, even though, as Wals (2009: 19) states, learning for ESD is "rooted in the life-worlds of people and the encounters they have with each other". The lack of collective and community approaches points to a barrier for the delivery of ESDGC in ACL but also an opportunity to utilise ACL's community engagement models.

Citizenship discourses and participation in the public sphere implies a world of relationships and interactions (Van Poeck \& Vandenabeele, 2012). The importance of paying attention to relationships, and the role they play in supporting and allowing dialogue and discussion as part of transformative learning, is highlighted by many authors (Lysaker \& Furuness, 2011; Murphy \& Brown,2012; Taylor \& Snyder,2012: 44-45). Relational learning in ESDGC is considered vital (Helne \& Hirvilammi, 2015; Sterling, 2010a).

An ecological ethos is a relational or systemic orientation, and Sterling $(2008,2010 a$, $2010 b$ ) is among those calling for this approach in ESD in line with the Earth Charter (Sterling, 2010b: 214). Interconnection, interrelationship and interdependence are more than rhetorical sound-bites; they embody the four ecological 'truths' or 'laws' as outlined by Commoner:

1. Everything is connected to everything else. There is one ecosphere for all living organisms and what affects one, affects all.

2. Everything must go somewhere. There is no "waste" in nature and there is no "away" to which things can be thrown.

3. Nature knows best. Humankind has fashioned technology to improve upon nature, but such change in a natural system is, says Commoner, "likely to be detrimental to that system"

4. There is no such thing as a free lunch. Exploitation of nature inevitably involves the conversion of resources from useful to useless forms. (Commoner, 1971)

A basic understanding of these laws contributes to an ecological literacy, which has been discussed by many authors (Kahn \& Kahn, 2010; Orr, 1994; Sterling, 2010a).

The reconceptualisation proposed here rests on a theoretical orientation that is critical and holistic and is underpinned by an ecological orientation or ethos. This gives prominence to relational, community, social, collective and connate discourses to inform theory and practice. In this re-framing, critical transformational learning theory integrates the emotional, affective domain and explores care theory as the means of connecting ethical and political discourses and making them relevant to everyday life. 


\subsection{Key elements in a pedagogy for ecological global citizenship education}

\subsubsection{New paradigms, new pedagogy}

The current research found that the 'how to' of teaching ESDGC was lacking, and in this context 'how' we teach is possibly more important than 'what' we teach. This was the feeling of some research respondents: "It is about good practice now not policy, that has been done. We need to look at the how to do it" (Operational Manager); "How do I embed ESDGC into my lessons? I would like some ideas on how to do it" (Tutor). Examining pedagogy therefore becomes essential and given the all-encompassing scope of ESDGC and the lack of resources available, developing new approaches to pedagogy that facilitates the exploration of complex and contested issues would seem to be an expedient course of action.

It has been suggested that "whilst there has been considerable progress in the UK, many of the activities have resulted from government policy initiatives that may not have been based on broader educational debates and thinking" (Bourn, 2008: 203). From what ACL practitioners in Wales described, and from the analysis of the findings and the wider policy context, it appears that this was indeed the case with ESDGC in Wales. Learning outcomes were not clearly articulated, even though "One of the major rationales for introducing planned change in education concerns the idea of bringing about improvement in [pupils'] learning outcomes" (Nudzor, 2013: 79). Learning outcomes for ESDGC were nebulous and evidence suggests that it was more concerned with behaviour change than with exploring new pedagogies.

Pedagogy is not equivalent to education, which includes policy, programme design and curriculum (Fenwick, 2006: 11), nor is it equivalent to learning, which can, and does occur without pedagogy. In pedagogy there is an intentional mediation of knowledge and a creative process focusing on learning transactions. One definition is "the social, political and cultural mediation of the process of knowledge reconstruction" (Bernstein, 1996: 6).

Pedagogy is grounded not only in community and in social relations, but also in the natural, the biological (Burns, 2015; Ellis, 2015; Fenwick, 2006: 17). Bowers calls for a radical reappraisal of adult education in line with eco-pedagogy: 
Only as adult education addresses these challenges will there be the possibility of altering the course of our current environmental and cultural crisis. An ecologically informed adult education should lead to a general rethinking of the core of education and the processes inherent within it. (Bowers, 2017: 53)

It is proposed that solidarity and democracy are inherent in a re-alignment with a critical eco-pedagogy (Torres, 2013: 60).

A shift from the tripartite elements of 'environment', 'society' and 'economy' which are often used to explain sustainable development and ESD is proposed. The Venn diagram below is a simple representation of key elements in a pedagogy for ecological global citizenship.

Fig 8.2 A simple model for ecological global citizenship education

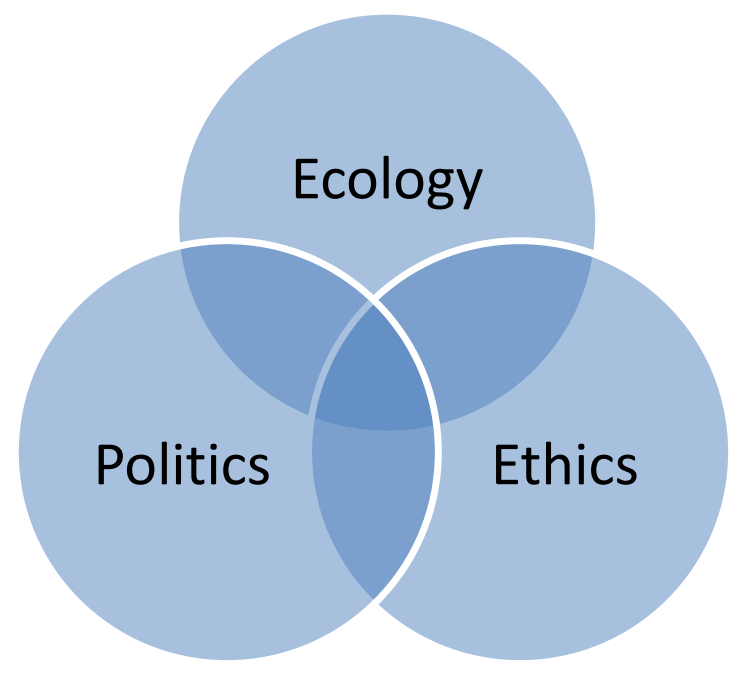

The use of 'politics', 'ecology' and 'ethics' is proposed as a first step or shift to a reframing of ESDGC, where the concerns and approaches of a critical and holistic pedagogy integrate ecology with the moral and political philosophy inherent in EGC.

- Ecology is used in place of environment, foregrounding interdependence, relationships and the four laws of ecology as discussed previously.

- Politics - including this necessitates an explicit examination of the public sphere, power relations and ideology.

- Ethics - values and attitudes and care theory can be included under the rubric of ethics and moral philosophy. 
The ecological can be seen as an underpinning or encompassing ethos, as in the diagram below, which is another, and possibly more accurate representation of the proposed model:

Fig 8.3 Key elements of an ecological global citizenship education

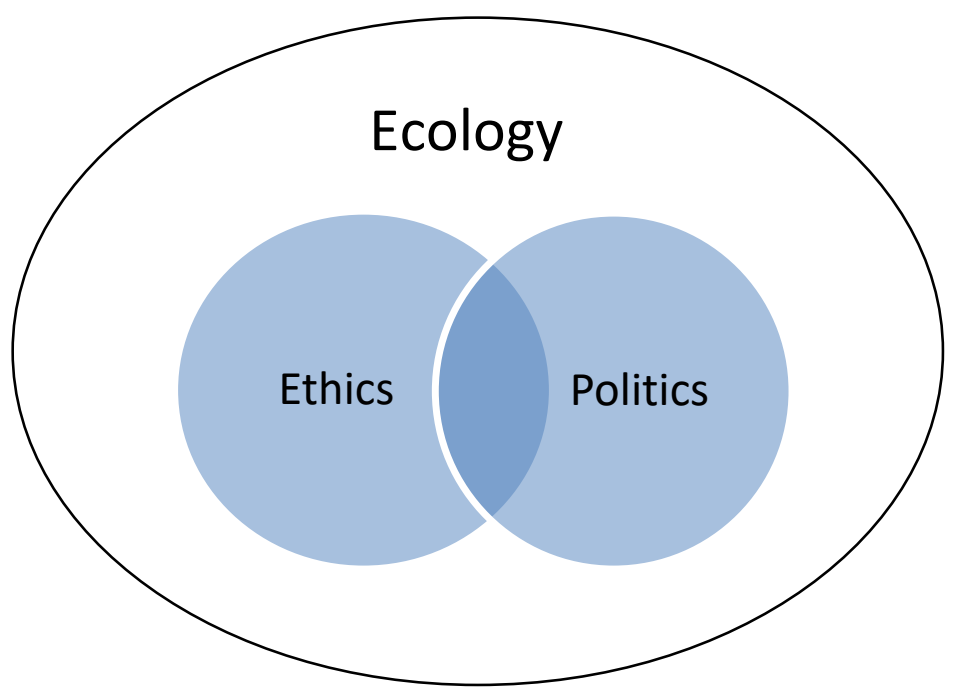

Terming the domains under consideration as 'Ethics' and 'Politics' necessitates a philosophical examination, a deeper questioning and exploration of issues and of ourselves as human beings both socially and individually.

Misiaszek (2016: 600) and Whiting et al. (2018: 7) represent the key elements in this form of education as 'individual' and 'society'. The discourses of 'future citizens' and 'the earth' are included in this model of ecopedagogy. Although this vision is critical and inclusive, and points to a similar reconceptualisation of ESD and EGC as proposed in this current thesis, Misiaszek's model of 'global environmental citizenship' (Misiaszek, 2017) is different, and hence the emphasis is different. Many other authors discuss connecting and reconceptualising ESD and EGC including Dobson (2003a), Huckle (2001a, 2001b, 2015) and Huckle and Wals (2015). MacGregor (2011), Kahn (2008) and Kahn and Kahn (2010) link these ideas explicitly to ecopedagogy and Fenwick (2006) discusses the ideas from an ACL perspective. Each model has a different nuance and theoretical perspective; however, their purpose is similar and in accord with the model proposed in this current thesis. 


\subsubsection{Dialogue for uncomfortable learning}

As we bring together ethical, political and ecological issues together with local and personal concerns, learning can become uncomfortable, and controversial and emotive issues frequently arise (Hess, 2004: 160). ACL practitioners and policymakers in Wales recognised the challenges inherent in this, as a tutor said: "people could get upset in the classroom". A policy level interviewee could see the difficulties but also recognised potential for change: "ESDGC is not about content alone. It is about transforming the way we teach as well, the whole ethos underpinning it ... about methods, new ways of knowing. Quite radical in a way, can be contentious."

A dialogic pedagogy is suggested as a method to engage with uncomfortable issues, to develop critical consciousness and holistic understandings. "For the Brazilian educator Paulo Freire, dialogue is a hinge concept, one that potentially connects scientific with humanistic knowledge, theory with practice, and human nature with human behaviour" (Cissna \& Anderson, 2012: 173). Dialogue is central to transformative learning and is a dialectic where learners at times teach and teachers are open to learning from students (Freire, 1970a; Torres, 2013). "Education based on dialogue is one that places appropriate weight on both the teacher's influence and on the student's capacities, interests and needs" (Guilherme \& Morgan, 2009: 568). Becoming engaged in dialogue in a classroom enables us, as Todd (2015) says, to face our humanity and rethink cosmopolitanism. It can have a profound role in shaping a new agenda for re-aligning the purpose and pedagogy of adult education to an ecological global citizenship education. Gaudelli (2009: 78) states that dialogue "deserves attention in global citizenship curriculum theorizing and implementation". It is becoming more important in an age when "The public sphere is also complicated by an increasing citizen mistrust of the new electronic media/information environment, and at times by a cynicism that freezes citizens into inaction" (Cissna \& Anderson, 2012: xv). Encouraging and supporting dialogue in the classroom can support public dialogue.

Dialogue has the advantage that it can be employed in a range of classroom contexts without the need for a great many resources: it is accessible practice. It has two broad purposes: it is a method where content is learned and understood through interaction and communication, and it also develops critical skills (Larsson, 2000). Useful life-skills that can be learned through dialogue include the ability to listen, to articulate thoughts and feelings, 
to develop emotional intelligence, to respond appropriately to others, to formulate arguments and to express our views confidently (Vella, 2002).

There is certainly a place for technical dialogue, but here we are considering dialogue in a deeper sense, where it involves the whole person: reason and emotions, rationality and feelings, and "The ethics of care is hospitable to the methods of discourse ethics, [though] with an emphasis on dialogue that empowers its participants to express themselves" (V. Held, 2006: 20). Dialogue embodies relational learning (Lysaker \& Furuness, 2011; Murphy \& Brown, 2012; Noddings, 2013a; Sterling, 2010a), allows meaning to be made in the classroom where understandings are reached, and can help people to express different perspectives and realise their common interests (Brookfield \& Holst, 2011: 59). Selby, in relation to ESD, envisages radical new ways of seeing the world emerging from dialogue, as new contexts, climates and personal and collective dispositions are created (Selby, 2009: 70).

Issues in ESDGC are often controversial. Facing difficulties and uncomfortable realities and using them in learning is not easy for teacher or learners: it is frequently uncomfortable, and this discomfort is referred to by different names including 'disorienting dilemma' (Mezirow, 2000), 'disjuncture' (Jarvis, 2006a: 74, 77), 'dissonance' (Todd, 2010), and a pedagogy of 'dissensus' (Andreotti, 2011), and Selby and Kagawa (2011) use the term 'blessed unrest'.

The History Association's publication on teaching emotive and controversial history (History Association, 2007) underlines the assertion made by Bowers (2001) that it is difficult to talk about some issues without reverting to 'goodies and baddies'. Many authors including Eidoo et al. (2011: 78) emphasise the need to "Move beyond dangerous binaries and oversimplifications of global issues" and "to engage with complexity and conflict in classroom practice". For example, they argue that "race is much more than a black and white binary. It is complex, ever-shifting, dynamic, and context-driven" (Eidoo et al., 2011: 78). Facilitating learning on these subjects requires a great deal of skill and sensitivity on the part of the teacher. Learning how to plan for, and conduct effective dialogue and discussion is essential (Brookfield, 2006, 2011; Brookfield \& Preskill, 2012). In her work on teaching controversial environmental issues, Cotton (2006) found that even though teachers thought they should adopt a 'neutral' or 'balanced' approach, this was not a realistic expectation and was not sustainable as their own beliefs emerged more than they had hoped. 
One of the barriers to implementing the ESDGC strategy and embedding it into teaching and learning was the reticence of $A C L$ tutors to broach ethical and political questions and issues. ACL tutors in Wales were afraid of being partisan, in line with the research findings of Cotton (2006):

It can often be seen as a very political and it is a big-ask for tutors. Tutors will hold beliefs and biases, and there can be a danger of tutors preaching a particular message that they sign up to or blocking information on other points of view. (Tutor)

Tutors need training to facilitate dialogue and discussion effectively so that their own and learners' beliefs and values can be honestly explored and challenged. It is vital that a bland neutrality or cultural relativism does not prevail and that learning outcomes are understood and agreed with adult learners.

Post-colonial discourses, for example, encompass issues where controversy emerges. In critical adult education, these discourses are conceived by English and P. Mayo (2012) as all-embracing, accounting for the process of domination that has its basis in European colonisation. However, many of the issues have relevance within the UK, and many of the comments by tutors were related to identity, cultural power relations and prejudice within the UK. These conversations are complex, often controversial and emotive, and it is critical that we include them, no matter how uncomfortable.

Connecting Welsh issues with global ones for example is possible through examining postcolonial discourses in the UK; this could be useful starting points in EGC. Ireland, Scotland and Wales are recognised by many as colonised lands ${ }^{50}$. Similarities exist between the processes of colonial and post-colonial practices around the world including the systematic destruction of culture and language (wa Thiong'o, 1981: 1992), exploitation of land and resources and identifying colonised people as 'primitive'. One, not so distant episode in Welsh history is the example of The Blue Books, a three-volume report on Welsh schools, compiled by three English law graduates in 1847 on the behest of a member of parliament. They "gratuitously exceeded their brief by traducing the morals and language of the

\footnotetext{
${ }^{50}$ https://www.walesonline.co.uk/news/wales-news/wales-first-final-colony---2070487 https://www.newstatesman.com/politics/2007/04/welsh-language-wales-england http://www.iwa.wales/click/2015/11/wales-country-or-colony/
} 
people: The Welsh were liars and cheats; their women were primitive and unchaste; they clung to an absurd vernacular" (Jenkins, 2007: 213 - 214). As a result of the report, the 'Welsh Not' was introduced in Welsh schools, a wooden board worn around the neck of a child caught speaking Welsh, circa 1850 into the early 20th century (Jenkins, 2007; Tyson Roberts, 1998). The Nobel prize winning Kenyan novelist Ngugi wa Thiong'o wore a wooden tablet around his neck as a child. Any child speaking KiSwahili or Gikuyu would be given the board until they pointed out another child doing the same. The child with the block around their neck at the end of the day would be beaten. This is the exact same method used in Wales. Davies and Davies (1990) point out the racist character of the many edicts and acts imposed in Wales, Ireland, Scotland and many other countries and cultures across the world. There is a wealth of literature on this subject (Davies, 2014; Davies, 2000; Davies \& Davies, 1990; Gillingham, 2000), but the thesis only raises it as an example because of the comments made by $\mathrm{ACL}$ tutors regarding Welsh culture and the opportunities within the Cwricwlwm Cymreig.

In a climate where we are witnessing political polarisation, media censorship and civic apathy, discussing so-called controversial issues becomes important (McAvoy \& Hess, 2013). Discussing difficult subjects has the potential to generate ideas and enables the exploration of uncharted territory as assumptions are challenged and perspectives altered through employing critical approaches. Tensions, conflicts and emotions can create the ground for positive learning experiences in global citizenship education, according to L. Davies (2008) and others:

There is considerable evidence concerning the educational outcomes promoted by the constructive use of controversy. Effectively managed controversy promotes much higher achievement than does either in-effectively managed controversy or the avoidance of any possibility of controversy through individualistic learning procedures. (Johnson, 1981: 8)

In the literature on emancipatory citizenship education in $\mathrm{ACL}$, engaging with ambiguity and dissonance is seen as being vital by English and P. Mayo (2012); encountering disorientating learning dilemmas can be a fruitful learning exercise. This is often part of the learning cycle as our assumptions are challenged and we integrate new knowledge and understandings (Mezirow, 1990, 1995, 2000). Uncomfortable, transformative learning highlights the importance of engaging with emotions if we are to respond intelligently and humanely to troubling questions. Dialogue is at the heart of a pedagogy that encompasses and encourages uncomfortable, transformational learning in an ecological global citizenship education. 


\subsubsection{A realistic and hopeful pedagogy}

How can we conceive hope, so it does not become a grand narrative, but an ethically justifiable entry point? How can we dwell in hope with passion and desire, but without tyranny? One answer may lie in looking more closely at the processes of pedagogy, at how it actually works (Fenwick, 2006: 16).

Hope is integral to being human and it is significant in an ecological global citizenship education. Freire is associated with 'Pedagogies of Hope' and declared that hope is a core underpinning of education and all its processes (Freire, 2007a: 87). Hope is, however, complex, and "best understood as a socially mediated human capacity with varying affective, cognitive and behavioural dimensions" (Webb, 2013: 398) that can, as well as having an emancipatory purpose, operate as part of neoliberal ideology as we hope to fulfil our material desires. There are, indeed, many kinds of hopes, but here, in this context, it is about possessing and nurturing hope, in the face of global, community, ecological, institutional and individual challenges, for an ecologically healthy, peaceful, equitable world now and in the future.

The current research found that amid the pessimism, ACL practitioners hoped that ESDGC could and would contribute to a better world for future generations and help to raise awareness about the issues. Freire (1994) wrote that hope is an ontological need, and teachers and tutors in post-16 education can be bearers of hope as they themselves hope that interactions in the classroom can make a difference.

Pedagogy is inherently audacious. But in the practices of educators it presumes to invade people's lives and minds in the name of hope: hope for a better world, hope for more meaningful existence. Educators' alliances with pedagogy infuse our work with a moral purpose: educators hope to make a difference. (Fenwick, 2006: 9)

Educators can "encourage a movement to less grand and totalising, more local and contingent orientations" where hope can flourish (Fenwick, 2006: 9). Ethics and ecology are the elements of what Fenwick conceptualises as an open, generative and compassionate orientation in ACL pedagogy, congruent with the model proposed by this current thesis.

Some of the more hopeful orientations in pedagogy have been discussed in the literature review (Chapter 2), such as the future-facing orientation of Hicks $(2001,2002)$ and Sterling (2013a), and the work of M. Mayo (1997) concerned with imagining alternatives for the future and with creative problem-solving. This is not about normative Utopias or blueprints for society, but about serious consideration of how we could think and live differently; it is 
about re-imagining self, relationships and community, place, identity and our place in the world. "Education begs the question of what constitutes a desirable future or even a desirable or healthy system" (Wals, 2009: 26).

In contrast to hopeful tropes, denial emerges as a prevalent threat to engagement with the issues in ESDGC. In a book about climate change, Marshall (2014) comments that the epoch we are living in might, when looking back from some future date, will be called the 'age of denial'. This alludes to the way in which we are ignoring threats to the planetary ecosystem and conducting business as usual (Jackson, 2009; Steffen et al., 2011, 2015). This denial is part of the response to overwhelming global problems and there is a "manifest destiny" mentality in the rational, progressive vision with a linear concept of time and a Darwinian evolutionary view of progress and development (O'Sullivan, 1999: 52). The rhetoric of economic growth follows this rationality and is the foundation for neoliberalism and the exponential growth (and destruction) patterns we are witnessing (Milana et al., 2016; Steffen et al., 2015). Challenging this paradigm is part of a hopeful pedagogy in ecological global citizenship education.

"How can you teach this all the time? It is so depressing" is a quotation from a manager in $\mathrm{ACL}$, a response often encountered. "It has become almost axiomatic amongst global and environmental educators to say that undiluted exposure to 'gloom and doom' is disabling and disempowering for the learner" (Selby and Kagawa, 2011: 6). However, a denial of the realities in our lives and in the world makes learning impotent and can also disempower practitioners and learners (Huckle, 2012b). Todd (2009, 2015), Fenwick (2006) and Huckle (2012b) discuss realism associated with the issues in ESDGC; a realistic look at the issues can empower and offer a hopeful pedagogy. Huckle asserts that realism is the basis for learning in ESD and EGC and he feels we should be

More alert to issues of inequality, social class, and sustainability politics; more firmly anchored in the realities of the dominant forms of unsustainable development and underdevelopment shaping the contemporary world; and more attentive to the struggles of the workers and citizens to introduce more sustainable alternatives. (Huckle, 2012b: 35)

Experiencing and understanding emotions such as anger, frustration or fear and being able to face them, understand and articulate them, is valuable learning, achieved through interactions that involve critical reflection and the interplay of the cognitive and affective aspects of ourselves in a dialogic relationship with others. We can learn a repertoire to 
understand and deal with emotions, our own and others', to overcome apathy and develop hope.

This is a challenging idea. Feelings and emotional intelligence are not explicitly valued in education; the discourses of care have not been prominent and facilitating controversial discussions is frequently avoided. Nonetheless, a reticence to engage with difficult or contentious subjects was a feature inhibiting the implementation of ESDGC. As we engage with a range of issues that provoke a range of responses, it is vital that $A C L$ practitioners are trained, confident and motivated to do so.

\subsection{Conclusion}

This chapter has been a forward-facing one that has focused on synergy and potential ways in which ESDGC can be theorised and implemented in the future. It has examined the purpose of $A C L$ and its synergy with ESDGC to demonstrate the potential of using $A C L$ 's community, participatory approaches to empower learners, increase democratic participation and make the issues more relevant for practitioners and learners. The sections on citizenship and global citizenship have demonstrated reasons for the confusion and lack of engagement with EGC that was evident in the findings and point to a need for clarification and deeper engagement with the concepts of citizenship and global citizenship. In troubling and unsettled times, a radical reappraisal of our purpose as educators and a critical examination of existing pedagogies are required (Fenwick, 2006). A reappraisal can also address what Ellis $(2013,2015)$ and Armstrong $(2011)$ perceive as a lack of coherence in theory and praxis relating to global citizenship education.

Critical and holistic transformational approaches have been discussed and these not only underpin the 'latent' contribution of ACL to ESDGC but also provide theoretical and practical ways forward through their integration. Pedagogy was not made explicit in the ESDGC strategy and this chapter has considered several elements, including care theory and a realistic yet hopeful ethos that uses dialogue to address difficult issues and foster deeper learning outcomes.

Clarifying and promoting a pedagogy that places dialogue at the centre is, despite the structural barriers, one way to realise the potential of, and open up possibilities for this form of education. This requires a commitment in policy to support teachers to engage in a 
more immediate form of learning where they can discuss and use controversial issues for learning, and to develop an openness to becoming learners themselves. 


\section{Chapter 9 \\ Conclusion and Recommendations}

\subsection{Introduction: the research aims and questions}

This thesis has explored the development and implementation of the ESDGC strategy in $\mathrm{ACL}$ in Wales and the contextual features surrounding this. A case study design was chosen to explore one particular policy during a particular time in Wales and address the research questions which are re-stated below. Although this is a unique situation it shares features with other policy introduction and implementation processes in other contexts. The case study approach can allow for similarities and differences to be identified and explored. This can consequently contribute to a better understanding, geared to ensuring more successful policy processes in future.

The research sought the views of those developing the ESDGC strategy and managers and tutors in the ACL sector in Wales who would implement the strategy. The policy level includes those at the Welsh Government and members of the ESDGC panel; at the meso layer are the senior, strategic and operational managers across all sectors delivering $A C L$, who form the bridge between policymakers at the macro level and tutors at the micro level. The manager's role is to communicate or translate the aims and objectives of the strategy so that tutors, delivering the broad ACL curriculum, can embed ESDGC into their practice. At times, as a function of their different roles, managers and tutors, perceived issues differently and expressed different, although frequently overlapping, concerns.

A range of qualitative data collection methods were used. These, and the rationale for the case study design are discussed in Chapter 4. Following the analysis of the data, and with direction from supervision in the Department of Politics and Culture, a further literature review and analysis was undertaken to better understand the conceptual confusion amongst all groups of research respondents regarding EGC. This has not only informed the data analysis, it also informs the recommendations.

Sections 9.2 to 9.5 specifically address the four research questions (restated in 9.1.1) and following this there is a discussion on the significance and contribution of the thesis, the limitations and lessons learned. Recommendations for policymakers and researchers and suggestions for practice are outlined before the final conclusions. 


\subsubsection{The research questions addressed by this thesis}

1. What were the background and contextual features which influenced the development and implementation of the ESDGC strategy?

2. What were the features described by respondents which subsequently contributed to the 'piecemeal' delivery and provision of ESDGC in ACL in Wales?

3. From the literature and from the data, can we distinguish the 'latent' contribution of $A C L$ to ESDGC, and how this contributes to an understanding of implementation processes in translating policy to practice?

4. How can features emerging from the research assist in identifying some of the difficulties surrounding the implementation of EGC? Can these inform a reconceptualisation of ESDGC more aligned to the translation of policy into practice in the future?

\subsection{The background features which influenced the ESDGC strategy development and implementation}

\subsubsection{Policy context}

Providing a policy background in Chapter 3 contextualised ESDGC and ACL in Wales, the UK and internationally. Changing conceptualisations of ESD and EGC, the role of adult education and wider policy discourses that have shaped the context of this thesis were examined.

The review of policy began by examining the United Nations' global response to environmental issues. Over a period of more than four decades conferences, summits and publications by the UN informed and helped shape ESDGC. For example, the Belgrade workshop on environmental education (UNESCO-UNEP, 1977) brought the concept of interdependence to the fore and the Earth Summit of 1992 and the resulting Agenda 21 were pivotal in raising awareness about the links between social, political, economic and environmental issues. The two events emphasised the important role of lifelong learning and informal education. In 2002 the Earth Charter consolidated an international commitment to an ethically informed education.

UK policies leading up to the publication of the ESDGC strategy demonstrate congruence, and their influence on the Welsh situation is discernible. Policies often focus on the formal 
sector (UK Government, 2005); citizenship and EGC are not always linked to ESD (LSC, 2005), and global aspects are weak in many documents (DfES, 2003). A major driver for ESDGC and this form of education in the UK was the United Nations Decade of ESD (2005 2014), and two reports evaluating the Decade (UK National Commission for UNESCO, 2010, 2013) outline lessons and recommendations that resonate with the findings of this thesis. The key ones of relevance are firstly, the need for greater involvement of the voluntary sector and secondly the need for collaboration and congruence across post-16 education sectors.

There was, at the time of conducting the empirical research (between 2008 and 2010), a political climate that was supportive of ESDGC. Following devolution in 1998, sustainable development became the organising principle of the Welsh Government and the policy document, One Wales One Planet (Welsh Government, 2009), for example, includes ESDGC as part of lifelong learning. In 2010, the UK policy landscape changed considerably with the new coalition government; the UK Sustainable Development Commission ceased operating in 2011 and support for ESD and ESDGC has since seen a decline.

The UK Government appointed its first minister for lifelong learning in 1997 and policy was supportive of ACL. The learning society and the knowledge economy became embedded in policy rhetoric (Fryer, 2010; Jarvis, 2006b, 2007, 2008b; Preece, 2006) and ACL in Wales was widely supported as part of the policy fabric. However, over the past two decades ACL has been under pressure to respond to changing government priorities. The imperative for economic growth identified by the Leitch report (2006) consolidated a view that ACL should focus on vocational skills, and over the following years the sector experienced cuts. At the time of data collection, services were being curtailed and the requirement to accredit courses and deliver vocational programmes meant that the liberal curriculum and flexibility that ACL once had was disappearing. These factors severely affected the sector's capacity and ability to engage with and deliver ESDGC. Milana et al. (2016), in relation to sustainable development, and Field (2006), Jarvis (2008b) and many others, in relation to ACL, highlight the constant tension between economic growth and broader social and individual wellbeing.

The Welsh context between 2010 and 2016 was outlined in Chapter 3 (3.9.2). In brief, the ESDGC Champion role was discontinued and ESDGC lost its funding; it is now presumed to be mainstreamed. The longer-term actions indicated in the ESDGC strategy include developing professional standards with LLUK and working with Agored on accrediting 
courses. The ESDGC professional standards were developed (LLUK, 2009) but LLUK was dissolved in 2011; Agored remain engaged and an officer has a remit to promote ESDGC, which is included in appropriate Agored modules. Research undertaken in 2010 on the support needs of the sector (Appendix B) recommended a network and communities of practice but there were no resources or mechanisms to take these forwards. Whilst the development of the ESDGC strategy was supported by the Welsh Government, it is safe to say that its implementation has not been. This has contributed to the piecemeal situation in ACL observed by Estyn in 2008 and in this research. In 2014, Cyfanfyd lost its funding and no longer operates, which means another loss to the development of ESDGC. ESDGC and the institutions and organisation that support it have, for some time, been experiencing a hiatus.

\subsubsection{The situation since 2016}

In 2018, ESDGC remains as a cross-curricular theme in ACL, and Estyn have maintained it as part of their Common Inspection Framework, which states:

Learners should have opportunities to extend their knowledge of global citizenship and sustainable development (ESDGC). Inspectors should consider the extent to which the curriculum and extra-curricular activities help learners to develop the knowledge, skills and values of ESDGC, for example: the development of a social justice perspective; an appreciation of global diversity; and the development of citizenship. (Estyn, 2015: 25)

This statement is broad in its scope, and the only guidance offered by Estyn is a reference to the ESDGC Strategy (Welsh Government, 2008a). The Common Understanding in ACL (Welsh Government, 2012), which was explicitly a guidance document, is not mentioned. This demonstrates an incoherence and the dismissal of the guidance and ideas in the Common Understanding.

Even though the Well-being of Future Generations (Wales) Act in 2015 heralded, in its very title, an ethical orientation for sustainability, it contains only one reference to education and this is linked to the goal of 'A prosperous Wales' (3.8). This underlines an economic imperative and not an ethical or sustainable one. Cynnal Cymru whose original remit included public engagement and awareness are now focusing more on low-carbon business and carbon reduction; this is indicative of learning for sustainability and global citizenship becoming secondary to more immediate and instrumental goals. In 2018, there is an ESDGC 
website $^{51}$, and documents are available on 'Learning Wales' online learning portal ${ }^{52}$, but there have been no further developments in ESDGC since 2010.

In contrast, a great deal of change has taken place in the ACL sector in Wales: NIACE Dysgu Cymru was restructured in 2016 and merged with the Centre for Economic and Social Inclusion to become the Learning and Work Institute ${ }^{53}$, and in the same year WEA Cymru merged with the YMCA Wales Community College to form 'Adult Learning Wales'. Cooperation, equal opportunities and a student-centred approach remain as priorities, although ESDGC is not visible in 2018.

The statutory sectors delivering $\mathrm{ACL}$ are also experiencing change. The most recent letters of remit and funding to local authorities from the Welsh Government (2015 - 2017) remind them that the overarching priority for $\mathrm{ACL}$ is tackling poverty through improving employability. This is achieved by providing courses for adult literacy and numeracy, digital literacy (ICT), and English for speakers of other languages (ESOL) (Estyn, 2016). The rationale for this is set out in the most recent policy statement for adult learning in Wales:

Helping people to gain the skills they need to enter the workplace is a clear priority for Welsh Government. 23 per cent of the population of Wales continues to live in relative poverty. This is the highest proportion in the UK outside London. Wales also has the highest percentage of children living in poverty - one in three - of any nation in the UK. Evidence shows that well-paid work is the best route out of poverty; and we aim to provide the support that people need to access work. (Welsh Government, 2017: 4)

The document reminds us that the $\mathrm{ACL}$ sector has faced significant reductions in funding and that the future remains vulnerable to additional cuts. Whilst focusing on employment, it acknowledges the wider benefits of adult learning and cites a report by Fujiwara (2012) that shows the positive effects on health, social relationships and volunteering.

Adult learning and education in a global context, is described and discussed in a UNESCO Institute of Lifelong Learning report (2016) where adult education is seen as playing a vital role in challenging the 'post-truth' society' and in achieving the Sustainable Development Goals (Walters \& Watters, 2017). The need for political education and literacy is stressed. However, examining the background policy context in Wales has shown a decline in

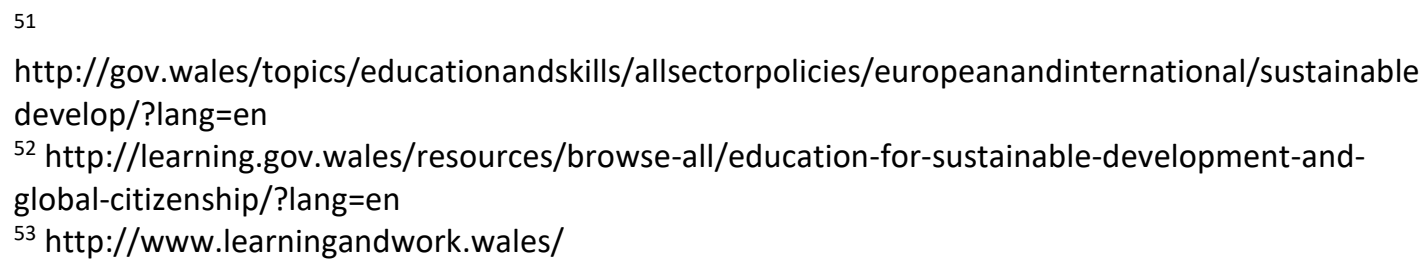


support for the wider ACL offer. Provision that is not delivering skills and employability related content is now termed 'leisure' classes. Although it maintains a commitment to work with disadvantaged or 'hard to reach' learners, it does not have the same capacity to deliver the more liberal or negotiated curriculum. Inequality of opportunity is exacerbated by the fact that courses cannot be delivered locally as a result of venue closures, and learners cannot afford or have little access to transport (Estyn, 2016: 3). Despite a lack of funding, informal learning continues through the establishment of self-organised, learner and tutor-run clubs and groups, and community learning centres continue to support $\mathrm{ACL}$ through working with NGOs and with charitable funding.

\subsection{The features contributing to the 'piecemeal' delivery and provision}

\subsubsection{Policy and infrastructure issues}

This research question is answered with reference to the evidence from research respondents who had differing relationships with, and expectations of the ESDGC strategy, dependant to a large extent on their professional positions. Some, at a policy level, were or had been practitioners in $\mathrm{ACL}$, and these people described similar responses to managers; they had similar perspectives, influenced by an understanding of the sector and its practical concerns. There was a degree of empathy with practitioners. Others, who did not have experience of the $\mathrm{ACL}$ sector, did not offer many comments on operational issues. They focused on positive aspects of the strategy and its implementation.

Whilst policymakers described a more positive landscape overall, managers and tutors in ACL struggled with a range of features and issues. Tutors' concerns frequently revolved around values, principles and associated characteristics, and they were generally opposed to the imposition of a top-down, ideologically driven policy. A 'dialogue of values' referred to by Blewitt (2008: 21) was not taking place, and many ACL practitioners viewed ESDGC as 'preaching', or as the imposition of a political agenda: "The autonomy of teachers to decide what is appropriate content is disappearing and being dictated according to a very political agenda" (Tutor). This perception of an imposed political or normative, values agenda is discussed in the policy literature (Blackmore and Lauder, 2005; Nudzor, 2013) and seen as a factor in resisting change. 
Managers, who were closer to the policy process described features such as the lack of representation by the $\mathrm{ACL}$ sector at a policy level during the initial deliberations and the lack of clear and consistent communication with the sector subsequently. They commented on the hurried production of the ESDGC strategy and the lack of dialogue between the policy level and the ACL sector. The result was that information and clear messages did not reach tutors, who then perceived the strategy as an imposition and were not fully aware of its relevance and potential as this comment suggest: "Concerned that it will add to my already strained schedule for the sake of more jargon and bureaucracy!" (Tutor).

The ESDGC panel did not consider ACL until 2005, when NGOs working in the field approached them. Initially, schools were the focus, reinforcing a view that education is for the young. A lack of awareness of the ACL sector by those developing policy contributed to its marginalisation, and it did not 'catch-up' with other sectors. Literature on policy development and implementing change in education stresses the need to involve practitioners, those expected to implement innovation. However, managers and tutors in $A C L$, who are key stakeholders in ESDGC, were not involved. The current research found that the process of developing and implementing the ESDGC strategy flew in the face of evidence and received wisdom on educational change (Coffield et al., 2007; Nudzor, 2013; Rees, 2011).

Tensions were observed between the policy level and managers in the voluntary sector delivering ESDGC. Reasons for this include the lack of dialogue with NGOs who had a great deal of experience and expertise that could have been utilised in the development and implementation of the strategy. NGOs worked with community groups and with BME groups who were, by default, not involved in developing the strategy. Policy, as discussed in the literature (Hill, 2009; Trowler, 2003: 48), should be a dialogic and dynamic process, but this was not observed during this research.

NIACE Dysgu Cymru and the WEA had considerable experience in working in ACL. However, funding cuts limited their capacity to take ESDGC forward. Together with Cyfanfyd, these two organisations developed the Common Understanding in ACL (Welsh Government, 2012) which precipitated disagreements with the Welsh Government, such that compromises had to be reached before its publication. The document was different to those in other sectors; it was more theoretical and political, and the ESDGC Champion did not feel it was a first-step guide for inexperienced practitioners. The lack of guidance 
available until the document's publication online in 2012 added to the frustration of practitioners and often to their antipathy.

The integration of community and sustainable development discourses identified in the literature (Agyeman, 2005a, 2005b; M. Mayo, 1997; Tilbury \& Wortman, 2008; Warburton, 2013), and spoken about by some practitioners, was not explored in ESDGC. Community development was an area identified for future work in the strategy, but this did not transpire due to factors including lack of funding. A consequence of the disconnect with local ecologies and cultures was that the links between local and global citizenship and opportunities to more fully engage with EGC were not realised. If the ESDGC strategy had been integrated with other Welsh Government policy initiatives such as the Communities First programme, it might have been more successful. Community development and antipoverty strategies were aligned in purpose with ESDGC and a lack of congruence was evident, "Right now, it is very vague for organizations like Communities First who are not ACL providers but involved in ACL" (Senior Manager).

$A C L$ infrastructure and delivery mechanisms are unlike any other sector. $A C L$ is delivered by NGOs, local authorities, and by FE and HE; this contributes to a lack of coherence that makes developing and delivering policy difficult. The $\mathrm{ACL}$ strategic partnerships were part of actions by the Welsh Government to introduce a more strategic approach to $\mathrm{ACL}$ planning and delivery, but they were not tasked with including ESDGC. A strategic, networked and 'joined-up' approach to ESDGC was recommended by Estyn $(2008: 5,6)$ and the partnerships might have facilitated this. A failure to prioritise ESDGC in ACL policy at this level contributed to a lack of consistency and to piecemeal delivery and provision. ESDGC was not being included at the meso level, within institutional and service delivery policies. Guidance and direction were needed as the head of a local authority ACL service said in interview:

Let's have ESDGC as a core principle, at the beginning of everyone's plans: the service plan describes, it spells out what the priorities are, what we want to achieve across the service in the county over the coming academic year and how we will go about using the resources, e.g. targeting Communities First. There is no guidance on this [for ESDGC].

With no unifying policy framework, and without one voice or umbrella body such as Colegau Cymru ${ }^{54}$ for $\mathrm{FE}$, no central location, and delivery across a range of providers, the $\mathrm{ACL}$ sector posed many challenges for policymakers. The ESDGC Champion commented on

${ }^{54} \mathrm{http} / / /$ www.collegeswales.ac.uk/ 
this. Estyn had a great deal of influence on developing and communicating the ESDGC strategy; they are a bridge between policy and practitioners. Their Common Inspection Framework includes ESDGC and this is an incentive for institutions and organisations across all sectors (except $\mathrm{HE}$ ), who rely on a good Estyn inspection to secure funding. However, managers working in ESDGC-related areas expressed concern regarding Estyn's expertise and experience.

\subsubsection{The perceptions, hopes and concerns of managers and tutors}

The hopes and fears that practitioners described are based on their perceptions of ESDGC and the strategy. They reveal some of the features contributing to the patchy and piecemeal delivery of ESDGC.

Policy level interviewees and senior managers felt that, in principle, most people supported ESDGC and were in favour of it being embedded into policy and practice. Approximately half the tutors who responded to the research hoped that ESDGC would be embedded seamlessly. They were concerned however, that it was not forced into the curriculum. Tutors hoped for more training, guidance and continued momentum, but many felt that no matter what their hopes were for ESDGC, it would not be fully supported in practice. "We need the time to be able to develop this, it takes a lot of effort to embed new curriculum. We have not had training and no resources available to give us time or training" (Tutor). Managers also expressed a certain degree of pessimism and stressed that successful implementation depended on funding and follow-up measures.

Overall, managers expressed more optimism than tutors and they were more confident of being able to take the ESDGC agenda forward in their institutions. There were many hopeful voices: "I hope that the sector will work to make the values and principles underlying ESDGC a reality, and that the sector will work together to allow ESDGC to develop naturally" (Operational Manager). At a policy level the optimism was more consistent, and Estyn stated that ESDGC was there for the foreseeable future and publication of the LLUK professional standards (LLUK, 2009) was a positive way forward according to the Welsh Government.

There was a widespread recognition that the issues in ESDGC should be taken seriously but people were not aware of its relevance 
If people understood what it was - if tutors really understood why, purpose. What it is trying to achieve. If they had it explained to them better. They would be more likely to be behind it, they could then see its relevance. they just don't see the point, not a lot of incentive for them is there? (Operational Manager)

Tutors expressed hopes that ESDGC could contribute to a better world and they hoped that, in the longer term, ESDGC could contribute to more interesting and meaningful learning experiences. The learner experience was their primary concern. The more strategic concerns of senior managers were linked to the need for coherence, efficiency and quality. Some hoped the ACL sector could come together to share expertise and resources, and others emphasised the need for coherence across the post-16 education sector. Some senior managers commented on the need for more incentives to embed ESDGC. "We need to incentivise in order for the sector to implement this worthwhile but complex initiative" (Senior Manager, chair of an ACL partnership).

A common perception held amongst tutors was that ESDGC was an imposed political and ideological agenda. Because the ACL sector had not been involved in deliberations about the ESDGC strategy, tutors perceived it as an imposition that represented a threat to their professional autonomy. They wanted to be trusted to teach their subjects and did not want to be burdened with paperwork or have to comply with what they perceived as a tick-box exercises. They did not want to detract from their subjects and what they termed 'real learning'.

Learner autonomy was a key concern for both managers and tutors. Adult learners choose to attend courses and they pay for them. Self-directed learning, which "is proposed as the distinguishing characteristic of adult learning" (Brookfield, 1986: 25), where learning is driven and directed by the learner, is a model in ACL which calls for negotiation and not imposition (Brookfileld \& Holst, 2011; Knowles et al., 2014; Tough, 1979).

Advocating that people should be in control of their own learning is based on the belief that if people have a chance to give voice to what moves and hurts them, they would soon show that they were only too well aware of the real nature of their problems and of ways to deal with these. (Brookfield \& Holst, 2011: 39)

The Common Understanding in ACL underlines the importance to learners of "being encouraged to believe that everyone can make a difference" (Welsh Government, 2012: 8). The harsh and depressing subjects and issues that ESDGC deals with were mentioned many times by tutors. One conclusion from this is that a pedagogy of hope is necessary. 
Fears and concerns outweighed the hopes of practitioners, and it is the analysis of these, within the overall context, that highlights the factors and features that contribute to a patchy engagement with ESDGC and piecemeal provision and delivery in ACL.

\subsubsection{The policy - practice gap}

Bennell and Norcliffe (2010) found that in the school sector, there was a general belief that ESDGC would continue and develop, but the ACL sector did not feel this way overall. Other initiatives and cross-curricular themes had been introduced and not given enough time or resources to become embedded, and practitioners could see the 'writing on the wall', as Estyn was changing its priorities. ESDGC had no statutory leverage apart from Estyn requirements, and without the means to implement the strategy it was unlikely to succeed. A policy - practice gap became ever more visible as ESDGC remained un-supported by longterm commitment and resource allocation; the ACL sector's cynicism was understandable.

Practitioners across the sector knew what they needed to be able to embed ESDGC: managers and tutors wanted training, guidance and resources. Even though some training was available, it was limited and inconsistent and this was a distinct barrier to engagement and delivery. The part-time employment terms of most tutors who had to undertake training in their own time added to this. In addition, tutors perceived ESDGC as an added bureaucratic burden when tutors already felt overworked. Managers understood this situation and expressed these concerns on behalf of tutors; they wanted to be able to support them. All practitioners wanted more direction and incentives from government, and tutors wanted institutional support from their employers. Despite good intentions, with few resources, and limited guidance, training and support, practitioners became pessimistic and cynical. "Tackling the largest issues on the planet on a shoestring" as one senior manager said.

The perception of ESDGC as an imposition disempowered tutors. It was perceived as a threat to their professional integrity and concern for learner autonomy was evident across the $\mathrm{ACL}$ sector causing a certain amount of resistance amongst tutors. The Welsh Government was not aware that this was a contributing factor to piecemeal provision, indicating a gap in understanding between the policy level and those expected to deliver ESDGC. 
The Welsh Government did not harness the knowledge, good will and energy of people working in the $\mathrm{ACL}$ sector. The location of learning in the classroom and the vital relationship between tutors and learners was not highlighted in the strategy, and pedagogy was ignored. Coffield et al. (2007: 736), in their work in ACL in England found "no evidence of the direct or simple transmission of policy into teaching practices". This is echoed in the findings of this thesis.

\subsubsection{Conceptual confusion and pedagogy}

A certain amount of conceptual confusion about ESDGC was evident across all groups of research respondent. This arose largely due to the lack of a shared vision and clear, consistently articulated messages about the purpose of ESDGC. Tutors were unsure of ESDGC's relevance to courses and peoples' lives. Some managers, both strategic and operational, wondered how ESDGC could be made relevant to learners, particularly learners from poorer areas and 'hard to reach' groups as they are termed. Many adult learners face social exclusion and poverty. A tutor commented that "Some learners might think this is a middle-class issue, it's all right for you. Some people have more important things to think about, day-to-day concerns. But this is an issue for everyone" (Tutor). Burningham and Thrush (2001) explored this issue in their work on the perceptions of global environmental issues in poorer communities. "Start where people are, looking at what issues are important to them, what people are interested in, what concerns them in their lives" said one operational manager reflecting the person-centred, experiential model in ACL. It relates closely to issues of making ESDGC relevant because it is 'an issue for everyone'.

Tutors commented on the overwhelming scope of ESDGC and the research found that global citizenship was typically not understood - "Global citizenship, what's that?" (Tutor). Environmental issues dominated: "I make sure I keep printing to a minimum and we recycle as much as possible" (Tutor). The themes and concepts were misunderstood and contested; Estyn and the Welsh Government promoted the themes, whereas NGOs felt that although the concepts can appear abstract they could, alongside the themes, provide the foundation for a more comprehensive form of learning. Some NGOs that had been delivering ESDGC felt that a social justice model was not promoted by government and issues of race, conflict and Islamophobia, for example, were not seen as part of ESDGC. The 
vagueness of what constitutes global citizenship and EGC contributed to this situation. There were clearly conceptual barriers to engagement.

By its very nature ESDGC deals with controversial issues, but practitioners did not have the confidence to be able to harness controversy creatively for learning. Tutors were unsure about incorporating potentially controversial subjects into their classes, and managers were unsure about how to support them in their professional practice. The need for more information and a fear of appearing partisan when discussing political and ethical issues were barriers for tutors. It is not surprising that many practitioners opted to focus on the more tangible environmental aspects of ESDGC. This, in the words of a senior manager, resulted in "a shallow form of ESDGC". Race and equality, as dimensions of ESDGC had been developed in a document produced by ACCAC (Welsh Government, 2002) but omitted from the final strategy. "Working with race etc. has been omitted. This is a glaring omission, but nobody talks about it. Is it too uncomfortable?" (Focus Group Discussion)

Meaningful learning experiences were among the hopes expressed by tutors but, apart from critical thinking, learning outcomes were not articulated and pedagogy was missing from the ESDGC strategy. It did not claim to be a guidance document; however, no reference to the 'how' led to narrow interpretations and inaction. From the secondary research, the omission, or scant reference to affective learning in ESDGC has implications for how people engage with and understand issues. They can remain abstract without recourse to the affective domain which includes values and attitudes as well as emotions and feelings which have been the focus in this thesis. Feelings and emotions are ways of learning (Dirkx, 2008; Jarvis, 2006a: 18) and not only aligned to holistic and relational approaches, but also vital in critical dialogue and reflection as discussed by Murphy and Brown (2012).

The omission of references to pedagogy and community development agendas has contributed to practitioners not fully understanding the relevance of ESDGC. A clear articulation of the purpose of ESDGC and its benefits for both practitioners and learners was not forthcoming and these and the other factors discussed above, such as infrastructure and capacity issues, have all contributed to the piecemeal provision and delivery of ACL in ESDGC. The policy process was piecemeal, and an approach informed primarily by the formal education sector did not work for ACL. Without investment and follow-up measures, the intentions of the ESDGC strategy were not realised. Without adequate guidance or training, a lack of clarity became a barrier to engagement and 
without a shared vision for ESDGC the sector floundered. "So DCELLS and ESTYN gave ESDGC a high in profile, but no resource or no kind of any real guidance about requirements, so there is a huge variety of responses". (Senior manager at policy level)

\subsection{What is the 'latent' contribution of ACL to ESDGC and how can this contribute to translating policy into practice?}

An additional feature within this sector is that there are similarities between ESDGC principles and adult and continuing learning approaches. These similarities may mask the 'latent' contribution that this sector may have to the incorporation of ESDGC within teaching and learning activities. (Welsh Government, 2008a: 70 - 71)

The reference made to the 'latent' contribution in the Welsh Government's ESDGC strategy was vague, and Chapter 8 of this case study has examined this. Here the main points emerging from the data and the literature are outlined. One of the similarities between approaches in $\mathrm{ACL}$ and those promoted in ESDGC is the informal and flexible nature of much of ACL delivery, which encourages a learner-centred approach, drawing on and valuing learners' experiences. ESDGC shares similarities with $A C L$ in recognising the importance of a learner centred-approach which encourages critical thinking and is aimed at empowering the student to participate in decision making (Welsh Government, 2012: 5). Other similarities are engagement with equal opportunities, participatory methods and active learning. Despite the recent move towards vocational skills and an employability agenda, $A C L$ is still understood as having many social as well as individual benefits. It helps adults to survive, cope and thrive in an ever-changing world (Welsh Government, 2017: 2), and to participate to direct and influence change (Usher et al., 2011).

Other elements of ACL theory and practice demonstrate clear synergy with ESDGC, including the empowerment and transformational learning models in $\mathrm{ACL}$, which are built on critical thinking, dialogue and action for change (Mezirow, 2000). Learning for deliberative democracy, citizenship and social justice are foundational discourses in $\mathrm{ACL}$ (Annette, 2009a, 2009b; Biesta, 2011; Dewey, 1916; Jarvis, 2008b, M. Mayo \& Annette, 2010) that support the aims of ESDGC to enable people to participate in decision making (Welsh Government, 2002: 6). This emancipatory, social justice model in ACL addresses the larger structural and ideological problems at the root of environmental destruction (Clover 
et al., 2013) and social and economic inequality (Taylor \& Cranton, 2012). The Common Understanding in $A C L$ states:

ACL and ESDGC share a common goal of empowering individuals and facilitating their development as active and aware citizens recognizing the needs of learners to engage independently and critically with the processes and networks developing as a result of global change. (Welsh Government, 2012: 7)

In the literature, models of critical and ecological pedagogy such as those advocated by Huckle (2001b, 2014, 2015), Huckle and Wals (2015) and Ellis (2013, 2015), and the holistic, systemic models of ESD discussed by Sterling $(2009,2010 a)$, can align with the transformational approaches in $\mathrm{ACL}$ discussed in Chapter 8. The literature in $\mathrm{ACL}$ includes broad visons for learning that encompass the cosmological and spiritual, the political and ethical and the deeply personal, as authors such as Jarvis (2008a, 2008b), O'Sullivan (1999) and Swartz and Tisdell (2012) maintain.

The literature review ascertained the need to explore and create new understandings of citizenship and new practices in citizenship education in the light of globalization and ecological trends. According to much of the literature, this is of paramount importance (I. Davies et al., 2005; Dei, 2008; Dobson, 2003a; Ellis, 2015; Huckle, 2015; Valencia Sáiz, 2005). More inclusive pedagogies are needed that treat global citizenship as a concept and as a learning, living process (Cabrera, 2010; Torres, 2006, 2015). This was not the case in ESDGC in Wales where the links between EGC and a range of issues that are more familiar to people such as equality and diversity, poverty and local, community development were not articulated or realised. ACL's work in communities could help with translating ESDGC into relevant learning experiences for people. The language of citizenship and of ESDGC obfuscates at times, and a learner-centred approach can find common ground and starting points based in lived experience, where local and global concerns are not separated. The latent contribution of $A C L$ to ESDGC is in its critical citizenship education traditions and in its community development approach where learning and local and global development are interlinked: "Local people should be involved, local communities, local activities, links to community business and social enterprise should be made. Use everyday resources in classroom such as local newspapers. It must be organic development, local democracy" (Focus Group Discussion).

ACL's traditional links with communities and community development theories and practices provides a foundation for the latent contribution to ESDGC. Here is the location of participation and citizenship, where policy translates into practice. Within communities, 
adult education has a broad reach and practitioners stressed their hopes for change through this; as a senior manager noted: "ACL is seen as a key stakeholder for change in public attitude to areas such as ESDGC". Community learning is the location for a Freirian pedagogy of empowerment in ESDGC (Warburon, 2013).

\subsection{Features illustrating some of the difficulties surrounding the implementation of EGC and a possible re-conceptualisation}

\subsubsection{Education for global citizenship}

Amongst tutors, the perception that ESDGC was about 'green' or environmental issues predominated. These subjects were perceived as being easier than the more political issues raised by EGC which appeared nebulous and abstract. Managers did not make many points about EGC, and policymakers were unclear and skirted around the issue in interview. International links, student exchanges, multiculturalism and aid were some examples given of EGC by managers, tutors and policymakers, these were, in the words of a senior manager: "'Neat' ways of making global connections". There was little understanding of what global citizenship was: "Preparing people to be global citizens in the $21^{\text {st }}$ century what the hell does this mean?" (Tutor), and from the literature, it appears that this stems partly from a lack of understanding about the concept of citizenship (Ellis, 2015: 216). Whilst the current research has disclosed an overall lack of understanding, a valuable area for future research would be to probe further into perceptions of EGC, to determine the dimensions of, and reasons behind, the general paucity of understanding and to examine future training needs for practitioners.

NGOs and those working in global and development education were of course engaging with EGC and they frequently mentioned participatory and critical methods, social justice and issues of race and conflict, for example. Making connections between local and global issues was not evident in the responses from the majority of research participants, and often problems were perceived as 'elsewhere' within a third world deficit model. The bringing together of personal, local and community concerns with global issues and a critical engagement with ideology was identified by some as an area that needed addressing. However, the perception was that the Welsh Government were not encouraging this approach. Identity, whilst not being a focus of this research, was 
mentioned many times by tutors, particularly Welsh identity and culture; this is fruitful ground for introducing perspectives such as de-colonial, history and globalization as discussed in Chapter 8 (8.5.2).

Potentially difficult subjects and controversy will inevitably emerge in a classroom that engages with the issues in EGC. This proved challenging for tutors who were not trained or supported. They were afraid of appearing partisan, the feared that people would become emotional and so avoided dealing with potentially controversial issues. "It can often be seen as very political, and it is a big ask of tutors to teach this" (Focus Group Discussion). This is an explanatory factor for disengagement with EGC. Linking EGC with ESD added another layer of complexity in Wales, and simultaneously created the potential for a more holistic and meaningful education. However, there was very little integration of sustainability and global citizenship education and without guidance and support, the conceptual confusion discussed above contributed to a lack of engagement with EGC amongst practitioners. Some people at the policy level were unsure about global citizenship and EGC, and clear explanations were not forthcoming. This made it difficult to implement EGC and therefore ESDGC.

The knowledge gaps, difficulties and lack of engagement that surrounded EGC prompted the decision to conduct a literature review focusing on citizenship and EGC. There was an imperative to better understand the concepts and therefore people's perceptions of them. Baumgartner and Korhonen (2010), for example, think the separation between ESD and EGC can be explained in part by the scientific foundation of ESD, and EGC's connection with the humanities. Many authors, such as Fenwick (2006) and Todd $(2019,2015)$, discuss the need for an embodied and relational as well as cognitive and rational education in this context. The literature demonstrates a breadth of perspectives that can contribute to a reconceptualisation of ESDGC, where EGC is not at the periphery, as observed in the present research.

Care theory, an engagement with emotions and a focus on dialogue as a method have been discussed in Chapter 8 as elements of a framework for ESDGC that places EGC at the centre in an ecological global citizenship education. EGC is overtly political and ethical and figures 9.2 and 9.3 below show how the model can be visualised. These elements and approaches can possibly make EGC more relevant and interesting for learners and tutors. 


\subsubsection{A re-conceptualisation of ESDGC as an ecological global citizenship education}

The re-conceptualisation of ESDGC proposed in this thesis is informed by the findings and the literature and policy reviews. The rationale stems from the conceptual confusion, the misunderstandings of EGC, the lack of integration with ESD and identified difficulties and gaps. Difficulties relate to the challenge of foregrounding politics and ethics and gaps point to the need for critical and cognitive discourses to combine with holistic and affective ones, with emotions and feelings. This can underpin effective teaching of controversial subjects and empower tutors to facilitate dialogue and discussions for higher-order learning outcomes in ESDGC. A non-dualistic ecological ethos that underpins pedagogy and is informed by transformational learning theories in $\mathrm{ACL}$ is suggested.

Global citizenship is not an ideal term, but at the heart of an ecological approach or paradigm that connects with the immediate concerns of learners and communities, it can be re-conceptualised in a way that makes it relevant, inclusive and plural. Adult education is political (Torres, 2013) and education is understood as an ethical enterprise (Lauder et al., 2006). The Venn diagram (Fig 8.2) presents a useful visualisation of the proposition to educators, where ecology, politics and ethics are interlocking domains instead of the economic, social and environmental as traditionally seen in association with ESDGC. Even though this is not fully adequate, it represents an accessible model for teaching and learning in ACL. Figure 8.3 provides another, and possibly more accurate, representation.

Within ecological global citizenship education, hope and realism are essential elements; $\mathrm{ACL}$ practitioners saw ESDGC as not only contentious and controversial, but also depressing. ESDGC asks us to open our eyes to human suffering and planetary degradation, to critically engage with the issues and use our emotional responses in learning and explore alternatives together. Hope and realism go hand in hand within a dialogic pedagogy where, as Freire said, we love the world enough to care and have the courage to be educators (Freire, 1973). Many practitioners in ACL in Wales expressed the view that they wanted to know "how to translate policy into reality without becoming a burden - but being a positive thing to do" (Senior Manager). 


\subsection{Contribution of the research, generalisability and reflections}

\subsubsection{Contribution}

With its focus in $\mathrm{ACL}$, this case study contributes to an under-researched area. In Wales, research in ESDGC in the formal sector exists, but this is the first study focusing solely on $\mathrm{ACL}$ and consulting with $\mathrm{ACL}$ practitioners across Wales.

A key contribution of the case study is its well-developed context, which grounds the data and its analysis and provides readers with information to understand the situation of $A C L$ practitioners and the ESDGC strategy in Wales. The methodology provides a well-rounded picture with the inclusion of different actors and groups providing a nuanced view, such that individual and collective voices are clearly identifiable. A central concern in the design of the study is that theory, policy and practice are linked to inform practice. As Torres (2013: 55) states: "Educational research faces the constant challenge of linking theory, research, and praxis, as well as policy and policy implementation." This thesis has sought to interlink these domains and many threads are brought together. The breadth allows generalisations and recommendations to be made with respect to different elements. Whilst adding to the context and discussions, it is acknowledged that this desirable level of complexity can also complicate and cloud matters. Consequently, attention has been paid to providing clear and well-evidenced interpretations.

Investigating the policy process in ESDGC from the ACL sector's perspective has provided insights that can inform the future development and the introduction of other initiatives and innovations. Many of the factors contributing to the 'piecemeal' delivery and provision in $\mathrm{ACL}$ were linked to the policy process. This thesis contributes to an understanding of policy development and implementation, particularly identification of some of the barriers in translating policy into practice. Challenges in understanding, communication and practical implementation were encountered and described by all groups of research respondents. The main barriers have been discussed above. In summary, features that impeded the development and implementation of the ESDGC strategy in $\mathrm{ACL}$ in Wales include: a lack of initial and continued dialogue with the $\mathrm{ACL}$ sector; a failure to recognise ACL's distinct ethos and delivery by those at policy level; a lack of investment in guidance and training; narrow conceptions of ESDGD; conflict with educators' autonomy; conflict 
with adult learners' autonomy; fear of teaching controversial issues. Each one points to areas for future research.

The findings corroborate evidence from the literature, particularly regarding practitioner and voluntary sector involvement. This has implications for future policy development. "The failure of social and educational research to serve practice - or at least to do so in the ways or to the extent desired - has been a recurrent theme of discussion both within the research community and outside (Gomm, 2002: 59). Serving the needs of policymakers and practitioners is difficult as they, as well as academic researchers inhabit 'different social worlds' (Gomm, 2002: 80). However, it is the relationship and communication between these 'worlds' that is important if all three can contribute to each other.

If the barriers observed in this current research can be overcome, then this study suggest that $\mathrm{ACL}$ theory and practice can make a significant contribution to ESDGC. With its foundations in radical traditions of social emancipation and a well-developed learning theory informed by various perspectives, particularly pragmatism, humanistic psychology and critical theory. ACL brings insights and a praxis aligned with ESDGC including the participatory, community elements, often at odds with more liberal traditions. This, I suggest, can be seen as an ecological approach, one which is holistic and at the same time critical. As discussed in this thesis, learning and community awareness are not separate, and the links between sustainable development and community development are recognised as learners are empowered as global citizens. These elements are brought together and highlighted in this current research, providing a valuable contribution to the literature and to theory, policy and practice in ESDGC and ACL.

Many adult learners struggle to cope with the challenges of day-to-day life and the issues in ESDGC can appear distant and abstract. It was apparent from the data that an experiential and community-based model, which is prevalent in $\mathrm{ACL}$, was not being utilised in ESDGC. The importance of this study is that it has identified and highlighted these omissions in the rhetoric to inform potential ways forward in ESDGC in post-16 education.

By focusing on providing evidence to support practice in ESDGC, the thesis ultimately has a practical intent and makes explicit proposals for practice (9.7.3). From examining the synergy between $A C L$ and ESDGC, and the latent potential of $A C L$ for ESDGC, the practical outcome has involved highlighting theories and approaches that can contribute to pedagogy. Anodyne approaches in ESDGC have not been successful, hearts and minds have 
not been engaged, and therefore combining theoretical and practical approaches and examining new ones is suggested. For example, care theory was discussed as a means of examining ethics and controversy in ESDGC; it is discussed and examined in relation to EGC (Gaudelli, 2003; V. Held, 2006) and it could be more fully and usefully integrated into a pedagogy for ESDGC.

The need to reframe or reconceptualise ESD and EGC is reiterated throughout the literature: "[This premise leads us to] suggest combining the emerging theory and practice of sustainability or sustainable citizenship with that of ecopedagogy and global citizenship education" (Huckle \& Wals, 2015: 493). It is necessary if barriers to non-engagement are to be addressed. Adopting an ecological ethos where interconnection and interdependence are overarching concepts in this essentially systemic approach to global citizenship education is represented in Figs 8.2 and 8.3. Ethics and politics are central in a theoretical framework for an ecological global citizenship education and global citizenship and EGC are addressed within a complex, open systems that include the natural: the biological and physical. This model is in keeping with a critical realist perspective.

The dichotomy of environmental and citizenship/global citizenship discourses, and the inclusion of a more collective, participatory pedagogy to counter-balance more liberal traditions, are discussed in this thesis through the lens of $A C L$ theories and purpose. Transformational critical and holistic learning and pedagogies in ACL contribute insights for reconceptualising ESDGC. The proposed combining of critical and holistic theoretical approaches within a transformational and ecological framework is a contribution to the literature and to the development of new frameworks for ESDGC and ACL.

Alongside the theoretical perspectives identified and discussed in this current research including de-colonial, critical, dialectic and holistic ones, there are others that, through a review of the literature, consideration of the findings and $A C L$ theories present themselves as areas for further work in this area. Neuroscience (Immordino-Yang, 2015) for example, points to the importance of attending to our emotional selves in learning, and this aspect of holistic adult education theory, along with a grounded spiritual perspective (English, 2013; Fenwick \& English, 2004; Tisdell, 2003) provides a theoretical basis for developing new pedagogies. Care theory (V. Held, 2006) is another example of an under-explored area in ESDGC and ACL. It is advocated as a starting point, as it connects the political and ethical and the private and public, and it resonates with many different theoretical and practical threads in this current research. 


\subsubsection{Generalisability}

The decision to gather data from as many ACL practitioners in Wales as possible was influenced by the possibility of being able to generalise to other populations. However, since beginning this research in 2008, ACL services and provision in Wales have changed considerably: therefore, the professionals who responded to the survey in 2010 will differ from those employed in $A C L$ in 2018. The ACL sector has changed and has differing priorities, influenced by global and national trends, but recognisable principles and services remain. Within post-16 education certain elements of this case study will be generalisable and the policy process will have elements in common with many other contexts where generalisations are possible.

Thomas's view is that our expectations about generalisations in education should be moderate (Thomas, 2010: 576), and there are some researchers such as Usher at al. (2011) who consider that in educational research interpretation, meaning and insights are more valuable than generalisations. It has been said that case studies are too subjective, but as Donmoyer notes, "case study research might be used to expand and enrich the repertoire of social constructions available to practitioners and others" (Donmoyer, 2009: 51-2).

Given its specificity in time and place, the whole case is not replicable. However, certain elements are transferable and can be compared with other cases and incorporated into a wider body of knowledge (Yin, 2009). Usefulness is paramount, and honest descriptions of process, robust data and analysis provide credibility and validity that other researchers may evaluate, judge and use. The reader determines, using their own experience, whether the findings are applicable to other cases. This is what Stake $(1995,2009)$ calls 'naturalistic' generalisations and others (Lincoln \& Guba, 2009) have called 'transferability'. Donmoyer (2009) points out that examining differences can be as important as looking for similarities in making one case significant for another.

Different terms and ways of categorising the different forms of generalisations have been used (Gomm et al., 2009a, 2009b; Simons, 2009: 165) and some of these have been discussed in Chapter 4. Generalisations related to processes and mechanisms are relevant in this case study as the development of an educational strategy and its implementation has similarities independent of the content. Processes are applicable in various contexts (Simons, 2009: 166) including certain protocols and the elements of representation, consultation, lines of communication and leadership. It is reasonable to assume that many 
of the contextual features identified in relation to the difficulties associated with ESDGC in ACL will hold for similar policy to practice processes.

In the naturalistic category, researchers, practitioners and policymakers can identify elements within this case that are comparable to others. It is possible to make reasoned hypothesis about another case or cases based on the evidence (Thomas, 2010).

Populations, for example, are part of the naturalistic category. Adult education tutors, even given the devolved context in Wales, will have similarities across the UK and indeed in other countries. Their practice in the classroom is informed by similar theories and they work within similar institutions and infrastructures. Managers in ACL will likewise have recognisable roles across other cases, and $\mathrm{ACL}$ practitioners at all levels are influenced by similar international imperatives and national policies. Differences as well as similarities can be recognised, and the reader can discern where generalisations or hypotheses are, or are not valid (Gomm et al., 2009: 98).

Universal generalisations are possible in this form of in-depth case study. It is possible to capture the essence of a case in a way that is recognisable, even where the context is unfamiliar to the reader (Simons, 2009: 167). Whilst conducting the research, remaining open to the tensions, contradictions and paradoxes was vital in maintaining engagement with the local circumstances, which enabled insights into, and realisations of, the universal. Both in-depth particularisation and universal understandings can extend the use of findings from a single case to other situations.

One of the limitations of this research is that the situation as it was between 2008 and 2010 when the empirical research was conducted, has changed considerably in ACL and in ESDGC. However, despite the changing macro-political situation influencing priorities and funding, there are lessons to be learned. ESDGC remains valuable, if peripheral, and the insights for policy and for teaching and learning can be useful.

\subsubsection{Reflections and lessons learned}

The case study design was appropriate for this research, and the data collection methods provided robust qualitative data which, through iterative interpretation and triangulation, provide robust findings. Pursuing a line of enquiry into global citizenship and pedagogy added to the complexity of the case study; however, it contributed different perspectives 
and dimensions to the thesis. The initial intention, in 2008, was to conduct a second phase of empirical research, but this was not possible in the circumstances. Nonetheless, the case study benefited from the more conceptual line of enquiry.

An analysis based on the differing roles of practitioners and their perceptions of ESDGC might have yielded further insights. Separating strategic and operational managers and developing an analysis around professional roles would have altered the focus of the research. Different and useful insight may be gained from examining values and beliefs of different actors in more depth, and this is recommended for future work. However, a choice was made to develop a more holistic picture and the specific analysis of roles and values and beliefs, whilst they are visible in the findings, are not foregrounded.

\subsection{Recommendations for the future}

\subsubsection{Policymakers}

The Welsh Government has introduced and is implementing many policies impacting on ACL. The Learning Country promoted ESDGC (Welsh Government, 2001), but the most recent ACL policy document does not mention it (Welsh Government, 2017) and in 2018, ESDGC is no longer a priority for government. However, the research provides data and insights of broader value for policymakers. The features inhibiting the consistent and coherent implementation of the ESDGC strategy have implications for a range of future educational innovations that the Welsh Government, or any statutory body, intend to develop and implement in ACL.

Institutions and organisations delivering ACL found it difficult to co-ordinate the activities required to embed ESDGC into practice. The reasons for this have been discussed in the findings (Chapters 5 and 6) and in the discussions in Chapters 7 and 8; they are summarised above. Exploring a cross-sector, post-16 approach to ESDGC is recommended. This would entail combining work-based learning, FE, HE and some youth work with $\mathrm{ACL}$ and it should be based on evidence and research from the sectors (See 9.7.2). At present, Adult Learning Wales is taking an integrated approach to $A C L$ in Wales, and ESDGC could be useful in this endeavour insofar as it equates to 'meta-learning', "learning which occurs across the boundaries between different institutions, literacies and practices" (Scott \& Gough, 2003: 
78). Adult Learning Wales can promote ESDGC as 'meta-learning' in post-16 education that can contribute to a re-alignment or re-purposing of ACL (Blewitt, 2004; Torres, 2013).

A strong recommendation is that $\mathrm{ACL}$ managers and tutors are included in developing innovations such as ESDGC, which they are expected to implement. They should be consulted at an early juncture, involved in creating a shared vision and in discussing implementation plans. The way in which the ACL sector was not represented and how this led to tensions is illustrated in Chapter 5 and the issues, discussed in the context of the literature in Chapter 7, demonstrate how and why innovations in education are not successful (Ball, 1991, 2017; Kirland \& Sutch, 2009; Nuzdor, 2013; Trowler, 1998; Coffield et al., 2007).

NGOs and voluntary sector practitioners who are experienced and have expertise in the field should be consulted, and more closely involved in developing strategies such as ESDGC. Their input and the input of others with relevant experience would add to the relevance and legitimacy of the content of strategy. The recommendation is that where policymakers seek to innovate in relation to educational curriculum, they should ensure that the knowledge to be delivered has conceptual clarity and is of the highest quality and authenticity possible.

It is recommended that continuation of ESDGC rests on a clear re-formulation or reconceptualisation with clear descriptions of what it is, what it is not, and how educators can take it forward in their practice. This includes raising awareness through articulating the purpose and benefits and describing learning outcomes and relevant curriculum and pedagogy.

Currently in Wales ESDGC is not integrated into community development or other relevant policies. The lack of congruence between ESDGC and other government policy priorities was identified by those at a policy level and by ACL practitioners as one of the reasons why it did not become embedded widely in the $\mathrm{ACL}$ sector. The recommendation is that strategies such as ESDGC are more closely aligned, at policy and practitioner level, with other government initiatives such as Communities First and public health programmes. "We support the intention completely. If it was linked more closely to other strategies it would have a greater chance of success" (Policy level interviewee).

Strategic innovations require long-term resource allocation. Managers and tutors need training, resources and guidance, and both formal and informal support systems are 
needed in order facilitate the implementation of innovations in education (Kirkland \& Sutch, 2009). These include networks and communities of practice. The recommendation is that when developing and implementing a strategy such as ESDGC, policymakers should have longer-term, sustainable plans and funding allocations.

In addition to investing in curriculum, the recommendation is that efforts are focused on the training of adult education tutors. There is much in the literature on developing the critical consciousness of learners (Freire, 1970a; M. Mayo 1997); however, it is recommended that practitioners become the focus of future intervention and investment. This is a more effective way forward for the implementation of innovations such as ESDGC. ACL tutors are the mediators of meaning and facilitators of learning. On PGCE postcompulsory education and training programmes, very little time is allocated to crosscurricular themes, of which ESDGC is just one. The courses generally concentrate on professional practice and teaching methods, and the method of facilitating dialogue and discussion can be the location for effective engagement with ESDGC and related issues, as discussed in Chapter 8.

\subsubsection{Researchers}

It is suggested that researchers explore what 'good' and 'poor' practice' in ESDGC looks like to a wide range of practitioners in post 16 education. Questions could include: what criteria could be used to decide on good and poor practice? What contributes to perceptions of 'good' and 'poor' practice and how that varies according to organisational role or professional position.

Policy development and implementation in areas related to the Well-being of Future Generations Act and its links with lifelong learning offers a rich area for researchers in Wales, but also a complex, shifting set of contexts. Awareness of the wider political context and shifting priorities need to inform any construction and delivery of research in these areas. As stated above, examining professional roles and values and beliefs as part of the policy process are possible lines of inquiry.

Given the climate of austerity, there are limitations to what institutions, organisations and individual tutors can do. There is only so much that tutors can reasonably be expected to teach. Further research could examine in more detail exactly what does and could inspire, 
motivate and empower ACL practitioners to embed ESDGC, or similar cross-curricular themes, into their practice.

Researching post-16 teacher training is suggested. Initial questions could include: Where is ESDGC in the curriculum? Is there congruence across different institutions? This could lead to research that sought to understand the perceptions of ESDGC amongst those developing and delivering programmes and also students.

$\mathrm{ACL}$ has traditionally engaged with disadvantaged communities, and such communities are fruitful ground for realising the aims of ESDGC. Yet this remains an under researched area where practice in ESDGC is also underdeveloped. It is recommended that research is conducted in some of the community learning programmes that engage with disadvantaged groups. Research with practitioners and learners might explore perceptions of ESDGC and features inhibiting and promoting its implementation.

\subsubsection{Suggestions for practitioners}

These are not recommendations as such, they are suggestions that, without policy levers and funding, practitioners might nonetheless be able to take forward.

In an examination of global citizenship, Tully (2014) poses the idea of a public philosophy approach, which has much in common with $\mathrm{ACL}$ in that it is not concerned with developing normative theories. It is self-reflective and critical, affording primacy to practice and questioning deeply held assumptions. Its aim is to empower people to participate. A public or community philosophy ${ }^{55}$ model such as the model that is part of SAPERE and Philosophy for Children (P4C) is one where people come together to discuss, debate and learn about a range of issues; forums can be informal or more structured and facilitated. These models are realistic and can be starting points for developing new forms of learning in $\mathrm{ACL}$ centred on ecological global citizenship education. With learning clubs and tutor and learner-led classes already replacing the traditional ACL learning programmes, this is an approach worth exploring.

A dialogic pedagogy is advocated in this thesis. It is a method that is flexible and, although it can be time consuming, it does not otherwise demand many resources. Practice can be

\footnotetext{
${ }^{55}$ http://www.sapere.org.uk/Members,Schools,Partners/CommunityPhilosophy.aspx
} 
developed around this and managers can possibly develop and deliver training on facilitating dialogue and discussion, even within the constraints $A C L$ is currently experiencing. Clarifying and promoting a pedagogy that places dialogue at the centre is, despite the structural barriers, one way to realise the potential of, and create new possibilities for this form of education. This requires a commitment from the teacher to engage in a more immediate form of learning that includes the affective domain, a willingness to discuss and use controversial issues for learning, and to develop an openness to becoming learners themselves.

\subsection{Final Conclusions}

Policy innovation, development and implementation remains a complex, shifting area for research of urgent interest to all those interested in education and how it works as part of the wider social and global context. This thesis describes ESDGC as an innovation, its partial development and subsequent incomplete translation into practice in $\mathrm{ACL}$ in Wales. It is reasonable to expect that there are commonalities shared with many other policy innovations in other education sectors and the processes of more, or less successfully, translating them into practice. On the basis of the research, successful translation of ESDGC into practice would have included the following:

If ESDGC had been successfully communicated and implemented in $\mathrm{ACL}$ in Wales, tutors would have some clarity about what it was and be open to learning more about it. They would have understood its purpose and relevance. The curriculum would have been informed by discussion and contributions from people with experience in ESDGC and these discussions and contributions would be available to practitioners. A range of learning outcomes would be understood by managers and tutors as tangible benefits of engaging with and embedding ESDGC into ACL practice; and there would be resources to help tutors and managers understand how to integrate ESDGC into a range of subjects. Training would be available for senior managers to enable them to understand policy relevance, and for operational managers to enable them to support tutors. Tutors could access training on issues ranging from awareness-raising to more sophisticated courses, including facilitating discussions in controversial issues. Each ACL partnership would promote ESDGC and make connections with other policy priorities from diversity to drainage. Community development practitioners and groups would be fully engaged in ESDGC-related learning 
projects. This is a snapshot of what success in ESDGC in ACL might look like, and it is a picture painted largely from the negative information gathered in this research.

ESDGC has not been embedded consistently in the policy or practice of $A C L$ in Wales, even though there was a great deal of good will and support for it. Factors contributing to this situation have been described and discussed using data from a range of actors. Cynicism, confusion and sometimes resistance was encountered amongst managers and tutors and there was a profound lack of communication and understanding at times between the ACL sector and policymakers, and a lack of communication about ESDGC between managers and tutors. Lack of investment typified the policy-practice gap, and without resources ESDGC, even with good will, was not going to succeed.

In 2018 ESDGC has no prospect for longer term investment. Some ACL practitioners saw it as a zeitgeist and a passing trend in education. Even though the Welsh Government demonstrated an enthusiasm to support it in furtherance of its commitment to sustainable development, other priorities became more pressing. Of concern was the low PISA ${ }^{56}$ (The OECD Programme International Student Assessment) results, where Wales performed badly in this international comparison of learning outcomes. Like many other areas of social policy ACL was subject to 'policy overload' and, as this research found, policy hovered between a set of complex economic and social expectations (Ball, 2017: 4). However, despite funding cuts in ACL and a hiatus in ESDGC, as Holford (2016: 558) says: "If an educational project, programme or movement has died, we should assume neither that its life had run its natural course, nor that it had nothing further of value to offer".

In challenging times, the fundamental questioning of the purpose of education and our purpose as educators is what is required (Orr, 1994; Fenwick, 2006). A paradigm shift or systemic change in education is required according to much of the literature (Huckle \& Wals, 2015; Selby \& Kagawa, 2014; Sterling, 2009) but ESDGC did not promote this, and from the findings it is apparent that a behaviourist model informed the strategy. The emphasis was on ecological issues and lifestyle changes, not on developing critical consciousness. Sterling calls for deeper attention to education itself, including paradigms, policies, purposes and practices (Sterling, 2008: 63). In ESDGC in ACL in Wales learning outcomes and higher-order learning were not emphasised, purpose was not fully

${ }^{56} \mathrm{http}: / /$ www.oecd.org/pisa/ 
articulated, policies lacked coherence and there was a certain amount of conceptual confusion inhibiting a critical examination of paradigms.

Global ecological issues and inequalities are not being addressed in education because education is promoting and operating within the paradigm that created the situations we find ourselves in. The following quotation conveys the importance of continued engagement and debate:

Nowadays, to say that we are clever animals is not to say something philosophical and pessimistic but something political and hopeful - namely, if we can work together, we can make ourselves into whatever we are clever and courageous enough to imagine ourselves becoming. This is to set aside Kant's question 'What is man?' and to substitute the question 'What sort of world can we prepare for our great grandchildren?' (Rorty, 1998: 175)

Many tutors in ACL in Wales who responded to the research wanted to contribute to a peaceful planet where ecological integrity is valued and where there is solidarity, respect and understanding amongst human beings. In an age of 'alternative facts' and 'fake news' this thesis contributes to ongoing conversations about learning and teaching and the purpose of education and how we can implement policies effectively to realise these aims. 


\section{Appendix A - Permission form}

Dear

Thank you for agreeing to be interviewed as part of my $\mathrm{PhD}$, which is researching Education for Sustainable Development and Global Citizenship in the Adult and Community Learning Sector in Wales. The study is looking at policy and the strategies driving ESDGC in Wales with a focus on the experiences and views of tutors and managers and how the strategies are being perceived, interpreted and implemented. Your interview forms a valuable part of this research.

\section{Confidentiality and Anonymity Assured}

I would like to emphasise that confidentially and anonymity are assured. After analysing the interviews, should I find something that I think is worth including but that could identify you, or a quote that I would like to ascribe to you I will seek your written permission and send a draft for your approval.

\section{Participant's Consent Form}

I confirm that I have read and understood this letter; I also understand and accept the following

1. The researcher will remove any information that could identify me by name from the data which I contribute to the project.

2. Reports and publications may be written about this research after its completion.

3. Part of what I say may be quoted but nothing identifying me will be made public without my written consent.

4. My identification details will be kept separate from the data which I contribute to the project, and all records will be destroyed two years after the project is completed.

The researcher will not give any personal information about me to anyone else.

\begin{tabular}{l|l|}
\cline { 2 - 3 } Signed: & \\
\cline { 2 - 3 } Name: & \\
\cline { 3 - 3 } Date: & \\
\cline { 2 - 3 } &
\end{tabular}




\title{
Appendix B - Executive Summary DCELLS Report 2010
}

\author{
The Support Needs of the Adult and Community Learning Sector in Wales for \\ Embedding Education for Sustainable Development and Global Citizenship into \\ Provision at all Levels and the Possibilities for Effective Support Networks.
}

A research study for DCELLS by Alyson Jenkins, March 2010

\section{Executive Summary}

1.1 This was a 6-month research project to identify the support needs of the Adult and Community Learning ( $\mathrm{ACL}$ ) Sector in Wales for embedding Education for Sustainable Development and Global Citizenship (ESDGC) into the delivery of learning and at an institutional and organisational level; with a focus on effective support networks to support and promote this. Consultations with $\mathrm{ACL}$ strategic partnerships across Wales were central to the study, enabling channels for research with tutors and more in-depth interviews. NAICE Dysgu Cymru and the WEA networks were also used. The research explored the possibilities for and purpose of support networks for ESDGC; it also looked at preferred form and mechanisms for these. In the process, the networks for taking forward the agenda have been identified and awareness of embedding ESDGC at operational and strategic levels has been increased.

1.2 An inclusive approach was adopted, ensuring that a wide range of stakeholders across Wales were able to feed into the study. All sectors delivering $A C L$ were involved: $\mathrm{HE}$, $\mathrm{FE}$, local authorities and the voluntary sector. Consultations with $\mathrm{ACL}$ partnerships, focus groups, questionnaires administered by email and online and one to one interviews were the main research methods employed. There was generally a good response, especially to the tutor online questionnaires.

1.3 At all meetings, in discussions, training events and at the focus groups the Common Understanding Document for ESDGC in ACL (in press) was introduced and the vision of developing a whole organisational and interconnected approach to ESDGC, endorsed by senior management was presented. The LLUK Application Guide was also presented and awareness of these documents was raised. Many practitioners were keen to emphasise the good work that is already going on in the sector. Where good practice has been outlined this will be fed into future work on disseminating good practice.

1.4 The data was analysed so as to reflect the views of tutors and managers as well as the differences and similarities between sectors. There was consistency amongst tutors across sectors, their context is similar, teaching in a classroom in a community venue or on a campus; managers across sectors displayed a wider variety of responses reflecting different working contexts. 
Support needs include:

- adopting cross sector approaches to promoting and supporting the embedding of ESDGC;

- maintaining awareness raising initiatives whilst developing training on embedding ESDGC into teaching and learning with a subject specific focus;

- dedicated staff to take ESDGC forward was seen by many managers as one of the best ways to realise ESDGC objectives;

- time to develop resources was needed;

- resource needs were clearly expressed with starting points and subject specific resources across all provision being a priority;

- funding for all these was an issue and a concern;

- practitioners felt that it was important not to lose the momentum that had been established by a top down policy driven approach and that future developments should involve feedback from all stakeholder groups in order to take forward the embedding of ESDGC in the ACL sector;

- the sharing good practice and resources was a priority.

1.5 The idea of effective support networks was welcomed by tutors as they often feel isolated; managers also supported it. A Web $2^{57}$ option is favoured along with face to face regional networks, but a mix to enable participation was seen as best. Most people could not commit time and therefore a web portal seems the best solution, the web option could also encompass a means for the sharing of resources and good practice - this was a key priority for future developments. Other suggestions included a newsletter, blogs and a support forum for tutors. A cross sector approach was advocated by many, especially in the context of sharing resources, best practice, shared funding bids and also joint training event. The ACL partnerships are key in future developments as it is envisaged that many of the recommendations could be taken forward through them.

57 "Web 2.0" refers to web applications that facilitate communication and interactive information sharing and collaboration on the World Wide Web. 


\section{Appendix C - Letter, ESDGC Champion}

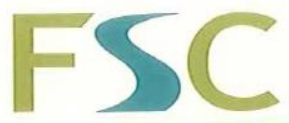

BRINGING

ENVIRONMENTAL

UNDERSTANDING TO ALL

$9^{\text {th }}$ March 2018

To Whom It May Concern

Alyson had already begun research for a $\mathrm{PhD}$ which explored education for sustainable development and global citizenship (ESDGC) in Adult and Community Learning (ACL) in Wales. DCELLS (Department of Children, Education, Lifelong Learning and Skills) at the Welsh Government fully supported her to include questions into her research tools for her $\mathrm{PhD}$ which was looking to conduct a study on the support needs of the ACL sector in Wales for embedding into provision and the possibilities for effective support networks.

It was agreed that the $\mathrm{PhD}$ questions would not be onerous and would add to the focused work that DCELLS were undergoing at the same time. The questions were reviewed by myself, the ESDGC Champion at the time. All respondents were made aware of the reasons for the research and the PhD and confidentiality and anonymity was assured at all times.

The information from these questions added to the DCELLS work and Alyson's PhD will help inform policy and practice in this important field.

Yours sincerely

Claire Fowler

Director of Education 


\title{
Appendix D - Example of data: Notes from ACL Partnership meetings
}

\author{
ACL Partnership - Ceredigion
}

\section{General views on ESDGCG}

It is seen a bit as a favour of the month - now we are already on to Learner voice! - this is ESTYN's new priority.

$\mathrm{GH}$ - Aberystwyth University; we don't have Estyn requirement in HE but some individuals there are keen. Is Estyn asking learners what they want or think? Inspirational talks have helped.

We need inspiration and being reminded about why we are doing it - why it is important. We want some inspiration about LOCAL ISSUES not just rainforests - but how they link up. Relevance - joining it up - for example Aberaeron flooding and flood defences.

We have Basic skills awareness course - we need ESDGC awareness courses - but with emphasis on how to embed into lessons - who can deliver this - 1 or even 2 day course (not necessarily accredited as this would cost more)?

Relevant packs for tutors needed - eg - Arts and crafts - specific curriculum areas.

What we need are good idea and then sharing good practice

A network for tutors - virtual perhaps.

Many people still not e-literate though!

Ymlaen Ceredigion have done some staff development - they are based in Coleg Ceredigion.

\section{South West Wales Partnership}

There is no recognition of continuing education around this. One off - quick input - slap dash done!

Embedding is what is needed - training to do this.

If WAG is serious and sees this as a strategic priority this should be reflected in uplift/incentives. CPD - tutors investing time in ESDGC training are not reimbursed.

What about qualifications? What are their value?

WEA and Sazani offering some training - not enough! This should be mapped to the LLUK Application guide - LLUK document sets out the ideal.

CPD needed - and CPD resources - TRAINING TRAINING TRAINING!!! - tutors need this BADLY. WHAT IS ESDGC? some do not know.

There are resources - the Welsh Baccalaureate has a lot - FE have a lot. Fforwm going to have a moodle.

There has to me a MECHANISM for sharing resources - this MECHANISM IS IMPORTANT

CONSIDERATION.

This has to be addressed at a network level and at a regional level.

Good framework needed for support mechanisms to work.

Local partnerships supporting tutors is the issue.

Operational management - this is where the need for training is.

You cannot force ESDGC - learner rights/autnomy.

Links with Communities First, community development and regeneration! Where are they? 


\section{South East Wales Partnership - 5 counties}

Why is this so fragmented? ESDGC for FE, HE, youth, ACL, WBL.

Why not have a post-16 approach? It would be easier - one portal - sharing resources and good practice and systems - also more of a shared approach. The WBL sector have a toolkit - so why not use this across other sectors when appropriate. Why can't we have a more joined up and efficient approach?

VIRTUAL LIBRARY - ONE PORTAL.

Providers to have a provider toolkit and evaluation.

If and when we embed ESDGC - there is no recognition of it - no funding for CPD in it.

No training for tutors - this is a big issue!!

There are no incentives in $\mathrm{ACL}$ - we need some. Are there credits around this?

If they see it as a priority - then must recognise that teachers and tutors need skills and knowledge - what progression career wise is there for tutors in this area?

I have noticed more of an emphasis on the sustainable development than on the global citizenship - this needs to be addressed!

One person went on about ... China and international exchanges and having people from the third world in - this is not it - frustrating - they recognised this in the group!

Pedagogy - this is important - why is it not talked about more? - Pedagogy and teacher training The pedagogy of empowerment - this is joined up thinking again.

We need a funded pilot - to look at resources, pedagogy and at embedding ESDGC - with international links.

SE Wales partnership happy to take a lead on this! The main thing is the way of teaching - critical thinking.

"What are the outcomes?"

\section{Pembrokeshire}

Representatives from Pembrokeshire College- from the local authority WEA, Princes Trust, Department of adult and continuing education at Swansea University (DACE).

There is no time to identify ESDGC in their practice - as there is so much else to do and to consider.

Learners pay for a specific course and to learn specific skills.

We need it to be a coherent whole.

Sharing resources is important - there is a lot already out there - we don't want to duplicate and waste effort developing stuff.

Portal for sharing - resources - ideas - best practice.

\section{North East Wales}

"we've just done the Self-Assessment" and so not had time to think about anything else It was Work Based Learning, but we looked at the wider provision - not looked at ESDGC. There was confusion at this meeting as to what $A C L$ was - somebody spoke of the Welsh Baccalaureate - clearly this is not part of ACL.

Work Based Learning was mentioned more than once - this is not $A C L-I$ felt I had to explain what $\mathrm{ACL}$ was.

CVS were there - they have/are developing training framework for the voluntary sector Very reticent when asked what they thought the sector needed for ESDGC. 
Only one person responded - tutors need to be kept up to date - a bulleting - email - with up to date into and resources.

"The basic work has been done with ACL tutors and other sector too" no examples.

They talked about the good work with ECO schools etc.

Key skills in ACL covered ESDGC - they thought.

\section{Merthyr Learning Partnership}

It was a large meeting - very welcoming. I am wearing 3 hats - DCELLS - PhD and also trainer and freelance practitioner.

The partnership is focusing on 5 themes.

ESDGC is most obvious in community development and Active Citizenship theme - everyone agreed on this point!

Where is ESDGC in all the partnership plans? It does not exist - Welsh Government not mentioning it.

Measuring - evidence and data collection is an issue.

Delivering Skills that Work for Wales is priority - Response to this by January $11^{\text {th }}$ - seminar on

Friday in all Nations Centre Cardiff.

Social Return on Investment analysis would be useful in $\mathrm{ACL}$

After my presentation - many questions

Community Development is promoting ESDGC where practitioners know about it and are keen why is DCELLS not looking at this and promoting it?

Communities First are not getting involved with ESDGC - what is happening?

ESDGC and citizenship were removed from the Communities Firsts remit/terms of ref - the vision framework! This is very short sighted - so in the new community dev programme this does not exist! There was a discussion about this.

\section{Vale of Glamorgan}

Tutor training is the key issue - they need an understanding of what it is and also how to embed in curriculum.

Also, the centres - practical things that can be done.

They are using recycling boxes - these are already there - we are already doing a lot e.g. wedding dress recycling.

The building - fair-trade items - suggested putting information on the walls - why it's fair trade why fair-trade is important - the growers' story etc.

Rainforest alliance cups - they had not noticed before - people need to know significance of them and other things - we had a great discussion and lots of ideas were generated Links with schools were fruitful for them.

They need: Resources - Project funding - small - to kick start activities and raise awareness Tutor training - we would like to pay them - not realistic though.

ESDGC newsletter for the sector.

Disseminating good practice - on line probably.

Readable and user friendly.

Keep momentum up - not just a policy gathering dust.

We want money to pay tutors we want a newsletter - these are two priorities - mainly in the first place, about awareness raising. 


\section{Chair - Cardiff Learning Partnership}

We are unique in Cardiff - We are focusing on Equality and diversity in our strategic plan - this is the focus and there is only so much you can do. ESDGC - have not addressed it! There were not many places to include ESDGC. It was Estyn that gave guidelines for this.

They are doing an equality impact assessment - based on Cardiff county council work - redoing whole strategy for the partnership in light of this!

ME - places to include global citizenship? - she did not see this! I mentioned it - she went on to say, "it is about equality of opportunity and the diverse communities of Cardiff - we are multicultural and yes I suppose we can make links with Global Citizenship through this - but we are not linking it to ESDGC."

We have a strong equality team in the council - they are helping us put it together - We are right at the beginning of all this - we will take it one step at a time

Asked if they needed support to embed ESDGC across ACL - she said haven't got secretariat - they shared resources of partnership - everything is a bit thin - so don't know what we want yet - have not considered it.

Did not know where to go to look for help or support - did not seem that keen. Did not see the point of ESDGC. What's the relevance to people in Cardiff's lives?

"WE are not sure what it is! We need someone to come along and tell us about it" I did an awareness session at their next meeting. There were questions about embedding - felt it needed to be done with the tutors - the need for training for them.

Questions about resources were raised - who will pay for the tutor CPD?

Reminded that tutors are part time paid sessionally and not likely to want more work! It is a burden.

There are some good examples in schools of gardens and growing and recycling - eco schools difficult to do in adult education - no building. 


\section{Appendix E - Example of Questionnaire to Managers (Condensed) \\ Education for Sustainable Development and Global Citizensh \\ Researching the needs of the Adult and Community Learning $S_{6}$}

Please highlight answers as appropriate and return to:

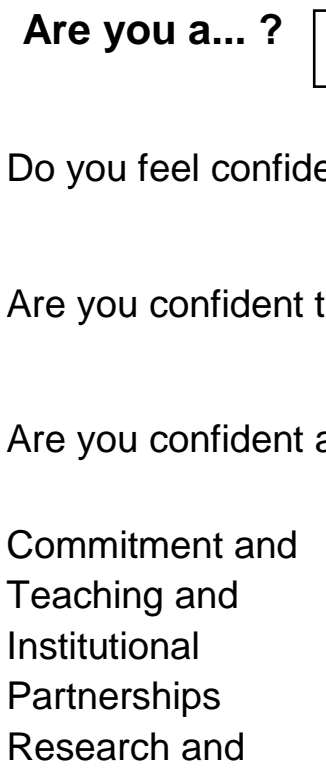

$$
\text { Senior Manager }
$$

\section{Operational/Middle Manager}

Officer

YES

YES

(
Other - please sta

Fairly con

to take ESDGC forward in your role? 
Do you have training needs?

We are always willing to learn more on this topic, therefore, any training or information would be valuable.

What would you like to know more about? What support do you need?

Embedding ESDGC into specific subject areas - are there any resources? What about training?

What are your anxieties or concerns for ESDGC in ACL?

Financial implications - we do not have the money to send tutors on training - and we can't buy in training either

Hopes and expectations for ESDGCG in the ACL sector?

A raised awareness $\&$ sharing of information in the community to hopefully contribute to making a difference in

\section{Support Networks and Networking in ESDGC}

Would you be interested in regional networks for ESDGC in ACL?

Would you find a Managers network helpful?

What sort of networking would you like?

What role and purpose could support networks have?

Sharing good practice mainlv - also good support

Any comment on ESDGC policy and its implementation? Any other general comments?

I think it is a good idea but without resources our hands are tied.

\section{Thank you for your co-operation.}




\section{Appendix F - Sample of a Manager Questionnaire}

\begin{tabular}{|c|c|}
\hline concerns & hopes \\
\hline $\begin{array}{l}\text { Ensuring that all tutors are familiar with what they can do in } \\
\text { their class - this is going to be difficult }\end{array}$ & in the next Estyn inspection, That ESDGC is fully embedded \\
\hline $\begin{array}{l}\text { To ensure it does not become a token gesture to satisfy external } \\
\text { requirements. Another tick box excersise }\end{array}$ & $\begin{array}{l}\text { That it becomes an integral part of thought and work regarding } \\
\mathrm{ACL}\end{array}$ \\
\hline $\begin{array}{l}\text { Not enough time or money to work with tutors. Also tutors not } \\
\text { buying into ESDGC and implementing into lessons. }\end{array}$ & $\begin{array}{l}\text { Hope to identify and share good practise. Learners and tutors are } \\
\text { actively supportive of ESDGC in their local areas. }\end{array}$ \\
\hline $\begin{array}{l}\text { The capacity to monitor its development and embedding within } \\
\text { the teaching and learning along with everything else. }\end{array}$ & It is becoming more embedded and hopefully will continue. \\
\hline $\begin{array}{l}\text { Tutor time to develop appropriate and relevant material - also } \\
\text { attend staff development }\end{array}$ & \\
\hline Financial implications & $\begin{array}{l}\text { A raised awareness \& sharing of information in the community to } \\
\text { hopefully contribute to making a difference }\end{array}$ \\
\hline $\begin{array}{l}\text { Most people, tutors and manager, take the easy route: the green, } \\
\text { eco-issues. Much more information on them and more } \\
\text { straightforward isn't it? global citizenship is a bit abstract, how } \\
\text { are we supposed to make sense of it let alone teach it? }\end{array}$ & \\
\hline $\begin{array}{l}\text { Outreach provision is heavily dependant on consumables, } \\
\text { everything needs to be portable and taken to the venues, often } \\
\text { tutors do not have contact with campus, everything comes out } \\
\text { of their car boot. Community centres rely on college resources, } \\
\text { students do not like to move out of their own areas. WAG } \\
\text { directives on Welsh bilingualism will come at a cost. }\end{array}$ & $\begin{array}{l}\text { To bring ESDGC to the for efront of everyone's mind in } \\
\text { outreach/community centres. Start making reductions in every } \\
\text { sector of ESDGC. }\end{array}$ \\
\hline $\begin{array}{l}\text { Outreach provision is heavily dependant on consumables, } \\
\text { everything needs to be portable and taken to the venues, often } \\
\text { tutors do not have contact with campus, everything comes out } \\
\text { of their car boot. Community centres rely on college resources, } \\
\text { students do not like to move out of their own areas. WAG } \\
\text { directives on Welsh bilingualism will come at a cost. }\end{array}$ & $\begin{array}{l}\text { To bring ESDGC to the forefront of everyone's mind in } \\
\text { outreach/community centres. Start making reductions in every } \\
\text { sector of ESDGC. }\end{array}$ \\
\hline
\end{tabular}

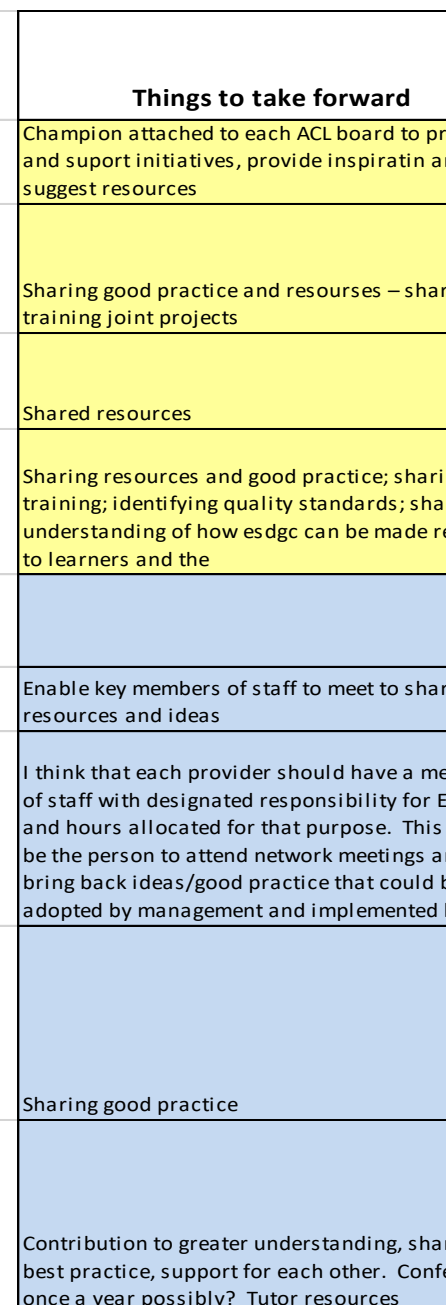




\section{Appendix G - Sample of tutor online questionnaire}

\section{Some examples of responses}

\section{Q4 If you teach or run training in ESDGC please give details}

- Advise tutors on embedding of ESDGC in schemes of work and lesson plans

- As an IT Tutor we try to incorporate ESDGC into our assignments and make all learners aware.

- Embedded in BS classes

- Embedded into ESOL lessons

- ESDGC is included as part of all our courses within the Council that ranges from research projects for internet courses, keying in letters, posters, designs for other software applications.

- I have taught classes and run workshops about using recycled materials in art and craft.

- I have to embed ESDGC in my teaching.

- I incorporate some ideas of ESDGC into ESOL lesson plans.

- I integrate ESDGC into my classes by: Encouraging my students to think carefully before printing anything. Writing exercises for the Pembrokeshire Portal with an ESDGC theme

- I run an ICT training course that combines learning the basics of Digital Photography and IT, with learning about local and global sustainability issues.

- My work relates massively to the concept of global citizenship as within my classes - self generating small communities are created where people become motivated to be together and make every effort to do so in a fun and relaxed manner. They develop their "community" skills within the safe haven of the community singing workshop and this will hopefully have a positive knock on effect with the way they deal with community issues within their own locality

- Since I work with people with many different backgrounds from all over the world and introduce them to everything they need to fend for themselves and continue to improve by themselves here in Wales (and the UK as a whole) after they have left my hands it seems that I am involved in Education for Sustainable Development and Global Citizenship.

- So far I have included one ESDGC unit into my craft units.

- Sustainable development and global citizenship is taught as part of the curriculum in secondary education. I have introduced ESDGC into my adult IT lessons. Including consumption of resources and globalisation.

- Understanding Home Energy Efficiency

- we incorporate ESDGC issues in our sessions whenever possible

- What exactly is ESDGC?

- Dysgu Cymraeg i oedolion, Dysgu yn y gweithle hefyd.

- Dim ond fel rhan o'r dysgu Cymraeg

- Rydym yn ceisio cyflwyno ADCDF o fewn ein gwersi nawr. Rhoddwyd poster i bob tiwtor a thri sesiwn hyfforddiant hyd yma.

- Sesiynau blasu fel rhan o hyfforddiant at weithredu Cwricwlwm Gwaith leuenctid 


\section{Comments following question on training}

- A short course with Lifelong Learning Swansea

- A small amount during a tutor meeting.

- Approximately 5 years ago I attended a workshop run by the WEA along the lines of the above.

- As Part of my induction

- Attended a short presentation at a tutor conference last year.

- Caerphilly CBC internal training

- City and County of Swansea Lifelong Learning, about 8 months ago. It was very informative but did not allow enough time for Q\&A.

- Coleg Gwent. Introduction to the concept only.

- Coleg Sir Gar -

- Course at Coleg Menai - by a nice young lady from South Wales.

- During our tutor conference last year in Plas Hyfyd with SK It was both informative and gave me a good insight.

- ESDGC training at Coleg Gwent

- Had an awareness raising session at a tutor conference, it was delivered by S K (Widening Participation Development Manager at Coleg Sir Gar) in March 2009. The session was interesting and informative and $S$ gave good introduction to the topic.

- I I am the one who develops ESDGC training courses. No one did it before me, so I decided to start working on it myself.

- I attended a course in Cefn Fforest it was very interesting

- I attended a tutor conference during March 2009 where one of the workshops led by SK was devoted to the subject. I came away from the conference wanting to find ways of integrating ESDGC issues into my classes

- I did a PGCE in secondary education in 20054-2005. I received training as part of my PGCE. the training was organised by UWIC. It was a lengthy Powerpoint presentation and very few practical ideas were provided.

- I did last year a training course in ESDGC with RCT. This was an excellent awareness building day course.

- I have a BSC and Masters in Environmental Conservation and Management as the basis, and have taken part in a course at Down to Earth in Murton Swansea for using ESDGC with hard to reach young people.

- I'm not really sure if I have but we've had various training like 'World in My Shoe' etc, I don't know if that sort of stuff counts. I've also taught Conversational English in Thailand. I attended a TEFL course and gained a certificate 2005

- It was run as part of a tutor training day. The day was arranged by Pembs County Council the trainer was from Carmarthen.

- Item included as part of Learning Pembrokeshire Tutor event in March 2008

- Last year basic principles outlined at staff development meetings and annual tutors meeting. This was a general introduction/overview that raised my awareness to the potential importance of this subject.

- ........... Caerphilly County Borough Council Community Education Excellent,

- No formal training as such

- Not formal training - just a talk from a guest speaker about 9 months ago

- Not specifically under that label

- Organised by Caerphilly County Borough Council Community Education Dept. 2009 not sure of exact date. Useful and very informative.

- Organised by Coleg Menai last July. AJ An outside speaker gave a presentation. 
- Please tell me about any training - who ran it? when? any comments on it?

- PLN tutor conference March 2009....... delivered a presentation overview of what ESDGC is about and its place in ACL.

- RCT CBC had a short course I attended 2008/9

- RCT Global Training day "Partners in progress"

- Small part of Carmarthenshire CC tutor training day. The session was all about why we should do it.

- Sophie in Newport for a regional training session last year

- STEP Project tutor meetings

- The subject was touched upon as part of my PGCE in Post Compulsory Education and Training, UWIC, completed 2010

- The WEA has run a few training sessions that I have been on. However, as I am employed to work in an FE college this has been a "lucky find" for as strictly, I do not work for them or for that client base

- Through my employer the WEA

- Training provided in house (external consultants invited in) OCN conference workshops - ACL conference workshops

- Training ran by Caerphilly County Borough Council in Dec 2008

- We have had an ESDGC awareness presentation

- WEA: Focus on raising awareness, gaining knowledge and on integrating ESDGCG into teaching CCBC: Session on raising awareness

- You are asking me to comment on something I know nothing about. How does it affect my painting class?

- Doeddwn i ddim yn rhydd

- diwrnod 2 flynedd yn ôl

- Dau sesiwn wedi'u trefnu gan Ganolfan Gwent

- hyfforddiant - Coleg Gwent

- Bras ar ADCDF: gan Alyson Jenkins dydd hyfforddiant yn Cwmbran (6/2/10) (Gwent Cymraeg i Oedolion)

- Cwrs TACIO Coleg Gwent

- sesiwn cyflwyno byr ar gwrs hyfforddiant

- Sesiynau hyfforddiant Coleg

- Beth yw ADCDF dw i ddim yn dda gyda enwau byr fel hyn

- $\mathrm{YMCA}(\mathrm{OCN} 1)$

- Daeth Alyson i ddiwrnod Hyfforddiant Mewn Swydd cyn Nadolig wedi'i drefnu gan Brifysgol Morgannwg. Cawson ni sesiwn hyfforddi

\section{Q9 What resources do you need to take ESDGC forward in your work?}

- Activities and conversation starters.

- Added courses designed to implement full understanding

- Additional time should be considered if this is to form part of the measure of performance of tutors. Adult learners have a specific aim when they attend evening courses There are inherent barriers to learning that must be overcome in many cases, ESDGC is an intangible benefit when these can be overcome. This intangible benefit needs to be measured statistically and regarded as a benchmark across the board allowing tutors dedicate their time to learners. 
- An easy to use website with interesting and suitable resources that could be downloaded. Information about events held locally that would be appropriate for learners.

- Any aimed at beginner/Entry One ESOL learners

- Booklets in easy-to-understand language about ESDGC to hand out to students.

- Classroom activities suitable for adult learners

- do not know $\times 12$

- Handbook of sample activities and resource links for my subject area. There appears to be more provision for e.g. craft and practical courses but less for the more academic subjects.

- Handouts, background info

- Have never heard of ESDGC

- I know nothing about it $\times 13$

- I need to have more extensive and flexible web access which can be used for Educational purposes currently blocked by tunnel-visioned IT policy developed without any input from educators and trainers. The internet is the best rapidly developing and constantly updating resource for trainers and all kinds of Educators. All the info I need is available online. A computer and interactive white-board or at least laptopprojector or in every classroom or at least in the IT suite please.

- I think simple units on the subject would be a good teaching tool. If they are presented in an interesting way they could be used as a fourth unit over the year. Tried and tested activities to use within the class. Leaflets on raising awareness. Ice breakers that implement ESDGC issues. Possibly funding to buy extra teaching props

- I will look at the information on the Portal. At the moment I do not feel I have a clear view of the aims and objectives of ESDGC and how they would impact on my working practices.

- I would like more information passed down to me as a tutor, explaining exactly what is required, and maybe ideas how to implement it into a Family History lesson

- I would like to be able to provide my classes with Fairtrade coffee and tea, as this might provide a basis for a discussion on the subject.

- I'm dealing with people on very low income, or no income at all. These people know exactly how much a $5 \mathrm{~min}$ shower costs because money is tight, and their electricity is on a meter. Having me tell them to change all their bulbs to energy efficient fitting is not going to work. My resource are my own common sense and sensitivity.

- info, worksheets, quizzes

- Information about what ESDGC entails x5

- Information packs

- Lesson samples, whereabouts of resources, websites etc

- Links, information, ideas $\times 10$

- List of resources available, websites and examples of good practice, what can be done within lesson/course/classroom $\times 5$

- Literature

- $\quad$ No idea $\times 5$.

- None $\times 12$

- Not sure $\times 5$

- Some facts, statistics, leaflets and some handouts for students

- Some information on expectations

- $\quad$ Time to prepare $x 7$ 
- to understand how my institution will embrace ESDGC. Good links to websites, creative lesson plans and resources an understanding of how ESTYN/ my institution want me to embed ESDGC

- Training $\times 3$

- Until I'm clearer about the actual meaning of sustainable development and global citizenship in the context of teaching ceramics, I couldn't say what resources I would need.

- Using IT is an advantage, information and research skills can be attained while gaining knowledge on the topic. As well as using graphs and statistical data.

- We deliver a small number of short courses ( $\max 3$ days in length) and feel that many of the themes may already be covered.

- Pa adnoddau sydd ar gael?

- gweithgareddau addas

- Dim byd nad ydw i'n gallu eu cynhyrchu fy hunan.

- DW I DDIM YN GWYBOD

- Sut i gyflwyno'r pwnc mewn dosbarth iaith

- $\operatorname{dim}$

- Mynediad dibynadwy i'r We

- Ar wahan i un poster hyd yma nid oes adnoddau penodol gennym

- DIm diolch

- Popeth - syniadau/Gweithgareddau - Mae gweithgareddau ymarferol yn bwysig. Wi'n dysgu 18 awr yr wythnos ac fydd dim amser gyda fi i baratoi deunyddiau fy hunan.

- Pecyn o syniadau sesiynau addas i'w cynnal mewn clwb ieuenctid.

- O ran y Brifysgol mae'n nhw'n datblygu anoddau ar gof bach ac edrych ar y byd technoleg gwybodaeth yn cyffredinol fel modd cyfathrebu. O ran y cyngor lleol (Addysg Bellach / Addysg i Oedolion), mae cyfathrebu a dogfennau i gyd ar bapur, rhai sustemau yn wastraffus iawn. Mae pob sefyliad yn wastraffus tu hwnt o ran goleuo di-angen / gwresogi adeiladau. Er enghraifft, sesiynau nos, adeilad cyfan ar agor am 3 dosbarth a tri llawr yn cael eu goleuo / gwresogi ayyb

- Dw i'n meddwl bod digon o adnoddau ar gael i diwtoriaid leithoedd Modern. Y brif broblem yw dod o hyd i amser i chwilio amdanynt ac amser hefyd i'w gwneud nhw yn ystod y cyrsiau.

\section{If Yes, What? Examples}

- A copy of suitable software to self-learn before being confident to teach.

- A refresher course will be useful.

- A session on embedding ESDGC in the ESOL curriculum with specific and practical suggestions, ideas and activities.

- Any and all training will be useful

- Any awareness/help to allow this area to be incorporated in my teaching

- any training would be ok $\times 7$

- Awareness of what it is $x 5$

- Building confidence in embedding ESDGC into my teaching and discovering new resources.

- comprehensive

- Currently doing a PGCE - not much in that about it

- Discreet ways of introducing ESDGC into my classes

- Discussion among other tutors and personnel about collective and consistent good practice re. ESDGC. 
- Dyslexia and ESOL

- ESDGC Awareness Training x 5

- Explain what the training of ESDGC all about is - very interested

- Find out what ESDGC involves and how it can be incorporated into the teaching of craft work.

- Further training $\times 6$

- Help in embedding and finding resources $\times 2$

- How do I exactly what these are if I don't know what ESDGC is?

- How to link ESDGC into Basic Skills courses

- I am not sure, but I think I need to be more aware of the WAG ESDGCD goals

- Updating on current developments

- Ways of teaching this in an interactive fashion

- what is ESDGC? $\times 9$

- Whatever is necessary to enable me to take ESDGC into my work $\times 8$

- Would like specific training for the two areas I Lead Tutor in (Languages and General Education) to give tutors more concrete examples and ways to embed ESDGC

- adcdf

- DW I DDIM YN GWYBOD . DW I DDIM YN GWYBOD BETH YW'R DISGWYLIADAU

- Ilyfrau/pamphledi? cardiau fflach yn egluro ADCDF

- Sut mae cyflwyno'r syniadau heb fynd mewn i wleidyddiaeth ar wahanol lefelau cyrsiau iaith ar amserlen dynn iawn

- iddeall am beth dych chi'n siarad ac wedyn efallai

- Popeth - cyflwyniad /ymwybyddiaeth am y peth.Wi ddim yn holol siwr beth yw ADCDF heb son am ei gynnwys mewn gwersi. Syniadau / Gweithgareddau

\section{Q11 What other support do you need - anything.....}

\section{Example of responses}

- A greater sense of this being the way forward and not just a trend.

- Administrator level permissions so that I can deal with and save student's work from being lost when we run into problems instead of having to shut down the computer because I "... do not have permission to perform this task. Please contact your network administrator" which will take three days, while the class will be over in 1 hour. Basically, it would be nice if the support side of things were more able to think outside of the box, to respond to the needs of rapidly developing educator techniques and capabilities. Currently I feel like a Processor stuck in a computer without the RAM to let me make the miracles happen which could happen if there was enough RAM. The facilities are a generation behind the new generation of facilitators. If Educators were software and institutions were Hardware, then the software is running in "safe-mode" because the Hardware does not currently meet the specifications to run the full version of the software. It would be nice to have a group designed for coming up with and developing creative ideas for how different things could be included in a curriculum for ESDGC such as instilling a sense of value for our own ancient European (and amazing Welsh) traditions to those who come to live here as well as some PR for the indigenous population to help us understand the advantages there are in exposure to non-European traditions without fear of our own identity being drowned out.

- As much as possible.

- Confident that I can have the support of my employer/colleagues

- Don't know x4 
- It is a great idea to get together with other motivated teachers to share ideas and to keep learning

- It is all well and good having a strategy, but will we have some back-up? support, resources?

- Less paperwork so there is more energy for teaching.

- More money and resources $x 4$

- On-going training and feedback

- Regular email updates on developments and training opportunities

- The ability to be able to prevent my students from buying the Sun and watching trash TV. To improve my students' knowledge of all things.

- The realization from those at the top (not meaning my centre manager) that my work and classes are actually valuable and worthwhile -as the no's attending show- and that they have a big positive effect on people's health, confidence, physical and mental wellbeing. When this is actually realised properly maybe then the classes will be given proper funding as savings to other "social" services in terms of treating people for breathing problems, depression etc are weighed against the cost of running a fun, positive, more preventative course.

- This should be a management issue with regular updated electronic newsletters placed on the desktop of all computers within the Borough. When learners log on they would see the newsletter and would be able to read the information.

- Training will be fine - thank you!

- Website and e-mailed information about good practice re. ESDGC

- Whatever

- Why not just send someone to each class once a year to do one session on the subject?

- Mae syniadau neu wybodaeth am ymarfer da wastad yn ddefnyddiol.

- Sut i addasu i wahanol dosbarthau, a edrych ar lefelau dosbarthau ynglyn a sgwrsio am y byd yn Gymraeg gyda'r dysgwyr.

- canllawiau, deunyddiau, hyfforddiant

- Dim byd. Synnwyr cyffredin yw hwn.

- Cylchlythyr hefo diweddariad o adnoddau sydd ar gael yn y maes yn dod allan yn gyson

- Angen i sefydliau arwain y ffordd,

\section{Is there anything you would specifically like to know more about? Examples}

- A briefing on the practical issues and expectations of tutors regarding embedding ESDGC into our teaching. This may help to identify other information needs.

- A complete overview

- all of it! $x 6$

- Always open to more information

- Can we make contact with other organisations in different parts of the world that share in this ethos?

- Embedding ESDGC into session \& planning

- Estyn's expectations

- General ideas and how it can be represented to students whose first language is not English

- How can this be brought into a yoga lesson?

- How I can incorporate this specifically in my teaching area $\times 8$

- I am sure that I would be able to obtain this from the CEO

- I don't know enough to answer this question. 
- I would like to have all information about ESDGC.

- I would like to know about issues other Tutors/trainers in the same area are facing on a regular basis and how they deal with them. I would also like to know about how ESDGC policies are being developed when no one has come to my classroom to ask me about what practical issues they need to think about in developing the policies.

- Is there advanced level training available in digital photography and post-camera manipulation?

- More about the Global Citizenship aspect

- More information about this generally.

- New ideas of how to embed ESGDC in my Maths lessons. I'm willing to share my ideas...

- Not at present. Updated training may provide me with more questions.

- Obtaining ESDGC information is not a problem.

- Sut mae pobl yn Ilwyddo i gynnwys ABCDF pan fo ychydig bach o iaith gan y dosbarth.

- YPWNC DAN SYLW

- Efallai taswn i'n deall mwy am ABCDF gallwn i gyflwyno i'r gwersi

- Sut mae ffyrdd i gymdeithas bach newid mwy o fewn y byd mawr!!

- Beth yw e? Sut mae wneud e?

\section{Q13 Do you have any anxieties or concerns for / about ESDGC in Adult and Community Learning? Examples}

- Again, this would be a good discussion topic among teachers generally - I'm not sure how this would affect my day to day teaching directly.

- Although it is obviously an essential element in current day teaching, it has to be presented to both tutors and students in a cohesive and persuasive manner, so that it is not viewed as some add-on element or as a box that has to be ticked.

- As with the inclusion of Welsh cultural content that was an outcome of a recent Estyn inspection, my anxiety is finding time to locate appropriate content and revisit existing resources to incorporate new material.

- Awareness raising, and discussion is fine, but when it comes to affecting behavioural change it is really difficult to measure impact. I find that adults and community groups are more difficult to work with on these subjects as they are often highly opinionated or set in their ways.

- Don't know enough about it specifically to comment

- Far too much paperwork generated even when email is used I still get hard copies of literature.

- Feel that the issue of ESDGC may be contrived to fit into basic skills scheme of work

- How to compete with the wants of society to have the latest thing. Running courses which promote recycling across a wide community is logistically difficult and to expand the provision will involve a lot of road miles which in turn impacts on the environment.

- How to embed it without extra work and cost implications

- I am concerned that deliverers will miss the point and incorporate their own agendas into the classes which might damage the point and or fail to supply learners with what they really need for harmonious interaction in society.

- I am concerned that I will not be able to keep up to date with current thinking or that I will make mistakes e.g. I didn't realise that batteries needed to be recycled separately. My learners now leave all their batteries with me, I have no place to store them and this is increasing my workload as I have to take them to the tip. 
- I am unsure how much of an impact Community Learning will make towards ESDGC, but I live in hope.

- I do not see it as my role to incorporate ESDGC into teaching a group of ladies, mostly senior citizens, who have come to learn a craft which they enjoy as a hobby. I have discussed your document with both of my classes and they all see it as highly inappropriate for them.

- I do not think it should form any part of our teaching.

- I don't feel comfortable teaching ESDGC, it is incorporated into lessons because I have to, and not because I want too. I feel as if I am teaching learners to suck eggs, the majority of whom are mature responsible adults and who are equally capable of researching information on recycling or global citizenship. Learners want to come to class to learn about IT not about climate change. Which is being pushed at every available opportunity until we are at the point of ESDGC overload.

- I don't really know enough about it to be concerned or aware if it is important.

- I find it easy to bring up issues informally, such as challenging stereotyping and inequality, because they are things I personally believe in, but pushing the ESDGC agenda too hard in subjects that do not naturally relate to it feels clumsy and counterproductive.

- I have concerns about people who harp on about sustainability on the one hand while the other hand gives you half a rainforest's worth of paper - not even recycled! - in the shape of useless forms to be filled in, rules, regulations, instructions and other sources of 'information' [which, as we know, is not knowledge], more often than not printed in two languages [one of which only a very small percentage of the population, despite some people's claims to the contrary, actually reads]. This is not in accord with 'sustainability' as I understand the term. The fact that this questionnaire has been put online is admittedly an improvement, but I should like to see more such improvements before I have any trust in the relationship between sustainability and adult education in Wales.

- Insufficient knowledge to answer

- It is sometimes difficult enough for students to admit to the need for basic skills. It then seems unfair for educational bodies to insist on using the opportunity to preach to them about the government's latest favourite topic - no matter how worthy the subject may be.

- losing focus on main subject and tokenism

- Maen swnio yn wleidyddol iawn

- Oes - bod yna rhagor o sesiynau hyfforddiant gorfodol yn mynd i ddod.

- wrth reswm. byd gwastraffus, heb feddwl am oblygiadau, effaith ar y byd a phobol eraill sut mae newid yr hen ffordd o wneud pethau? y sector gyhoeddus yn bell tu ol $i$ feddwl creadigol a datrys problemau - dim ond gorfodaeth / deddfwriaeth bydd yn gwneud iddyn nhw weithredu.

\section{Q14 What are your hopes and expectations for ESDGC in the ACL sector?}

- A balance must be struck to recognise that adult learners are more concerned with learning and should not be deterred from doing this because of side issues (measures) that are not important to them as individuals. Learning must be enjoyable and productive and ESDGCG should be part of this process without becoming too much of a political issue.

- A better and healthier environment to live in. 
- A broadening of learning and teaching experiences

- A centre of excellence which promotes a different approach to ESDGCG and ACL.

- A greater understanding of what ESDGCG is, and its implementation.

- By embedding ESDGCG into Information Technology lessons, people are learning what human development and globalisation means or could mean for them and their own communities naturally. My hopes are to make people more aware.

- Dissemination of information and more variety of recycling bins in class.

- don't know

- ESDGCG module development in higher education

- For awareness to be raised and for all tutors to include it within their working practice.

- Greater awareness

- greater understanding of the world

- Help students

- I am in favour of using the forum of adult community education to educate on the wider social/economic/environmental issues.

- I am sure it would be worthwhile, but I do not have enough info on how it is expected to be included in ESOL teaching

- I believe ESDG would enhance the attainment of the goals of the ACL sector.

- I believe that ESDGC is a very important element of general education. If it becomes second nature to tutors to be well-versed in it then it could be naturally integrated rather than shoe-horned in. Enormous care needs to be taken though not to make adult education too 'preachy'.

- I can always hope but my expectations are low.

- I hope this will continue to be promoted and most certainly utilise it in my sessions to make students more open minded of global factors that have affected history both past and present in local areas, by external events.

- $\mathrm{i}$ hope to include elements of ESDGCG in everything we do. I would also like a better acronym!

- I hope to receive more guidance on implementation and expect ESDGCG will become an increasingly important element in teaching ESOL.

- I think I am doing much of what ESDGCG seems to require and it would simply help me focus.

- I would hope to be able to promote greater awareness of ESDGC among my students so that it would impact their thinking and choices, especially my art students as this in an area where recycled materials can be used imaginatively and practically.

- Individuals take more ownership of their actions.

- It will become as second nature.

- It would be good to have a program to follow for ESDGC with adults, because I've only really come across resources for youth groups.

- My FE college has very low green credentials. (too much paperwork and duplication!) My hopes and expectations for the ACL sector are low, as they are with our society as whole. Reduce emissions by 2050 ? Must be joking. We are a consumer society and economic growth at all costs seems to be an universal panacea.

- My hopes and expectations are towards my students.: To raise awareness in a positive and constructive way, to enable and not to paralyze, to demonstrate and encourage responsibility within the close community and our global community. To set achievable targets to make positive changes.

- My only expectation is probably an increase in paperwork, which defeats the object of sustainability. 
- I hope that more Tutors in the ACL sector will become more aware of our role in delivering ESDGC and that there will be more buzz about it and what we can do about it. Currently our Educators are too bogged down with administrative tasks that our concentration on curriculum and our creativity with using resources to deliver the curriculum efficiently has been eaten away to its bare bones. At the moment Tutors are not at the level in the consciousness pyramid to be able to focus on the importance of ESDGCG and our role in delivering it because of lack of time. I hope and expect that as support and facilities improve, ESDGC will be what learners and educators come to expect from their classrooms.

- That is will be removed from the curriculum.

- That it becomes a successful integral part of any course that we undertake and actually starts to make a quantifiable and noticeable difference

- That it becomes the norm $\times 4$

- That it can be done seamlessly! X4

- That it will become a real "live " topic and be completely integrated.

- That people understand the above - but it is more of a dream than a hope at the moment.

- There is always room for raising awareness in community education. You would need to think carefully about how to help the tutors to embed this kind of theme or attitude in their classes.

- To be able to incorporate ESDGC issues into my handouts and promote interesting debates which will lead on to my students being more positive about issues such as Recycling

- To have a catalogue of resources and the confidence to embed successfully

- To have proper recognition and support for the importance of involvement with the outdoors, food production and environmental issues in engaging 'hard-to-reach' members of our communities in education. The morale boost such training results in is often the key first step towards further self-development and improved, usually highly productive, community involvement.

- codi diddordeb yn ydysgwyr

- Bod Estyn a'r Cynulliad yn gwneud llai o ffwdan amdano yn y dyfodol.

- DOES DIM GYDA FI

- Gobeithio byddem yn dysgu delio gyda'r cysyniad mewn modd adeiladol

- Na fydd yn treiddio'n ddyfnach i'r sector. Hoffwn weld diwedd ar y fath wastraff arian.

- Ddim yn berthnasol i'm mhwnc i (tai chi) o gwbl

- Modi'n gallu ei gynnwys yn fy gwersi

- Bod nhw wir yn ystyried o ddifrif eu cyfrifoldebau a dyletswyddau a gweithredau ar wella'r ffyrdd gwastraffus o weithio. Angen targedau gwastraff falle / lleihau defnydd adnoddau - neu fydd neb yn gwneud dim o'u gwirfodd, yn arbennig yn y cyngor lleol, hyd y gwelaf i. 


\section{Q19 Do you know anything about ESDGC policy and strategy in Wales? (178)}

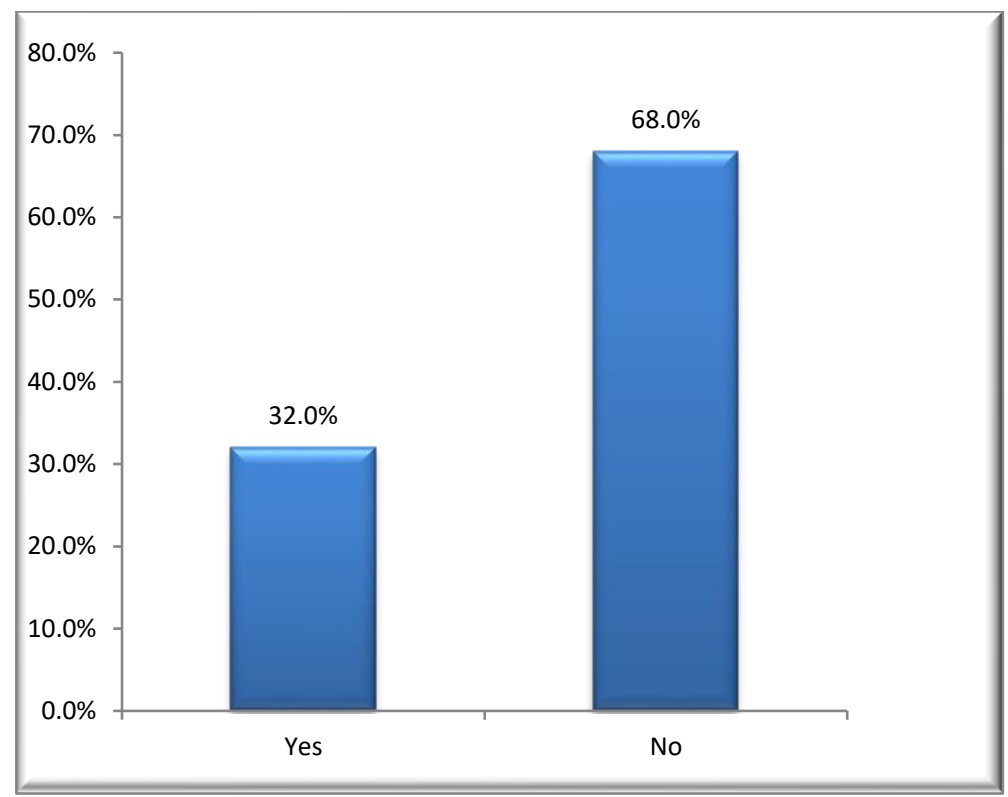

\section{Comment - Examples}

- A little x 5

- Am aware that WAG has a commitment to sustainability and to make us aware of our corporate responsibilities

- Everything that comes through the media. I can only disseminate what is available through the press. This information is also available to all our learners and therefore it is stale before it gets to class.

- Have been given the ESDGC - An Introduction sheet to read

- Have heard of it through working in the Adult Education Centre and will gain more knowledge from reading Jane's information

- I have read all of the main publications on ESDGC but I am still unclear as to how it will be assessed within the new Estyn inspection framework

- I have read items and am interested and support it but do not want to personally get involved

- information needed

- No - but interested though

- It is an aspiration to improve the key skills across the population.

- Not enough. This training only takes up a small amount of my job scope so there is little time to go searching through policy documents, but I would benefit from being kept up to date with policy changes and being sent things like this...

- Only an overview and bits picked up x 8

- Only that ESDGC must eventually or become the norm I.e. embedded into all curriculum areas.

- Only that it is being plugged and is seen as being politically correct. We all talk about it and say that it's a good thing etc. Why don't you embarrass people about their own $\mathrm{CO} 2$ emissions etc?

- This is the first that I have heard about ESDGC, sorry I have not been able to be much help in your survey.

- This is what surprises me, how could policy have been developed without consultation of the most important people in the process, i.e. the deliverers? 
- Very little

- What I have read about on websites and within local authority agendas also recommendations from Estyn and other education agencies.

- I am sorry to disappoint, but I just like teaching people to paint and draw and I am not interested in any of the political aspects/ tutor developments/etc. I also run a successful business in my own studio, both painting and teaching, and all this extra stuff just puts me off teaching for the community ed sector, although it is a job that I love.

- I feel that most of us are paying lip-service rather than changing our outlook and lifestyles. One or two of our tutors are very committed to sustainable living but most don't really think about it a lot.

- I have tried to read the strategy online, please could somebody write it in English and not in Jargon.

- I haven't had any training so it is difficult to give positive answers to these questions.

- I teach ESOL. My students want to learn vocabulary for their work, be able to read to their small children, learn tenses and when to use them, improve pronunciation and in general to gain confidence to speak English. Much class time is spent preparing for and taking OCNs which leaves little time for them to learn what is useful to them. Please don't add more things that others think is important for them. Trust the tutors to respond to their students' needs.

- If I can't radicalise my own children what hope do I have? Do we need to go for Direct Action?

- If sustainable development covers the areas of green interest, then yes, there is at least one thing I can do and that's more recycling of clay. However, without the help of a technician, I could not commit yet more of my own time to this and have reluctantly decided not to do this. I recycle my own clay, but not the Com Ed centre clay because it's very time consuming. Global Citizenship is a phrase I don't really understand. My only possible suggested link to pottery is the universality of making pots from clay.

- Let tutors do their job - teaching the subjects they signed up for.

- Not enough publicity is made about the various programs, especially in relation to training and education, launched by the Welsh Assembly.

- Please add me to a messaging list or discussion forum so that I can be involved. I would like to hear the ideas being thought of and offer suggestions and constructive criticism if and where necessary to assist in the development of a more effective and cost-efficient policy.

- Please don't burden us with more paperwork for these badly paid and non-accredited course that people come to for social reasons. How will more jargon and paper shuffling help anyone except those who are paid to create acronyms?

- The thing about clarity. 


\section{Bibliography}

Agyeman, J. (2005a). Sustainable Communities and the Challenge of Environmental Justice. New York University Press.

Agyeman, J. (2005b). Alternatives for community and environment: Where justice and sustainability meet. Environment: Science and Policy for Sustainable Development, 47(6), pp.1023, DOI: 10.3200/ENVT.47.6.10-23

Alcock, P., Haux, T., May, M., and Wright, S. (Eds.) (2016). The Student's Companion to Social Policy. Chichester: John Wiley \& Sons.

Aldridge, F. and Tuckett, A. (2005). Better News this Time. The NIACE survey on adult. Leicester: NIACE.

Andreotti, V. (2006). Soft versus critical global citizenship education. Policy and Practice: A Development Education Review, pp. 40-51. Available online at:

http://www.developmenteducationreview.com/issue3-focus4 [Accessed: 29/01/2016].

Andreotti, V. (2010). Postcolonial and post-critical 'global citizenship education'. In Elliott, G., Fourali, C. and Issler, S. (Eds.), Education and Social Change: Connecting Local and Global Perspectives (pp. 238-250). London: Bloomsbury.

Andreotti, V. D. O. (2011). (Towards) decoloniality and diversality in global citizenship education. Globalisation, Societies and Education, 9(3-4), pp. 381-397.

[de Oliveira] Andreotti, V. and de Souza, L. M. T. (Eds.) (2012). Postcolonial Perspectives on Global Citizenship Education. London: Routledge.

Anderson, L. W., Krathwohl, D. R., and Bloom, B. S. (2001). A Taxonomy for Learning, Teaching, and Assessing: A Revision of Bloom's Taxonomy of Educational Objectives. New York: Allyn and Bacon.

Anderson, T. and Kanuaka, H. (2003). E-Research: Methods, Strategies, and Issues, New York: Allyn and Bacon.

Andrews, R. and Lewis, G. (2000). Citizenship Education in Wales: Community, Culture and the Curriculum Cymreig. Paper presented at the British Educational Research Association Conference, Cardiff University, 7-10 September 2000. Available online at:

http://www.leeds.ac.uk/educol/documents/00001571.htm [Accessed: 02/04/2016].

Andrews, R. and Mycock, A. (2007). Citizenship Education in the UK: Divergence Within a MultiNational State. Citizenship Teaching and Learning, 3(1), pp.73-88.

Annette, J. (2003). Community, Politics and Citizenship Education. In Lockyer, A. Crick, B. and Annette, J. (Eds.), Education for Democratic Citizenship: Issues of Theory and Practice (pp. 139148). Aldershot: Ashgate. 
Annette, J. (2009a). Active learning for active citizenship' Democratic citizenship and lifelong learning. Education, Citizenship and Social Justice, 4(2), pp. 149-160.

Annette, J. (2009b). The theory and practice of deliberative democracy as the pedagogical basis for an adult education for inclusive and democratic citizenship. Proceeding of the fifth citizED conference. Available online at: http://www.citized.info/pdf/commarticles/John\%20Annette.pdf [Accessed: 30/01/2016].

Annette, J. (2010). Active leaning for active citizenship: Community-based learning and democratic citizenship. In Mayo, M. and Annette, J. (Eds.), Taking part: Active learning for Active Citizenship, and Beyond (pp. 16-40). Leicester: NIACE.

Antunes, A. and Gadotti, M. (2005). Eco-pedagogy as the appropriate pedagogy to the earth charter process. The Earth Charter in Action: Toward a Sustainable World. Amsterdam: KIT Publishers. Available online at: http://earthcharterinaction.org/pdfs/TEC-ENG-PDF/ENGAntunes.pdf [Accessed: 30/01/2017].

Armstrong, C. (2011). Global Citizenship: cosmopolitan Futures? In Stoker, G., Mason, A., McGrew, A., Armstrong, C., Owen, D., Smith, G., ... and Saunders, C. (Eds.), Prospects for Citizenship (pp. 153-173). London: Bloomsbury Publishing.

Arthur, J., Davies, I. and Hahn, C. (Eds.) (2008). Sage Handbook of Education for Citizenship and Democracy. London: Sage Publications.

Australian Government (2009). Living sustainably: the Australian Government's national action plan for education for sustainability. Available online at: http://www.environment.gov.au/system/files/resources/13887ab8-7e03-4b3e-82bb139b2205a0af/files/national-action-plan.pdf [Accessed: 23/10/2015].

Auth, K., Mastny, L., Prugh, T., Worldwatch Institute, Gardner, G., and Renner, M. (2015). State of the World 2015: Confronting Hidden Threats to Sustainability (State of the World). Washington: Island Press.

Axtmann, R. (2010). Democracy and globality. Studies of transition states and societies, 2(1), pp.22-35. Available online at:

http://www.ssoar.info/ssoar/bitstream/handle/document/37081/ssoar-stss-2010-1-axtmannDemocracy_and_Globality.pdf?sequence=1 [Accessed 19/09/2016].

Balarin, M. (2011). Global citizenship and marginalisation: contributions towards a political economy of global citizenship. Globalisation, Societies and Education, 9(3-4), pp. 355-366.

Ball, S. J. (1991). Politics and policy making in education. British Journal of Educational Studies, 39(4), pp. 450-453.

Ball S. J. (1994a). Researching inside the state: Issues in the interpretation of elite interviews. In D. Halpin, and B. Troyna, (Eds.), Researching Educational Policy: Ethical and Methodological Issues (pp. 107-129). London: Falmer Press. 
Ball, S. J. (1994b). Education Reform: A Critical and Post-Structural Approach. Buckingham: Open University Press.

Ball, S. J. (2012a). Politics and Policy Making in Education: Explorations in Sociology (2nd ed.). London: Routledge.

Ball, S. J. (2012b). Global Education Inc. New Policy Networks and the Neoliberal Imaginary. London: Routeldge.

Ball, S. J. (2015). Policy actors/policy subjects, Journal of Education Policy, 30(4), p.

467, DOI: 10.1080/02680939.2015.1038454

Ball, S. J. (2017). The Education Debate. Bristol: Policy Press.

Bamberg, S. and Möser, G. (2007). Twenty years after Hines, Hungerford, and Tomera: A new meta-analysis of psycho-social determinants of pro-environmental behaviour. Journal of environmental psychology, 27(1), pp. 14-25.

Bamber, P., Bullivant, A., Glover, A., King, B., and McCann, G. (2016). A comparative review of policy and practice for education for sustainable development/education for global citizenship (ESD/GC) in teacher education across the four nations of the UK. Management in Education, 30(3), pp. 112-120.

Bassey, M. (1999). Case Study Research in Educational Settings. Buckingham: Open University Press.

Bauman, Z. (1998). Globalization: The Human Consequences. New York: Columbia University Press.

Bauman, Z. (2001a). The Individualized Society. Cambridge: Polity Press.

Bauman, Z. (2001b). Community: Seeking Safety in an Insecure World. Cambridge: Polity Press.

Bauman, Z. (2007a). Collateral casualties of consumerism. Journal of Consumer Culture, 7 (1), pp. 25-56.

Bauman, Z. (2007b). Consuming Life. Cambridge: Polity Press.

Bauman, Z. (2013). Liquid Modernity (8th ed.). Cambridge: Polity Press.

Baumgartner, L. M. (2001). An update on transformational learning. New Directions for Adult and Continuing Education, 89, pp. 15-24.

Baumgartner, L. M. (2012). Mezirow's theory of transformative learning from 1975 to present. In Taylor, E. W. and Cranton, P. (Eds.), The Handbook of Transformative Learning (pp. 99- 115). San Francisco: Jossey-Bass.

Baumgartner, R. J. and Korhonen, J. (2010). Strategic thinking for sustainable development. Sustainable Development,18, pp. 71-75. DOI: 10.1002/sd.452

Beck, U. (1992). Risk Society: Towards a New Modernity (Vol. 17). London: Sage Publications. 
Beck, U. (2000a). What is Globalization? Cambridge: Polity Press.

Beck, U. (2000b). The Cosmopolitan Perspective: Sociology of the Second Age of Modernity.

British Journal of Sociology, 51 (1), pp. 79-105.

Beck, U. (2009). World at Risk. Cambridge: Polity Press.

Beck, U. (2011). Cosmopolitanism as imagined communities of global risk. American Behavioral Scientist, 55(10), pp.1346-1361.

Bennell, S. and Norcliffe, D. (2010). Education for sustainable development and global citizenship: a case study in policy formation. Educational Transactions. Bangor: Bangor University.

Bennell, S. (2011). The development of ESDGC initiatives in initial teacher training education and training in Wales. In Bennell, S., Egley, S., Norcliffe, D. and Sullivan, D. (2011). Citizenship Education in Wales. Bangor University, School of Education.

Bennell, S., Egley, S., Norcliffe, D. and Sullivan, D. (2011). Citizenship Education in Wales. Bangor University, School of Education.

Bernstein, B. (1996). Pedagogy: Symbolic Control and Identity Theory, Research, Critique. London: Taylor \& Francis.

Bhaskar, R. (1998). Philosophy and scientific realism. In Archer, M., Bhaskar, R., Collier, A., Lawson, T and Norrie, A. (Eds.), Critical Realism: Essential Readings (pp. 16-47). London: Routledge.

Bhaskar, R. (2013). A Realist Theory of Science. ( $4^{\text {th }}$ ed.) London: Routledge.

Bhola, H. S. (2005). Potential of adult and lifelong education for poverty reduction: Systems thinking for systemic change. International Journal of Lifelong Education, 24(5), pp. $405-417$.

Bhola, H. S. and Gomez, S. V. (2008). Signposts to Literacy for Sustainable Development. Hamburg, Germany: UNESCO, Institute for Lifelong Learning.

Biel, A. and Thøgersen, J. (2007). Activation of social norms in social dilemmas: A review of the evidence and reflections on the implications for environmental behaviour. Journal of Economic Psychology, 28, pp. 93-112.

Biesta, G. J. (2010). Why 'what works' still won't work: From evidence-based education to valuesbased education. Studies in the Philosophy of Education, 29, pp. 491-503.

Biesta, G. J. (2011). Towards the learning democracy. In Learning Democracy in School and Society (pp. 71-84). Sense Publishers.

Biesta, G. J. (2012). Becoming public: public pedagogy, citizenship and the public sphere. Social \& Cultural Geography, 13(7), pp. 683-697.

Blackmore, J., and Lauder, H. (2005). Researching policy. In Somekh, B. and Lewin, C. (Eds.), Research Methods in the Social Sciences (pp. 97-104). London: Sage Publications. 
Blewitt, J. (2004) Sustainability and lifelong learning: re-purposing adult education. Paper presented at SCUTREA $34^{\text {th }}$ Annual Conference, University of Sheffield, 6-8 July 2004. Available online at: http://www.leeds.ac.uk/educol/documents/00003583.htm. [Accessed: 29/04/2014].

Blewitt, J. (2008). Understanding Sustainable Development. London: Earthscan.

Blewitt, J. (2013). Sustainability and lifelong learning. In Blewitt, J. and Cullingford, C. (Eds.), The Sustainability Curriculum: Facing the Challenge in Higher Education ( $2^{\text {nd }}$ ed.) (pp. 24-42). London: Earthscan.

Blewitt, J. and Cullingford, C. (Eds.) (2013). The Sustainability Curriculum: Facing the Challenge in Higher Education ( $2^{\text {nd }}$ ed.). London: Earthscan.

Blunkett, D. (2003). Active Citizens, Strong Communities: Progressing Civil Renewal. London: Home Office.

Bohm, D. (2013). On Dialogue. London: Routledge.

Bohm, D., Factor, D. and Garrett, P. (1991). Dialogue: A Proposal. Available online at: http://www.dialogue-associates.com/files/files/Dialogue\%20A\%20Proposal.pdf [Accessed: 03/05/2016].

Bonnett, M. (1999). Education for sustainable development: A coherent philosophy for environmental education? Cambridge Journal of Education, 29(3), pp. 313 -324.

Bonnett, M. (2000). Environmental concerns and the metaphysics of education. The Journal of the Philosophy of Education, 34(4), pp. 591-602.

Bonnett, M. (2002). Education for sustainability as a frame of mind. Environmental Education Research, 8(1), pp. 9-20.

Bonnett, M. (2004). Retrieving Nature: Education for a Post-Humanist Age. Oxford: Blackwell. Bonnett, M. (2009). Systemic wisdom, the 'Selving' of nature, and knowledge transformation: Education for the 'Greater Whole'. Studies in Philosophy and Education, 28(1), pp. 39-49.

Bourne, D. (2000). Development education within the context of globalization and sustainable development. The Development Education Journal, 6, pp. 25-27.

Bourn, D. (2005). Education for sustainable development and global citizenship. The challenge of the UN-decade. ZEP: Zeitschrift für internationale Bildungsforschung und Entwicklungspädagogik, 28(3), pp. 15-19.

Bourn, D. (2008). Education for sustainable development in the UK: Making the connections between the environment and development agendas. Theory and Research in Education, 6(2), pp.193-206.

Bourn, D. (2011). Discourses on development education. Proceeding of the European Association of development Research and Training Institutes (EADI) General Conference: Rethinking 
development in an age of scarcity and uncertainty. York, UK. Available online at: http://eadi.org/gc2011/bourn-620.pdf [Accessed: 13/12/2015].

Bourn, D. (2014a). The Theory and Practice of Development Education: A Pedagogy for Global Social Justice. London: Routledge.

Bourn, D. (2014b). The theory and practice of global learning. Research Paper No.11 for the Global Learning Programme. London: Development Education Research Centre. Available online at: www.ioe.ac.uk. [Accessed: 27/01/2016].

Bowers C. A. (2001). Educating for Eco-Justice and Community. Athens, Georgia: University of Georgia Press.

Bowers, C. A. (2002). Toward an eco-justice pedagogy. Environmental Education Research, 8(1), pp.21-34.

Bowers, C. A. (2005). Is transformative learning the Trojan horse of western globalization? Journal of Transformative Education, 3(2), pp. 116-125.

Bowers, C. A. (2017). An ecojustice approach to educational reform in adult education. New Directions for Adult and Continuing Education, (153), pp. 53-64.

Bowers, C.A. and Apffel-Marglin, B. F. (2005). Rethinking Freire: Globalization and the Environmental Crisis. New Jersey: Lawrence Erlbaum Associates.

British Educational Research Association (2011). Ethical Guidelines for Educational Research. Available online at: http://tinyurl.com/bera-guidelines [Accessed: 01/12/2016].

Bronowski, J. (1973). The Ascent of Man. London: Little Brown.

Brookfield, S. D. (1981). Independent adult learning. Studies in Adult Education, 13(1), pp. 15-27.

Brookfield, S. D. (1983). Adult Learners, Adult Education and the Community. Milton Keynes: Open University Press.

Brookfield, S. D. (1986). Understanding and Facilitating Adult Learning. Buckingham, UK: Open University Press.

Brookfield, S. D. (1993). Developing Critical Thinkers (2nd Ed.). Milton Keynes: Open University Press.

Brookfield, S. D. (1995). Adult learning: An overview. In A. Tuinjman (Ed.), International Encyclopaedia of Education (pp. 375-380). Oxford: Pergamon Press.

Brookfield, S. D. (2006) Discussion as a way of teaching. Available online at: http://www.stephenbrookfield.com/Dr._Stephen_D._Brookfield/Workshop_Materials_files/Discu ssion_as_a_Way_of_Teaching_Packet.pdf [Accessed: 27/04/ 2014].

Brookfield, S. D. (2011). Teaching for Critical Thinking: Tools and Techniques to Help Students Question their Assumptions. San Francisco: John Wiley and Sons. 
Brookfield, S. D. and Holst, J. D. (2011). Radicalizing learning: Adult education for a just world. San Francisco: Jossey-Bass.

Brookfield, S. D. and Preskill, S. (2012). Discussion as a way of teaching: Tools and techniques for democratic classrooms (3rd ed.). San Francisco: John Wiley and Sons.

Brooks, R. M., and Holford, J. A. (2009). Citizenship, learning and education: Themes and issues. Citizenship Studies, 13(2), pp. 85-103. Available online at:

http://epubs.surrey.ac.uk/771873/1/Brooks_Holford-Citizenship-Learning-Education-CS2009.pdf [Accessed: 12/02/2018].

Buber, M. (1958). I and Thou. Trans. Ronald G. Smith, ( $2^{\text {nd }}$ ed.). New York: Scribner.

Burbules, N. C. (2000). The limits of dialogue as a critical pedagogy. In Trifonas, P. P. (Ed.), Revolutionary Pedagogies: Cultural Politics, Instituting Education, and the Discourse of Theory (pp. 251-273). London: Routledge.

Burningham, K. and Thrush, D. (2001). 'Rainforests are a Long Way from Here'. The Environmental Concerns of Disadvantaged Groups. York: Joseph Rowntree Foundation.

Burns, H. L. (2015). Transformative sustainability pedagogy: Learning from ecological systems and indigenous wisdom. Journal of Transformative Education, 13(3), pp. 259-276.

Bush, T. (2007). Authenticity in research: Reliability, validity and triangulation. In Briggs, A. and Coleman, M. (Eds.), Research Methods in Educational Leadership and Management (pp. 91-105). London: Sage Publications.

Cabrera, L. (2010). The Practice of Global Citizenship. Cambridge University Press.

Callan, E. (1997). Creating Citizens: Political Education and Liberal Democracy. Oxford University Press.

Campbell, J. (1995). Understanding John Dewey: Nature and Cooperative Intelligence. Open Court Publishing.

Carson, R. (1962). Silent Spring. New York: Houghton Mifflin.

Castells, M. (2008). The new public sphere: Global civil society, communication networks, and global governance. The Annals of the American Academy of Political and Social Science, 616(1), pp. 78-93.

Castells, M. (2010). The Rise of The Network Society (2nd ed.). Oxford: Blackwell.

Charmaz, K. (1996). The search for meaning: Grounded theory. In Smith, J. A., Harre, R. and Van Langehove, L. (Eds.), Rethinking Methods in Psychology (pp. 27-49) London: Sage Publications.

Charmaz, K. (2008). Grounded theory as an emergent method. I Nagy Hesse-Biber, S. and Oleavy, P. (Eds.), A Handbook of Emergent Methods (pp. 155-172). London: The Guildford Press. 
Chaney, P. (2016). Social Policy in Wales. In Alcock, P., Haux, T., May, M. and Wright, S. (Eds.), The Student's Companion to Social Policy (pp. 174-181). Chichester: John Wiley \& Sons.

Charmaz, K. (2014). Constructing Grounded Theory: A Practical Guide Through Qualitative Analysis. (2nd. ed.). Los Angeles: Sage Publications.

Charmaz, K., and Bryant, A. (2016). Constructing grounded theory analysis, grounded theory and credibility. In Silverman, D. (Ed.), Qualitative Research (5th ed.) (pp. 347-362).

Cissna, K. N., and Anderson, R. (2012). Moments of Meeting: Buber, Rogers, and the Potential for Public Dialogue. SUNY Press.

Clark, J. (2012). Using diamond ranking as visual cues to engage young people in the research process, Qualitative Research Journal, 12(2), pp. 222-237.

Clark, P. B. (1996). Deep Citizenship. Chicago: Pluto Press.

Clover, D. E. (2002). Traversing the gap: Concientizatión, educative-activism in environmental adult education. Environmental Education Research, 8(3), pp.315-323.

Clover, D. E. (2003). Environmental adult education: Critique and creativity in a globalizing world. New Directions for Adult and Continuing Education, 99, pp.5-15.

Clover, D. E., Jayme, B. D. O., Hall, B. L. and Follen, S. (2013). The Nature of Transformation: Environmental Adult Education, (Vol.11). Rotterdam: Sense Publishers.

Cobo, C. (2013). Skills for innovation: envisioning an education that prepares for the changing world. Curriculum Journal, 24(1), pp. 67-85.

Coffield, F. (2000a). The Necessity of Informal Learning. Bristol: Policy Press.

Coffield, F. (Ed.) (2000b). Differing Visions of a Learning Society: Research Findings (vol. 2). Bristol: The Policy Press.

Coffield, F., Edward, S., Finlay, I., Hodgson, A., Spours, K., Steer, R. and Gregson, M. (2007). How policy impacts on practice and how practice does not impact on policy. British Educational Research Journal, 33(5), pp.723-741.

Cohen, J., James, S. and Blewitt, J. (Eds.) (2002). Learning to Last: Skills, Sustainability and Strategy. Learning and Skills Development Agency. Available online at: http://www.voced.edu.au/content/ngv\%3A36728 [Accessed: 17/08/2016].

Cohen, L., Manion, L. and Morrison, K. (2007). Research Methods in Education (6 th $^{\text {ed.). }}$. Abingdon: Routledge

Cohen, L., Manion, L. and Morrison, K. (2011). Research Methods in Education ( $7^{\text {th }}$ ed.). Abingdon: Routledge.

Commoner, B. (1971). The Closing Circle: Nature, Man, and Technology. New York: Bantam books. Available online at: 
http://icternodisola.it/public/uploaded/manuale\%20della\%20qual/lim\%20Scuola\%20Secondaria/ percorso\%20economico-soc/letter/The\%20closing\%20circle\%20Commoner.pdf [Accessed: 30/12/2015].

Corbin, J. and Strauss, A. (2008). Basics of Qualitative Research: Techniques and Procedures for Developing Grounded Theory (3rd ed.). London: Sage Publications.

Corcoran, P. B. and Wals, A. E. (2004). Higher Education and The Challenge of Sustainability. Dordrecht: Kluwer Academic Publishers.

Cotton, D. R. (2006). Teaching controversial environmental issues: Neutrality and balance in the reality of the classroom. Educational Research, 48(2), pp. 223-241.

Cotton, D., Miller, W., Winter, J., Bailey, I. and Sterling, S. (2016). Knowledge, agency and collective action as barriers to energy-saving behaviour. Local Environment, 21(7), pp. 883-897.

Cranton, P. and Taylor, E. W. (2012). Transformative learning theory: Seeking a more unified theory. The Handbook of Transformative Learning: Theory, Research, and Practice (pp. 3-20). San Francisco: John Wiley \& Sons.

Crick, B. (1998). Education for Citizenship and the Teaching of Democracy in Schools. Final report of the advisory group on citizenship. London: Qualifications and Curriculum Authority.

Crick, B. (1999). The presuppositions of citizenship education. Journal of Philosophy of Education, 33(3), pp. 337- 352.

Crick, B. (2000). Essays on Citizenship. London: Bloomsbury Publishing.

Crick, R. D. and Wilson, K. (2005). Being a learner: A virtue for the 21st century. British Journal of Educational Studies, 53(3), pp. 359-374.

Cullingford, C. and Blewitt, J. (Eds.) (2013). The Sustainability Curriculum: The Challenge for Higher Education. London: Routledge.

Curry-Stevens, A. (2007). New forms of transformative education: Pedagogy for the privileged. Journal of transformative education, 5(1), pp. 33-58.

Cyfanfyd (2001). Global Citizenship and PSE. Cardiff: Cyfanfyd.

Cyfanfyd (2008). Education for Sustainable Development \& Global Citizenship in Lifelong Learning: Good Practice in Wales. Cardiff: Cyfanfyd.

Dasgupta, P. (2001). Human Well-Being and the Natural Environment. Oxford University Press.

Dasgupta, P. (2008). Discounting climate change. Journal of Risk and Uncertainty, 37(2-3), pp. 141-169.

Davies, I., Evans, M. and Reid, A. (2005). Globalising citizenship education? A critique of 'global education' and 'citizenship education'. British Journal of Educational Studies, 53(1), pp. 66-89.

Davies, J. (2014). Hanes Cymru (A History of Wales in Welsh) (2nd ed.). London: Penguin UK. 
Davies, L. (2001). Education for citizenship. Educational Review, 53(3), pp. 325-325.

Davies, L. (2004). Education and Conflict: Complexity and Chaos. London: RoutledgeFalmer.

Davies, L. (2005). Teaching about conflict through citizenship education. International Journal of Citizenship and Teacher Education, 1(2), pp. 17-34.

Davies, L. (2006). Global citizenship: abstraction or framework for action? Educational Review, 58(1), pp. 5-25.

Davies, L. (2009). Comparative education in an increasingly globalised world. In Globalisation, policy and comparative research, pp. 13-34. Springer Netherlands. Available online at: http://www.fe.hku.hk/cerc/ceshk/doc/CEB2004_07.pdf\#page=7 [Accessed: 27/01/2016].

Davies, R. R. (2000). The Age of Conquest: Wales 1063-1415 (Vol. 2). Oxford University Press.

Davies, R. R. and Davies, R. R. (1990). Domination and Conquest: The Experience of Ireland, Scotland and Wales, 1100-1300. Cambridge University Press.

Davis, B. and Sumara, D. (2009). Complexity as a Theory of Education. TCI (Transnational Curriculum Inquiry), 5(2), pp. 33-44.

Davy, I. (2011). Learners Without Borders: A Curriculum for Global Citizenship. International Baccalaureate Organisation. Available online at: http://www.godolphinandlatymer.com/_files/IB/B309322691ABF031CB793E9DDA47FE3A.pdf [Accessed: 19/03/2016].

Dawe, G., Jucker, R. and Martin, S. (2005). Sustainable Development in Higher Education: Current Practice and Future Developments. A report for the Higher Education Academy. Heslington, UK: The HEA.

Dei (2008). Anti-racism education for global citizenship. In M. Peters, M. Britton, A. and Blee, H. (Eds.), Global Citizenship Education: Philosophy, Theory and Pedagogy, (pp. 477-490). Rotterdam: Sense.

Delanty, G. (2000). Citizenship in a Global Age. Society, Culture, Politics. Milton Keynes: The Open University.

Delanty, G. (2006). The cosmopolitan imagination: Critical cosmopolitanism and social theory. British Journal of Sociology, 57(1), 25-47.

Delors, J. (1996). Report to UNESCO on Education for the 21st Century-Learning: The Treasure Within. Paris: UNESCO. Available online at: http://www.unesco.org/education/pdf/15_62.pdf [Accessed: 28/04/ 2014].

Democratic Life (2010). Citizenship education in Northern Ireland, Wales, Scotland and England. Briefing paper. Available online at: http://www.democraticlife.org.uk/wpcontent/uploads/2011/02/setting-the-record-straight.pdf [Accessed: 01/01/2016]. 
Denzin, N. K. and Lincoln, Y. S. (Eds.) (2005). The Sage Handbook of Qualitative Research. London: Sage Publications.

Denzin, N. K. and Lincoln, Y. S. (Eds.) (2008). Strategies of Qualitative Inquiry (3rd ed.). Los Angeles: Sage Publications.

Department for Education and Employment (DfEE) UK Government (2005). Developing a Global Dimension in the School Curriculum. Available online at:

http://webarchive.nationalarchives.gov.uk/20130401151715/http://www.education.gov.uk/publi cations/standard/publicationdetail/page1/DFES-1409-2005 [Accessed: 21/04/2017].

Department for Employment and Skills (DfES) UK Government (2003). Sustainable Development Action Plan for Education and Skills. Available online at:

http://webarchive.nationalarchives.gov.uk/20031220221854/http:/dfes.gov.uk/sd/action.shtml [Accessed: 03/01/2016].

Dewey, J. (1916). Democracy and Education: An Introduction to the Philosophy of Education. New York: Macmillan.

Dewey, J. (1938a). Education and Experience. New York: Simon and Schuster.

Dewey, J. (1938b). The Theory of Inquiry. New York: Holt, Rinehart \& Wiston.

Dirkx, J. (2001). Images, transformative learning and the work of the soul. Adult Learning, 12(3), pp.15-17.

Dirkx, J. M. (2006). Engaging emotions in adult learning: A Jungian perspective on emotion and transformative learning. New Directions for Adult and Continuing Education, 109, pp. 15-26.

Dobson, A. (2000). Green Political Thought (3rd. ed.). Psychology Press.

Dobson, A. (2003a). Citizenship and the Environment. Oxford: Open University Press.

Dobson, A. (2003b). Social justice and environmental sustainability: $\mathrm{Ne}^{\prime}$ er the twain shall meet? In Agyeman, J., Bullard, R. D. and Evans B. (Eds.), Just Sustainabilities: Development in an Unequal World. UK: Earthscan.

Dobson, A. (2005) Globalisation, cosmopolitanism and the environment. International Relations, 19, pp.259-273.

Donaldson, G. (2015). Successful Futures: Independent Review of Curriculum and Assessment Arrangements in Wales. Cardiff: The Welsh Government. Available online at: http://gov.wales/docs/dcells/publications/150317-successful-futures-en.pdf [Accessed: 01/03/2017].

Donmoyer, R. (2009). Generalizability and the single case study. In Gomm, R., Hammersley M. \& Foster P. (Eds.), Case Study Method (pp. 45-68). London: Sage Publications.

DOI: http://dx.doi.org/10.4135/9780857024367

Dowdeswell, E. (1995). Editorial, Our Planet, Paris: United Nations Environmental Programme. 
Dower, N. (Ed.) (1989). Ethics and Environmental Responsibility. Aldershot: Avebury.

Dower, N. (2000). The idea of global citizenship-A sympathetic assessment. Global Society, 14(4), pp. 553-567.

Dower, N. (2004) Discussion paper: how currently marginalised voices might best use ethical dialogue to shape the local, national and international development agendas. IIED. Available online at: http://pubs.iied.org/pdfs/13510IIED.pdf? [Accessed: 1/4/2016].

Dower, N. (2005a). The nature and scope of global ethics and the relevance of the Earth Charter. Journal of Global Ethics, 1(1), pp. 25-43.

Dower, N. (2007). World Ethics: The New Agenda. Edinburgh University Press.

Dower, N. (2010). Questioning the questioning of cosmopolitanism. In van Hooft, S. and Van dekerckhove, W. (Eds.), Questioning cosmopolitanism (pp. 3-20). Springer Netherlands.

Earth Charter Commission. (2000). The Earth Charter. The Hague.

Easton, G. (2010). Critical realism in case study research. Industrial Marketing Management, 39, pp. 118-128.

Edwards, R. and Usher, R. (2007). Globalisation and Pedagogy: Space, Place and Identity (2nd. ed.). London: Routledge.

Edwards, R., Raggatt, P, and Small, N. (Eds.) (2013). The Learning Society: Challenges and Trends (2nd ed.). London: Routledge.

Eidoo, S., Ingram, L. A., MacDonald, A., Nabavi, M., Pashby, K., and Stille, S. (2011). "Through the Kaleidoscope": Intersections between theoretical perspectives and classroom implications in critical global citizenship education. Canadian Journal of Education, 34(4), pp. 59-84.

Elliott, J. A. (1994). An Introduction to Sustainable Development: The Developing World. London: Routledge.

Elliott, J. A. (1999). An Introduction to Sustainable Development. (2nd ed.). London: Routledge.

Elliott, J. A. (2006). An Introduction to Sustainable Development. (3rd ed.). London: Routledge.

Elliott, J. (2012). An Introduction to Sustainable Development. (4th ed.). London: Routledge.

Ellis, M. (2013) The Personal and Professional Development of the Critical Global Educator. PhD thesis. Available online at: http://eprints.ioe.ac.uk/18010/ [Accessed: 01/12/2017].

Ellis, M. (2015). The Critical Global Educator: Global Citizenship Education as Sustainable Development. London: Routledge.

English, L. M. (Ed.) (2005). International Encyclopaedia of Adult Education. London: Palgrave. 
English, L. M. (2013). For whose purposes? Examining the spirituality agenda in adult education. In Groen, J. Coholic, D., and Graham, J. R. (Eds.), Spirituality in Social Work and Education: Theory, Practice, and Pedagogies (pp.17-33). Wilfrid Laurier University Press.

English, L. M. and Mayo, P. (2012). Learning with Adults: A Critical Pedagogical Introduction (Vol. 8). Springer Science and Business Media.

Estyn (2005). Questions to Ask in Relation to Standards in Sustainable Development and Global Citizenship. Cardiff: Estyn.

Estyn (2006). Establishing a Position Statement for ESDGC. Cardiff: Estyn.

Estyn (2008). Education for Sustainable Development and Global Citizenship in Adult and Community-Based Learning and Youth Work in Wales. Cardiff: Estyn.

Estyn (2014). Progress in Education for Sustainable Development and Global Citizenship. Cardiff: Estyn. Available online at: http://www.estyn.gov.wales/thematic-reports/esdgc-progresseducation-sustainable-development-and-global-citizenship-june-2014 [Accessed: 26/04/2016].

Estyn. (2015). Guidance for the Inspection of Adult Community Learning. Available online at: http://www.estyn.gov.wales/sites/default/files/documents/Guidance\%20for\%20the\%20inspectio n\%20of\%20adult\%20community\%20learning\%20-\%202015\%20handbook.pdf [Accessed: 05/09/2015].

Estyn (2016). Adult Community Learning in Wales. Available online at: https://www.estyn.gov.wales/thematic-reports/adult-community-learning-wales [Accessed: 11/05/2018].

Etzioni, A. (1991). The Responsive Communitarian Platform. Available online at: https://www2.gwu.edu/ ccps/rcplatform.html [Accessed: 01/12/2016].

Evans, M., Ingram, L. A., MacDonald, A., and Weber, N. (2009). Mapping the "global dimension" of citizenship education in Canada: The complex interplay of theory, practice and context. Citizenship Teaching and Learning, 5(2), pp. 17-34.

Fagan, G. (2013). Education and engagement for sustainability: the CADISPA approach. In Warburton, D. (Ed.), Community and Sustainable Development: Participation in the Future. (2nd ed.) (pp. 198-218). London: Routledge.

Faure, E. (1972). Learning to be: The World of Education Today and Tomorrow. Paris: UNESCO.

Feinstein, L., Hammond, C., Woods, L., Preston, J. and Bynner, J. (2003). The Contribution of Adult Learning to Health and Social Capital. London, Institute of Education, Centre for Research on the Wider Benefits of Learning.

Feketene Szakos, E. (2014). Learning as renewal: contribution to the present theoretical background of the lifelong learning policy of the European Union. International Journal of Lifelong Education, 33(4), pp. 504-522. 
Fenwick, T. J. (2000). Expanding conceptions of experiential learning: A review of the five contemporary perspectives on cognition. Adult Education Quarterly, 50(4), pp. 243-272.

Fenwick, T. J. (2001). Experiential learning: a theoretical critique from five perspectives. Information. Series No. 385. Available online at: http://files.eric.ed.gov/fulltext/ED454418.pdf [Accessed: 20/04/2017].

Fenwick, T. (2006). The audacity of hope: Towards poorer pedagogies. Studies in the Education of Adults, 38(1), pp.9-24.

Fenwick, T. (2009). Responsibility, complexity science and education: Dilemmas and uncertain responses. Studies in Philosophy and Education, 28(2), pp.101-118.

Fenwick, T. and English, L. (2004). Dimensions of spirituality: A framework for adult educators. Journal of Adult Theological Education, 1(1), pp. 49-64.

Field, J. (2006). Lifelong Learning and the New Educational Order. (2nd ed.). Stirling: Trentham.

Fien, J. (2000). 'Education for the environment: A critique-an analysis. Environmental Education Research 6(2), pp.179-192. Available online at:

http://www.tandfonline.com/servlet/linkout?suffix=CIT0018\&dbid=20\&doi=10.1080\%2F1350462 2.2013.833585\&key=10.1080\%2F713664671 [Accessed: 11/07/ 2012].

Fien, J. and Tilbury, D. (2002). The global challenge of sustainability. In Tilbury D., Stevenson, R.B. Fein, J. and Schreuder, D (Eds.), Education and Sustainability: Responding to the Global Challenge (pp. 1-13). Cambridge: IUCN,

Fien, J., Maclean, R., and Park, M. G. (Eds.) (2009). Work, learning and Sustainable Development: Opportunities and Challenges (Vol. 8). Springer Science and Business Media. Available online at: https://www.researchgate.net/profile/Maria_Lourdes_Baybay/publication/227241834_Learning_ to_Do_An_ESD_Resource_for_TVET/links/00b49534f2ef346a41000000/Learning-to-Do-An-ESDResource-for-TVET.pdf [Accessed: 18/03/2016].

Fien, J. and Maclean, R. (2009). Introduction. The legacy of the Bonn declaration. In Fien, J., Maclean, R. and Park, M. (Eds.), Work, Learning and Sustainable Development: Opportunities and Challenges. Springer Science and Business Media.

Fitz, J. and Halpin, D. (1994). Ministers and mandarins: educational research in elite setting in Walford, G. (Ed.), Researching the Powerful in Education, (pp 32-35). London: UCL Press.

Fitzpatrick, T. (2016). The Sustainability Challenge. In Alcock, P., Haux, T., May, M., and Wright, S. (Eds.), The Student's Companion to Social Policy (pp. 199-205). Chichester: John Wiley \& Sons.

Folke, C., Jansson, Å., Rockström, J., Olsson, P., Carpenter, S. R., Chapin III, F. S., ... and Elmqvist, T. (2011). Reconnecting to the biosphere. AMBIO: A Journal of the Human Environment, 40(7), pp. 719-738. DOI: 719-738DOI 10.1007/s13280-011-0184-y

Fowler, F. J. (2009). Survey Research Methods (4 ${ }^{\text {th }}$ ed.). London: Sage Publications. 
Freire, P. (1970a). Pedagogy of the Oppressed, trans. Myra Bergman Ramos. New York: Continuum.

Freire, P. (1970b). Cultural Action for Freedom. Harvard educational review. (pp. 476-521). Available online: http://www.thinkingtogether.org/rcream/archive/110/CulturalAction.pdf [Accessed:15/08/2016].

Freire, P. (1973). Education for Critical Consciousness (Vol. 1). London: Bloomsbury Publishing.

Freire, P. (1994). Pedagogy of Hope, trans. RR Barr. New York: Continuum.

Freire, P. (2004). Pedagogy of Indignation. Boulder: Paradigm Publishers.

Fryer, R.H. (2010). Promises of Freedom: Citizenship, Belonging and Lifelong Learning. Leicester: NIACE.

Fujiwara, D. (2012). Valuing the Impact of Adult Learning. Leicester: NIACE. Available online at: https://www.aoc.co.uk/sites/default/files/Valuing\%20the\%20lmpact\%20of\%20Adult\%20Learning \%20-\%20Full_Report-4.pdf [Accessed: 01/03/2018].

Fullan, M. (2014). Leading in a Culture of Change: Personal Action Guide and Workbook. John Wiley \& Sons.

Garratt, D. and Piper, H. (2008). Citizenship education in England and Wales: theoretical critique and practical considerations. Teachers and Teaching, 14(5-6), pp. 481-496.

Gaudelli, W. (2003). World Class: Teaching and Learning in Global Times. Mahwah, NJ: Lawrence Erlbaum Associates.

Gaudelli, W. (2009). Heuristics of global citizenship discourses towards curriculum enhancement. Journal of Curriculum Theorizing, 25(1), pp. 68-85.

Gerrits, L., and Verweij, S. (2013). Critical realism as a meta-framework for understanding the relationships between complexity and qualitative comparative analysis. Journal of Critical Realism, 12(2), pp.166-182.

Gerzon, M. (2010). Global Citizens: How Our Vision of the World is Outdated, and What We Can Do About It. London: Rider.

Gillham, B. (2005). Research Interviewing, The Range of Techniques: A Practical Guide. Maidenhead: Open University Press.

Gilligan, C. (1982). In a Different Voice: Psychological Theory and Women's Development. Cambridge, MA: Harvard University Press.

Gillingham, J. (2000). The English in the Twelfth Century: Imperialism, National Identity, and Political Values. Suffolk: Boydell \& Brewer Ltd.

Glaser, B.G. (1992). Basics of Grounded Theory Analysis: Emergence v Forcing. Mill Valley, CA: Sociology Press. 
Glover, A., Peters, C. and Haslett, S. (2011). Education for sustainable development and global citizenship: An evaluation of the validity of the STAUNCH auditing tool. International Journal of Sustainability in Higher Education, 12(2), pp. 125-144.

DOI: http://dx.doi.org/10.1108/14676371111118192

Glover, A., and Peters, C. (2013). A whole sector approach: Education for sustainable development and global citizenship in Wales. In Sustainability Assessment Tools in Higher Education Institutions (pp. 205-222). Springer International Publishing.

Glover, A., Jones, Y., Claricoates, J., Morgan, J. and Peters, C. (2013). Developing and piloting a baselining tool for education for sustainable development and global citizenship (ESDGC) in Welsh higher education. Innovations in Higher Education, 38, pp.75-86.

Gomm, R. (2002). Research and practice, two worlds forever at odds? In Hammersley, M (Ed.), Educational Research, Policymaking and Practice (pp. 59-82). London: SAGE Publications.

Gomm, R., Hammersley, M. and Foster, P. (Eds.) (2009a). Case Study Method: Key Issues, Key Texts. London: Sage Publications. DOI: http://dx.doi.org/10.4135/9780857024367

Gomm, R., Hammersley, M. and Foster, P. (2009b). Case study and generalization. In Gomm, R., Hammersley, M., and Foster, P. (Eds.), Case Study Method: Key Issues, Key Texts (pp. 98-115). London: Sage Publications. DOI: http://dx.doi.org/10.4135/9780857024367

Gorozidis, G. and Papaioannou, A. G. (2014). Teachers' motivation to participate in training and to implement innovations. Teaching and Teacher Education, 39, pp. 1-11.

Gorski, P.S. (2013) What is critical realism? And why should you care?" Contemporary Sociology, 42(5), pp. 658-670. DOI: 10.1177/0094306113499533

Grey, D. E. (2013). Doing Research in the Real World (3rd ed.). Los Angeles: Sage Publications.

Guardian (n.d.). Sustainable development goals: changing the world in 17 steps. Available online at: https://www.theguardian.com/global-development/ng-interactive/2015/jan/19/sustainabledevelopment-goals-changing-world-17-steps-interactive [Accessed: 05/01/2017].

Guilherme, A., and Morgan, W. J. (2009). Martin Buber's philosophy of education and its implications for adult non-formal education. International Journal of Lifelong Education, 28(5), pp.565-581.

Gunzenhauser, M. G. (2006). A moral epistemology of knowing subjects: Theorizing a relational turn for qualitative research. Qualitative Inquiry, 12(3), pp. 621-647.

Halpin, D. and Troyna, B. (Eds.) (1994). Researching Education Policy: Ethical and Methodological Issues. London: Falmer Press.

Hajer, M., Nilsson, M., Raworth, K., Bakker, P., Berkhout, F., de Boer, Y., ... and Kok, M. (2015). Beyond cockpit-ism: Four insights to enhance the transformative potential of the sustainable development goals. Sustainability, 7(2), pp. 1651-1660. DOI:10.3390/su7021651

Hammersley, M. (1995). The Politics of Social Research. London: Sage Publications. 
Hammersley, M. (1999). Taking Sides in Social Research: Essays on Partisanship and Bias. London: Routledge.

Hammersley, M. (2002). Educational Research, Policymaking and Practice. London: Sage publications.

Hammersley, M. and Gomm, R. (2002). Research and practice: two worlds forever at odds. In M. Hammersley (Ed.), Educational Research: Policy Making and Practice, (pp. 59-85). London: Paul Chapman Publishing.

Hammersley, M. (2008). Questioning Qualitative Inquiry. London: Sage Publications.

Hand, M. and Levinson, R. (2012). Discussing controversial issues in the classroom. Educational Philosophy and Theory, 44(6), pp. 614-629.

Harari, Y. N. (2014). Sapiens: A Brief History of Humankind. London: Random House.

Hartman, T. (2001). The Last Hours of Ancient Sunlight. London: Hodder and Stoughton.

Hay, C. (2002). Why we Hate Politics. Cambridge: Polity Press.

Hayden, P. (2005). Global Politics. Aldershot: Ashgate.

Heater, D. (2001). Does cosmopolitan thinking have a future? In K. Booth, T.E. Dunne and M. Cox (Eds.), How Might We Live? Global Ethics in a New Century (pp. 179-197). Cambridge University Press.

Heater, D. (2002). World Citizenship: Cosmopolitan Thinking and its Opponents. London: Continuum.

Heater, D. (2004). A Brief History of Citizenship. Edinburgh: Edinburgh University Press.

Heater, D. (2013). What is Citizenship? ( $5^{\text {th }}$ ed.). New Jersey: John Wiley \& Sons.

Heimlich, J. E., and Ardoin, N. M. (2008). Understanding behavior to understand behavior change: A literature review. Environmental Education Research, 14(3), pp.215-237.

Held, D. (1995a). Democracy and the Global Order. Cambridge: Polity Press.

Held, D. (2000). The changing contours of political community: rethinking democracy in the context of globalization. In B. Holden (Ed.), Global Democracy (pp. 17 -31). Cambridge: Polity Press.

Held, D. (2002). The transformation of political community: rethinking democracy in the context of globalization. In Dower, N. and Williams, J. (Eds.), Global Citizenship: A Critical Introduction, (pp. 92-100). Edinburgh University Press.

Held, D. (2010). Cosmopolitanism, Ideals and Reality. Cambridge: Polity Press.

Held, D. and Mc Grew, A. (2000). The great globalization debate. in Held, D. and McGrew, A. (Eds.), The Global Transformations Reader. Oxford: Polity Press. 
Held, D. and McGrew, A. (2002). Globalization / Anti Globalization. Cambridge: Polity Press.

Held, V. (2006). The Ethics of Care: Personal, Political and Global. New York: Oxford University Press.

Helne, T. and Hirvilammi, T. (2015). Wellbeing and sustainability: A relational approach. Sustainable Development, 23(3), pp.167-175.

Heron, J. (1992). Feeling and Personhood, Psychology in Another Key. London: Sage Publications.

Hess, D. E. (2004). Controversies about controversial issues in democratic education. Political Science and Politics, 37(2), pp. 257-261. Available online at:

https://people.ucsc.edu/ ktellez/hess.pdf [Accessed: 01/04/2016].

Hess, D. E. (2009). Controversy in the Classroom: The Democratic Power of Discussion. New York: Routledge.

Hess, D. and Avery, P. (2008). Discussion of controversial issues as a form and goal of democratic education. In Arthur, J., Davies, I., and Hahn, C. (Eds.), The Sage Handbook of Education for Citizenship and Democracy (pp. 506-518). London: Sage Publications.

Hess, D. and Stoddard, J. (2007). 9/11 and terrorism:" The ultimate teachable moment" in textbooks and supplemental curricula. Social Education, 71(5), pp. 231-236.

Hicks, D. and Holden, C. (1995). Exploring the future: A missing dimension in environmental education. Environmental Education Research, 1(2), pp.185-193.

Hicks, D. (2001a). Citizenship for the Future, A Practical Classroom Guide. Godalming: WWF.

Hicks, D. (2001b). Re-examining the future: the challenge for citizenship education. Educational Review, 53(3), pp. 229-240.

Hicks, D. (2002). Lessons for the Future: The Missing Dimension in Education. Psychology Press.

Hicks, D. (n.d). http://www.teaching4abetterworld.co.uk/index.html [Accessed: 20/04/2018].

Higher Education Academy - HEA (2009). Education for Sustainable Development and Global Citizenship (ESDGC), Review of a Curriculum Audit in Wales. Heslington, UK: HEA.

Higher Education Academy (2012). Education for sustainable development and holistic curriculum change. Available online at:

https://www.heacademy.ac.uk/system/files/esd_artwork_050412_1324.pdf [Accessed: 30/09/2015].

Higher Education Academy - HEA/QAA (2014). Education for Sustainable Development: Guidance for UK Higher Education Providers. Available online at:

https://www.heacademy.ac.uk/knowledge-hub/education-sustainable-development-guidanceuk-higher-education-providers [Accessed: 03/03/2017].

Hill, M. J. (1997). The Policy Process in the Modern State. London: Prentice Hall. 
Hill, M. (2009). The Public Policy Process (5th ed.). London: Routledge.

Hill, M. and Hupe, P. (2014). Implementing Public Policy: An Introduction to The Study of Operational Governance ( $2^{\text {nd }}$ ed.). London: Sage Publications.

Historical Association (2007). T.E.A.C.H. Teaching Emotive and Controversial History 3-19. Available online at: https://www.history.org.uk/resource/780 [Accessed 04/03/2017].

Hobsbawm, E. J. (1994). The Age of Extremes: The Short Twentieth Century 1914 - 1991. London: Michael Joseph.

Hodgson, A., Spours, K. and Waring, M. (2011). Post-compulsory education and lifelong learning across the United Kingdom: Policy, organisation and governance. London: Institute of Education.

Hodgson, A., Spours, K., Waring, M., Gallacher, J., Keep, E. and Rees, G. (2011). Post-compulsory education and lifelong learning across the UK: moving from managed divergence to a new period of uncertainty. In Hodgson, A., Spours, K. and Waring, M. (Eds.), Post-compulsory Education and Lifelong Learning across the United Kingdom: Policy, Organization and Governance (pp. 148-167). London: Institute of Education.

Holford, J. (2016). The misuses of sustainability: Adult education, citizenship and the dead hand of neoliberalism. International Review of Education, 62(5), pp. 541-561.

Hopwood B., Mellor, M. and O'Brien G. (2005). Sustainable development: Mapping different approaches. Sustainable Development, 13, pp. 38-52.

Houghton, C., Casey, D., Shaw, D. and Murphy, K. (2013). Rigour in qualitative case-study research. Nurse Researcher, 20(4), pp.12-17.

Huberman, M. and Miles, M. B. (2002). The Qualitative Researcher's Companion. London: Sage Publications.

Huckle, J. (1993). Environmental education and sustainability: A view from critical theory. In Fien, J. (Ed.), Environmental Education: A pathway to Sustainability (pp. 43-68). Deakin University Press.

Huckle, J. (1999). Education for sustainability: An invitation to join a debate. An unpublished exchange of views with Stephen Sterling (no longer available).

Huckle, J. (2001a). Education for sustainability and ecological citizenship in Europe: A challenge for teacher education in the $21^{\text {st }}$ Century. Proceedings of the conference at the University of Thrace, Alexandroupolis.

Huckle, J. (2001b). Towards ecological citizenship. In Lambert, D. and Machon, P. (Eds.), Citizenship Through Secondary Geography. (pp. 144-160). London: Routledge.

Huckle, J. (2004). Critical realism: A philosophical framework for higher education for sustainability. In Corcoran, P. B., and Wals, A. E. (Eds.), Higher education and the challenge of sustainability, (pp. 33-47). Netherlands: Springer. 
Huckle, J. (2006). Education for Sustainable Development. A briefing paper for the Training and Development Agency for Schools. Revised Edition, October 2006. London: TDA.

Huckle, J. (2008a). An analysis of New Labour's policy on education for sustainable development with particular reference to socially critical approaches. Environmental Education Research, 14(1), pp. 65-75.

Huckle, J. (2008b). Sustainable development. In Arthur, J., Davies, I. and Hahn, C. (Eds.), The Sage Handbook of Education for Citizenship and Democracy (pp. 342-354). London: Sage Publications.

Huckle, J. (2010). ESD and the current crisis of capitalism: Teaching beyond green new deals. Journal of Education for Sustainable Development, 4(1), pp.135-142.

Huckle, J. (2012a). Sustainable development. In Arthur, J. and Peterson, A. (Eds.), The Routledge Companion to Education (pp. 362 - 371). London: Routledge. Available online at: http://john.huckle.org.uk/download/2953/Chapter\%2038\%20Routledge.pdf [Accessed: 22/01/2016].

Huckle, J. (2012b). Towards greater realism in learning for sustainability. In Wals, E.J. and Corcoran, P. B. (Eds.), Learning for sustainability (pp. 35-48). Netherlands: Wageningen Academic.

Huckle, J. (2014). Education for Sustainable Citizenship: An Emerging Focus for Education for Sustainability. in Huckle J. and Sterling, S. (Eds.), Education for Sustainability (2nd ed.) (pp. 228 243). London: Routledge.

Huckle, J. (2015). Putting global citizenship at the heart of global learning: a critical approach. Geography, 100, pp. 76-83.

Huckle, J. and Sterling, S. (Eds.) (2014). Education for Sustainability (3rd ed.). London: Routledge. Huckle, J and Wals, A.E. (2015) The UN decade of education for sustainable development: Business as usual in the end. Environmental Education Research, 21(3), pp. 491-505.

Immordino-Yang, M. H. (2015). Emotions, learning, and the brain: Exploring the educational implications of affective neuroscience (The Norton Series on the Social Neuroscience of Education). WW Norton \& Company.

Immordino-Yang, M. H. and Damasio, A. (2007). We feel, therefore we learn: The relevance of affective and social neuroscience to education. Mind, brain, and education, 1(1), pp.3-10.

Irvine, A. (2011). Duration, dominance and depth in telephone and face-to-face interviews: A comparative exploration. International Journal of Qualitative Methods, 10(3), pp. 202-220.

Irvine A., Drew P. and Sainsbury R. (2013). 'Am I not answering your questions properly?' Clarification, adequacy and responsiveness in semi-structured telephone and face-to-face interviews. Qualitative Research, 13(1), pp. 87-106.

IUCN, UNEP \& WWF (1980). World Conservation Strategy. Living Resource Conservation for Sustainable Development. Gland, Switzerland: IUCN, UNEP, WWF. 
Jabareen, Y. (2009). Building a conceptual framework: Philosophy, definitions, and procedure. International Journal of Qualitative Methods, 8(4), pp. 49-62.

Jackson, L. (2008). Dialogic pedagogy for social justice: A critical examination. Studies in Philosophy and Education, 27, pp.137-148. DOI: 10.1007/s11217-007-9085-8

Jackson, S. (2007). Freire re-viewed. Educational Theory, 57(2), pp.199-213.

Jackson, T. (2009a). Prosperity Without Growth? The Transition to a Sustainable Economy. UK Government: Sustainable Development Commission. Available online at: http://www.sdcommission.org.uk/publications.php?id=914 [Accessed: 10/01/2015].

Jackson, T. (2009b). Prosperity Without Growth: Economics for a Finite Planet. Abingdon, Oxon: Earthscan.

Jarvis, P. (2004). Adult Education and Lifelong Learning: Theory and Practice. (3rd ed.) London: Routledge.

Jarvis, P. (2006a). Human Learning. London: Routledge.

Jarvis, P. (2006b). Beyond the learning society: Globalisation and the moral imperative for reflective social change. International Journal of Lifelong Education, 25(3), pp.201-211.

Jarvis, P. (2007). Globalization, Lifelong Learning and the Learning Society: Sociological Perspectives. London: Routledge.

Jarvis, P. (2008a). The Routledge International Handbook of Lifelong Learning. London: Routledge Jarvis, P. (2008b). Democracy, Lifelong Learning and the Learning Society: Active Citizenship in a Late Modern Age. London: Routledge.

Jenkins, G. H. (2007). A Concise History of Wales. Cambridge University Press.

Jickling, B. and Wals, A. E. (2008). Globalization and environmental education: Looking beyond sustainable development. Journal of Curriculum Studies, 40(1), pp.1-21.

Jickling, B. and Wals, A. E. (2012). Debating education for sustainable development 20 years after Rio: A conversation between Bob Jickling and Arjen Wals. Journal of Education for Sustainable Development, 6(1), pp. 49-57.

Jippes, E., Achterkamp, M. C., Brand, P. L., Kiewiet, D. J., Pols, J., and van Engelen, J. M. (2010). Disseminating educational innovations in health care practice: Training versus social networks. Social Science \& Medicine, 70(10), pp. 1509-1517.

Johnson, L. and Morris, P. (2010). Towards a framework for critical citizenship education. The Curriculum Journal, 21(1), pp. 77-96.

Johnson, D.W. (1981) Student-student interaction: The neglected variable in education. Educational Researcher, 10 (1), pp. 5-10. 
Jones, P., Selby, D. and Sterling, S. R. (2010). Sustainability Education: Perspectives and Practice Across Higher Education. London: Earthscan.

Jordi, R. (2010). Reframing the concept of reflection: Consciousness, experiential learning, and reflective learning practices. Adult Education Quarterly, 61(2), pp. 181-197.

DOI: $10.1177 / 0741713610380439$

Jucker, R. (2002). Our Common Illiteracy: Education as if the Earth and People Mattered. Environmental Education, Communication and Sustainability. Frankfurt am Main: Peter Lang.

Kahn, R. (2008). Towards ecopedagogy: Weaving a broad-based pedagogy of liberation for animals, nature, and the oppressed people of the earth. The Critical Pedagogy Reader, 2. London: Routledge.

Kahn, R., and Kahn, R. V. (2010). Critical Pedagogy, Ecoliteracy, \& Planetary Crisis: The Ecopedagogy Movement (Vol. 359). Peter Lang.

Kaufmann, J. J. (2010). The practice of dialogue in critical pedagogy. Adult Education Quarterly, 60(5), pp. 456-476.

Keating, A., Kerr, D., Benton, T., Mundy, E. and Lopes, J. (2010). Citizenship Education in England 2001-2010: Young People's Practices and Prospects for the Future: The Eighth and Final Report from the Citizenship Education Longitudinal Study (CELS). UK Government, Department for Education. Available online at: https://www.nfer.ac.uk/publications/CEE11 [Accessed: 07/02/2016].

Kellner, D. (1998). Multiple literacies and critical pedagogy in a multicultural society. Educational Theory, 48(1), pp.103-122.

Kelly, D. Harper, J and Landau, B (2008). Questionnaire mode effects in interactive information retrieval experiments in Information Processing and Management 1(44), pp. 122-141.

Kerr, D. (1999a). Re-examining citizenship education in England. In Torney-Purta, J., Schwille, J.\& Amadeo, J. A. (Eds). Civic Education Across Countries: Twenty-Four National Case Studies from the IEA Civic Education Project, (pp. 203-227). Amsterdam: IEA.

Kerr, D. (1999b). Citizenship education in the curriculum: An international review. School Field, 10(3-4), pp. 5-32.

Kerr, D. (1999c). Introduction to the Report: Citizenship Education: An International Comparison. A report to NFER/ Available online at: https://www.nfer.ac.uk/research/centre-for-informationandreviews/inca/TS\%20Citizenship\%20Education\%20an\%20International\%20Comparison\%201999.p df [Accessed: 03/01/2018].

Kerr, D. (2003). Citizenship Education in England: The Making of a New Subject. JSSE-Journal of Social Science Education, 2(2), pp. 1-10. Available online at: http://jsse.ub.unibielefeld.de/index.php/jsse/article/view/472 [Accessed: 03/01/2018]. 
Kirkland, K. and Sutch, D. (2009). Overcoming the Barriers to Educational Innovation: A Literature Review. Futurelab. Available online at:

https://www.nfer.ac.uk/publications/FUTL61/FUTL61_home.cfm [Accessed 06/06/2016].

Knowles, M. (1973). The Adult Learner: A Neglected Species. Houston: Gulf Publishing. Available online at: https://files.eric.ed.gov/fulltext/ED084368.pdf. [Accessed: 08/04/2014].

Knowles, M. S. (1980). The Modern Practice of Adult Education: From Pedagogy to Andragogy. New York: Cambridge.

Knowles, M. S., Holton III, E. F. and Swanson, R. A. (2014). The Adult Learner: The Definitive Classic in Adult Education and Human Resource Development. London: Routledge.

Koehn, D. (1998). Rethinking Feminist Ethics: Care, Trust and Empathy. London: Routledge.

Kolb, D. A. (1984). Experiential Learning: Experience as the Source of Learning and Development (Vol. 1). Englewood Cliffs, NJ: Prentice-Hall.

Kollmuss, A. and Agyeman, J. (2002). Mind the gap: why do people act environmentally and what are the barriers to pro-environmental behavior? Environmental Education Research, 8(3), pp. 239260.

Kopnina, H. (2012). Education for sustainable development (ESD): the turn away from 'environment' in environmental education? Environmental Education Research, 18(5), pp. 699717.

Kopnina, H. (2014). Revisiting education for sustainable development (ESD): Examining anthropocentric bias through the transition of environmental education to ESD. Sustainable Development, 22(2), pp. 73-83.

Kopnina, H., and Meijers, F. (2014). Education for sustainable development (ESD) Exploring theoretical and practical challenges. International Journal of Sustainability in Higher Education, 15(2), pp.188-207.

Kreber, C. (2010). Courage and compassion in the striving for authenticity: States of complacency, compliance, and contestation. Adult Education Quarterly, 60(2), pp. 177-198.

Kretz, L. (2013). Hope in environmental philosophy. Journal of Agricultural and Environmental Ethics, 26(5), pp. 925-944.

Kucukaydin, I. and Cranton, P. (2013). Critically questioning the discourse of transformative learning theory. Adult Education Quarterly, 63(1), pp. 43-56.

Kvale, S. and Brinkmann, S. (2009). Interviews: Learning the Craft of Qualitative Research Interviewing. London: Sage Publications.

Lankshear, C. and Knobel, M. (2004). A Handbook for Teacher Research. London: McGraw-Hill International. 
Larsson, B. (2000). Classroom discussion: A method of instruction and a curriculum outcome. Teaching and Teacher Education, 16, pp. 661-677.

Larsson, B. (2013). Practising democracy as an agonistic dialogue: A radical political dimension of popular education. In Laginder, A. M., Nordvall, H., and Crowther, J. (Eds.), Popular Education, Power and Democracy: Swedish Experiences and Contributions (pp. 169-18). Leicester: NIACENational Institute of Adult Continuing Education.

Lauder, H., Brown, P., Dillabough, J. A. and Halsey, A. H. (2006). Education, Globalization, and Social Change. Oxford University Press.

Leal-Filho, W. L. (1997). Lifelong Learning and Environmental Education. Frankfurt am Main: Peter Lang.

Learning and Skills Council (LSC) (2005). From Here to Sustainability: The Learning and Skills Council's Strategy for Sustainable Development. Coventry: LSC.

Le Blanc, D. (2015). Towards integration at last? The sustainable development goals as a network of targets. Sustainable Development, 23(3), pp.176-187.

Leenders, H., Veugelers, W. and De Kat, E. (2008). Teachers' views on citizenship education in secondary education in the Netherlands. Cambridge Journal of Education, 38(2), pp. 155-170.

Leitch, S. (2006). Prosperity for All in the Global Economy, World Class Skills. London: HMSO.

Lincoln, Y. S. and Guba, E. G. (2009). The only generalization is: There is no generalization. In Gomm, R., Hammersley, M., and Foster, P. (Eds.), Case Study Method: Key Issues, Key Texts (pp. 27-44). London: Sage Publications. DOI: http://dx.doi.org/10.4135/9780857024367

Linklater, A. (2002). Cosmopolitan citizenship. In F. Isin and B. S. Turner, (Eds.), Handbook of Citizenship Studies, (pp. 317-332). London: Sage Publications.

Linklater, A. (2010). Moral progress and world history: Ethics and global interconnectedness. In van Hooft, S. and Van dekerckhove, W. (Eds.), Questioning Cosmopolitanism, Studies in Global Justice (pp. 21-35). Netherlands: Springer. DOI: 10.1007/978-90-481-8704-1_2

Lister, R. (1997). Citizenship: Towards a feminist synthesis. Feminist review, 57(1), pp.28-48.

Lister, R. (2003). Citizenship: Feminist Perspectives, ( $2^{\text {nd }}$ ed.). Basingstoke: Palgrave Macmillan.

Lister, R. (2007). Inclusive citizenship: Realising the potential. Citizenship Studies, 11(1), pp. 49-61.

LLUK (2009). The Application of the Professional Standards for Embedding Education for

Sustainable Development and Global Citizenship in the Lifelong Learning Sector in Wales.

Available online at:

http://www.unece.org/fileadmin/DAM/env/esd/EGC/Relevant\%20materials/ESDGCApplicationsG uideEnglish.pdf [Accessed: 28/01/2015].

Lysaker, J. T. and Furuness, S. (2011). Space for transformation: Relational, dialogic pedagogy. Journal of Transformative Education, 9(3), pp. 183-197. 
MacKeracher, D. (2004). Making Sense of Adult Learning. (2nd ed.). University of Toronto Press.

MacGregor, S. (2011). Beyond Mothering Earth: Ecological Citizenship and the Politics of Care. UBC Press.

Maiteny, P. T. (2002). Mind in the gap: Summary of research exploring 'inner' influences on prosustainability learning and behaviour. Environmental Education Research, 8(3), pp. 299-306.

Malik, K. (1996). The Meaning of Race: Race, History and Culture in Western Society. NYU Press.

Malik, K. (2001). Universalism and difference in discourses of race. In Booth K, Dunne T. and Cox M. (Eds.), How Might We Live? Global Ethics in the New Century, (pp.155-179). Cambridge: Cambridge University Press.

Marshall, G. (2014). Don't Even Think About It: Why our Brains are Wired to Ignore Climate Change. New York: Bloomsbury.

Marshall, T. H. (1950). Citizenship and Social Class, and Other Essays. Cambridge University Press.

Martin, I. (2000). Re-theorising 'community': towards a dialectical understanding of inclusion, Paper presented at SCUTREA, $30^{\text {th }}$ Annual Conference, 3-5 July 2000, University of Nottingham.

Martin, I. (2003). Adult education, lifelong learning and citizenship: Some ifs and buts. International Journal of Lifelong Education, 22(6), pp. 566-579.

Martin, I. (2008). Reclaiming Social Purpose: Framing the Discussion. The Edinburgh Papers. Available online at:

http://www.communitydevelopmentalliancescotland.org/documents/Bulletin/TheEdinburghPape rs\%20pdf.pdf [Accessed: 29/01/2016].

Martin, S., Martin, M. and Cohen, J. (2008). UK: Developing the strategy for sustainable development in TVET. In Fien, J., Maclean, R. and Park, M. G. (Eds.), Work, Learning and Sustainable Development (pp. 247-260). Springer Netherlands.

Martin, S., Dillon, J., Higgins, P., Peters, C. and Scott, W. (2013). Divergent evolution in education for sustainable development policy in the United Kingdom: Current status, best practice, and opportunities for the future. Sustainability, 5(4), pp. 1522-1544.

Mayo, M. (1997). Imagining Tomorrow: Adult Education for Transformation. Leicester: NIACE.

Mayo, M. (2005). Global Citizens: Social Movements and the Challenge of Globalization. London: Zed Books.

Mayo, M. (2010). Competing perspectives, definitions and approaches. In M. Mayo, J. Annette, (Eds.), Taking part? Active Learning for Active Citizenship and Beyond (pp. 41-60). Leicester: NIACE.

Mayo, M. and Annette, J. (Eds.) (2010). Taking Part: Active Learning for Active Citizenship, and Beyond. Leicester: NIACE. 
Mayo, M., Gaventa, J. and Rooke, A. (2009). Learning global citizenship? Exploring connections between the local and the global. Education, Citizenship and Social Justice, 4(2), pp. 161-175.

Mayo, M. and Rooke, A. (2006). Active Learning for Active Citizenship Evaluation Report. London: Home office.

Mayo, P. (1999). Gramsci, Freire and Adult Education: Possibilities for Transformative Action. London: Zed Books.

Mayo, P. (2003). A Rationale for a transformative approach to education. Journal of Transformative Education, 1(1), pp. 38 - 57.

McAvoy, P. and Hess, D. (2013). Classroom deliberation in an era of political polarization. Curriculum Inquiry, 43(1), pp.14-47.

McCulloch, G. (2004). Documentary Research. London: Routledge.

McGivney, V. (1999). Informal Learning in the Community: A Trigger for Change and Development. Leicester: NIACE.

Merriam, S. B. (1998). Qualitative Research and Case Study Applications in Education. Revised and expanded from" Case study research in education". San Francisco: Jossey-Bass.

Merriam, S.B. (2001). Andragogy and self-directed learning: Pillars of adult learning theory. New Directions for Adult and Continuing Education, 89, pp.3-14.

Merriam S. B. (2009). Qualitative Research: A Guide to Design and Implementation. San Francisco: Jossey-Bass.

Merriam, S. B., and Brockett, R. G. (2011). The Profession and Practice of Adult Education: An Introduction ( $2^{\text {nd }}$ ed.). John Wiley \& Sons.

Merriam, S.B., Caffarella, R. S. and Baumgartner, L. M. (2012). Learning in Adulthood: A Comprehensive Guide (4th ed.). Hoboken, NJ: John Wiley and Sons.

Merrifield, J. (2010). Putting the learning into Citizenship. In Mayo, M. and Annette, J. (Eds.), Taking part: Active Learning for Active Citizenship, and Beyond (pp. 261-273). Leicester: NIACE.

Mezirow, J. (1981). A critical theory of adult learning and education. Adult Education (Adult Education Association of the USA, Washington), 32(1), pp. 3-24.

Mezirow, J. (1990). How critical reflection triggers transformative learning. In J. M. A. Associates (Eds.), Fostering Critical Reflection in Adulthood: A Guide to Transformative and Emancipatory Learning (pp. 1-20). San Francisco: Jossey-Bass.

Merizow J. (1991). Transformative Dimensions of Adult Learning. San Francisco: Jossey-Bass.

Mezirow, J. (1997). Transformative learning: Theory to practice. New Directions for Adult and Continuing Education, 74, pp.5-12. 
Mezirow, J. (2000). Learning to think like an adult: Core concepts of transformative theory. In Mezirow, J. (Ed.), Learning as Transformation: Critical Perspectives on a Theory in Progress (pp. 333). San Francisco: Jossey-Bass.

Mies, M. and Shiva, V. (1993). Ecofeminism. London: Zed Books.

Mignolo, W. (2010). Cosmopolitanism and the de-colonial option. Studies in Philosophy and Education, 29(2), pp. 111-127.

Milana, M., Rasmussen, P. and Holford, J. (2016). The role of adult education and learning policy in fostering societal sustainability. International Review of Education, 62(5), pp. 523-540.

Miles, M. B. and Huberman, A. M. (1994). Qualitative Data Analysis. Thousand Oaks: Sage Publications.

Miller, T., Birch, M., Mauthner, M. and Jessop, J. (Eds.) (2012). Ethics in Qualitative Research. London: Sage Publications.

Mishler, E. G. (1991). Research Interviewing. Harvard University Press.

Misiaszek, G. W. (2011). Ecopedagogy in the age of globalization: Educators' perspectives of environmental education programs in the Americas which incorporate social justice models. Los Angeles: University of California.

Misiaszek, G. (2012). Transformative environmental education within social justice models: Lessons from comparing adult ecopedagogy within North and South America. Second International Handbook of Lifelong Learning (pp. 423-440). Dordrecht: Springer.

Misiaszek, G. W. (2015). Ecopedagogy and Citizenship in the Age of Globalisation: connections between environmental and global citizenship education to save the planet. European Journal of Education, 50(3), pp. 280-292.

Misiaszek, G. W. (2016). Ecopedagogy as an element of citizenship education: The dialectic of global/local spheres of citizenship and critical environmental pedagogies. International Review of Education, 62(5), pp. 587-607.

Misiaszek, G. W. (2017). Educating the Global Environmental Citizen: Understanding Ecopedagogy in Local and Global Contexts. London: Routledge.

More, W. S., Woodruff, J. D. and Gottschalk, W. (1974). Emotions and Adult Learning. Farnborough: Saxon House.

Moreland, R. and Lovett, T. (1997). Lifelong learning and community development. International Journal of Lifelong Education, 16(3), pp.201-216.

Murphy, K. (2012). The social pillar of sustainable development: A literature review and framework for policy analysis. Sustainability: Science, Practice, \& Policy, 8(1), pp. 15-29.

Murphy, M. (1999). Transforming Ourselves, Transforming the World: An Open Conspiracy for Social Change. London: Zed Books. 
Murphy, M. and Brown, T. (2012). Learning as relational: Intersubjectivity and pedagogy in higher education. International Journal of Lifelong Education, 31(5), pp. 643-654.

DOI:10.1080/02601370.2012.700648

National Training Federation Wales (n.d.). Education for Sustainable Development and Global Citizenship (ESDGC) in work-based learning. Available online at: https://www.ntfw.org/wpcontent/uploads/2011/11/ESDGC-Ebook.pdf [Accessed: 26/04/2016].

Neale, J. (2016). Iterative categorization (IC): a systematic technique for analysing qualitative data. Addiction, 111(6), pp. 1096-1106.

Noddings, N. (2002). Starting at Home: Caring and Social Policy. Berkley: University of California Press.

Noddings, N. (2010). Moral education and caring. Theory and Research in Education, 8(2), pp. 145151.

Noddings, N. (2013a). Caring: A Relational Approach to Ethics and Moral Education (2nd ed.). Berkley: University of California Press.

Noddings, N. (2013b). An ethic of caring. In R. Shafer-Landau (Ed.), Ethical Theory: An Anthology (Vol. 13). (pp. 699-712). Chichester, UK: John Wiley and Sons.

Norcliffe, D. and Bennell, S. (2010). Analysis of views on the development of education for sustainable development and global citizenship policy in Wales. International Journal of Development Education and Global Learning, 3(1), pp. 39-58.

Northern Ireland Executive (n.d.). Focus on the Sustainable Development Implementation Plan 2011-14. Available online at: http://www.sustainableni.org/sustainable-development/the-sdstrategy-2010/index.php [Accessed: 14/11/2015].

Nudzor, H. P. (2013). The big question: Why do change initiatives in education often fail to yield desired results? Educational Futures, 6(1), pp. 79-94.

Nussbaum, M. (1997). Cultivating Humanity: A Classical Defence of Reform in Liberal Education. London: Harvard University Press.

Nussbaum, M. (2002). Education for citizenship in an era of global connection. Studies in Philosophy and Education, 21, pp.289-303.

Nussbaum, M. C. (2010). For Love of Country? A New Democracy Forum on the Limits of Patriotism. Boston: Beacon Press.

O’Neil, O. (2000). Bounds of Justice. Cambridge University Press.

Organisation for Economic Co-Operation and Development (OECD) (2003). Beyond Rhetoric: Adult Learning Policies and Practices. Paris: OECD.

O'Riordan, T. and Stoll-Kleemann, S. (Eds.) (2002). Biodiversity, Sustainability and Human Communities: Protecting Beyond the Protected. Cambridge University Press. 
Orr, D. W. (1994). Earth in Mind: On education, Environment, and the Human Prospect. Washington DC: Island Press.

Osler, A., and Starkey, H. (2005). Changing Citizenship. London: McGraw-Hill Education.

Osler, A., and Starkey, H. (2006). Education for democratic citizenship: A review of research, policy and practice 1995-2005 1. Research Papers in Education, 21(4), pp. 433-466.

O'Sullivan, E. (1999). Transformative Learning: Educational Vision for the $21^{\text {st }}$ Century. London: Zed Books.

O'Sullivan, E., and Taylor, M. M. (2004). Learning Toward an Ecological Consciousness: Selected Transformative Practices. Palgrave Macmillan.

Oxfam (1997). Curriculum for Global Citizenship. Oxford: Oxfam. Oxfam, Education, Resources (n.d.) https://www.oxfam.org.uk/education/resources [Accessed: 29/04/2014].

Oxley, L, and Morris, P. (2013). Global Citizenship: A typology for Distinguishing its Multiple Conceptions. British Journal of Educational Studies, 61(3), pp. 301-325.

Palmer, J. A., Suggate, J., Robottom, I. and Hart, P. (1999). Significant life experiences and formative influences on the development of adults, environmental awareness in the UK, Australia and Canada. Environmental Education Research, 5(2), pp. 181-200. DOI:

10.1080/1350462990050205

Parker, J and Wade, R. (Eds.) (2008). Journeys Around Education for Sustainability. London: South Bank University.

Parker, J., Wade, R. and Atkinson, H. (2013). Citizenship and community from local to global: Implications for higher education of a global citizenship approach. In Culllingford C. and Blewitt J. (Eds.), The Sustainability Curriculum: The Challenge for Higher Education ( $2^{\text {nd }}$ ed.), (pp. 63-77). London: Earthscan.

Pashby, K. (2011). Cultivating global citizens: Planting new seeds or pruning the perennials? Looking for the citizen-subject in global citizenship education theory. Globalisation, Societies and Education, 9(3-4), pp. 427-442.

Pashby, K., Ingram, L. A. and Joshee, R. (2014). Discovering, Recovering, and Covering-up Canada: Tracing Historical Citizenship Discourses in K-12 and Adult Immigrant Citizenship Education. Canadian Journal of Education, 37(2), pp. 2.

Pattie, C., Seyd, P. and Whiteley, P. (2004). Citizenship in Britain: Values, Participation and Democracy. Cambridge University Press.

Patton, M. Q. (1990). Qualitative Research and Evaluation Methods. London: Sage International. Pettigrew, M. and Roberts, H. (2006). Systematic Reviews in the Social Sciences: A Practical Guide. Oxford: Blackwell. 
Preece, J. (2006). Beyond the learning society: the learning world? International Journal of Lifelong Education, 25(3), pp. 307-320.

Priestley, M., Biesta, G. J. J. and Robinson, S. (2015). Teacher agency: what is it and why does it matter? In R. Kneyber and J. Evers (Eds.), Flip the System: Changing Education from the Bottom Up, (pp.1-11). London: Routledge.

Pykett, J. (2016). Changing Behaviour. In Alcock, P., Haux, T., May, M., \& Wright, S. (Eds.), (2016). The Student's Companion to Social Policy (pp. 55-60). Chichester: John Wiley \& Sons.

Redclift, M. (1989). Sustainable Development: Exploring the Contradictions. London: Routledge.

Redclift, M. (2006). Sustainable development (1987-2005): An oxymoron comes of age. Horizontes Antropológicos, Porto Alegre, 12(25), pp. 65-84. Available online at: http://socialsciences.scielo.org/pdf/scs_a02.pdf [Accessed: 17/01/2016].

Rees, G. (2011). Devolution, policy-making and lifelong learning: the case of Wales. In Hodgson, A., Spours, K. and Waring, M. (Eds.), Post-Compulsory Education and Lifelong Learning across the United Kingdom, (pp. 58-74). London: Institute of Education, University of London.

Reichertz, J. (2007). Abduction: The logic of discovery of grounded theory. In Bryant, A. and Charmaz, K. (Eds.), The Sage Handbook of Grounded Theory (pp. 214-228). London: Sage publications. DOI: http://dx.doi.org/10.4135/9781848607941

Reichertz, J. (2013). Induction, deduction, abduction. In the Sage Handbook of Qualitative Data Analysis (pp. 123-134). London: Sage Publications.

DOI: http://dx.doi.org/10.4135/9781446282243.n9

Rogers, A. (2002). Teaching Adults. Buckingham: Open University Press.

Rogers, A. (2003). What is the Difference? A New Critique of Adult Learning and Teaching. Leicester: NIACE.

Rogers, C. R. (1995). On Becoming a Person. Houghton Mifflin.

Rorty, R. (1989). Contingency, Irony and Solidarity. Cambridge University Press.

Rorty, R. (1998). Truth and Progress: Philosophical Papers (Vol. 3). Cambridge University Press.

Rorty, R. (1999). Philosophy and Social Hope. London: Penguin.

Rudd, T. P. (2013) Teachers as Agents of Change: Blending Research and Practice and Thoughts on Future Teacher Professional Development Opportunities, in L. Y. Tay. L. Y. and Lim, C. P. (Eds.), Creating Holistic Technology Enhanced Learning Experiences: Tales from a Future School in Singapore (pp. 201-207). Rotterdam: Sense.

Sauvé, L. (1996). Environmental education and sustainable development: A further appraisal. Canadian Journal of Environmental Education, 1, pp.7-34. 
Sauve, L. (1999). Environmental education: Between modernity and postmodernism: searching for an integrating educational framework. Canadian Journal of Environmental Education, 4, pp. 935.

Sayer, A. (1992). Method in Social Science: A Realist Approach (2nd ed.). London: Routledge.

Sayer, A. (2000). Realism and Social Science. London: Sage Publications.

Schattle, H. (2008a). The Practices of Global Citizenship. Plymouth, UK: Rowman \& Littlefield.

Schattle, H. (2008b). Education for global citizenship: Illustrations of ideological pluralism and adaptation. Journal of Political Ideologies, 13(1), pp.73-94.

Schattle, H. (2012). Globalization and Citizenship. Plymouth, UK: Rowman \& Littlefield.

Schön, D. A. (1973). Beyond the Stable State: Public and Private Learning in a Changing Society. Harmondsworth: Penguin.

Schuller, T. and Watson, D. (2009). Learning Through Life: Inquiry into The Future for Lifelong Learning. Leicester: NIACE.

Scott, D., and Usher, R. (2010). Researching Education: Data, Methods and Theory in Educational Enquiry. (2nd ed.). London: Bloomsbury.

Scott, W. and Gough, S. (2003). Sustainable Development and Learning: Framing the Issues. London: RoutledgeFalmer.

Scott, W. and Gough, S. (Eds.) (2004). Key Issues in Sustainable Development and Learning: A Critical Review. London: RoutledgeFalmer.

Scottish Executive Social Research (2006). Sustainable development: A review of the literature. Available online at: http://www.gov.scot/Publications/2006/05/23091323/0 [Accessed: 14/11/2015].

Scottish Government (2011). Achieving a Sustainable Future: Regeneration Strategy. Edinburgh: The Scottish Government. Available online at:

http://www.gov.scot/Resource/Doc/364595/0123891.pdf [Accessed: 14/11/2015].

Seidman, I. (2013). Interviewing as Qualitative Research: A Guide for Researchers in Education and the Social Sciences (4th ed.). New York: Teachers College Press.

Selby, D. (2006). The firm and shaky ground of education for sustainable development. Journal of Geography in Higher Education, 30(2), pp.351-365.

Selby, D. (2009). Researching into the holomovement: Bohemian perspectives on social leaning for sustainability. In Wals, A.E.J. (Ed.), Social Learning Towards a Sustainable World: Principles, Perspectives and Praxis (pp.65-80). The Netherlands: Wageningen Academic Publishing. 
Selby, D. and Kagawa, F. (2010). Runaway climate change as challenge to the 'closing circle' of education for sustainable development. Journal of Education for Sustainable Development, 4(1), pp.37-50.

Selby, D. and Kagawa, F. (2011a). Development education and education for sustainable development: Are they striking a Faustian bargain? Policy \& Practice-A Development Education Review, (12), pp. 15-31.

Selby, D. and Kagawa, F. (2011b). Unleashing blessed unrest as the heating happens. Green Teacher, (94), pp.3-15.

Selby, D. and Kagawa, F. (2014). Striking a Faustian bargain? Development education, education for sustainable development and the economic growth agenda. In McClosky, S. (Ed.), Development Education in Policy and Practice (pp. 143-157). Palgrave Macmillan, London.

Shephard, K. (2008) Higher education for sustainability: Seeing affective learning outcomes. Higher Education for Sustainability, 9(1), pp. 87-98.

Shiva, V. (1988). Staying Alive: Women, Ecology and Survival in India. New Delhi: Zed Press.

Shiva, V. (1999). Ecological balance in an era of globalization. In Low, N. (Ed.), Global Ethics and Environment, (pp. 47-69). London: Routledge.

Silverman, D. (2001). Interpreting Qualitative Data: Methods for Analysing Talk, Text and Interaction. London: Sage.

Silverman, D. (2013). Doing Qualitative Research: A Practical Handbook (4th ed.). London: Sage Publications.

Silverman, D. (2014). Interpreting Qualitative Data. London: Sage Publications.

Simons, H. (1996). The paradox of case study. Cambridge Journal of Education, 26(2), pp. 225-240.

Simons, H. (2009). Case Study Research in Practice. London: Sage Publications.

Singer, P. (2004). One World: The Ethics of Globalization. ( $\left.2^{\text {nd }} e d.\right)$. Yale University Press.

Singer, P. (2011). Practical Ethics. (3rd ed.). Cambridge University press.

Smith, M. J. (1998). Ecologism: Towards ecological citizenship. Oxford University Press.

Smith M. K. (1999, 2003). Learning theory. Available at: http://www.infed.org/biblio/b-learn.htm [Accessed: 20/06/ 2016].

Smith, R. (Ed.) (2013). Education Policy: Philosophical Critique. Chichester: Willey Blackwell.

Smithson, J. (2000). Using and analysing focus groups: Limitations and possibilities. International Journal of Social Research Methodology, 3(2), pp.103-119.

Smithson, J., Bloor, M., Franklin, J., Thomas, M. and Robson, K. (2002). Focus Groups in Social Research. London: Sage Publications. 
Smithson, J. (2008). Focus Groups in Alasuutari, P. Bickman, L and Brannen, J. (Eds). The Sage Handbook of Social Research Methods (pp. 537-370). London: Sage Publications.

Somekh, B. and Lewin, C. (2005). Research Methods in the Social Sciences. London: Sage Publications.

SQW Consulting (2009). Education for sustainable development and global citizenship (ESDGC): Analysis of good practice in Welsh higher education institutions. A report to the Higher Education Funding Council for Wales (HEFCW). Cambridge, UK: SQW Consulting.

Stables, A. and Scott, W. (2002). The quest for holism in education for sustainable development. Environmental Education Research, 8(1), pp. 53-60.

Stake, R. E. (1978). The Case Study Method in Social Inquiry. Educational Researcher, 7(2), pp. 5-8.

Stake, R. E. (1995). The Art of Case Study Research. London: Sage Publications.

Stake, R.E. (2009). The Case Study Method in Social Inquiry. In Gomm, R., Hammersley M. and Foster P. (Eds.), Case Study Methods (pp. 18-26). London: Sage Publications.

Steffen, W., A. Sanderson, A., Tyson, P.D., Jäger, J., Matson, P.A., Moore III, B., Oldfield, F., Richardson, K., Schellnhuber, H.J., Turner, B.L. and Wasson, R.J. (2004). Global Change and the Earth System: A Planet Under Pressure. Berlin: Springer-Verlag. Available online at: http://www.igbp.net/download/18.56b5e28e137d8d8c09380001694/1376383141875/Springerl GBPSynthesisSteffenetal2004_web.pdf [Accessed: 21/02/2017].

Steffen, W., Persson,Å., Deutsch, L., Zalasiewicz, J., Williams, M., Richardson, K. and .... Molina, M. (2011). The Anthropocene: from global change to planetary stewardship. Ambio, 40(7), pp.739-761.

Steffen, W., Richardson, K., Rockström, J., Cornell, S.E., Fetzer, I., Bennett,E.M., and ... Folke, C. (2015). Planetary boundaries: Guiding human development on a changing planet. Science, 347(6223), 1259855. DOI: 10.1126/science.1259855

Sterling, S. (2001). Sustainable Education: Re-Visioning Learning and Change. Totnes, Devon: Green Books.

Sterling, S. (2003). Whole Systems Thinking as a Basis for Paradigm Change in Education: Explorations in the Context of Sustainability (Doctoral dissertation, University of Bath). Available online at:

http://ethos.bl.uk/OrderDetails.do?uin=uk.bl.ethos.413906 [Accessed: 30/12/2015].

Sterling, S. (2004). Higher education, sustainability, and the role of systemic learning. In Corcoran, P. B., and Wals, A. E. (Eds.), Higher Education and the Challenge of Sustainability: Contestation, Critique, Practice, and Promise (pp. 49-70). Dordrecht: Kluwer Academic Publishers.

Sterling, S. (2008). Sustainable education-towards a deep learning response to unsustainability. Policy \& Practice-A Development Education Review, (6), pp. 63-68. 
Sterling, S. (2009). Riding the storm: towards a connective cultural consciousness. In Wals, A. E. (Ed.), Social Learning Towards a Sustainable World: Principles, Perspectives, and Praxis (2nd ed.) (pp. 63-82). The Netherlands: Wageningen Academic Publishing.

Sterling, S. (2010a). Ecological Intelligence, viewing the world relationally. In Stibbe, A. (Ed.), The Handbook of Sustainability Literacy: Skills for a Changing World. Totness: Green Books.

Sterling, S. (2010b). Living in the earth: Towards an education for our time. Journal of Education for Sustainable Development, 4(2), pp. 213-218.

Sterling, S. (2011a). Transformative learning and sustainability: Sketching the conceptual ground. Learning and Teaching in Higher Education, 5(11), pp. 17-33.

Sterling, S (2011b). The Future Fit Framework: An Introductory Guide to Teaching and Learning for Sustainability in HE. York: The Higher Education Academy. Available online at: https://www.heacademy.ac.uk/knowledge-hub/future-fit-framework [Accessed: 03.05.2016].

Sterling, S. (2013a). The Future Fit Framework: An introductory guide to teaching and learning for sustainability in HE (Guide). Journal of Education for Sustainable Development, 7(1), pp. 134-135.

Sterling, S. (2013b). An analysis of the development of sustainability education internationally: Evolution, interpretation and transformative potential. In Cullingford, C., and Blewitt, J. (Eds.), The Sustainability Curriculum: The Challenge for Higher Education ( $2^{\text {nd }} \mathrm{ed}$.) (pp. 56-75). London: Routledge.

Stern, P. C. (2000). Toward a coherent theory of environmentally significant behavior. Journal of Social Issues, 56(3), pp. 407-424.

Stevenson, R. B. (2006). Tensions and transitions in policy discourse: Recontextualizing a decontextualized EE/ESD debate. Environmental Education Research, 12(3-4), pp. 277-290.

Sturges, J. E. and Hanrahan, K. J. (2004). Comparing telephone and face-to-face qualitative interviewing: a research note. Qualitative Research, 4(1), pp. 107-118.

Sullivan, D. (2011). Education for Citizenship: Wales and the Global Dimension. In Bennell, S, Egley, S., Norcliffe, D. and Sullivan, D. (Eds.), Citizenship Education in Wales (pp. 77-90). Bangor, Wales: Bangor University, School of Education.

Sund, L. and Öhman, J. (2014). On the need to repoliticise environmental and sustainability education: rethinking the postpolitical consensus. Environmental Education Research, 20(5), pp. 639-659.

Suter, W. N. (2011). Introduction to Educational Research: A Critical Thinking Approach ( $2^{\text {nd }}$ ed.). London: Sage Publications.

Swartz, A. L. and Tisdell, E. J. (2012). Wisdom, complexity, and adult education: emerging theory and meanings for practice. Adult Education Research Conference 2012. Conference Proceedings, pp. 321-327. Available online at: 
http://newprairiepress.org/cgi/viewcontent.cgi?article=3093\&context=aerc [Accessed: 14/04/2016].

Tarozzi M., Inguaggiato C., (Eds.) (2016) "Global Citizenship Education in Europe. A Comparative Study on Education Policies across 10 EU Countries". Research deliverable issued within the European project "Global Schools". Trento, Italy: Provincia Autonoma di Trento.

Tawil, S. (2013). Education for 'Global Citizenship': A Framework for Discussion. UNESCO Education Research and Foresight: Working papers [ERF Working Papers Series, No. 7]. Paris: UNESCO. Available online at:

http://www.unesco.org/new/fileadmin/MULTIMEDIA/HO/ED/pdf/PaperN7EducforGlobalCitizens hip.pdf [Accessed: 06/01/2016].

Taylor, E. W. (2007). An update of transformative learning theory: a critical review of the empirical research (1999 - 2005). International Journal of Lifelong Education, 26(2), pp. 173-191.

Taylor, E. W. (2008). Teaching and emotions in a nonformal educational setting. New Directions for Adult and Continuing Education, 120, pp.79-87. DOI: 10.1002/ace.318

Taylor, E. W. and Cranton, P. (Eds.) (2012). The Handbook of Transformative Learning: Theory, Research, and Practice. San Francisco: John Wiley \& Sons.

Taylor, E. W. and Snyder, M. J. (2012). A critical review of research on transformative learning theory, 2006-2010. In Taylor, E. W. and Cranton, P. (Eds.), The Handbook of Transformative Learning: Theory, Research, and Practice (pp. 37-55). San Francisco: John Wiley \& Sons.

Thomas, G. (2010). Doing case study: Abduction not induction, phronesis not theory. Qualitative Inquiry, 16(7), pp. 575-582.

Thomas, G. (2011). A typology for the case study in social science following a review of definition, discourse, and structure. Qualitative Inquiry, 17(6), pp. 511-521.

Thomas, I. (2009). Critical thinking, transformative learning, sustainable education, and problembased learning in universities. Journal of Transformative Education, 7(3), pp. 245-264.

Thomas, R. (2014). How the Further Education Sector is Adopting Sustainable Development as a Central Organising Principle. Cynnal Cymru. Available online at: http://www.sd-charter.net/wpcontent/uploads/2014/12/Further-Education-Report.pdf [Accessed: 16/08/206].

Thornberg, R. (2012). Informed grounded theory. Scandinavian Journal of Educational Research, 56(3), pp. 243-259.

Thornberg, R. and Charmaz, K. (2014). Grounded theory and theoretical coding. In the Sage Handbook of Qualitative Data Analysis, (pp.153-169). London: Sage Publications.

Tight, M. (1996). Key Concepts in Adult Educating and Training. London: Routledge.

Tilbury, D. (1995). Environmental education for sustainability: Defining the new focus of environmental education in the 1990s. Environmental Education Research, 1(2), pp. 195-212. 
Tilbury, D. (2009). Learning based change for sustainability: perspectives and pathways In Wals (Ed.), Social Learning Towards a Sustainable World: Principles, Perspectives, and Praxis (2nd ed.) (pp. 117-131). The Netherlands: Wageningen Academic Publishing.

Tilbury D., Stevenson, R.B., Fien, J. and Schreuder, D. (Eds.) (2002). Education and Sustainability: Responding to the Global Challenge. Cambridge: IUCN.

Tilbury, D. and Wortman, D. (2004). Engaging People in Sustainability. Cambridge, UK: IUCN.

Tilbury, D. and Wortman, D. (2008). How is Community Education Contributing to Sustainability in Practice? Applied Environmental Education and Communication,7(3), pp. 83-93.

Timmons, V. and Cairns, E. (2010). Case study research in education. Encyclopaedia of Case Study Research, 1, pp. 99-102.

Tisdell, E. J. (2003). Exploring Spirituality and Culture in Adult and Higher Education. San Francisco Jossey-Bass.

Tisdell, E. J. (2011a). Working toward wisdom in adult education in changing times. Explorations in Adult Higher Education, 31, pp. 31-37.

Tisdell, E. (2011b). The wisdom of webs a-weaving: Adult education and the paradoxes of complexity in changing times in Tisdell, E. and Swartz, A. (Eds). Adult Education and the Pursuit of Wisdom. New Directions in Adult and Continuing Education, no 131. (pp.5 - 13). San Francisco: Jossey-Bass.

Tobias, R. (2000). The boundaries of adult education for active citizenship: Institutional and community contexts. International Journal of Lifelong Education, 19(5), pp. 418-429.

Todd S. (2010). Living in a dissonant world: Toward an agonistic cosmopolitics for education. Studies in Philosophy and Education, 29, pp.213-228. DOI: 10.1007/s11217-009-9171-1

Todd S. (2011). Educating beyond cultural diversity: Redrawing the boundaries of a democratic plurality. Studies in Philosophy and Education, 30, pp. 101-111.

Todd, S. (2015). Toward an Imperfect Education: Facing Humanity, Rethinking Cosmopolitanism (2nd ed.). London: Routledge.

Torres, C. A. (1998a). Democracy, Education, and Multiculturalism. Oxford: Rowman \& Littlefield.

Torres, C. A. (2006). Democracy, education, and multiculturalism: Dilemmas of citizenship in a global world, in Lauder, H., Brown, P., Dillabough, J. and Halsey, A.H. (Eds.), Education, Globalization and Social Change. Oxford: Oxford University Press.

Torres, C. A. (2013). Political Sociology of Adult Education. Springer Science \& Business Media.

Torres, C. A. (2015). Solidarity and competitiveness in a global context: Comparable concepts in global citizenship education? International Education Journal: Comparative Perspectives, 14(2), pp.22-29. 
Tough, A. (1979). The Adult's Learning Projects: A Fresh Approach to Theory and Practice in Adult Learning. Toronto: Ontario Institute for Studies in Education.

Trier-Bieniek, A. (2012). Framing the telephone interview as a participant centred tool for qualitative research: a methodological discussion. Qualitative Research, 12(6), pp. 630-644.

Trowler, P. (2003). Education Policy: A Policy Sociology Approach ( $2^{\text {nd }}$ ed.). London: Routledge.

Tuckett, A. and Aldridge, F. (2010). A Change for the Better: The NIACE Survey on Adult Participation in Learning 2010. Leicester: NIACE.

Tully, J. (2008). Two meanings of global citizenship: Modern and diverse. The Meanings of Global Citizenship Conference, Liu Centre and Trudeau Foundation, UBC, September 9-10, 2005. Global Citizenship Education: Philosophy, Theory and Pedagogy, pp. 15-39.

Tully, J. (2014). On Global Citizenship: James Tully in Dialogue. London: Bloomsbury.

Tyson Roberts, G. (1998). The language of the Blue Books: The Perfect Instrument of Empire. Cardiff: University of Wales Press.

UK National Commission for UNESCO (2010). Education for Sustainable Development in the UK in 2010. London: UK National Commission for UNESCO. Available online at: http://seed.co.uk/edu/wp-content/uploads/2014/02/Report_-ESD-in-the-UK_2010_UKNCUNESCOv4.pdf[Accessed: 8/11/2015].

UK National Commission of UNESCO (2013). Education for Sustainable Development (ESD) in the UK - Current Status, best practice and opportunities for the future. London: UK National Commission for UNESCO. Available online at: http://www.unesco.org.uk/wpcontent/uploads/2015/03/Brief-9-ESD-March-2013.pdf [Accessed: 21/07/2016].

UK Government (2005a). Securing the Future, The UK Government Sustainable Development Strategy. London: The Stationary Office. Available online at: https://www.gov.uk/government/publications/securing-the-future-delivering-uk-sustainabledevelopment-strategy [Accessed: 15/08/2016].

UK Government (2005b). Securing the Future: Delivering UK Sustainable Development Strategy. Available online at: https://www.gov.uk/government/publications/securing-the-futuredelivering-uk-sustainable-development-strategy [Accessed: 21/07/2016].

United Nations (UN) (1987). Brundtland Commission. Our Common Future: Report of the World Commission on Environment and Development. Available online at: http://www.undocuments.net/our-common-future.pdf [Accessed: 29/04/2014].

United Nations (UN) - United Nations Environment Programme (UNEP)(1992a). The Rio Declaration. Available online at: http://www.unesco.org/education/pdf/RIO_E.PDF [Accessed: 20/10/2016].

United Nations (UN) - United Nations Environment Programme (UNEP) (1992b). Agenda 21. Available online at: https://sustainabledevelopment.un.org/content/documents/Agenda21.pdf. [Accessed: 20/04/2017]. 
United Nations (UN) (2002). Johannesburg Declaration. Available online at: http://www.undocuments.net/jburgdec.htm [Accessed: 20/12/2015].

United Nations Educational, Scientific and Cultural Organization. UNESCO-UNEP (1972).

Stockholm 1972: Report of The United Nations Conference on the Human Environment. Available online at: http://www.unep.org/Documents.Multilingual/Default.asp?DocumentID=97 [Accessed: 15/08/2016].

United Nations Educational, Scientific and Cultural Organization (UNESCO-UNEP) (1977). The International Workshop on Environmental Education, Belgrade, Yugoslavia, 13-22, October 1975. Available online at: http://unesdoc.unesco.org/images/0002/000276/027608EB.pdf [Accessed: 15/08/2016].

United Nations Educational, Scientific and Cultural Organization (UNESCO-UNEP) (1978). Intergovernmental Conference on Environmental Education, Tbilisi, USSR, 14 - 26 October 1977. Available online at: http://www.gdrc.org/uem/ee/EE-Tbilisi_1977.pdf [Accessed: 15/08/2016].

United Nations Educational, Scientific and Cultural Organization (UNESCO) (1979). Intergovernmental Conference on Environmental Education. Available online at: http://www.gdrc.org/uem/ee/EE-Tbilisi_1977.pdf [Accessed: 29/04/2014].

United Nations Educational, Scientific and Cultural Organization (UNESCO) (1997). Educating for a Sustainable Future: A Transdisciplinary Vision for Concerted Action. Available online at: http://www.unesco.org/education/tlsf/mods/theme_a/popups/mod01t05s01.html [Accessed: 20/12/2015].

United Nations Educational, Scientific and Cultural Organization (UNESCO) (2002). Education for Sustainability: From Rio to Johannesburg - Lessons Learnt from a Decade of Commitment. Paris: UNESCO. Available online at: http://unesdoc.unesco.org/images/0012/001271/127100e.pdf [Accessed: 8/11/2015].

United Nations Educational, Scientific and Cultural Organization (UNESCO) (2003). United Nations Decade of Education for Sustainable Development (2005-2014) Framework for the International Implementation Scheme. Available online at: 32 C/INF.9, available at:

http://unesdoc.unesco.org/images/0013/001311/131163e.pdf [Accessed: 05/05/2016].

United Nations Educational, Scientific and Cultural Organization (UNESCO) (2005). United Nations Decade of Education for Sustainable Development (2005-2014) International Implementation Scheme. Available online at: http://unesdoc.unesco.org/images/0014/001486/148654e.pdf [Accessed: 8/11/2015].

United Nations Educational, Scientific and Cultural Organization (UNESCO) (2009). Bonn Declaration. UNESCO World Conference on Education for Sustainable Development, 30 March 2 April 2009. Available online at: http://unesdoc.unesco.org/images/0018/001887/188799e.pdf [Accessed: 19/08/2016]. 
United Nations Educational, Scientific and Cultural Organization (UNESCO) (2013). Global Citizenship Education: An Emerging Perspective. Available online at:

http://unesdoc.unesco.org/images/0022/002241/224115E.pdf [Accessed: 01/11/2017].

United Nations Educational, Scientific and Cultural Organization (UNESCO) (2014a). Shaping the Future we Want: UN Decade Of Education for Sustainable Development (2005-2014) Final Report. Paris: UNESCO.

United Nations Educational, Scientific and Cultural Organization (UNESCO) (2014b). Sustainable Development Begins with Education. Available online at:

http://unesdoc.unesco.org/images/0023/002305/230508e.pdf [Accessed: 13/04/2018].

United Nations Educational, Scientific and Cultural Organization (UNESCO) (2015). Rethinking Education: Towards a Global Common Good? Paris: UNESCO. Available online at: http://unesdoc.unesco.org/images/0023/002325/232555e.pdf [Accessed: 01/11/2017].

United Nations Educational, Scientific and Cultural Organization (UNESCO) (2016). Citizens for Sustainable Development. Available online at: http://unesdoc.unesco.org/images/0024/002468/246888e.pdf [Accessed: 30/10/2017] UNESCO Institute for Lifelong Learning. (2016). 3rd Global Report on Adult Learning and Education III: Key Messages and Executive Summary. Hamburg: UNESCO. Available online at: http://unesdoc.unesco.org/images/0024/002459/245917e.pdf [Accessed: 12/08/2018].

Usher, R., Bryant, I., and Johnston, R. (2011). Adult Education and the Postmodern Challenge. Learning Beyond the Limits (3rd ed.). London: Routledge.

Valencia Sáiz, A. (2005). Globalisation, cosmopolitanism and ecological citizenship. Environmental Politics, 14(2), pp. 163-178.

van Hooft, S. and Vandekerckhove, W. (2010). (Eds.), Questioning Cosmopolitanism (Vol. 6). Springer Science and Business Media.

Van Poeck, K. and Vandenabeele, J. (2012). Learning from sustainable development: education in the light of public issues. Environmental Education Research, 18(4), pp. 541-552.

Van Poeck, K., Vandenabeele, J. and Bruyninckx, H. (2009). Sustainable citizenship and education. In CRLL Conference, Lifelong Learning Revisited: What Next? University of Stirling. Available online at: https://lirias.kuleuven.be/bitstream/123456789/329860/1/Paper_081_Katrien [Accessed: 09/09/2017].

Veen, R. V. D. and Preece, J. (2005). Poverty reduction and adult education: Beyond basic education. International Journal of Lifelong Education, 24(5), pp. 381-391.

Vella, J. (2002). Learning to Listen, Learning to Teach: The Power of Dialogue in Educating Adults. San Francisco: Jossey-Bass.

Veugelers W. (2011). The moral and the political in global citizenship: Appreciating difference in education. Globalisation, Societies and Education. 9(3-4), pp. 473-485. 
Vicsek, L. (2007). A Scheme for analyzing the results of focus groups. International Journal of Qualitative Methods, 6(4), pp. 20-34.

Villarreal Larrinaga, O. (2017). Is it desirable, necessary and possible to perform research using case studies? Cuadernos de Gestión, 17(1), pp.147-171.

Von Hippel, E. (2005). Democratizing Innovation. Massachusetts Institute of technology (MIT) press. Available online at: http://web.mit.edu/evhippel/www/democ.htm [Accessed: 30/04/2017].

Walford, G. (2011). Researching the powerful. British Educational Research Association on-line resource. Available online at: http://www.bera.ac.uk/wp-content/uploads/2014/03/Researchingthe-Powerful.pdf [Accessed: 07/03/2016].

Walford, G. (2013). Researching the Powerful in Education (2nd ed.). London: Routledge.

Wals, A. E. J. (Ed.) (2009). Social Learning Towards a Sustainable World: Principles, Perspectives, and Praxis (2nd ed.). The Netherlands: Wageningen Academic Publishing.

Wals, A. E. (2011). Learning our way to sustainability. Journal of Education for Sustainable Development, 5(2), pp. 177-186.

Wals, A. E. and Corcoran, P. B. (2006). Sustainability as an outcome of transformative learning. In Holberg, J. and Samuelsson, B. E. (Eds.), Drivers and Barriers for Implementing Sustainable Development in Higher Education (pp. 103-110). Paris: UNESCO.

Wals, A. E. and Corcoran, P. B. (Eds.) (2012). Learning for Sustainability in Times of Accelerating Change. Wageningen Academic Publishers.

Wals, A. E. and Jickling, B. (2002). 'Sustainability' in higher education: From doublethink and newspeak to critical thinking and meaningful learning. International Journal of Sustainability in Higher Education, 3(3), pp. 221-232.

Walters, S. (Ed.) (1997). Globalization, Adult Education and Training: Impacts and Issues. London: Zed Books.

Walters, S. and Watters, K. (2017). Reflecting on the Global Report on Adult Learning and Education in the 'Post-Truth Society'. Adult Education Quarterly, 67(3), pp. 228-237.

Warburton, D. (Ed.) (2013). Community and Sustainable Development: Participation in the Future (2nd ed.) London: Routledge.

Waring, M. (2012). Finding your theoretical position. In Arthur, J. (Ed.), Research Methods and Methodologies in Education (pp. 15-22). Los Angeles: Sage Publications.

wa Thiong'o, N. (1992). Decolonising the Mind: The Politics of Language in African Literature. London: East African Publishers.

Wa Thiong'o, N. (1981). Writers in Politics: Essays. London: East African Publishers. 
Webb, D. (2013). Pedagogies of Hope. Studies in Philosophy and Education. 32, pp.397-414. DOI $10.1007 / \mathrm{s} 11217-012-9336-1$

Webb Review (2007). Promise and performance: the report of the Independent Review of the Mission and Purpose of Further Education in Wales in the context of the Learning Country: Vision in to Action. Available online at: http://dera.ioe.ac.uk/7317/5/A9RFC2B_Redacted.pdf [Accessed: 20/10/2017].

Welsh Government, (n.d.) ESDGC. Available online at: http://www.esd-wales.org.uk/ [Accessed: 29/04/2014].

Welsh Government (2000). Learning to Live Differently. Cardiff: Welsh Government.

Welsh Government (2001). The Learning Country. Cardiff: Welsh Government. Available online at: http://gov.wales/dcells/publications/publications/guidanceandinformation/learningcountry/learn ingcountry-e.pdf?lang=en[Accessed: 17/08/2016].

Welsh Government (2002). Education for Sustainable Development and Global Citizenship: Why? What? How? Birmingham: Qualifications, Curriculum and Assessment Authority for Wales (ACCAC).

Welsh Government (2003). The Sustainable Development Action Plan, 2004 - 2007. Available online at:

http://webarchive.nationalarchives.gov.uk/20060715141954/http://new.wales.gov.uk/caec/publi cations/susdevactionplan/plane.pdf?lang=en [Accessed 27/03/2017].

Welsh Government (2004a). Starting to Live Differently. Cardiff: Welsh Government. Available online at:

http://webarchive.nationalarchives.gov.uk/20060715141954/new.wales.gov.uk/topics/sustainabl edevelopment/publications/startlivedifferently/?lang=en [Accessed: 14/11/2015].

Welsh Government (2004b). The Sustainable Development Action Plan 2004 - 2007. Available online at:

http://webarchive.nationalarchives.gov.uk/20060715141954/http://new.wales.gov.uk/caec/publi cations/susdevactionplan/plane.pdf?lang=en [Accessed: 14/11/2015].

Welsh Government (2005a). The Learning Country, Vision into Action. Available online at: http://www.learningobservatory.com/uploads/publications/565.pdf [Accessed:17/08/2016].

Welsh Government (2005b). Global Citizenship Secondary School Map -Education for Sustainable Development and Global Citizenship. Cardiff: Welsh Government. Available online at: http://www.learningobservatory.com/uploads/publications/678.pdf [Accessed: 8/11/2015].

Welsh Government (2006). Education for Sustainable Development and Global Citizenship: A Strategy for Action. Available online at: http://wales.gov.uk/docs/dcells/publications/110825esdgc-strategy-for-action-en.pdf [Accessed:29/04/2014].

Welsh Government. (2007). One Wales: A Progressive Agenda for the Government of Wales. Cardiff: Welsh Government. Available online at:

http://news.bbc.co.uk/1/shared/bsp/hi/pdfs/27_06_07_onewales.pdf [Accessed:15/08/2016]. 
Welsh Government (2008a). Education for Sustainable Development and Global Citizenship: A Strategy for Action. Available online at:

http://gov.wales/docs/dcells/publications/081204strategyactionupdateen.pdf [Accessed:

04/02/2016].

Welsh Government (2008b). ESDGC: A Common Understanding for Schools. Cardiff: Welsh Government. Available online at:

http://gov.wales/docs/dcells/publications/081204commonunderstschoolsen.pdf [Accessed:08/11/2015].

Welsh Government (2008c). Delivering Skills that Work for Wales: A New Approach to Adult Community Learning. Cardiff: Welsh Government.

Welsh Government (2008d). Skills That Work for Wales: A Skills and Employment Strategy and Action Plan. Cardiff: Welsh Government.

Welsh Government (2009). One Wales, One Planet: The Sustainable Development Scheme of The Welsh Assembly Government. Available online at:

http://wales.gov.uk/topics/sustainabledevelopment/publications/onewalesoneplanet/?lang=en [Accessed:08/11/2015].

Welsh Government (2010). Delivering Community Learning for Wales. Cardiff: Welsh Government. Available online at:

http://gov.wales/docs/dcells/publications/101126deliveringcommunitylearningen.pdf [Accessed: 16/08/2016].

Welsh Government (2011). The Learning County: Vision into Action. Cardiff: Welsh Government. Available online at:

http://gov.wales/dcells/publications/publications/guidanceandinformation/learningcountry/learn ingcountryvis-e.pdf?lang=en [Accessed:05/12/2015].

Welsh Government (2012). Education for Sustainable Development and Global Citizenship: A Common Understanding for the Adult and Community Learning Sector. Available online at: http://wales.gov.uk/docs/dcells/publications/120508esdgcen.pdf [Accessed: 29/04/2014].

Welsh Government (2013). The Cwricw/wm Cymreig: History and the Story of Wales. Available online at: http://learning.gov.wales/docs/learningwales/news/130424-cwricwlwm-cymreigreport-en.pdf [Accessed: 05/09/2015].

Welsh Government, (2015a). The Well-Being of Future Generations (Wales) Act. Available online at: http://www.legislation.gov.uk/anaw/2015/2/pdfs/anaw_20150002_en.pdf [Accessed: 21/01/2017].

Welsh Government, (2015b). The Well-Being of Future Generations (Wales) Act 2015- the essentials. Available online at: http://gov.wales/docs/dsjlg/publications/150623-guide-to-the-fgact-en.pdf [Accessed: 8/11/2015]. 
Welsh Government, (2017). Adult Learning in Wales. Available online at:

https://gov.wales/topics/educationandskills/learningproviders/communitylearning/adultlearning-in-wales/?lang=en [Accessed: 20/05/2018].

Welsh Government, (2018). Employability Plan. Available online at:

https://gov.wales/topics/educationandskills/skillsandtraining/employability-plan-forwales/?lang=en [Accessed: 20/05/2018].

Welton, M. (2002). Listening, conflict and citizenship: towards a pedagogy of civil society. International Journal of Lifelong Education, 21, pp. 197-208.

White, P. (2012). Making political anger possible: A task for civic education. Journal of Philosophy of Education, 46(1), pp. 1-13.

Whiting, K., Konstantakos, L., Misiaszek, G., Simpson, E. and Carmona, L. (2018). Education for the Sustainable Global Citizen: What Can We Learn from Stoic Philosophy and Freirean Environmental Pedagogies? Education Sciences, 8(4), 204, pp.1-14. Available online at: https://www.mdpi.com/2227-7102/8/4/204 [Accessed: 06/01/2019].

Williams, M. and Humphrys, G. (Eds.) (2003). Citizenship Education and Lifelong Learning: Power and Place. New York: Nova Science Publishers.

Wolvin, A. D. (Ed.) (2010). Listening and Human Communication in the 21st Century. Oxford: Wiley-Blackwell.

World Commission on Environment and Development (WCED) (1987). Our Common Future. Oxford: Oxford University Press. Available online at: http://www.un-documents.net/wcedocf.htm [Accessed: 8/11/2015].

Wynn Jr, D. and Williams, C. K. (2012). Principles for conducting critical realist case study research in information systems. MIS quarterly, 36(3), pp. 787-810.

Yin, R. K. (2009). Case Study Research: Design and Methods (4 ${ }^{\text {th }}$ ed.). London: Sage Publications. Yin, R.K. (2011). Applications of Case Study Research (3rd ed.). London: Sage Publications.

Zhao, K. and Biesta, G. (2012). The Moral Dimension of Lifelong Learning: Giddens, Taylor, and the 'Reflexive Project of the Self'. Adult Education Quarterly, 62(4), pp. 332-350. 